\title{
Walking My Talk as an Intentional, Embodied, (Co)constructed Environmental Educator
}

\author{
A Dissertation \\ Submitted to the Faculty of Graduate Studies and Research \\ In Partial Fulfillment of the Requirements \\ For the Degree of \\ Doctor of Philosophy \\ In \\ Education \\ University of Regina
}

By

Peta Jay White

Regina, Saskatchewan

April 2013

Copyright 2013: P.J. White 


\section{UNIVERSITY OF REGINA \\ FACULTY OF GRADUATE STUDIES AND RESEARCH \\ SUPERVISORY AND EXAMINING COMMITTEE}

Peta Jay White, candidate for the degree of Doctor of Philosophy in Education, has presented a thesis titled, Walking My Talk as an Intentional, Embodied (Co)constructed Environmental Education, in an oral examination held on April 29, 2013. The following committee members have found the thesis acceptable in form and content, and that the candidate demonstrated satisfactory knowledge of the subject material.

External Examiner: $\quad$ *Dr. Leesa Fawcett, York University

Supervisor: $\quad$ Dr. Paul Hart, Curriculum \& Instruction

Committee Member: $\quad$ Dr. Carol Schick, Curriculum \& Instruction

Committee Member: $\quad$ **Dr. Warren Wessel, Curriculum \& Instruction

Committee Member: $\quad$ Dr. Roger Petry, Luther College

Chair of Defense: Dr. Dongyan Blachford, Faculty of Graduate Studies and Research

${ }^{* *}$ Not Present at Defense

${ }^{*}$ Participated via SKYPE

Note: Due to exceptional circumstance, student Participated via Video Conference 


\begin{abstract}
Exploring the question (how) can I use personal change to inspire educational and social/cultural change, this work was embodied and action orientated with a thesis that the doing (action) is as important as the thinking and talking about it. A threedimensional model of exploring personal change through transformative education leading to social/cultural change was employed throughout this research. A critical poststructural ecofeminist frame undergirded an autoethnographic self-study where I changed my living practices to become more sustainable while living within society, and used this as a platform for how I could become a better environmental educator and activist. I reduced my ecological footprint from 16.4HA to 1.8HA and taught a preservice teacher course in environmental education, where I explored student resistances, power and relationships, a critique of curriculum, and personal change as a result of transformative education. One particular pedagogical strategy, the Action Learning Group Project, was developed and used to support others to undergo personal change through transformative education leading to social/cultural change. And finally, I use this work as an opportunity to undertake environmental education activism working to generate social/cultural change.
\end{abstract}

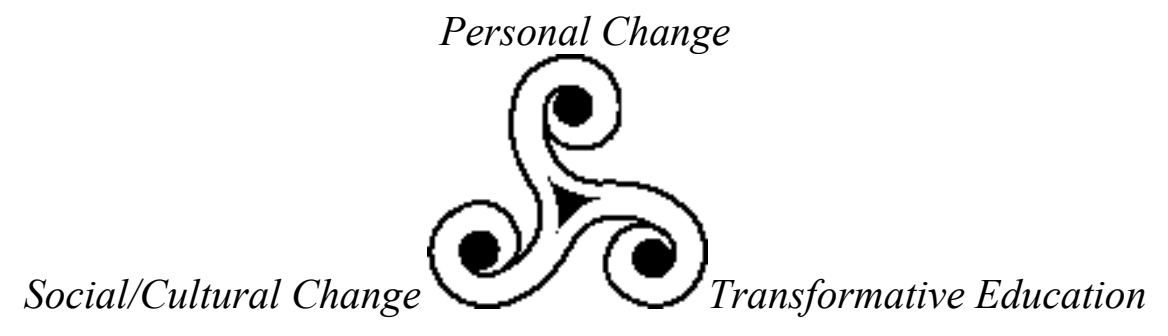




\section{Acknowledgements}

Tell me, what is it you plan to do with your one wild and precious life?

(Oliver, 1992, p. 94)

I would like to acknowledge and thank my supervisor Dr. Paul Hart: without his open offer I would not have embarked upon this journey and enjoyed the adventures. Considerable thanks to my committee: Dr. Carol Schick, Dr. Warren Wessel, Dr. Roger Petry, and Dr. Christine Crowe.

Thanks to my critical friends: Dr. Paul Hart, Dr. Amy Cutter McKenzie, Catherine Hart, Dr. Wanda Lyons, Dr. Michael Cappello, Julie Machnaik, and Phil Smith.

Thanks to the Faculty of Education, University of Regina for providing a home and to the Faculty of Graduate Studies and Research, University of Regina for funding and support.

Thanks to the people in the organisations that facilitated much of this work, collegiality, and fun times: SOEEA, EECOM, and NAAEE - many roles and many friends.

Thanks to my folks (Sue and Dick White) for being a constant support, unwavering in their happy, considerate ways that make the world seem a little brighter each day.

Thanks to my friends - there and here, human and better. Special thanks to: Phil Smith, Sarah Rankin, Sally Madden, Lyndel Taylor, Dimity Wehr, Cheryl Bradley, Alby Holdsworth, Barry Corke, Yvette Crane and Ian Monteith, Scott Snider, Neil Christopher, Audrey Aamodt, Jocelyn Crivea, Chelsea Schaefer, Mike Cappello, Julie Machnaik, Wanda Lyons, Margaret Dagenais, Nirach Suapa, Lori Eastmure, Tara Stuckless, Bill Jones, Mark Sexton, Madeleine Le Page and Del Lyngseth, Gabrielle Henry, Kimberley Lawrence - my yogic calm and body booster, Scout, Atlas, Saffron, Georgia, and Jude.

With special appreciation for Prairie Savannah White... my best mate!

And, finally, thanks to my students, it was wonderful to learn with you. Best wishes for an amazing and sustainable life! 


\section{Table of Contents}

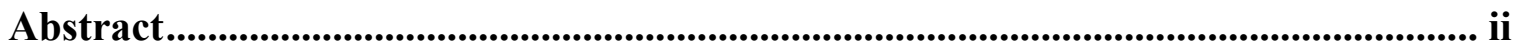

Acknowledgements .................................................................................................................. iii

Table of Contents ....................................................................................................................

List of Figures............................................................................................................. vii

Chapter 1. Introduction............................................................................................................1

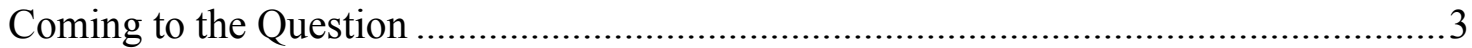

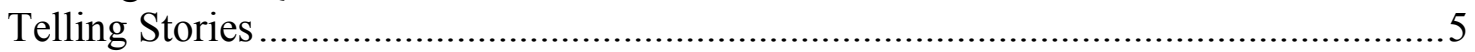

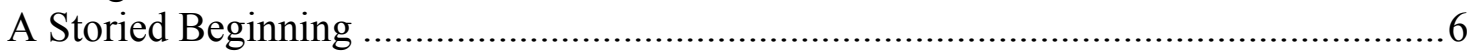

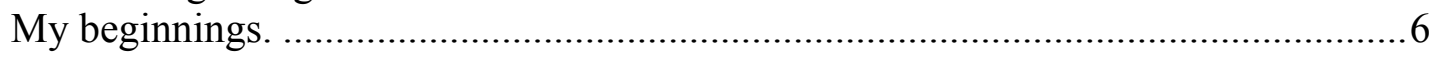

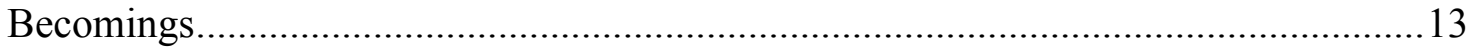

Becoming an environmental educator. …………….........................................14

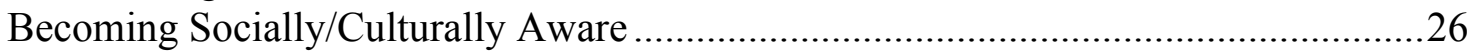

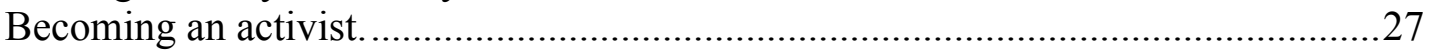

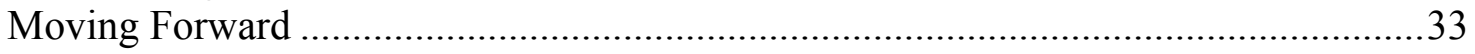

Chapter 2. Literature Review .................................................................................................35

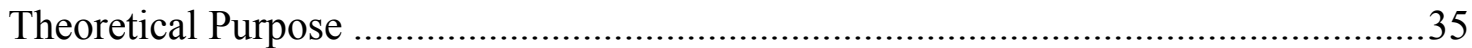

Social/Cultural to Personal: Poststructuralism to Ecofeminism …………………..........36

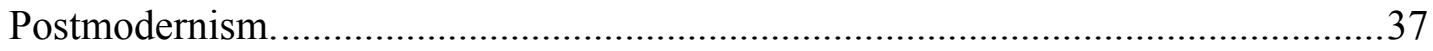

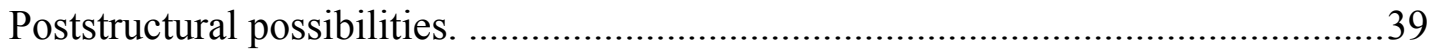

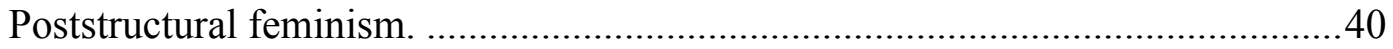

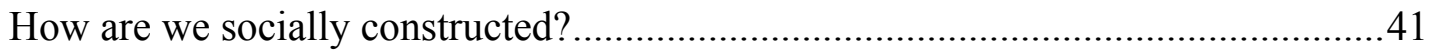

Activism as an expression of agency...............................................................4

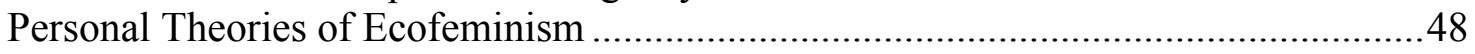

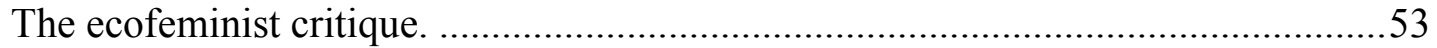

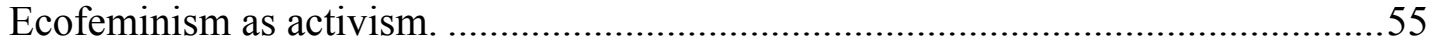

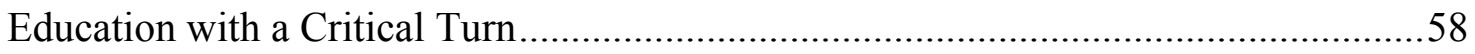

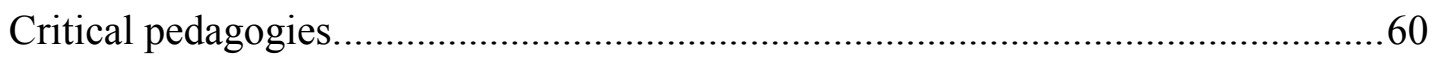

What, then, is the role of the teacher (or the teacher's teacher) to bring about

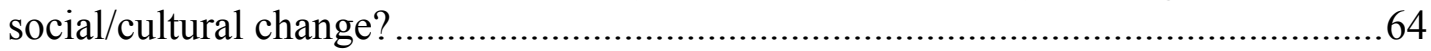

Chapter 3. Methodology .........................................................................................................68

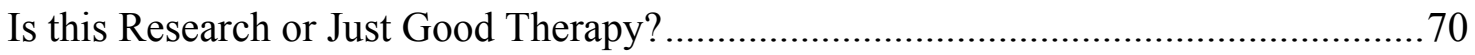

Autoethnographic Methodology: Personal Change ...................................................... 81

Autoethnographic explorations of my sustainable living practices. ...........................85

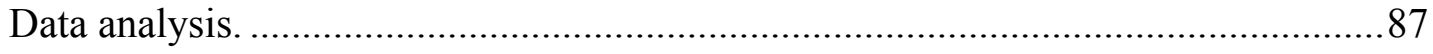

Self-study Methodology: Transformative Education....................................................89

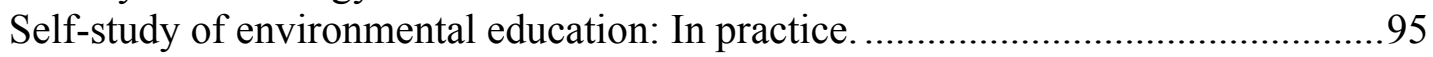

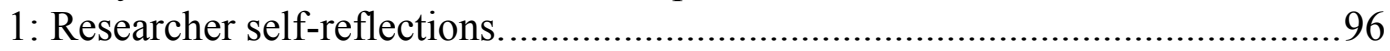

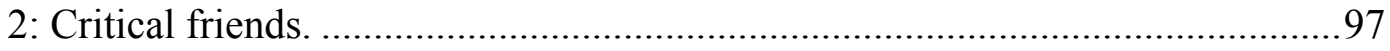




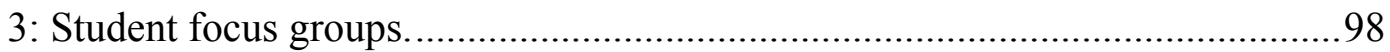

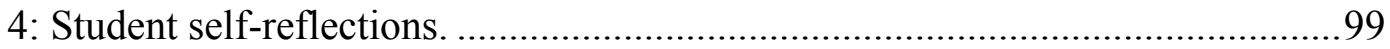

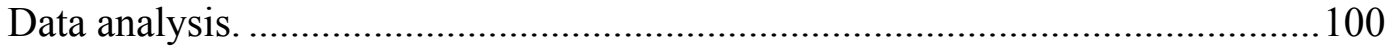

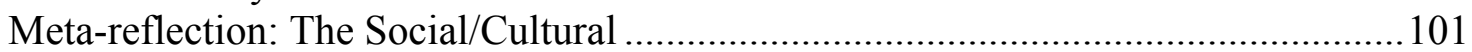

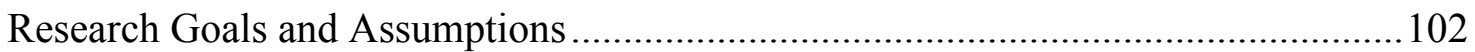

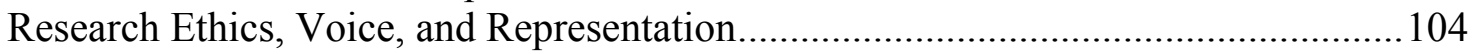

Chapter 4. Findings ….....................................................................................................106

The Story of Sustainable Living Practices: An Autoethnography ................................107

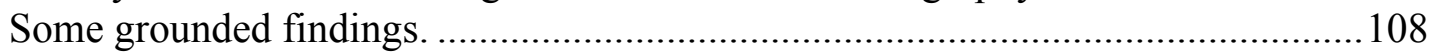

The ecological footprint: Theory and practice........................................................112

My decision making process............................................................................120

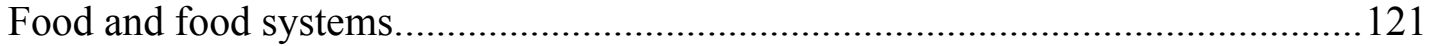

Food... and how to ethically provide nutrition to a female body..........................122

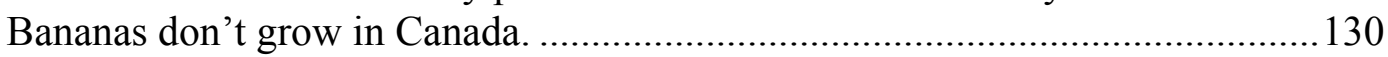

Community Gardens - growing my own, preserving my own............................131

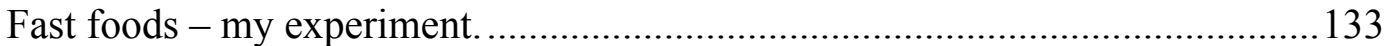

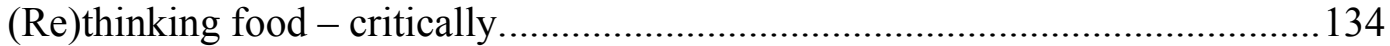

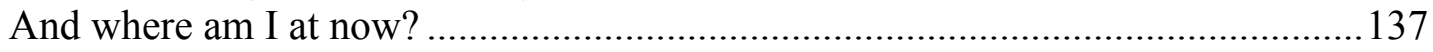

Becoming a Transformative Environmental Educator: My Self-study ........................138

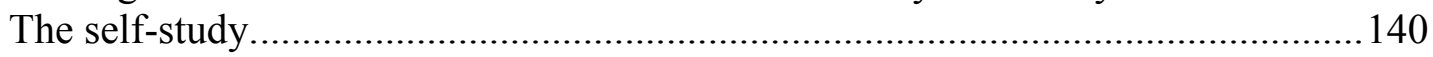

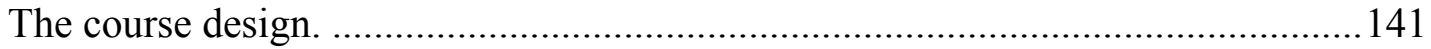

The 'Action Learning Group Project'........................................................................ 144

Background to the Action Learning Group Project. ............................................... 144

The presentation of the critical pedagogical strategy............................................148

Student responses to the Action Learning Group Project....................................152

A critique of curriculum.....................................................................................154

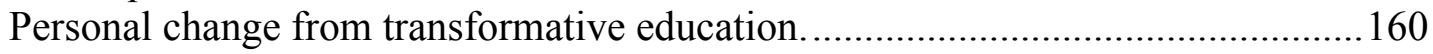

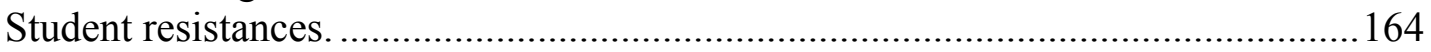

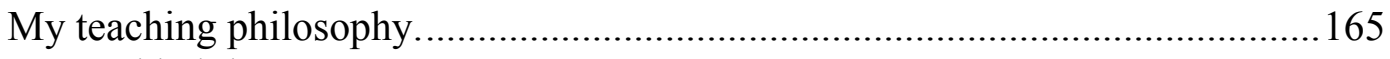

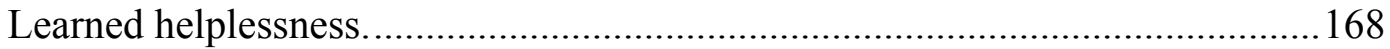

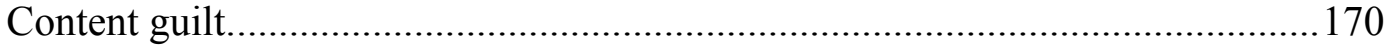

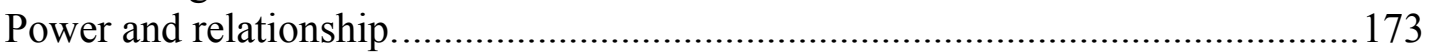

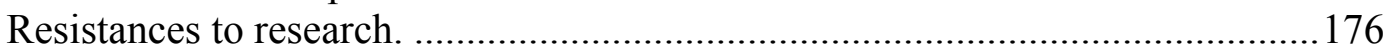

My positioning as an educator in this program.................................................177

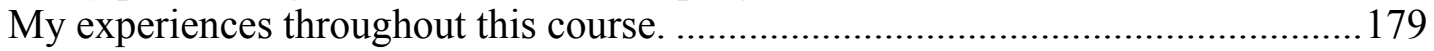

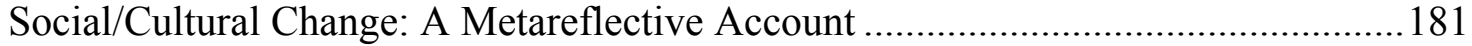

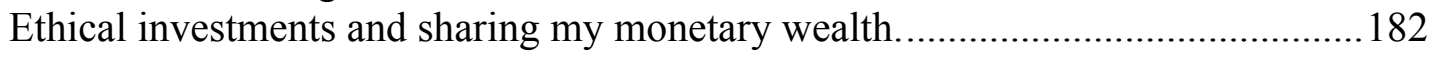

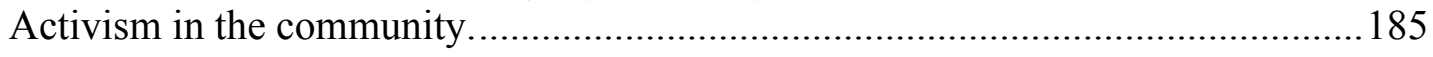

Chapter 5. So What?...........................................................................................................187

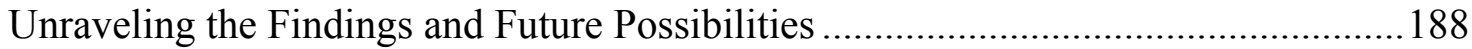

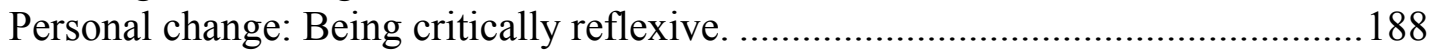

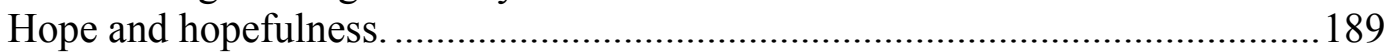

Transformative education: Critical pedagogy .........................................................193

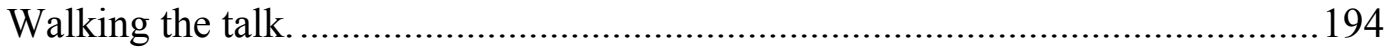

Social/cultural change: Ecofeminist activism.......................................................202 


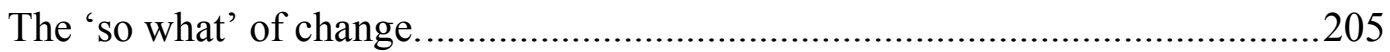

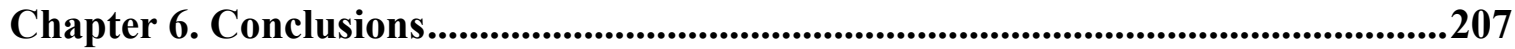

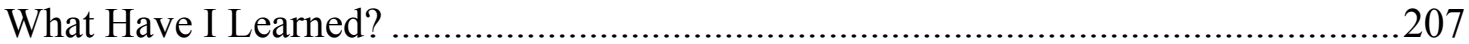

Theoretical grounding: What did it allow and disallow.......................................210

Methodological grounding: What did it allow and disallow. ...............................213

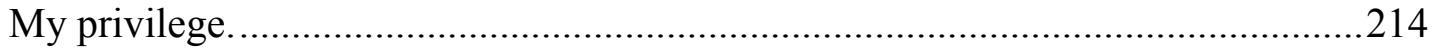

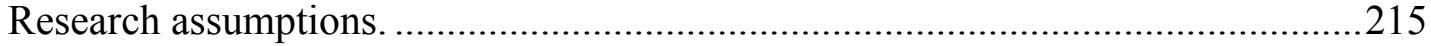

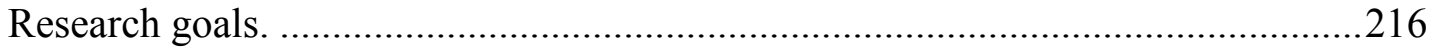

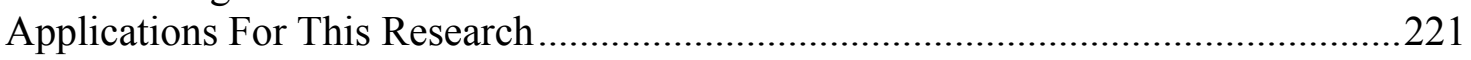

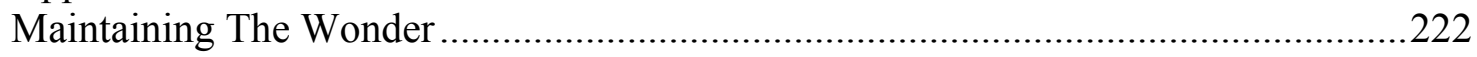

References ...............................................................................................................................224

Appendix 1: Reasearch Ethics Board Approval ......................................................240

Appendix 2: Course Syllabus ........................................................................................2241 


\section{List of Figures}

Figure 1. Presented in a limiting dualistic way, yet urging us to consider our Earth systems differently suggesting movement from hierarchical organisation (Wrong) towards greater systems thinking and interdependence (Right) (Occupy Santa Ana, 2012).

Figure 2. The graphic representation of my ecological footprint analysis from July 2005 through to January 2010. The blue line illustrates the actual hectare result while the red line is the calculated number of earths required if everyone lived like me.

Figure 3. A visual representation of the issues addressed and actions taken to reduce my ecological footprint to become an intentional practitioner learning to live more sustainably in western society.

Figure 4. A visual representation of how diminished our seed stocks have become. The comparison is presented from 1903 (the top numbers) to 1983 (the bottom numbers) for a variety of vegetables (Rural Advancement Foundation International, 2012).

Figure 5. A visual representation of the corporatisation of our food producing companies. From the great variety once established there are now only ten corporate identities involved with this food production (The Illusion of choice, 2012).

Figure 6. The nautilus shell and spiral shape of the diagram represents the reflexivity of the process, encouraging constant reflection, reconsideration, and eventually leading to a possible repeat of the entire cycle. Each step title is presented under the diagram

Figure 7. Countries where I have offered loans to agricultural based projects with Kiva.org 


\section{Chapter 1. Introduction}

"I tell you this to break your heart, by which I mean only that it break open and never close again to the rest of the world" (Oliver, 2005, p. 54).

I have found myself, throughout my experiences as an educator, drawn to environmental education. Fascinated by the engagement my students demonstrated for living beings and outdoor, real life examples, I learned to love what this field of education could do for my educational practice. My fascination has now infiltrated every ontological expression (ways of being reflecting one's worldview) regarding how I practice living. Because, if I am to value environmental education in my teaching practice, I should be walking my talk and living with an environmentally conscious and responsible practice.

'Walking the talk' refers to someone's ability to do as they say they will do: to follow their own teachings by taking action. As a phrase, 'walking the talk', has its origins in the Alcoholics Anonymous program from the 1960s era as a program that works to establish awareness and support individuals towards changing their practices (Thurston, 1962, p. 6). As such, I embody this phrase as I work toward deepening awareness around my living practices and taking action that leads me towards living with a lower impact and in more sustainable ways, while still living within my (western) society, and educating others to consider undertaking similar actions leading the way to social/cultural change.

My thesis is grounded through action in that, along with thinking about it, it is the doing that is important in creating and sustaining change. As Dewey stated in 1929, in the Quest for Certainty, "theory separated from concrete doing and making is empty and 
futile" (p. 281). Similarly, I suggest that intentional, embodied (mind and body) practice infers choice, careful thought, and consciousness leading to critical action, or action that desires change. Thus, the practice of being intentional and embodied in how I choose to live in more sustainable ways is pivotal or undergirds much of my worldview, which has become core to how I (can) perform as an environmental educator.

Through my practice, I believe that, in addition to the title of environmental educator, I evoke the title of 'activist'. Activism is an intentional act towards generating change, and, in an educational setting, could be considered to be a useful frame although there is an apparent marginalisation, especially within academia (Tripp \& Muzzin, 2005) and use of the term seems limited and contested. It is my hope to reinscribe this term and to 'use its powers for good': to generate social/cultural change. I believe activism requires having a voice about the intentions and actions taken. It is not enough to want to change, I need to understand how to change and what the implications of change are, then change myself and talk about it with others, supporting their developing awareness, conscious (re)consideration, and possible change.

With a constant ebb and flow, I have been refining, challenging, embracing, and even rejecting living practices as they bump up against my worldview and desire for critical engagement leading to social/cultural change. The implication is that I am a composite of various learnings as each practice I undertake has been encouraged from somewhere else and it is the choice to embody a given practice that is my first action. A (co)constructed environmental educator is one who acknowledges that she has been taking onboard thoughts, ideas, and actions from her peers, students, and her communities. I acknowledge that I am socially constructed and I strive to understand my (co)construction so that I might become aware, critical, and find ways to take an activist 
stance, especially in this time when I believe the need for change is beginning to feel inevitable and imperative.

We exist in a time where social pressure and desire to conform encourages us to live in excess and wastefully (Leonard, 2010), yet we are seeing increasingly unstable climatic events (Gore, 2011). For example, we are hearing reports from many scientists that suggest that we can, and should, be making changes in how we live (Gilding, 2011). We are past the place of hiding in denial regarding the need for change (Gore, 2011). "We must accept the world as we know it is going to change" (McKibben, 2010, p. 176), yet finding ways to engage others in social/cultural change towards living more sustainably is challenging.

\section{Coming to the Question}

My passion for living sustainably is not about the feeling of satisfaction and selfrighteousness that might arise from such practice (Beavan, 2009). My interest and passion comes from a deeper, less easily satiated, place. It is not only about what I want for myself, but what I consider seems fair for all, including the non-human others with whom we share this space/place and rely upon to jointly and equitably participate in our living Earth systems. The understandings and values necessary to live responsibly and in harmony with natural systems seem to me to be obvious and basic, yet they do not take precedence in formal schooling and are not often obvious teachings in communities and families, especially in our western societies (Gray-Donald \& Selby, 2008). Palmer (1998) noted a similar lack in formal education when she offered this statement:

Environmental education is a field characterised by a paradox: whilst few would doubt the urgency and importance of learning to live in sustainable ways, 
environmental education holds nowhere near the priority position in formal schooling around the world that this would suggest. (p. ix)

I believe that learning to live in sustainable ways takes practice, and, if I am to be the educator I want to be, I need to be sure I can confidently live sustainably and educate from this informed, embodied, (co)constructed position. Through my research I explored Palmer's paradox to determine what I could do to transform my educational practice. I asked, (how) can I use personal change to inspire educational and social/cultural change?

Ultimately, I want to live this change for myself and then support others (future teachers specifically) to engage in learning opportunities that are critically framed so that they, too, can come to appreciate the need for change in their own living practices. Through their transformational education experiences and the resulting ontological or worldview change that may come from such work, these future teachers may offer the same opportunity to their students. And so the cycle continues and the education system facilitates movement towards achieving broader social/cultural change.

Implemented with an autoethnographic self-study methodology and the theoretical framings of critical, poststructural, ecofeminism, my research attempts to draw autobiographical experiences into autoethnographic awareness. Once I learned how to practice living more sustainably myself, I embraced an environmental education opportunity where I led a class of third year university students (undertaking an education degree) through my self-study where I reflected and critically appraised what it is to become an intentional, embodied, (co)constructed environmental educator. The transformational education experiences and critical pedagogies supported these students to reflect on their own living practices and to consider making changes towards living 
more sustainably. In addition, these students are now prepared, through personal experiences and educational strategies that can be implemented in their future classrooms, to influence their students and their communities towards embracing more sustainable living practices.

\section{Telling Stories}

My dissertation reveals, often through story, a journey of self-discovery (personal change), professional development (transformative education with critical pedagogies), and activism (social/cultural change), as I become a changed practitioner and educator working to create change in the education system and society. In this Introduction (chapter 1) I use three autoethnographic short stories to illustrate how I found my research question hidden in a desire to successfully perform as an environmental educator who walks her talk. The Literature Review (chapter 2) draws upon critical poststructural ecofeminist theoretical framings (that mirror my personal ontological positioning and worldview) to investigate what my action and activism can do to transform education and unpack the problems of the environmental crisis and the possibilities of living more sustainably. The Methodology (chapter 3) offers the methodological framing that details how I used autoethnographic self-study to embody change through rigorous processes. The work of this research was to commit to living more sustainably while effectively participating as a critical educator and an activist in society. In the Findings (chapter 4) I present stories from the journey, focusing on what I believe I achieved and describing some of the challenges along the way. These stories and their implications are unpacked in 'So What?' (chapter 5) where I ask 'so what can this mean?' drawing out the usefulness of self-focused research with critical awareness and action. The Conclusions 
(chapter 6) offer some summarising statements and thoughts, setting me on a continuing journey of becoming.

\section{A Storied Beginning}

I begin this exploration with an autoethnographic representation of three life experiences, coming to understand why I believe, think, and feel the way I do. I use autoethnography for three reasons. Firstly, it allows me to share pieces of myself, situated within, and framed by, my culture. Secondly, I enjoy learning through story, especially stories that are designed to reveal more than just the events at play as they look more deeply into the culture in which they were constructed. Finally, because of my use of autoethnography as a methodology, framing the research that follows, it seemed to make sense to use this methodology from the beginnings. I am aware of the critiques of autoethnography and address some concerns prior to unpacking and describing how I use autoethnography specifically in the Methodology (chapter 3).

My autoethnographic stories are told in a different, more personal, voice and describe important parts of the journey that bring me to this place of wonder and research. I chose to present these stories in italics to constantly remind the reader that there is a different voice telling these stories. I repeat this strategy (personal stories depicted by a different, a more personal style of writing, and presented in italics) in other places throughout the dissertation.

\section{My beginnings.}

Growing up on a farm in the southwest of Western Australia established a deep understanding about many aspects of life, living, and death. I was intimately involved with the discourse and practice of food production. We grew cattle, sheep, goats, pigs, 
chickens, turkeys, and ducks: all for consumption (our own and for others). We had a large orchard and vegetable garden and lived next door to one of the largest operational orchards in the southern hemisphere. We also grew some crops that fed our livestock and other crops that were sold to feed people, often in other countries. There was a cycle, a food web in action, right there, on our few thousand acres.

Food was something I knew, as I participated in its production, preparation, and consumption. I checked for eggs and milked the cow; I mustered the sheep and helped feed the cattle. I even helped grandpa kill an occasional sheep (well, I stood around and watched). At shearing time I navigated a bizarre gender balance between helping Mum prepare the shearers food and helping Dad get the sheep in and back out. I liked to help although mostly because helping allowed me to do the things that I thought were fun... like riding my pony, Mykonos, and doing a bit of cooking, always feeling the importance of being involved and included in the practices of our family.

Animal production means that at particular times of the year there are babies all around. I loved looking after lost or orphaned lambs, kids, and the odd calf. At times we would have a little flock of up to 15 lambs to feed. Having this number of orphaned lambs meant that it was a bad year, but I loved it. Feeding three times a day, making the milk (mmm the smell of the milk powder), cleaning the lambs' house and the milk bottles, and naming the lambs. Not many survived, only a few each year. These lambs grew into 'the pet sheep' and were a constant bother for the rest of their natural lives-you see, you couldn't eat or sell a pet! It was partly the nurturing and caring, but mostly the responsibility that I enjoyed. Having something totally dependent on me made me feel necessary, important, and alive. I was no longer the littlest thing around, I had purpose and I was needed!

Being a second child and the only girl (or only a girl - depending on the day) afforded me a shadow pass through these worlds. I could, for the most part, choose my adventure. Sometimes I preferred to cook with Mum (and she could always use the help) but mostly I liked to carry the food from the house to the shed, so that I could have an excuse to hang around and watch the shearers, hear their stories, and, at "smoko" (morning tea), join in by eating the food while drinking hot sweet tea. These men lived lives that were so different to mine; I couldn't even imagine. Their humour was mean; 
they liked to play jokes on each other. They lived and played hard. I knew that because I saw them roll in at 7am; bloodshot eyes, rough faces, and stiff, unhealthy bodies.

Yet, this was no 'Ma and Pa' operation, we were an agribusiness. We grew food that fed the world. We were not close to being self-sufficient; we were too busy for that. We would go to the local Co-op to do our weekly shopping, like regular people. We valued the modern appliances that made our lives easier. I remember getting our first clothes drier and complete cycle washing machine. However, I also remember the wood stove that doubled as the water heater, not particularly modern, but practical and efficient. We walked that line - the line of practical efficiencies.

Choices around production were made from research and experience. Dad would read The Countryman and Elders magazines and watch particular TV shows like Landline, or listen to The Country Hour on the radio (Australian Broadcasting Commission - ABC, of course). Diversity in farming practices was the name of the game... so diversify we did! We began an intensive pig production unit, we began to grow trees commercially, and we grew grain, just for the profit. And, many years, thankfully, we made some (profit that is) because farming expenses were high and the profit margins were low.

And then I was twelve... and sent off to boarding school. One hot summers day, life, as I knew and loved it, ended. Boarding school was a necessity (our local high school only went to grade ten, and still does); however, I was sent to board from grade seven (generally considered to be one year early). I bravely endured six years of boarding school, living three hours away from my home and feeling increasingly removed from what grounded my being.

My developing awareness of discourses and their effect as constructing devices that shape and even manipulate my way of being and thinking in this world has been a (recent and ongoing) revelation. Unpacking the (above) story in such a way that reveals some of these discourses and many of the social constructions has proven to be instructive and revealing. Finding that these personal and seemingly individual thoughts and ideas are, in fact, socially designed and manufactured to allow and disallow my way of being 
has, simultaneously, delivered great freedom and certain concern. I now look to others experiences to make sense of my own.

From my beginnings I was immersed in the discourses of the environment. Terms such as land use, resource management, soil salinity, clearing, re-vegetation, erosion, agri-business, production, economic argument, animal ethics, food sovereignty, and many others were common. I understood them from an academic position (through my zoological education) and also from the personal experiences gained while living and working on our farm. Such deep immersions have influenced how I can see and be in the world and is the basis of my environmental ethic and my ever evolving worldview.

When looking for ways to continue to reveal and articulate my ontological beliefs or worldviews I discovered others shared similar thoughts. Leopold's (1949) Land Ethic suggests that we are not the conqueror of the land-community but a member or citizen, implying the need for respect for fellow-members and the community itself. "Man the conqueror versus man the biotic citizen: Land the slave versus land the collective organism" (p. 223). Economic self-interest and profit drive agribusiness (Leopold, 1949, p. 208), the interests of the community are not often considered; however, a good practitioner (farmer) will not degrade his resource base (farm). The latter statement is the land ethic I came from; in fact, I can still hear my Dad saying almost exactly that.

Leopold (1949) offers that "[n]o important change in ethics was ever accomplished without an internal change in our intellectual emphasis, loyalties, affections, and convictions" (p. 209-210). While my brother continued to grow and develop with the family farm and its agribusiness ethic, I was 'otherwise encouraged' to stay away from the farm to undertake 'women's work' and, consequently, have developed differing ethics. Perhaps it was my interest in animals that eventually resulted in a 
zoology degree, perhaps it was the refocus of this passion towards science education that led me to teaching, perhaps it was the combination of the two that brought me to environmental education, or perhaps it was more about my passion for activism that led me to develop an ethic that more closely followed Leopold's thinking, disagreeing that in order to be of value, an economic gain had to be realised (p. 210).

Land then, is not merely soil; it is a foundation of energy flowing through a circuit of soils, plants, and animals. Food chains are the living channels which conduct energy upward; death and decay return it to the soil. (Leopold, 1949, p. 216)

Some might offer alternative framings, such as deep ecology (Naess, 1973), ecofeminism (Warren, 1995) or being ecocentric (Rowe, 1994), and, generally, I accept these titles and aspects of the frames for myself. I find myself agreeing with Leopold again, in that " $[\mathrm{t}] \mathrm{he}$ evolution of a land ethic is an intellectual as well as emotional process" (p. 225) where "our present problem is one of attitude and implements" (p. 226) stemming from generations of withdrawal, alienation, and disconnection. It is time to join intellect with emotion again, and to re-inscribe an ecocentric land ethic deep within our society, undergirding the change (back) toward sustainable living.

Rowe (1994) offers a rich description of ecocentrism where the entire ecosphere is of greater significance and consequence than just one species, Homo sapiens (p. 106). The opposite perspective is anthropocentrism, where humans perceive the environment is there solely for our use and benefit. Leopold's (1949) Land Ethic paved the way for articulating ecocentric thinking and understanding that the integrity and health of the whole Earth system requires its component parts to also be (balanced) working systems. Humans have over-stepped our mark, currently our population is well beyond the Earths carrying capacity (Gilding, 2011), effectively consuming capacity from other species, 
leading to a greater mass extinction than ever seen before (Watson, n.d.). I want to continue to critique my practices ensuring that I learn to live and practice teaching in critical ways that honour my ever developing and deepening ecocentric worldviews, that I have a place within integrated, complex Earth systems, but not dominion over them.

As I move towards a deeper understanding of how to name and frame my worldviews I can begin to articulate where the beliefs that undergird my practices might come from, and to see similarities with others worldviews. Perhaps coming to understand how my worldviews interact with others may allow me to develop deeper, more informed, relationships in my teaching practice, which will, ultimately, render my practice more effective and critical (Hart \& Kindle Hodson, 2004). Knowing that not all see the world as I do encourages me to be more inclusive in how I conceive, plan, and implement teaching experiences for my students. If, as Leopold suggests (above), our problems stem from disconnection, alienation, and withdrawal, I can knowingly attempt to address this through my teaching practice. Without any awareness, I may not think to do so, as I don't personally feel alienated or withdrawn and I constantly practice connection. Demonstrating how the struggle to come to know and understand then learning to embody this awareness and change my practice may lead me to become a better educator. My personal experiences with critically engaging these ideas, learning new ways of being, and becoming a careful practitioner affords me the ability to respond personally to the struggles my students may face. Coming to know and understand my society and culture through my own construction, via autoethnographic inquiry, can lead me to become aware of our potentially limiting social constructions. Coming to know 
and understand can also provide some notions as to how to re-inscribe alternative possibilities or how to reconsider (deliberate) and work to change my practice.

I can now see how socially constructed discourses relating to gender, class, and race ran strongly through all that could be, and was, in and around our small, rural community. Social constructionism encourages us to critically reflect on our assumptions regarding what we know and believe. Knowledge is filtered through social processes that enable a deeper (and possibly different) understanding of history and culturally relevant ideas determining what may develop into our shared understandings (Burr, 1995, pp. 3-5). Understanding the concepts around social construction affords certain insider perspectives. When applied to my embodied (mind and body) experiences, considering that I am socially constructed has provided a depth of knowing that has stayed with me, framed my perceptions, and helped to shape how I can see and be in the world. I think that I have come to appreciate the lenses through which I perceive culturally, and therefore, personally.

To offer an example, we, in western society, are becoming increasingly disconnected from our earth systems that we are part of and that support us (Davis, 2009: Gilding, 2011; Kingsolver, 2007; Leonard, 2010; Nhat Hahn, 2008; Roszak, 1978). Commitment to overcoming the "conventional division between humanity and nature" (Salleh, 1993, p. 225) requires a reconceptualisation of our western capitalist systems that seem to override all Earth system considerations. Deep ecology and ecofeminism, for example, are philosophies that bring opportunities for dialogue about disconnection as they explore more harmonious ways of living with/in the Earth systems. Living with awareness and active commitment to privileging Earth systems over capitalist economic 
systems will take agency (the capacity to make choices) and preparedness to step outside the scope of 'normal' social practice, for a while, until a new normal is established. Western society has experienced cultural change before (for example, the Hippie movement of the 1960s and the agricultural revolution post World War II (Kingsolver, 2007)) and therefore we can understand what efforts are required to undergo change. Working towards cultural change feels like a worthy pursuit, and one that I will continue to explore (and work towards) through my research and beyond.

\section{Becomings}

There were a few moments that, upon reflection and with a developing awareness of my construction, framed how life moved from these strongly grounded (through place, environment, food, and worldview) beginnings. These stories are islands in an ocean, yet somehow, they have become footholds for forward momentum upon a trajectory that could not have been foretold. My second story explores a field of education in which I began to find a home or, at least, a place of comfort. As I learned about environmental education and, more recently, began unpacking my worldviews in relation to others, and, in light of my social constructions and the available and comfortable discourses, the connections became apparent between how I could practice education inline with my worldviews.

Following my second story is an examination of our dominant mechanistic western worldview and how, through this worldview, our education system was designed to reinscribe tendencies of human supremacy over all other aspects of the earth (anthropocentrism). Environmental education was born from this system and continues to struggle with fundamental issues and inconsistencies from this inherited mechanised 
orientation. The relatively recent attempt to impose the language of 'education for sustainable development' as a substitute for 'environmental education' offers little relief and alternative. However, environmental education, in its finest and most critical form, acts as a suitable critique to our western, mechanistic education system and should be celebrated, embraced, and upheld (Hart, 2011; Stevenson, 2007a). A brief and selected history of the field of environmental education is offered as grounding thoughts.

\section{Becoming an environmental educator.}

"Will she ever grow up and leave school?" A taunt my family like to tease me with, at every opportunity, and, to be clear, there are many opportunities! I have often reflected on the purpose of such teasing. It could be a light-hearted slap, prompting me to get a socially appropriate job because they feel concern or even embarrassment about my seeming lack of fitting career choices. It could be a request for me to follow a more traditional role for western white females of rural background (which is basically to marry, clean, bake, and breed). It could be nothing more than teasing, which seems to be the Australian way! Despite this, I celebrate my path in and through education, feeling fortunate for many amazing experiences and an ability to gently touch lives, for a while.

I love learning. I love being in a place that values curiosity, critical thoughts, and careful articulations. I have been fortunate to have stumbled upon and taken advantage of many great learning opportunities. With a confidence that has taken many years to generate, I feel a sense of privilege at being able to accept these opportunities and take the time to delve, question, consider, change, and, eventually, do and be.

I love teaching. It is a relational experience where groups of people have a desire to gain some conceptual and contextual experiences and understandings. Teaching was my first job... as a horse-riding instructor. From here I changed sports and spent many years teaching swimming during the long hot Western Australian summers where being in a pool or at the beach and being paid was the greatest way to be employed. From here it took some effort for me to finally realise that I loved teaching as a vocation not a 
vacation and, as a result, I headed back to school (and the family add "and she never left").

Years spent teaching in the classroom consolidated my desire to remain in this profession. However, it also prompted me to look beyond the immediate satisfaction found in secondary science classrooms. I took myself off to Jurien Bay (a coastal town about three hours from where I was teaching) for some professional development. I'm not sure how I heard about this event, what I thought I was going to achieve, nor why I went, other than Jurien Bay is a beautiful place. However, upon arrival I discovered a field of education and colleagues that turned my educational experiences upside down. I found a new space and place - and it felt comfortable and familiar, just like home. I found environmental education!

At Jurien Bay we spent time outside, played around in the intertidal zone, learned games that were ecologically thought provoking, checked out resources, held discussions and had a wonderfully fun time. What my students and I enjoyed doing suddenly had a name, friends/colleagues, and resources. I was excited and a little peeved that I was only learning about this field now, where was this in my education training? Better late than never, I suppose.

I went back to my school and started getting connected. I found there was a national association and there was even an active state branch: The Western Australian Chapter of the Australian Association for Environmental Education (AAEE - pronounced A squared, E squared): I promptly joined. I started meeting people who used environmental education in their classroom, people who supported classroom teachers to do amazing environmental programs, and people who created resources. My teaching practice became richer and more locally focused. I began to use resources (people, packages, programs, and places) and my students responded positively, enjoying the engaging opportunities that were coming our way. More students tuned into what we were doing and became invested, involved, and interested in learning about their local ecosystems. I felt more confident and more supported in my teaching and I was learning more about my local environment alongside my students.

I seized employment opportunities that broadened my sphere of influence beyond the students and their families of one school to a number of schools and their 
communities. I reveled in an environmental education focus, however quickly realised how marginalised this important (in my mind, critical and foundational) learning focus was. So, I stepped sideways to gain valuable insight and understandings about how the education system could benefit from environmental education. I took a job supporting teachers to implement the newly mandated curriculum; working to infuse their unit plans with environmental learning. I enjoyed a deeper conceptualisation of what a curriculum could be and I found a way to work with teachers who were engaged (refreshing my sagging spirits).

I wanted to know how to initiate and sustain change towards deeper environmental consciousness and practice throughout the education system, not just in one school, or district, but the entire system. So, I took a job in the Central Office of the Department of Education as a Curriculum Consultant to learn the machinations of this beast - the education system. I was searching for the 'chink in the armour', the place to initiate change, the way to infiltrate with environmental ethic and practice. I couldn't find it but I learned about the system, and it frightened me! There was such rigidity in the structure and ego in the individual. I worked less with the teachers who shared my passions for a better way and concerns for the system and more with the system itself. I didn't enjoy this experience so I found a plausible escape route, and took it.

Fortunately, while enjoying this escape/adventure I met colleagues with integrity, intellect, and attitude that, once again, inspired me. I was captivated and followed my hearts desire to embrace a positive, critical way of being. I went back to school!

Gray-Donald and Selby (2008) suggest that a "mechanistic worldview has penetrated the assumptions and perceptions of mainstream western thinking to such an extent it has significantly influenced every area of human endeavour and enquiry" (p. 3). They go on to suggest that reductionism is how we come to know things in a mechanistic worldview and it implies that each component of the Earth system can be knowable and reifies the separation of mind from body and humans from nature. The unfortunate result has been the "hubris and dysfunction of the notion of human uniqueness, the underside of 
which is the modern sense of alienation and of existential crisis" (Gray-Donald \& Selby, 2008, p. 4). Carson (1962) gave ample exemplification in Silent Spring when she exposed our apparent misunderstanding of Earth systems through documenting the impacts on the environment of the use (and abuse) of chemicals (herbicides and pesticides) in agriculture. "The dominant western worldview is not based on seeing synergies and connections but on making distinctions and seeing differences" (Robinson, 2009, p. 254). Education systems reflect the social complexities of the times, so that "[f]or centuries, the human mind has been shaped by education that treated the universe as a machine, and humans as cogs in the machine" (Shiva, 2009, p. xi).

A 'worldview' is both a projection as well as a reflection on how I see the world. "The cultural worldview, or social paradigm, is a story about the way the world works. It is "the basic way of perceiving, thinking, valuing, and doing associated with a particular vision of reality (Harman, 1988, p. 10)" (Sterling, 2007, p. 66). Bateson suggests that the dominant western worldview contains epistemological errors in our habits of thought at deep and partly unconscious levels where there is a perception of and belief in separateness (Sterling, 2007, p. 66). An ecological worldview offers a suitable alternative as it can be described as "a living systems or relational view, wherein everything, including human agency, unavoidably participates in the dynamic condition and future of the whole because everything is part of the whole" (Sterling, 2007, p. 67).

I choose to see the earth as a series of interrelated systems. I am part of many systems and rely on them and many more for my survival. I have no right to overly influence any other system, and I acknowledge that doing so may, ultimately, (negatively) influence my own survival. Figure 1 graphically depicts aspects of ecocentric ontology, my ecological worldview, and my ecofeminist beliefs (named "Right") as opposed to the 
dominant discourse (named "Wrong"). Although this is a critical representation of western perspectives to our Earth system, this diagram (see Figure 1) maintains dualisms, suggesting a binary that is somewhat helpful to broadening our perceptions, although still limited. Man is not the pinnacle species (and gender) to which all others are subservient. We co-exist in an interrelated, interdependent system: an Earth system. We assume with compassion, attempt greater understanding and connectivity, and have intentions leading to action towards a systemic wisdom that is more integrative and ecological (Sterling, 2007). We expand, connect, and integrate (Sterling, 2007).
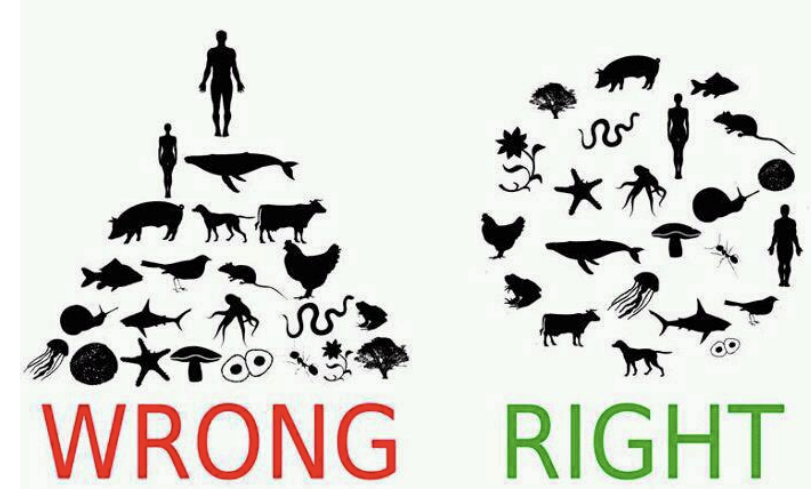

Figure 1. Presented in a limiting dualistic way, yet urging us to consider our Earth systems differently suggesting movement from hierarchical organisation (Wrong) towards greater systems thinking and interdependence (Right) (Occupy Santa Ana, 2012).

I conclude, from my experiences in education and the opinions of others, that possibilities for transformative learning are limited in opportunity by the establishment of policy and process that is more interested in offering an average education to all rather than individualising education and working to design a brighter future (Apple 2007; Gray-Donald \& Selby, 2008; Orr 1992b; Orr, 1994). Robinson (2010) demonstrates, in a carefully animated story, how education, as we know and have experienced it, was "conceived and designed in the intellectual culture of the enlightenment and in the economic circumstance of the industrial revolution" (2:11 mins) of the 1600s to $1800 \mathrm{~s}$. 
The aim was to produce workers who could cope in factories and continue to consume products, therefore promoting continued economic growth. It was thought possible to know and come to understand how our world worked and that education provided a linear path to this success, for some. It seems that we are continuing to produce students with these intellectual and economic premises in mind (Orr, 1992a, p. 83), which is poor practice given what we know about the current state of most Earth systems and the unfolding realisation of the unsustainability of unlimited economic growth in a finite Earth system (Leonard, 2010).

Twenty years ago, Orr (1992b) offered an interesting observation when he stated, "we are still educating the young as if there were no planetary emergency. Remove computers, a scattering of courses throughout the catalog, and a few programs, and the curriculum of the 1990s looks a lot like that of the 1950s" (para. 4). I believe that the same can be said of our education system today and that nothing much has changed in the last twenty years. Orr (1992b) called for:

1: a refocus on how we determine truth (away from the need to count, measure, and quantify as the ONLY measure of truth), recognising that we are moving beyond the Enlightenment period towards an acknowledgement that truth is always perceived and interpreted through each individual's lens.

2: close attention be paid to the hidden or implicit curriculum and western society's basic assumptions that subtly support human domination over the environment; continuous growth of the economic system; belief that all knowledge is equally valuable; and, that material progress is a human right.

3: awareness against teaching in support of individualism and not for citizenship and shared responsibilities. Teaching for individualism results in the lack of understanding 
that we live as citizens of biotic communities. We could be working towards a global identity that is established from a place of deep cultural identity.

4: critique of our reliance on technology to fix our issues, which we adhere to with an almost sci-fi fantasy. Technology can provide appropriate alternatives to many of our damaging practices, yet it is not useful to consider it the only solution available.

Twenty years on, I believe we could still benefit from taking up these suggestions as little has changed in our classrooms, our society, and with our general disregard for our place/space in the Earth system. Each of the four points listed have been taken up through my research in some way, for example, the hidden or implicit curriculum was carefully regarded and explicitly critiqued through my self-study of teaching.

Our current system of education is operating under an industrial metaphor with keywords being: utility, linearity, conformity, and standardisation: while many suggest we need to move towards an organic metaphor with keywords such as: vitality, creativity, diversity, and customisation (Apple 2007; Gray-Donald \& Selby, 2008; Orr, 1994; Orr 1992b). We are teaching students now who will likely retire in 2065 from jobs that, perhaps, haven't yet been conceived and we can't even imagine. We are unable to say, with any confidence, what we will be employed to do in ten years time, let alone in 53 years. So are we really preparing these students well if we are educating them in the same worldview of the Enlightenment and economic linearity of the $20^{\text {th }}$ century?

Within formal education there are fields that offer opportunities to critique and challenge the status quo of a mechanistic education system. Environmental education has been named as one such field (Bowers, 1997; Gray-Donald \& Selby, 2008; Orr, 1992a). Strong argument by Stevenson (2007) reveals how rhetoric and philosophy may not 
match what is playing out in the classroom, creating a "rhetoric-practice gap" (p. 266) in formal education (Stevenson, 2007; 2007a; 2007b).

The notion of an interconnected web of social and environmental issues is accepted at the rhetorical but not concrete level. The view of the human relationship with nature offered within environmental education is primarily anthropocentric (human centered) and instrumental. (Gray-Donald \& Selby, 2008, p. 4)

Others (Bowers, 1997; 2011; Orr, 1992b) might suggest that most education reform is based in ecologically destructive cultural assumptions. Environmental education challenges these assumptions.

Environmental education has a long history that stems from early $19^{\text {th }}$ century urban and rural studies focusing on teaching history, geography, and local nature studies (Palmer, 1998, p. 4). One of the first formally recognised definitions published from the International Working Meeting on Environmental Education in the School Curriculum (IUCN) in 1970 (Palmer, 1998, p. 7), can be synthesised into decision-making skills and a code of behaviour following beliefs and values that recognise the inter-relatedness of man, his culture, and Earth systems. Through subsequent iterations, and two years later, the goals of environmental education from the Belgrade Charter, were published:

Environmental education, properly understood, should constitute a comprehensive lifelong education, one responsive to changes in a rapidly changing world. It should prepare the individual for life through an understanding of the major problems of the contemporary world, and the provision of skills and attributes needed to play a productive role towards improving life and protecting the environment with due regard given to ethical values.

The goal of environmental education is to develop a world population that is aware of, and concerned about, the environment and its associated problems, and which has the knowledge, skills, attitudes, motivations, and commitment to work 
individually and collectively toward solutions of current problems and the prevention of new ones. (The Belgrade Charter, 1975, p. 1)

Including governmental representation in these international meetings came to fruition at the Tbilisi meeting of the United Nations Educational, Scientific and Cultural Organisation (UNESCO) in 1977 and the outcome was amendments to the goals, objectives, and guiding principles. The goals stated were:

1. to foster clear awareness of, and concern about, economic, social, political, and ecological interdependence in urban and rural areas;

2. to provide every person with opportunities to acquire the knowledge, values, attitudes, commitment, and skills needed to protect and improve the environment;

3. to create new patterns of behaviour of individuals, groups, and society as a whole towards the environment. (The Tbilisi Declaration, 1977, p. 1)

Twenty years after the Tblisi Declaration was the UNESCO sponsored International Conference on Environmental Education: The Ahmedabad Declaration, 2007. The language used in this declaration has shifted slightly to reflect the discourse of sustainable development, or, more specifically, education for sustainable development. Unfortunately, the language of sustainable development stems from the mechanistic world and does not bring to life an Earth systems approach that is called for by Bowers (2011), and many others (Gray-Donald \& Selby, 2008; Orr, 1992a; O’Sullivan, 1999).

The Ahmedabad Declaration (2007) Call to Action was devised, stating,

We must reconsider our tools, methods and approaches, our politics and economics, our relationships and partnerships, and the very foundations and purposes of education and how it relates to the lives we lead. In making our choices we draw on, and are inspired by, much work that has gone before us... Environmental Education processes support and champion Education for 
Sustainable Development. Such education processes must be relevant, responsive and accountable. Research is encouraged to provide additional rigour and credibility and to identify increasingly effective methods of learning and sharing knowledge. (The Ahmedabad Declaration, 2007, p. 1)

Acknowledging that there are many complexities when any field shifts, and that changing the language is just one action, however; the above call to action might actually work to reify the mechanistic, anthropocentric worldviews that support the rhetoric-practice gap Stevenson (2007) articulates leaving us to ponder Einstein's quotation “[w]e can't solve problems by using the same kind of thinking we used when we created them." Environmental education can be (should be) so much more as suggested by Saylan and Blumstein (2011) in their recently published book The Failure of Environmental Education: And how we can fix it. The obviously inflammatory title has generated considerable interest, which is a great starting place when working towards generating change.

It is time to look for alternative philosophies, which can inform different practices and work towards

a greater openness to new approaches, and different ways of thinking and working, more understanding across cultures about who we are and what we know, and a stronger research focus on understanding the relationship between sustainability, society and learning. (Scott, 2009, p. 155)

Scott (2009), at the Fourth World Environmental Education Congress in 2007, suggested a way to move towards a brighter, more engaged, future for environmental education is to look closely at the research in and beyond the field looking to unravel the relationships.

It seems timely to also question the varied discourses at play, as there is, for example, consternation around the notion of sustainability. 
[E]nvironmental education contributes to the double bind of helping to address environmental problems while at the same time reinforcing the use of the language/thought patterns that underlie the digital phase of the Industrial Revolution we are now entering on a global scale. (Bowers, 1997, p. 141) For example, Payne (1999) argues that a "critical ecological ontology for educational inquiry” (p. 5) provides a necessary complement to the 'socially-critical' perspective highlighting the personal politic required for socioecological praxis. In doing so, he reminds us that we benefit from considering our assumptions, epistemological biases, and our uncritical ways of being. Reviewing the dominant discourses and their expression in our field might enable changes in practice towards seeing and being differently. Allowing a letting go of the privileged dominant discourses and moving towards greater critical consideration of our ecological positioning is one way forward. It is the way I chose to explore in this research, using autoethnographic methodologies to come to understand the discourses that construct my ways of being and worldviews.

Environmental education is an exciting field and offers much by way of critique to the education systems and current education reforms. Work undertaken to deeply consider the philosophical underpinnings of current practice is necessary work. Close attention to the assumptions underlying environmental education practice will need to become everyday work and Payne $(1999 ; 1997)$ offers us many ideas. I have taken up some of his ideas for further exploration through my research, namely the notions around practicing critical awareness about the relationships I have with possessions/food/stuff and how I might bring my practices inline with my ontological beliefs or worldviews. Achieving change in thought and practice has required creativity and determination and has been transformative. 
Similarly, O'Sullivan (1999) cautions against educating for the global economic marketplace, suggesting that we need new levels of creativity to move our collective western consciousness towards addressing our vital needs for planetary survival (p. 181). To achieve this end, he defines integral transformative learning.

It involves experiencing a deep, structural shift in the basic premises of thought, feeling, and actions. It is a shift of consciousness that dramatically and permanently alters our way of being in the world. Such a shift involves our understanding of ourselves and our self-locations; our relationships with other humans and with the natural world; our understandings of relations of power in interlocking structures of class, race, and gender; our body-awareness; our visions of alternative approaches to living; and our sense of the possibilities for social justice and peace and personal joy. (O'Sullivan, 2002, p. 11)

Transformative learning has been described as "teaching for change" (Taylor, 2009, p. 3) as students are challenged to assess their values and worldviews and are, subsequently, changed through the experience. The core elements of transformative learning have been defined by Taylor (2009) and include: individual experience, critical reflection, dialogue, a holistic orientation, awareness of context, and an authentic approach (p. 4). These elements are necessarily delivered within a learner-centered teaching practice (Taylor, 2009, p. 14), which leaves questions around how teachers teach and are taught to teach. I take up these questions in my research, exploring through self-study how I teach from a critical, grounded, experiential, environmentally aware position and with a transformative, action-oriented practice. My research is conducted within a teacher education program, where consideration is given as to how these teachers may take up questions and practices for themselves, following their, recently reviewed, critical considerations and worldviews. 


\section{Becoming Socially/Culturally Aware}

Future society, it seems to me, will look considerably different from what our society looks like now. I see that change can come either through education and a desire to change, mandate and the need for change, or through catastrophe and no choice but to change. I am actively working towards choosing the first option. I have put my body into living the changes I desire to see. I have been walking my talk and feeling what it is like. With this embodied experience I designed a pre-service teachers education course that supported my students, who were future teachers, to experience their own embodied changes. The hope for the future is that these students, encouraged by their personal experiences, will maintain these changes and look for further opportunities to bring about personal and social/cultural change. Additionally, these future teachers may enable their students to undertake similar experiences of change, which may influence their families and communities to also change. Thus, a ground swell begins and social/cultural change follows.

The final introductory story describes my journey coming to understand the social/cultural implications of living sustainably and education as activism. The pressure of professional embarrassment helped me decide that I needed to change how I was living so that I could perform appropriately as an environmental educator. Embracing an opportunity to go back to school was instrumental in facilitating the space to make this change. Through my experiences I have hoped to positively and critically influence others and I hope this influence continues to flow forward and outwards, as more take up the challenge to live lightly on our earth. 
Following my third story is a brief exploration into the theory of transformational learning and critical pedagogy, as I believe that I have undergone my own critical and transformational experience and worked, through my research, to facilitate a similar journey for others. I conclude this chapter with an exploration into what social/cultural change is and can be, suggesting that transformational learning is part of the process.

\section{Becoming an activist.}

I knew that I needed to STOP! I wanted time to think, to read what others had thought about, and to understand more completely. And I couldn't think of a job that would encourage this important work. Each time I told someone about my desire for time and space they said, "Well, it sounds like you need to go back to grad school". And suddenly, it was done! I was living in Canada, enrolled at university, again, and late for my first graduate class in Curriculum Theory.

The rollercoaster ride began. I found myself immersed in a different culture; learning to stay put after a year on the road (literally, having circumnavigated North America); and starting a graduate program. I discovered an entirely new language (that I didn't realise existed); how it felt to be othered; that Canada and Australia are similar cultures, but certainly not the same; and, that life as a student was difficult, especially at 35. The learning curve was exponential.

One of my coping strategies was to generate personal resilience. I maintained connections to friends and family at home and cultured new relationships here. I volunteered my way into organisations in Saskatchewan taking up activism here and at the national and international level. I found ways to surround myself with other living beings (plants and animals) that somehow satisfied part of who I am, and, eventually, I bought a home and $a$ dog and became a Canadian citizen. I created a new life with a great community of places and beings.

As I started to build my new life and began taking the time I wanted to ask questions and seek answers, I realised, with great embarrassment, that I embodied the problem, not the solution, to many environmental issues.

"Hi, my name is Peta, I moved to Canada to study environmental education 
and I have an ecological footprint of 16.4 hectares $\left(H A^{1}\right)$ '”.

The Canadian average (in 1999) was 6.9 HA (Royal Saskatchewan MuseumEcological Footprints, 1999). If everyone in the world lived like I was, we would vastly exceed the carrying capacity of our planet. In fact, if everyone on our planet lived like me, we would need 8.7 earths. On top of that, if we also valued biodiversity and required at least 70 percent of the biodiversity present today to still be around and to have space to live, we would need 34.9 earths. That's 35 planets!

I am not suggesting that we need to return to the days before international flight, year round oranges, and computer technology; however, I suggest that we use these and other luxuries of our modern era with awareness and critical consideration. I like to challenge myself to be aware of the implications of my choices and by doing the work before I make my choice I can lessen my impact on the environment.

I find that in our society there is a great deal of dependency on others'. Convenience literally means saving time and energy by paying to have someone else do it for you. We apply this to our personal grooming, all aspects of gathering and preparing our food, and even decorating our homes. Taking back responsibility for managing ourselves seems like a wonderful place to begin and a worthy challenge for myself.

My favourite environmental issues are those that relate to how we choose to manage our health and food. There are other issues that resonate too, such as: transport, housing, clothing, and consumerism in general and specifically how it relates to showing love and goodwill in our society (especially at Christmas and birthdays). Food and health, however, are interrelated and have become areas where we often seek others' advice, opinion, and products looking for that golden bullet, fast fix, and cure-all. Food and health are wonderful areas where personal challenges to embrace a more sustainable practice can be rewarding and relatively easy to undertake.

The food systems of western society, especially in North America, have become corporatised where priority is given to economic growth rather than consumer health. Documentaries such as Food Inc. (Kenner, 2008) demonstrate some of the problems and present the issues in a clear, easy to comprehend, medium. Additionally, Michael Pollan (2006) has written extensively on how to reconsider our food choices from McDonald's to

\footnotetext{
${ }^{1}$ The ecological footprint calculation is measured by hectares (HA).
} 
growing and gathering our own foods. Barbara Kingsolver (2007) moved her entire family to a location where they could begin to live without the corporatised food system. They learned to grow and prepare their own food and consume local products. Ifound this inspirational and, in my own way, began to emulate the journey towards taking responsibility, working towards practicing greater sustainability, and finding healthier ways of nourishing myself.

Health care, as it relates to food, can be as easy as reading and understanding the ingredients in the products we choose. Many products that we eat and apply to our bodies are neither good for us nor safe for consumption. I understand the trust and unquestioned belief that suggests we couldn't make the purchase if it wasn't safe, yet the safeguards that should protect the consumer are not in place as we might hope and they really don't deserves our trust. Consumers should investigate these issues and make their own informed decisions. Additionally, many of the processes that our food goes through before it gets to us are alarming and could result in serious health issues. This includes: pesticide use and excessive artificial fertilising, packaging, canning, high heat extrusion, transportation around the world, and often back again, waxing, and preserving, with a special mention of genetic engineering.

I have changed the way I feed myself. I only shop around the edges of the supermarket, if I go there at all, preferring local food markets or organic shops. I support the local Farmers' Market, preferring to buy from people with whom I have relationships. I make most of my food from scratch having sourced local providers. I have even grown much of my own food and preserved it where I can: dehydrating, canning, and freezing vegetables. Living in a place that is frozen for over half the year has increased challenges. And, as a consequence, I have learned about sprouting where I can produce my own fresh, local nutrients throughout the year. I refuse to purchase strawberries year round as they are a seasonal fruit, I don't eat bananas as they are not grown on this continent, and I won't eat beef that isn't locally grown, grass-fed in pasture and locally processed.

Many of these choices cost me time and energy and, occasionally, more money. Yet they offer so much more: increased nutrients leading to a better value, better health, exercise, clear choices with most of the implications revealed, and a significantly 
increased level of responsibility for my food consumption and personal and environmental health. I have learned a lot about food and food preparation and I enjoy the connections I've made with local producers. I am proud of the efforts I have made towards becoming a more responsible and sustainable consumer.

I continue to learn about myself, how to live more sustainably within my society, and how I want to carry on becoming an environmental educator/activist through intentional embodied action. I am deeply committed to living through intentional practice and using embodied experiences with my students to facilitate their own experiences leading them to become committed, critically reflexive, practitioners. My research reaches out beyond the temporal and literal constraints of the last seven years and its current representation, to enjoy ongoing life in the practice and experiences of my students, their students, and my own future practice.

My research holds me to an articulated, conscious, intentional, and deeply personal journey that has been, and still is, life changing and transformative. Coming to this work took some courage, yet amazing and wonderful people came forward to support me in my adventures. Graduate work revealed a whole new world, complete with its own language, which has enabled me to seek understanding about my chosen field and how I operate in/through/with it. I needed to become an activist: exploring my own assumptions ontologically, epistemologically, and axiologically, (re)aligning my practices towards my ecocentric way of being, and teaching others about how and why changing the ways we practice living are important in a social/cultural context. This work is good practical research and not just good therapy. I aim to present these thoughts in such a way that it might be interesting, somewhat inspirational, and, ultimately, useful. I have included a few of the teaching tools I use to walk my students through similar journeys, thus making it easier for others to consider such adventures either personally or with their students. My research puts theory into practice and practice into theory. It is political, working in the social realm, yet it is also obviously personal. It is action orientated as much of the work is in the doing, as well as theorising about it working with others to (co)construct new, critical, ways of being. 
Apple (2007) questions, in the afterward of an important text called Social Learning Towards a Sustainable World, "[w] hat is the place of education in responding to the crisis we are experiencing?" (p. 507). He encourages searching for the education and learning that is organised around interrupting dominant assumptions, policies, and practices. Apple goes on to comment in a conversation with Freire,

[E]ducation must be a critical dialogue... [and] must hold our dominant institutions in education and the larger society up to rigorous questioning and at the same time this questioning must deeply involve those who benefit least from the ways these institutions now function. (Apple, 2007, p. 507)

Thus, suggesting that democratic education, engaged citizenry, and critical learning are what we must aim for in our educational practices.

Some, however, are looking at the larger picture and suggest that a need for societal worldview change comes first. For example, Worts (2010) states, "human beings have created cultures that are unsustainable" (p. 241). A sustainable society is possible, however it will come at a cost, which will include a "radically different economic system, political system, geography of settlements and cultural system" (Trainer, 2010, p. 6). To define culture, Schein (2001) says that it "is a basic pattern of assumptions invented, discovered, or developed by a given group as it learns to cope with its problems of external adaptation and internal integration" (p. 240). These assumptions are produced through culturally dominant discourses where new members are exposed to these disciplining discourses, learning and continuing to enact them. Thinking about culture in this dynamic way reinforces how all aspects of human endeavour work to evolve our cultures (Worts, 2010, p. 245). Hope for our culture to make the radical changes vital to our survival will come from thinking about ourselves as dynamic, dominant discourse 
constructed beings, and the challenge is to get the discourses correct. According to Worts,

[i]t seems increasingly important to recognize how we, as individuals, do not arrive at the lives we live just through our personal experiences and choices. Rather, we are largely defined by the values, attitudes, beliefs and deeds of those who preceded us. (Worts, 2010, p. 243)

However, culture is not solely rooted in the past. As implied by Schein's (2001) definition, it is the process of active adaptation and internal integration that moves culture and enables change. Adaptive renewal infers an adaptive process to culture, where the "ever-changing contexts within which humans live" (p. 245) deserves attention. As we progress towards greater urbanisation and globalisation, human culture is changing. Culture reinforced by heritage related to place has been disrupted as local spaces are now inhabited by a diversity of cultures and identity is more complex and layered into dynamic relationships.

Worts (2010) calls for the development of feedback and monitoring systems so that governments, businesses, and each citizen "can monitor how actions at all levels sends both positive and negative ripple effects across the planet" (p. 250). He goes on to ask what it will take to craft a "global framework for a 'culture of sustainability' that not only respects the heritage of each individual, but also brings everyone together in the spirit of peace and happiness for all?” (p. 250). He is optimistic that human ingenuity will meet this challenge although he suspects that we will have to experience a crisis of significant scale to precipitate meaningful social/cultural change.

Fostering a culture of sustainability begins with us as individuals and continues into our cultural, social, and economic systems. We will benefit from seeing differently 
and re-conceiving how we can be and what we can do in this Earth system. Berry (1999) suggests, "the missing element is the relation of humans to the other-than-human components of the world that we live in" (p. xi). Disrupting our place in the Earth system will require just this type of humility. Education, in many forms, can be a part of this transformation, with environmental education leading the way. Action orientated, transformative learning with critical pedagogies could be the first step to re-engaging our learners and developing the human ingenuity, optimism, and to foster a culture of sustainability. I trust that it is and I consider my research to be part of the first steps towards this worthy goal.

\section{Moving Forward}

My research investigates social/cultural change by exploring my own worldview and how this plays out in my teaching practice and how my students embody change and influence change in a broader social/cultural context. (How) can I use personal change to inspire educational and social/cultural change? My research question encourages me to look for opportunities for action based transformational experiences and critical pedagogies to manifest in our educational experiences by focusing on my own journey.

It is not my intention to suggest that my personal worldview was superior to that of my students. My intention was to provide my students with a supported and facilitated experience that enabled them the possibility to see things differently and to make their own informed and embodied choices around embracing change for their future. I hope that if these future educators make the choice to change how they live towards a more sustainable practice, that they will then encourage their future students similarly, with action orientated, critical, and supported learning opportunities, rather than through 
indoctrination. Action based learning employs personal embodiment and it is my thesis that the doing is integral to bringing about personal change, which may then lead to social/cultural change.

Action orientated learning is clearly articulated in the early goals and definitions of environmental education and forms a solid pedagogical base for such a foundational field of education. Embodying change and taking an activist role in supporting others to do the same is one way of succeeding as an environmental educator. Positioning these actions and activist acts in a higher education setting, where teaching teachers can be a transformational experience for both the teacher and learners, might just be what our society needs to lead us all to a brighter, more sustainable, future.

The next chapter (2), the Literature Review, will unpack the research question: (How) can I use personal change to inspire educational and social/cultural change? I look from my own personal worldview (or ontological positioning) where critical poststructural ecofeminist theoretical framings undergird how I can come to the question. Then I explore the educational possibilities as critical pedagogy and transformational education is explored. Finally, I (re)focus on the bigger social/cultural picture to investigate aspects of the environmental crisis. 


\section{Chapter 2. Literature Review}

...there was a new voice which you slowly recognized as your own, that kept you company as you strode deeper and deeper into the world, determined to do the only thing you could do determined to save the only life you could save. (Oliver, 1986, p. 38)

The three-dimensional model established in the Introduction (chapter 1) includes working from the personal through transformative education and critical pedagogy while keeping the bigger social/cultural change piece in mind. In this chapter (Literature Review), the model is not explored with the same linearity. I begin with the possibilities for how social/cultural change might be best theorised through exploring poststructuralist theories and the socially constructed nature of discourses that manage and maintain what is, and can be, in our society. An examination of poststructural feminism is offered that reveals a perspective of ecofeminist theory that has assisted me to understand my activist practices and my ecocentric worldview through intentional, embodied action, which could be described as providing personal epistemological expression. Finally, the possibilities of transformative education are then unpacked through the theory and language of critical pedagogies as it represents my educational practice and critical theory framework.

\section{Theoretical Purpose}

Theoretical frameworks apply lenses through which my research is delimited and undergirded. Systems of assumptions, expectations, beliefs, and theories that support, sustain, and inform this work are made clear through theoretical frameworks as they exemplify ways others have learned to see differently (Maxwell, 2005, p. 43). It is my experience that they prompt the development of questions that allow for different 
possibilities. Similarly, they offer examples of similar research opportunities and researchers who have manipulated these theories to be able to see differently in specific circumstances. The employment of useful and appropriate theoretical frameworks is imperative in research that matters (Maxwell, 2005). My research draws upon three theoretical frameworks, each supporting my coming to understand in different ways.

Theory offers an explanation of the relationships rather than the object itself (Maxwell, 2005). All research observations are shaped (consciously or unconsciously) by versions of social theory that either highlight or erase; either way manipulating the interpretations of the object that are fundamentally inseparable from the historical dynamics that have shaped it (Maxwell, 2005). Embracing aspects of one or more theoretical framework I can support focused research design (Maxwell, 2005), where each theory acts as a spotlight, illuminating what is useful about the theory in this research (Maxwell, 2005). I have taken aspects of three theoretical frames (ecofeminism, poststructuralism, and critical theory) to act as a scaffold and support for the action orientated and transformative research I have performed on myself and, indirectly, my students, and, optimistically, their students and the wider community. My research explores the relationships between self, teacher, learner, community, the environment, and our past, present, and future through an action orientated process.

\section{Social/Cultural to Personal: Poststructuralism to Ecofeminism}

The following review describes how I have come to understand poststructuralist theories as postmodern perspectives. I specifically consider what and how poststructuralism supports me to come to understand as the poststructuralist looks at what is said and done as much as what is not: the spaces, the in-between notions, and what is 
avoided becomes of interest. Once I have explored this theoretical frame I provide an application by investigating how we are socially constructed. As the social/cultural carries through to the personal (and visa versa) I use poststructural feminism to inform the ecofeminist frameworks I choose to enlist in this research. My ecocentric worldviews find support and shared language through ecofeminist frameworks. The possibility of agency is considered and activism is given as an example of its application.

\section{Postmodernism.}

Postmodernists are skeptical of the meta-narratives created in modern theories and thought that seek to control discourses (Cherryholmes, 1988). Modern thinking emerged with the Enlightenment and the meta-narratives developed were used to "guide a discipline by specifying rules and conditions for producing knowledge" (Cherryholmes, 1988, p. 9). The postmodernist perspective treats the perceptions, interpretations, and explanations that constitute our understanding and experience of reality as meaning fashioned from human actors who are limited in their social and cultural resources, rather than fact. This is not to suggest that there are no facts, and that belief in them is misplaced, rather that the representation of all fact is socially constructed (Cheek \& Gough, 2005). "Representations of the world are effects and artifacts of discourse practices" (Cheek \& Gough, 2005, p. 303). Postmodern perspectives do not transpose alternative meta-narratives; they remain "a loose collection of ways of thinking about how to go beyond modernist perspectives" (Cheek \& Gough, 2005, p. 303). Postmodern perspectives bring different interpretations to what may be possible.

“Too ephemeral for ritual, or perhaps even for rationality, postmodern events are allegedly things of flux and plurality, always forward-looking, continuously emerging, 
forever absorbing the past as [parody]" (Stonach \& MacLure, 1997, p. 79).

(Re)conceiving of our living practices in western society from a position of ephemeral, plurality, forward-thinking, and as continuously emerging is beautifully refreshing. Through choosing to operate in the postmodern my research challenges the metanarratives that were devised to control and inscribe societies, cultures, and environments.

Pragmatically, living as a postmodernist could imply consciousness of the dominant discourses of society and a critical awareness around our constructions, positioning, and subjectification. The usefulness of postmodernism is that it demands a deeper understanding of societal interactions (specifically power, discourses, and the subjectification processes). McKenzie (2005) indicates that she finds "post" perspectives "promising in their support of non-prescriptive, yet counter-hegemonic, ways of knowing and being, and in their demands for us to consider which things 'new' and 'old' we might want to reclaim or work against” (p. 485). And as Pillow (2000) suggests,

$[\mathrm{m}]$ any postmodern researchers forefront the necessity of continuing to do our work even while making visible the myriad of ways such work is (un)graspable, (im)possible, (un)intelligible, (un)knowable, and provisional. This is not a failure of postmodernism - this is the work of postmodernism. (p. 22)

Where, in a modernist view, one might see a tree with its implied hegemonic structure, a postmodernist might see beyond the expected and notice a more rhizomatic construct where more interconnections are possible and the structure of power and domination are not implied. It was the ability to see around the socially constructed ways of understanding the possibilities of environmental education that were called for in this research. 


\section{Poststructural possibilities.}

Poststructural theories question the construction of the individual in the essentialising terms of humanist theories by examining the ways the social inscribes itself on the individual. These theories show how power works not by forcing particular ways of being but by making those ways of being desirable such that they are actively taken up (inscribed) (Davies \& Gannon, 2005, p. 318). Poststructural analyses suggest that language produces and constructs (Burr, 1995, p. 56). "Language (in the form of discourses) provides our subjective experience of the world" (Burr, 1995, p. 59). Youngblood Jackson (2001) offers a path forward, with critical awareness and possibility. "When we see how certain structures and discourses get produced and regulated (and others silenced), then we might contest them, reconfigure them, and make space for new ways of learning to teach and reward difference rather than identity" (p. 396). Davies (2004) offers,

poststructuralist theory, in its openness to meanings not yet thought of, and in its dedication to not getting stuck in old clichés and explanations is often surprising,

joyful and energizing, bringing life to research and to teaching -breathing life into the educational institutions in which we are (always becoming) subjects. (p. 9) Poststructural analyses tend to focus on discourses and discursive and regulatory practices, deconstructing them to search for deeper understandings. They seek to transcend the individual/social divide and to find the ways in which the social worlds we inhabit, and the possibilities for existence within them, are actively spoken into existence (Davies \& Gannon, 2005, p. 318). Poststructural analyses offer tools to investigate these disciplining messages and codes that pervade discourse. Decoding (deconstructing) the discourses affords an opportunity to become aware and ultimately to work towards 
unraveling the subjectification. Subjectification is the historically specific process whereby one is subjected to the discursive regimes and regulatory frameworks through which gendered individuals and their social contexts are also, and through the same process, constructed (Butler, 1993; Foucault, 1980; Davies \& Gannon, 2005).

Poststructural theories provide interpretations of self beyond that of a singular coherent entity and encourage personal agency as critical in finding meaning (Butler, 1993). Using these theories to frame this research allows for the deeper exploration of power, dominant discourses, disruptions, and re-inscriptions of practice, and the deconstruction of binary hierarchies based on assumptions of singular meaning. Subjectification, multiple subjectivities, and positioning are explored under these frameworks. The personal is political, and there are greater political implications for such work.

\section{Poststructural feminism.}

My research grew from feminist poststructural perspectives which foreground issues of power (Somekh \& Lewin, 2005), while focusing on the possibilities of moving beyond what is already known and understood. By providing ways to examine socially available discourses and ways in which people take them up, poststructural feminism opens up the possibility of change (Barrett, 2005, p. 10). It is the possibility of change that is exciting and holds promise, from the perspective of a woman seeking equality, a woman who values her environment, and a woman who is active in her society. Feminist poststructuralist analysis is political work towards a better future.

Its task is not to document differences between men and women, but to multiply possibilities, to demassify ways of thinking about 'male' and 'female' - to play 
with the possibility of subjectivities that are both and neither - to understand power as discursively constructed. (Davies \& Gannon, 2005, p. 319)

Feminist poststructuralism seeks to trouble the taken for granted categories and binaries that comprise our society focusing on the processes of gendered subjectification whereby one is constructed by and subjected to discursive regimes and regulatory frameworks (Davies \& Gannon, 2005). "It shows how relations of power are constructed and maintained by granting normality, rationality and naturalness to the dominant half of any binary, and in contrast, how the subordinate term is marked as other, as lacking, as not rational" (Davies \& Gannon, 2005, p. 318).

Through working to come to understand my actions, my pedagogy, and myself, I required different ways of seeing and hearing. I had to develop and (re)learn ways to come to understand how I was disciplined and how I disciplined, how I was responsive and responsible. The theoretical framing provided through postmodern perspectives, those of poststructuralism and, to a certain extent, poststructural feminism, provide ways to understand how our society comes to understand our position as part of the Earth system. I found that thinking with and through a 'post' perspective enabled my development and practice of a more ecocentric worldview and ecofeminist epistemology, leading myself to practice living more sustainably and transforming my education pedagogies. And, if such framing can do this for me, hopefully it can do it for my students as they become teachers and for others members of society as well.

\section{How are we socially constructed?}

Through exploration into how western society has been, and is constantly being, socially constructed, the term is defined. Understanding this term enables us to consider 
strategies with which the social reaction to current environmental issues is addressed, or not. If we constantly see the world through the frames that are made possible and available to us, then changing the framing and language might change what and how we can see and be and, ultimately, our available discourses and possible worldviews.

To believe in social constructionist theory is to be critical (questioning our assumptions) about how we see and understand the world: realising that all that we know is sustained through social processes, interactions, and social action (Burr, 1995, pp. 4-5). Our task is to carefully deconstruct our assumptions, and to recognise that these assumptions are historically and culturally constituted. Newbery (2003) suggests that “experiences are never transparent, but are constructed, read, and understood through sets of social meanings" (p. 209). How we come to and take up social meanings is important if we are to change how we live in western society.

Suggesting that a rejection of grand theories and meta-narratives for a coexistence of a multiplicity and variety of situationally dependent ways (Burr, 1995, pp. 13-14) avoids the fundamental assumptions of modernism and the Enlightenment. Social constructionists examine where the notions of truth and structure to our society comes from. The essentialist belief of a core personality that pre-determines what it is to be human, beginning as a set of characteristics inside each of us, is replaced with a more generous understanding of us enjoying multiple subjectivities where we are the product of social encounters and relationships, creating ourselves over time. Within this framing, human nature is not fixed; it is historically and culturally bound. The notion of self is not true or false against one personality, but rather an expression of our life memory that may provide consistency and continuity towards our identity (Burr, 1995, pp. 28-30). 
The process of becoming socially constructed is embedded in language. In fact, people are constructed through language (Burr, 1995, p. 34; Weedon, 1987, p. 21) and individuals alone cannot accomplish this, as language is social phenomenon. "Language is the place where actual and possible forms of social organisation and their likely social and political consequences are defined and contested" (Weedon, 1987, p. 21).

Poststructuralists claim that meaning in language is never fixed (as opposed to Saussure's structuralist notion of the fixed sign and signifier), is always contestable, and is a site of potential disagreement leading to conflict. Thus, language becomes a place where power relations are contested and identities are built, maintained, and challenged. As such, "language is the crucible of change" (Burr, 1995, p. 43) or of stability.

"The constructive force of language in social interaction ensures a fragmented, shifting and temporary identity for all of us" (Burr, 1995, p. 40). Language is also "the place where our sense of ourselves, our subjectivity, is constructed" (Weedon, 1987, p. 21). Subjectivity is socially produced through discursive practices and is a site of disunity and conflict (Weedon, 1987). The innate, genetically determined notion of one central identity was limiting how I could conceive of change. Thus poststructural theory has opened up a new language and with this a new possibility for transforming my practice and myself and, in the end, my society.

Language can be structured into a number of discourses (or "a system of statements which constructs an object" (Parker, 1992, p. 5)) where the meaning of any signifier is drawn from the context of the discourse. These are not abstract ideas: discourses are coherent systems of representation that produce, allowing us to see things that may or may not actually be there. Discourses often wield power as they provide frames of reference and ways of interpreting the world, giving it meaning that is 
culturally embedded (Burr, 1995, p. 59). Language, in the form of discourses, provides our subjective view of our experiences.

Every discourse, conscious and unconscious, works to fashion subjects and constitute communities, identity investments, and discursive practices.

Discourses authorize what can and cannot be said; they produce relations of power and communities of consent and dissent, and thus discursive boundaries are always being redrawn around what constitutes the desirable and the undesirable and around what makes possible particular structures of intelligibility and unintelligibility. (Britzman, 2000, p. 36)

Dominant discourse relates to a collection of expectations and assumptions that are taken for granted through spoken, written, and behavioural practices as shared within a cultural grouping. Here, the 'accepted' rules of everyday, as practiced by the decision-makers (dominant group), are taken up as 'normal'. This is how social construction works.

That is not to say that humans have status only as manifestations of discourses, where social structures, social practices, and their associated discourses just play out. The alternative "humanist" view would suggest that because we "experience ourselves as having goals, purposes and intentions we are the sole source and free agents of our actions" (Burr, 1995, p. 90). An individual's ability to critically reflect on historical information, and to choose which discourses to take up, leaves them with a degree of agency (Britzman, 2000, p. 36).

Agency, where a subject can make choices outside of the dominant discourses and take action, is a contested concept. There are many theories around how agency is, or is not, possible in social constructionist theory (Britzman, 2000; Burr, 1995). “Agency can... be viewed, not as freedom from discursive constitution, but as the capacity to recognize that constitution and to "resist, subvert, and change the discourses themselves" 
(Davies, 2000, p. 67)" (McKenzie, 2004, p. 183). I accept that social/cultural change is possible with the availability of alternative discourses through awareness, education, and action, which widens the discourse choices available. However, we do not all have access to all discourses as, for example, our age, class, gender, and ethnicity, apply obvious restrictions and our historical and social positioning restricts what may be possible.

From the above theoretical exploration of social constructionist theory, exemplification of one possible expression of agency in the individual, leading to social change, is considered. Activism provides an opportunity to bring our communities into awareness and action towards a better future through exploring alternative discourses.

\section{Activism as an expression of agency.}

Activism has been defined as the doctrine or practice that emphasises direct vigorous action especially in support or opposition to one side of a controversial issue (Activism, n.d.). Gerum (2007) stated that activism was "being the change, actively leading a life that reflects the kind of world you want to live in, and it's about creating action beyond yourself and acting as an agent of change" (p. 193). Thus, activism is about embodying change as well as enabling others to see the need for undertaking their own change processes. Schugurensky (2007) offered the following statement at a conference titled "Educational activism: social justice in classrooms, schools and communities" held at the Ontario Institute for Studies in Education, Toronto, Canada in November 2007.

Activism is any intentional action, individual or collective, to make a better world. By a better world I mean a world where all human beings can develop their full potential, a world that is more democratic, just, peaceful, sustainable and 
enjoyable than the world that we have today. I am aware that there is another type of activism, one that moves in the opposite direction, that is, towards a world characterized by more unequal distribution of wealth and opportunities, violence, oppressive relations, war, poverty, pollution, discrimination, and so forth. (p. 1) While playing with possibilities here, Schugurensky exemplifies a critical theory of uptake of discourses. While some might choose to take "activism" up as an alternative view of the dominant discourse (environmentalism perhaps), others choose the dominant view itself (such as capitalist consumerism); however, often this choice to follow the dominant discourses are not acknowledged as intentional choices as they are the socially acceptable choices.

Activism, or active and engaged citizenship, can be working towards establishing different dominant discourses around a variety of issues. These issues might include:

Tackling large public issues, local problems, improving livability, reducing conflict, bridging towards stronger democracy, rekindling a sense of community, alternative pathways to better health, and increasing social capital. (Dobson, 2003, p. 4)

And regardless of the different types and scopes of activism, a common feature is that often these activities are beyond what is expected from us in our daily lives; activism is something that we do because we believe in the goodness of the cause, usually on a voluntary basis.

Renowned educational activist, hooks (1994) states, [m]y commitment to engaged pedagogy is an expression of political activism. Given that our educational institutions are so deeply invested in a banking system, teachers are more rewarded when we do not teach against the grain. The choice to work against the grain, to challenge the status quo, often has negative 
consequences. And that is part of what makes that choice one that is not politically neutral. (hooks, 1994, p. 203)

hooks (1994) further describes how her pedagogical philosophies were designed and tested and how she practices with the aim of being critical and political creating opportunities for transformation (of her students and herself, as she continues to learn with her students) through activism within her classroom. She also demonstrates personal agency as she makes the decision to "teach against the grain" (with "grain" representing the dominant discourse) (hooks, 1994, p. 203).

Intentionality, or choice, is integral to activist practice. Taking time to explore alternative discourses, to come to know the implications of one choice over another, and making thoughtful value judgments as to which is more appropriate is the basis of activism, as this intentionality precedes any action. In this way activism may be an appropriate method employed to expose and explore problems in dominant discourses. Kumashiro (2004) suggests activists

work to change laws and policies by lobbying legislators or staging protests, they teach others to break through the glass ceilings or challenge discriminatory employment or housing or healthcare practices, and they organize community or school groups for political action. And as they teach us to become dissatisfied and uncomfortable with the norms of society, they ask us to examine why we have already become uncomfortable with the "queers" of society. (Kumashiro, 2004, p. 45)

He goes on to liken activism to teacher education, which mirrors my feelings regarding the opportunity (and responsibility) provided through transformative education and critical pedagogies towards supporting social/cultural change towards a more sustainable 
society. The choice to practice transformative education is activism and an example of personal/political agency.

Given the above exploration of critical dimensions of social constructionism with activism as a specific example of agency, which could be considered to be the alternative of being socially constructed, I now broaden my perspective to consider where and how ecofeminists take up these ideas. Ecofeminism offers a specific frame to my research that focuses notions of domination within society by the powerful. I look to the usefulness of these framings and to the common critique of ecofeminism as a way of providing theoretical undergirding to my practice as informed through my ecocentric worldview.

\section{Personal Theories of Ecofeminism}

I revealed, in the Introduction (chapter 1), how I have come to embody an ecocentric orientated worldview, similar to Leopold (1949), as he described in the Land Ethic. My worldview developed from years of interaction with Earth systems, specifically with animal species, and formed a strong desire to take my place within this system as opposed to attempting to dominate and manipulate these systems to my liking and for my use. I now believe that my worldview can be augmented philosophically and epistemologically through theories of ecofeminism. Linking feminism with environmentalism, or 'ecological feminism', or 'ecofeminism', is somewhat comfortable as I am aware of and have experienced, patriarchal domination myself. Similarly I observed, on countless occasions, similar forms of domination applied to specific niches or species within the environment. Thus, finding connections between these "unjustified dominations of women, people of color, children, and the poor and the unjustified domination of nature" (Warren, 2000, p. 1) and theoretical support for coming to 
understand my ways of knowing and those through which I practice education has been valuable.

'Eco-feminisme' was coined by d'Eaubonne in 1974 when she implied the historical, experiential, symbolic, and theoretical domination of nature was the same as that of women (Warren, 1995, p. 213) and she hoped this call would bring "attention to women's potential to bring about an ecological revolution" (Warren, 2000, p. 21). The political ecofeminist movement began in the early 1970s (Warren, 2000), similar to the genesis of the field of environmental education, and both are recognised internationally. Although there is some disagreement as to exactly what the term ecofeminism might encompass, it is usually considered an umbrella term, referring to a "plurality of positions" (Warren, 2000, p. 21).

Ecofeminism offers a critique of male domination over women and nature and "attempts to frame an ethic free of male-gender bias about women and nature" (Merchant, 1996, p. 7). Multiple perspectives are called upon in ecofeminist theories, in ways that are not usual in male-dominated spaces where non-masculinist voices are typically omitted. "An ecofeminist perspective is thereby...structurally pluralistic, inclusivist, and contextualist, emphasizing through concrete example the crucial role context plays in understanding sexist and naturist practice" (Warren, 1988, p. 151). Ten types of "women-other human-others-nature interconnections" (Warren, 2000, p. 21) can be described from the literature on ecofeminism. These are: historical (typical, causal), conceptual, empirical, socioeconomic, linguistic, symbolic and literary, spiritual and religious, epistemological, political, and ethical interconnections (Warren, 2000; Warren, 1996). I identify with several of these ecofeminist types and four (historical, conceptual, linguistic, and ethical interconnections) are worth exploring as they provide details of the 
groundings and theoretical support I find in and draw from this epistemological and/or philosophical framework.

Plumwood (1996) offers a historical and conceptual perspective through a critique of rationalism, stating that damaging assumptions came with this (rationalist) tradition, specifically the definition of rational thought as "the hallmark of humanness" which results in the elevation of "humans over nonhuman animals and nature on grounds of humans' superior abilities to reason" (Warren, 2000, p. 23). Plumwood goes on to state that the human/nature value dualism supports other harmful value dualisms, such as: masculine/feminine, reason/emotion, spirit/body, culture/nature, human/nature, and that these dualisms are both human-centered (anthropocentric) and male-centered (androcentric) (Warren, 2000, p. 23). Anthropocentrism assumes human superiority over nature and is historically connected (in western philosophy) to androcentrism, which assumes male superiority over women (Plumwood, 1996). The origins of patriarchy may never be resolved yet the ramifications are the "twin dominations of women and nature" (Plumwood, 1996, p. 173) and the "exaggerated focus on reason and rationality divorced from the realm of the body, nature, and the physical" (Warren, 2000, p. 24). Warren (2000) calls this the "logic of domination" (p. 24).

Another ecofeminist type that seems to reflect my own philosophies is that of linguistic interconnections, where philosophers argue that "the language one uses mirrors and reflects one's concept of oneself and one's world" (Warren, 2000, p. 27). Therefore, language plays a crucial role in concept formation and in "keeping intact mutually reinforcing sexist, racist, and naturist views of women, people of color, and nonhuman nature" (Warren, 2000, p. 27). Working in the environmental field ensures that I have experienced these linguistic interconnections many times. I have been called a greenie, 
tree-hugger, hippie, and granola. None of these are particularly sexist-naturist but each has an edge that is reinforcing of the dominant culture (that doesn't respect ecocentrism). Finally, the ecofeminist type called ethical interconnections interests me. Here it is both Cuomo's (1998) concept of 'flourishing' and King's (1990) call for between cultural (or spiritual ecofeminism) and socialist feminism within ecofeminism that extends ecofeminist theory towards seeking change. Flourishing, or well-being, is intended to encompass individuals, species, and communities and Cuomo (1998) suggests there is a "dynamic charm" (p. 37) when flourishing presumes a degree of physical health and self-directedness towards adapting to or resisting change. I like these terms and consider them useful as they imply a level of conscious consideration, similar to activism, towards designing an ecocentric way of being in this world. Similarly, King (1990) reminds us that nature is the central category of analysis in ecofeminism and calls for rethinking our relationship between humanity and the rest of nature, "including our natural, embodied selves" (p. 107). The suggested reconsideration has been a useful action as I have discovered through my own practice and this research.

"Ecofeminist philosophy draws on feminism, ecology and environmentalism, and philosophy in its analysis of human systems of unjustified domination ("isms of domination")" (Warren, 2000, p. 43) assuming that these dominations are, in fact, not justified or inevitable. Ecofeminism is an engaged philosophy that is based in these claims: 1) there are important interconnections between the unjustified domination of women, other human others, and nonhuman nature; and 2) these need to be understood in terms of solutions where feminist philosophy and gender issues include ecofeminist insights (Warren, 2000, p. 43). The work of ecofeminism is summarised by Cuomo (1998) in the following 
Within any human activity are embedded assumptions about nature and about what it means to be human, social, encultured, embodied, contingent, matter. As Western conceptions of humans and of cultural life are founded on beliefs that the human is somehow separate from and superior to nature, we can trace ways that the devaluation of the nonhuman realm is enacted in human social practices and institutions. We can also notice the complexity of responses to the complicated reversals and contradictions that keep the shifting nature/culture divide in place. (Cuomo, 1998, p. 150)

Unpacking the complexity, watching for embedded assumptions, and the shifting nature/culture divide though embodied, activist work is the work of my research.

Warren (2000) suggests "nature is a feminist issue" (p. 1), meaning that naming something as 'a feminist issue' implies gaining insight and further understanding of the oppression, subordination, or domination of women.

According to ecofeminists, trees, water, food production, animals, toxins, and, more generally, naturism (i.e., the unjustified domination of nonhuman nature) are feminist issues because understanding them helps one understand the interconnections among the dominations of women and other subordinated groups of humans, on the one hand, and the domination of nonhuman nature, on the other hand. (Warren, 2000, pp. 1-2)

The 'feminist approach' to researching issues uses gender analysis where gender is the initial lens through which the inquiry begins. The implication is not that gender offers any greater importance than other forms of oppression, rather that a focus on women "reveals important features of interconnected systems of human domination" (Warren, 2000, p. 2). For example, it is often the women of specific human groupings (people of colour, poor people, elderly, colonised peoples) who "suffer disproportionately higher risks and harms than men" (Warren, 2000, p. 2). However, in working the feminist approach falling into the binary of male versus female is not useful (it is, in fact, 
essentialist and works to maintain the meta-narratives it purports to rupture). It is possible for ecofeminist theorising to reify a simple gender divide between male and female when it should complicate the identification of gender. Maintaining awareness of this poststructural feminist perspective of ecofeminism is necessary for it to remain a valuable theoretical frame. Without a poststructural push away from the dualisms that establish binary thinking and with careful consideration of the mechanisms of power (Weeden, 1987, p. 10), language, and discourse, ecofeminism could become paralysed and limited. Awareness of further critiques of ecofeminism is needed.

\section{The ecofeminist critique.}

The greatest claim against ecofeminism is that it essentialises women and nature, suggesting a unifying bond or merging categories (Kheel, 2008). What ecofeminism is not, as Sandilands (1999) states, is motherhood environmentalism, where women are essentialised as mothers and nurturers, who manifest "natural protective instincts towards home and family" (p. xiii). She suggests that this "distressingly common discursive chain" (p. xiii) offers a return to patriarchal and heterosexual "family values" where healthy and "natural" (p. xiii) families and nature will endure. "It is a naturalized morality tale of private women embodying particularistic, nuclear-family-orientated, antifeminist, heterosexist, and ultimately apolitical interests" (p. xiii). The claim that all women are more attuned to nature implies some level of superiority over men, reinforces notions of domination, and limits the effectiveness of ecofeminism. I have found motherhood environmentalism in the guise of ecofeminism regularly as I read, and it reminds me to be diligent. 
Archambault (1993) summarises two similar arguments. The 'body-based argument' claims that women are closer to nature and can more readily connect due to the body processes that women experience (ovulation, pregnancy, child birth etc.). The 'oppressive argument' claims that women experience a separated social reality to that of men due to the oppressions historically (and to this day) enforced, resulting in women developing "a special insight and connection with nature" (Archambault, 1993, p. 19). While it is fair to say that women and men encounter differences in the reproductive experience, suggesting that this limits men's experience while over-privileging women's experience is counter productive (and reinforces forms of domination and binaries). Additionally, this argument becomes confused when applied to women who have not given birth in the same way that the oppressive argument does for men who also suffer oppression.

Another important critique of ecofeminism is leveled at Warren's (2000), afore mentioned, "logic of domination" (p. 24). Feldman (1998) carefully teases the issues suggesting that we cannot assimilate the domination of women by men to the domination of nature by humans as this argument is based on the Enlightenment framework where women and men have free will, and nature does not. Although ecofeminism rejects an Enlightenment view (Feldman, 1998), it appears that, at this philosophical level, further theorising is required to imply equality in the domination of women and nature together when applying a moral justification.

As I write this I am reminded that the joining of women and nature as 'the dominated' seems to imply that men are the only ones dominating with moral impropriety. Indeed, this is not always the case and it is necessary in an ecofeminist practice to remember that women, too, may practice the moral domination of others 
(children, elderly, people of colour, the poor) and nonhuman others (nature) in western society. I take this thought as a reminder to consider my own practices around social and environmental justice, steeped within ecofeminist epistemologies/philosophies, with care. Similarly, this is a poignant time to remind myself of the extreme privilege I bring to this work, as my placement in society is one where I have the ability to choose alternatives to how I practice.

Kheel (2008) looks for some usefulness in the common critique of ecofeminism

(its essentialising tendencies) when she refers to Sturgeon's claim that "rather than simply dismissing all expressions of essentialism, it is helpful to understand where essentialist tendencies came from and what functions they serve" (Kheel, 2008, p. 9). This momentary adoption or acceptance can enable "activists to politically unite across the lines of race, class, and national identity" (Kheel, 2008, p. 9). Similarly, Salleh (1997) agrees that "understanding how experiences are shared by women across special and discursive boundaries is crucial to ecofeminist mobilization" (Salleh, 1997, p. 171). And in this space of awareness and shared consciousness, I look for opportunities to undertake transformative education leading to social/cultural change.

\section{Ecofeminism as activism.}

Cuomo (1998) offers understandings about how ecofeminist activism can, and should, include working with theory, as there are many relationships between ecological feminist theories and practice. She poses this interesting question,

[i]f ecological feminism is a theory, a movement and/or a critique that aims to address the intersecting oppressions of women, nature, people of color, the poor, and others categorized as inferior by phallocratic systems, then what counts as ecological feminist activism? (p. 141) 
An effective feminist understands how to utilise power, and how to discursively construct, or deconstruct, as is necessary. The addition of 'eco' to these already powerful theoretical frames provides opportunities to work deep investigative theories and possibilities into aspects of environmental consciousness and environmentalism, providing insight to how we construct our environment through and by ourselves, within and by our societies bringing about social/cultural change. Perhaps this counts as ecological feminist activism.

Cuomo (1998) takes up a call to activism by exploring the "slipperiness of the space between the concepts 'theory' and 'practice"' (p. 142). She suggests that writing theory is a bodily activity (although quite dissimilar to participating in a demonstration) and that the outcome of written theory may not have any less direct impact than that of a demonstration. Additionally, the expected forms of activism (bodies doing things like sitting, yelling, and speaking) can be as intellectual and conceptually grounded as writing theory. "Activism entails movement, and this movement can be theoretical and thoughtful, as well as physical" (Cuomo, 1998, p. 142). Theory gains meaning from its relation to practice (Bickford, 1993). "[I]t is not nonsensical to think of theory as a form of activism - as a practice" (Cuomo, 1998, p. 142). In fact, it is this "thoughtful practice" (p. 143) that Cuomo (1998) refers to that I take up in my activism, reminded by Dewey's (1929) previously stated assertion that "theory separated from concrete doing and making is empty and futile" (p. 281).

Understanding the science behind our environmental crises, along with the social theories that apply an historical lens and understanding to how we got here, is as necessary as putting lifestyle choices into practice that lead to more sustainable Earth systems and to supporting and encouraging others to understand and change their 
practices similarly. The theory is as important as the practice and the doing is as important as the thinking, as suggested by Cuomo (1998) when she states that "ecological feminist theorists should use [their] skills not only in the creation of articles, books, and lectures, but also in helping to make the more hand-dirtying steps toward change" (p.148). She also suggests that it is "the thoughtfulness of citizens (be they lawyers, food servers, computer programmers)" (p. 147) that is needed to engage in "political deliberation, strategizing, and action" (p. 147). Making personal choices regarding living practice is steeped in politics, as is activism (Cuomo, 1998).

In so far as ecological feminism influences personal choice it is a contributor to social, ecological change. But ecological feminists also organize together to identify and work against interlocking systems of oppression that are harmful to women, people of color, the poor, the environment, and animals. (Cuomo, 1998, p. 148)

Thinking, doing, and changing practice for oneself must be linked to working with others, such as supporting transformative education leading to social/cultural change. Yet, Cuomo (1998) goes on to suggest that there is more at stake here. If ecological feminist analyses and agendas are to have a wide-scale effect on contemporary understandings of the mechanisms and causes of oppression, and the interrelatedness of various social and environmental issues, these agendas must be presented and pursued in ways that make these connections clear. If ecological feminism is to have a prominent place in contemporary global politics and significantly affect social and political decisions, ecological feminist activism must be identifiable, powerful, and complex. (Cuomo, 1998, p. 148)

And so, I feel compelled to name my work not only as activism, but, more clearly, as ecofeminist activism. Through personal change undergirding transformative education, I hope to enact social/cultural change. With a close eye to the assumptions reinscribed 
through dominant discourse, power relationships, and language, I hope to continue to create awareness and practice that leads myself and, hopefully, others towards a more sustainable way of living and future.

\section{Education with a Critical Turn}

The intention of my research is emancipation from the limiting discourses and hegemonic power relations of a capitalist society; where expressions of success are tied to materialistic wealth and the environment is continually subsidising economic growth; where we are already painfully aware that linear systems and unlimited growth are not possible in a finite world (Leonard, 2010). Western society is currently operating as an unsustainable model and I desire change, transformation, and intentional embodiment of different ways of being. I am working toward embodying a new way of being that allows for more sustainable societies and cultures where mechanised, anthropocentric choices are left behind in preference for ecocentric justice for all beings. Through this research I hope to bring change (certainly to myself and hopefully to others) through practicing living more sustainably and transforming my educational practice. Both are critical practices that demand awareness of power and discourses so that poststructurally informed ecofeminist activism can produce agentic communities that are not slaves to the established and reified economic systems.

The application of critical theories offers close examination of our society and culture with intentions towards bringing about change (Giroux, 1994; Kincheloe, 2008). When applied to the field of environmental education, action within this field can be based on the critical ethnographer's question of 'what could be' rather than simply 'what is'. The field, then, has an opportunity to lead society towards a more sustainable future, 
exemplifying the concerns and problems that arise from our current practices, and opening spaces for action and careful consideration for different ways of living: working towards challenging the status quo and actively establishing a vision of a better future.

We need to bear in mind that the multiple "critical" traditions in education have roots within modern culture just as much as the conservative economic models of education do. Rather than abandoning these traditions as outdated, we need to "reread" them consistent with new theoretical insights and in light of current cultural developments. (Carlson \& Apple, 1998, p. 3)

It is the intention of my research to look closely at my own living practices, critically becoming more sustainable with the desire to use my knowledge and embodied experience to develop educational experiences (critical pedagogical strategies) that will, hopefully, support my students to undergo similar transformative and critical educational experiences.

Critical theories offer the potential of emancipation through the critique of systems of domination or dependence, thus being critical is being political (Ellsworth, 2005, Kincheloe, 2008, Shor, 1992; Shor, 1999, Stronach \& MacLure, 1997). The employment of critical theory demands that the researcher considers her self-production and construction and how this process shapes how she (co)constructs her world. It is in the practice of critical theory that forms of self-reflection are gainfully engaged as the practitioner is in a constant state of becoming. In particular, offering transformative education that is critical in nature and that works at the level of ontology, epistemology, and axiology, is one way to bring about social/cultural change: transformation via education for myself, my students, my students' future students, and our communities.

The following exploration will consider critical possibilities in transformational education, or as Taylor (2009) calls it "teaching for change" (p. 3), as discussed in the 
Introduction (chapter 1). Undergirding transformational education and the desire to teach for change are critical pedagogies.

\section{Critical pedagogies.}

Pedagogy can be described as being "the production and transmission of knowledge, the construction of subjectivity, and the learning of values and beliefs" (Kincheloe, McLaren, \& Steinberg, 1997, p. xiii). Pedagogy can refer "to knowledge as a thing made [as well as] knowledge as in the making" (Ellsworth, 2005, p. 1). Therefore, the experiences of the learner during "the means and conditions, the environmental and events of knowledge in the making" (Ellsworth, 2005, p. 1) are open to exploration. And, as such, pedagogy can be (re)considered

... as the impetus behind the particular movements, sensations, and affects of bodies/mind/brains in the midst of learning, and it explores the embodied experiences that pedagogy elicits and plays host to: experiences of being radically in relation to one's self, to others, and to the world. (Ellsworth, 2005, p. 2)

The state of becoming is constantly (re)informed by the simultaneous experience of what is becoming while learning and what is learned while becoming. "Pedagogy, like painting, sculpture, or music, can be magical in its artful manipulation of inner ways of knowing into a mutually transforming relation with outer events, selves, objects, and ideas" (Ellsworth, 2005, p. 7).

Being critical implies a central goal of "becom[ing] more skeptical toward commonly accepted truisms" (Burbules \& Berk, 1999, p. 45). Skepticism is useful when “our beliefs remain unexamined, [as] we are not free; we act without thinking about why we act, and thus do not exercise control over our own destinies" (Burbules \& Berk, 1999, p. 46). Learning to challenge commonly and socially accepted 'truisms' leads to self- 
sufficiency, and "a self-sufficient person is a liberated person... free from the unwarranted and undesirable control of unjustified beliefs"(Siegel, 1988, p. 58). Critical pedagogy, therefore, "illuminates the relationship among knowledge, authority, and power" (Giroux, 1994, p. 30).

Critical pedagogy is about engaging learners and stems from a rich history including the literacy campaigns established by Freire with the peasants of Brazil not just to increase their literacy, but also to work to empower and, ultimately, free these people from oppressive powers. Freire wrote Pedagogy of the Oppressed (1970/1995) and Pedagogy of Hope (2002) to share his experiences and to engage others in the possibilities of critical pedagogy.

The purpose of critical pedagogy is to engage learners in the act of what Freire calls conscientizacao, which has been defined as "learning to perceive social, political, and economic contradictions, and to take action against the oppressive elements of reality" (Freire, 1970/1995, p. 17). According to Freire, "reading the world always precedes reading the word, and reading the word implies continually reading the world" (Freire \& Macedo, 1987, p. 35). These two, intertwined literacies reinforce each other and are directed toward conscientizacao. Through reading the world as "political texts," teachers and students can engage in reflection and action, or 'praxis', in order to understand, and, where necessary, to change the world (Freire, 1970/1995; McLaren, 2003). For Freire, criticality or conscientizacao requires praxis, reflection and action, interpretation and change. As he puts it, "critical consciousness is brought about not through intellectual effort alone but through praxis, through the authentic union of action and reflection" (Freire 1970/1995, p. 48). 
Gruenewald (2008) suggests, "critical pedagogies are needed to challenge the assumptions, practices, and outcomes taken for granted in dominant culture and in conventional education" (Gruenewald, 2008, p. 308).

Unlike traditional perspectives of education that claim to be neutral and apolitical, critical pedagogy views all education theory as intimately linked to ideologies shaped by power, politics, history and culture. Given this view, schooling functions as a terrain of ongoing struggle over what will be accepted as legitimate knowledge and culture. In accordance with this notion, a critical pedagogy must seriously address the concept of cultural politics by both legitimizing and challenging cultural experiences that comprise the histories and social realities that in turn comprise the forms and boundaries that give meaning to student lives (Darder, 1991, p. 77). (Darder, 1995, p. 319)

Critical pedagogies implemented in schools have a big task ahead of them. Action orientated embodied strategies, like those used in my research, are examples of engaging students in challenging culture and social norms. Scaffolding these learning opportunities carefully works to support students through (re)thinking their experiences and learning to critique and bring about change.

Bowers $(1997,2001)$ critique offers that critical pedagogy often betrays a sweeping disinterest in the fact that human culture has been, is, and always will be nested in ecological systems. He suggests that the discourses of ecological systems are often lost as mechanistic and modernist views are privileged. I find his suggestion that we consider ecological systems as those within which others 'nest' as being useful, although more as a reminder of connection than with an implied hierarchy.

Noddings (2003) offers a critique on education that is critical when she writes about the need for happiness and/in education. Her argument is that education curricula hardly engages students with content that relates directly to their lives or that inspires a 
sense of happiness and human flourishing. Her thesis is that happiness is a desire that is “well-nigh universal” (Noddings, 2003, p. 74). Such happiness can come from the love of a place, explored in person, through literature, a cookbook or gardening, as examples. "With respect to education, I suggest that joy should preceded responsibility and that we should have more faith in both incidental learning and the choices children make in exploring the world" (Noddings, 2003, p. 137).

Similarly hooks (2010) reminds us that "thinking is an action" (p. 7) as it is "where visions of theory and praxis come together" (p. 7). The action of thinking is something that can (and has) become undervalued and under-utilised in our classrooms and so taking time to teach thinking skills and to engage students in the thinking processes becomes important to successful practice leading to social/cultural change. I suggest that hooks 'engaged pedagogy' can be considered as the practice of 'critical pedagogy'. “Engaged pedagogy emphasizes mutual participation because it is the movement of ideas, exchanged by everyone, that forges a meaningful working relationship between everyone in the classroom" (hooks, 2010, p. 21). The importance of having a unique voice and independent thought, where all contributions are 'worthy' and every student is encouraged to participate in the learning process in the ways that they feel most comfortable is the integrity of engaged pedagogy, hooks (2010) says. "To educate for freedom, then, we have to challenge and change the way everyone thinks about pedagogical process. This is especially true for students" (hooks, 1994, p. 144).

Critical pedagogies are those that engage us in thinking and actively working to understand and participate in different, new, and challenging ways: to think, as an action, about the issues that confront us. The content of such praxis can be varied; I believe it is appropriately applied to my research as I ask students to challenge themselves, through 
action, to change an aspect of how they currently live towards a more sustainable practice. Based on my own experiences at undertaking such critical work, I can model ways that I challenged myself, sharing my stories. In this way, my self-imposed challenges undergird my transformative education practices through critical pedagogies.

\section{What, then, is the role of the teacher (or the teacher's teacher) to bring about social/cultural change?}

Schools are sites of cultural and social transmission where skills, knowledge, and values are learned and maintained (Hart, 2011, p. 158). In recent years, teacher education has become a focus of concern (Hagger, Burn, Mutton, \& Brindley, 2008, p. 159) due, in part, to an assumption regarding the quality of schooling being primarily dependent on the quality of its teachers and their teaching (Hagger \& McIntyre, 2006, p. 1). While this assumption seems fair, it is not the only concern within the education system. It is, however, one that can be addressed (somewhat) and teacher education is a logical place to begin working to bring about social/cultural change towards greater sustainability (Bowers, 2008; Hey, 2002; Peterson, 2009).

Fien (1995) identifies a special commitment from teacher education institutions as necessity for reorienting teacher education towards sustainability. Which follows from an urgent request made by UNESCO-UNEP in 1991 for the preparation of teachers to be considered as "the priority of priorities" (Tilbury, 2007, p. 117). Peterson (2009) offers that "[i]n order to produce socially responsible students who are able to engage with the critical problems of our times, significant shifts are necessary within higher education pedagogy and research" (p. 541).

Hart (2011) suggests that, in a similar way to post-critical perspectives (that 
currently receive inappropriate consideration), theory from environmental education "attempts to shift the discourse of research and pedagogy from individualist conceptions of being/knowing "selves" to social relational onto-epistemological positionings" ( $\mathrm{p}$. 166). Within this social context concepts appropriate for bringing about dialogue and conversation regarding social/cultural change become possible. The experience with and creation of discourse around these issues generates awareness leading to action and, possibly, change.

For example, if we shift certain questions in teacher education so that, ultimately, teachers themselves learn to shift questions in schools, we can perhaps begin to think more deeply about what we think we are doing for/to students. We can begin to question the certainty of our preferred ways toward certain goals. We can learn to think about who we think the student, as subject, is. We can take up questions of how these subjects come to agency. (Hart, 2011, p. 161)

Such work requires careful preparation of the students along with the development of critical and transformative educational theory and practice where questioning held assumptions becomes appropriate and achievable.

Part of this preparation might be to establish critically reflexive practices amongst pre-service educators. Hart, Jickling, and Kool (1999) suggest the engagement of teachers in critical reflection of their practice and thinking as a way to improve the quality of environmental education in lieu of a more prescriptive approach. Robottom and Hart (1993) state that,

[e]nvironmental education must include provision for teachers to learn how to actively inquire into their own practices and to clarify their thinking as means of extending and developing their own theories, to take responsibility for their own actions, and to actively participate in the social and political reconstructions 
required to address intelligently education as well as social/environmental issues within complex, evolving social situations. (p. 60)

Looking to the cultural narratives inhabited by pre-service teachers, understanding the subjectification processes that have and continue to take place, looking for opportunities to decolonise and (re)inhabit appropriately, may support questioning leading to social and environmental critique, and ultimately, to social/cultural change.

Hart (2003) suggests that, like politics and religion, environmental issues are ethical issues often driven by the politics of human decision making, which includes emotional understanding, cultural understanding and many other capabilities and beliefs (p. 207). Environmental education is taken up by teachers who embody an ecocentric worldview with personal ethics or beliefs about what is important to teach (p. 199). Subjectivities play a crucial role in determining how to view and implement environmental education. Possible subjective positions are shaped by beliefs and experiences, or are (co)constructed socially. How teachers make sense of their experiences directly influences the way in which they react in their classrooms.

Where, in all of this, does desire come in? "We want teachers in teacher education to want to trouble their teaching" (Hart, 2011, p. 166). We want them to have detailed and deep understandings of the science and social implications of climate change, for example. And we want them to want to become agents of change, influencing their future students to critically (re)consider through questioning and action, their held assumptions, generate alternative discourses, and embark on social/cultural change towards a more sustainable future. The role of teacher will be taken up in my research through an embodied exploration into my role as a teacher/researcher questioning my 
ability to lead/inspire/activate students towards their own journeys of embracing sustainability discourses and practices. 


\section{Chapter 3. Methodology}

"One day you finally knew what you had to do, and began, though the voices around you kept shouting their bad advice" (Oliver, 1986, p. 38).

Qualitative inquiry stems from reformist roots in the early 1970s following interpretive and/or critical paradigms (Denzin \& Lincoln, 2002, p. ix) and, properly understood, "becomes a civic participatory, collaborative project, a project that joins the researcher with the researched in an on-going moral dialogue" (Denzin \& Lincoln, 2002, p. ix). There is often an implicit demand for social criticism and social action based on a foundation of interpretation. My research is located in the area of qualitative research that is "drawn to a broad, interpretive, postmodern, feminist, and critical sensibility" (Denzin \& Lincoln, 2002, p. x). Here, the researcher is no longer considered to be an objective observer, and may, in fact, be a participant in her own research as she struggles to represent her voice, and others (Denzin \& Lincoln, 2002, p. xi).

Given my research question ((how) can I use personal change to inspire educational and social/cultural change?) and the already detailed positionings through theoretical frames, the methodological groundings for this research could only be embodied, critically reflexive, and action orientated. Such framings (theoretical and methodological) support an exploration of the identity, subjectivity, and the agency complex, along with issues of power (power relations and power expression), discursive constructions, and subjectification required with research focused on the study of self within society.

My research doesn't push the boundaries of what is possible in research; however, it claims methodological grounding from a contemporary and somewhat emergent area of 
inquiry from within the qualitative realm. Autoethnographic self-study positions me, the researcher, at the centre, hoping to draw from and extract ideas regarding change in my ways of being and becoming and coming to know, at this time and in this society and culture. In a time when how we can legitimately "be" in this world is so contested and somewhat unknown (Leonard, 2010; Moore Lappé, 2011), what is possible for one may become possible for others. I suggest that what is revealed through critical, action orientated inquiry of one person's experience at (re)considering how she practices (personal change, transformative education, and social/cultural change) might provide some usefulness for others who seek similar change.

My autoethnographic self-study was methodologically designed to question what could become known about teaching transformative environmental education through critical pedagogy from an insider's perspective, by someone who practices what she teaches, or walks her talk. Based on a desire and foundation of coming to know the ontological, epistemological, and axiological frames of my conscious positioning as researcher, and then considering my practice as an implication and action, this work lives the contradictions: it is personal, social, critical, and political. The research question is implemented and critiqued via intentional, embodied practice as a critical, transformative environmental educator, and activist.

The model used in this research (personal change, transformative education, and social/cultural change) will be used again in this chapter. Personal change is framed methodologically through autoethnography, transformative education is framed through self-study, and the social/cultural considerations follow an autoethnographic tradition embedded within a narrative inquiry that results in a critical meta-reflection. The application, or layering, of autoethnographic methodology around my personal living 
practices and my activist efforts facilitates a closer inspection of self within culture and the work here provides a platform upon which my practices as an environmental educator become possible and are explored via self-study. Initially, however, space is given to further explore the concept of these self-focused methodologies through a conversation. I have evoked the voice of Alice (from Alice's Adventures in Wonderland by Carroll, 2004) to enable a conversation with researchers from the field. Here the question is asked 'is this good research or just good therapy?'. Then an exploration into autoethnography is followed by a similar exploration into self-study. The methods and data analysis strategies employed in each aspect (personal change, transformative education, and social/cultural change) are addressed after each methodology is explored. This chapter concludes with a description of the research goals and assumptions and a description regarding the research ethics protocols, including consideration of voice and representation.

\section{Is this Research or Just Good Therapy?}

Critical theory suggests useful social research must be reflexive, where it studies and critiques itself as well as the subject, and is necessarily political. Bourdieu (1977) also suggests that a goal of research is to uncover and demystify ordinary events. It is with this in mind that I come to critique my research (with a focus on the qualitative, selffocused methodology). How we are choosing to live is an important social consideration, it carries a political imperative for action, and requires change towards a more sustainable and just living practice for all, especially for those of the western society who are privileged by birth and economic good fortune and who remain among the most capable to generate change for all. 
I reflect back to Carroll's (2004) rendition of Alice's Adventures in Wonderland and specifically to Alice's conversation with the Cheshire cat...

"Cheshire-puss," she began, rather timidly...

"Would you tell me, please, which way I ought to go from here?"

"That depends a good deal on where you want to get to," said the cat.

(Carroll, 2004, p. 73)

Does it matter which way you go, if you are not sure about where you want to be at the end? By using another autoethnographic influenced strategy, the following dialogue attempts to resolve the question... can my self-focused research be considered to be legitimate research? What if I were Alice (my voice represented with a different font - Chalkboard), similarly unsure of myself as I embark on a journey into research wonderland. Who might I recall in support of my desire to find direction? The selected 'researchers' (whose voices are represented with a different font - Arial Narrow) offer thoughts in response, and so unfolds the story...

Alice: If this autoethnographic self-study research were legitimate, scholarly, and defensible as well as critical, useful, and relevant, what would it need to look like, sound like, and feel like?

Denzin and Lincoln (2000): Well Alice, back in 1994 "[t]here [was] no question that the legitimacy of postmodern paradigms [were] well established and at least equal to the legitimacy of received and conventional paradigms" (p. 164). So practicing qualitative research within a social science realm is certainly legitimate in most quarters.

Alice: So the stage was set for a proliferation of research paradigms and yet when a researcher offers to locate their research in a newer paradigm they are still questioned as to the legitimacy of their quest through the once disciplining bastion of current research practice - peer review publication.

I wonder at this collective policing, especially as success in this research arena requires the collaborative admiration of others and the ability to 'stake your own claims', the simile to naming your own species in positivist biological 
research. How do these research practices (of peer review for example) limit actions, undermining their very own cry for freedom?

Guba and Lincoln (2005): Remember Alice that "in the wake of poststructuralism, the assumption that there is not single "truth" - that all truths are, in fact, partial truths; that the slippage between the signifier and signified in linguistic and textual terms creates re-presentations that are only and always shadows of the actual people, events, and places; that identities are fluid rather than fixed - leads us ineluctably towards the insight that there will be no single "conventional" paradigm to which all social scientists might ascribe in some common terms and with mutual understanding" (p. 212).

Alice: Right, so with poststructural framing the desire to produce one unified truth is relieved and acknowledgement of individual interpretation is privileged. This then allows for researchers to explore their own practices as a form of social research as their own practice is social.

Bouma \& Ling (2004): Remember, too, Alice that "knowledge... is a product of social processes" (p. 3). Beginning with a group realising that there is a deficit of understanding then funding is sought to support proposals to carry out research and produce findings, which are published with peer review for endorsement. The way this knowledge is then used is up to groups to decide. In this way "knowledge is both a product and the property of social groups" (p. 4). We have a well-developed research process or "generally adopted approach to doing research" (p. 5) that is "guided by rules and principles for making confident statements about knowledge" (p. 5). "Research provides answers to researchable questions with evidence that is collected and evaluated in a disciplined manner. This is how we know... Doing research in a disciplined way is how we know we know" (p. 20).

Alice: If I was to practice self-focused research, turning the lens of critique directly onto myself, asking more of myself than I ever could ask of any one else, yet still keeping appraised of the social discourses surrounding my practice, could this be considered research?

Ellis and Bochner (2000): Of course Alice as "[t]he stories we write put us into conversation with ourselves as well as our readers. In conversation with ourselves we expose our vulnerabilities, conflicts, choices, and values. We take measure of our uncertainties, our mixed emotions and the multiple layers of our experience. Our accounts seek to express the complexities and difficulties of coping and feeling resolved, showing how we changed over time as we struggled to make sense of our experience" (p. 748). 
Alice: So in making sense of our own experiences we offer insight to others, with the desire that in reading our own sense-making journey they, too, will make some sense of their own journeys. In this way a research endeavour that investigates and critiques one's own practice offers windows of understanding to others struggling with critiquing or deepening their own understandings, either regarding their own practices or those of a particular culture.

Richardson (2000): Remember Alice that "[0]ur sense of Self is diminished as we are homogenized through professional socialization, rewards and punishments.... Homogenization occurs through the suppression of individual voices and the acceptance of the omniscient voice of science as it if were our own" (p. 925).

Alice: And so the individual voice has a place, a story worthy of conveyance and deeper understanding. One's experience is worthy of critique as this one occurrence can be considered exemplary of the social experience.

Richardson (2000): Yes, Alice and "[l]anguage is how social organization and power are defined and contested and the place where our sense of selves, our subjectivity, is constructed" (p. 929).

Alice: And so the conversation possible with oneself throughout a journey of exploration creates the opportunity of conversation with others as the written form of that journey unfolds.

Richardson (2000): "Because individuals are subject to multiple and competing discourses in many realms, their subjectivity is shifting and contradictory, not stable, fixed, rigid" (p. 929).

Alice: Which leads me to question what is truth and legitimacy, and why our society craves these things, when each and every retelling is interpreted on a sliding scale of subjectivity.

Richardson (2000): I concur Alice, "[w]riting from our Selves should strengthen the community of qualitative researchers and the individual voices within it, because we will be more fully present in our work, more honest and more engaged" (p. 924).

Alice: This, then, speaks to the legitimacy of the methodological framings useful with autoethnographic inquiry and self-study.

Reed-Danahay (1997): Alice autoethnography is "a form of self-narrative that places the self within a social context. It is both a method and a text" (p. 9).

Richardson (2000): "Autoethnographies are highly personalized, revealing texts in which authors tell stories about their own lived experiences, relating the personal to the cultural" (p. 931). 
Alice: Yes and self-study, my other methodological framing, "brings to the forefront the importance of self, it makes the experience of teacher educators a resource for research, and it urges the experience of teacher educators to be critical of themselves and their roles as researchers and teacher educators" (Feldman, Paugh, \& Mills, 2004, p. 943).

And although this practice (self-study) has methodological guidelines and principles that differ from autoethnography I will continue to maintain the focus on the self, as this is the crux of these questions - where is the legitimacy in self-exploration as useful research.

Ellis and Bochner (2000): "Often our accounts of ourselves are unflattering and imperfect, but human and believable. The text is used, then, as an agent of self-understanding and ethical discussion" ( $p$. 748).

Richardson (2000): "We understand ourselves reflexively as persons writing from particular positions at specific times; and second, it frees us from trying to write a single text in which we say everything at once to everyone" (p. 929). "Writing is not just a mopping-up activity at the end of a research project but a way of "knowing", a method of discovery and analysis" (p. 923).

Foucault (1985): "A new ethics of writing is advocated, an ethics of narrative that demands that writers put their empirical materials into forms that readers can use in their own lives.... In so doing, writers strip away the veneer of self-protection that comes with professional title and position. With nothing any longer to hide, writers are now free to excavate the personal in the name of the political.... These texts must also work as cultural criticism, as tools for critique and political action. At this level they join the personal with the political. They work as venues for ground level criticism aimed at the repressive structures of everyday life" (pp. 137-138).

Alice: So this is not a "free write" experience. There are strategies and protocols to implement (as described in the following methodological exploration and method descriptions) that shape this research. I wonder what critiques of these forms of research might reveal?

Gannon (2006): Alice, "having claimed a space for the author to represent herself, 'much autoethnographic work leaves the speaking self relatively untroubled in the text.' I propose that poststructural, autoethnographic writing needs to further 'de-stabilise the authority of the self who writes and knows himself or herself as a discrete and autonomous subject' by continually theorising the 'self' within the autoethnographic relationship" (p. 477). 
Alice: Reflecting on cultural discourses that socially "allow and disallow" specific practices, disciplining practices that constrain, and disruptive strategies that open and provide possibilities for alternate reinscription might be considered appropriate destabilising authorities. Looking into our everyday experiences, and the embodied experience of implementing changes in our practices through these lenses can enable a deeper exploration of the possibilities. The critical examination of practices within a culture is revealing.

Manning (2008): "Autoethnographic writing offers me a way to bring to the fore values and beliefs I unknowingly brought into my research and examine the impact they have on the entire project" ( $p$. 14).

Alice: Many unconscious practices and ideals could have been missed, not understood, or not taken up as important without the critical lens of autoethnography. Having a methodological imperative to delve deeper into the practices looking for cultural signifiers can be important. We are looking for ways to understand our actions, and inactions, in light of our social conditioning and construction.

Armando (1986): "One should write or paint that which hides itself between knowing and understanding" ( $p$. 161, cited in Manning, 2008, p. 14).

Alice: WOW, Armando, that is right - we are looking for the spaces. This is the place to trouble and critique.

Starr (2010): I agree Alice, it is the "space between self and culture." We need to explore "[a]ction based on reflection and reflection based on action" (p. 7).

Alice: It seems that the critique of self-study lies around the ability to ask 'so what' (questions of significance) of the research. As the researcher walks a fine line between biography and history and as the research focus should not be on the self, per se, but on the space between the self and the practice engaged in (Bullough \& Pinnegar, 2001, p. 15). The tension between the elements of autoethnography and self-study requires careful negotiation as tipping too far towards self can result in a confessional and the result of tipping too far the other way turns autoethnography and self-study into traditional research. 
Mills (1959): "Know that many personal troubles cannot be solved merely as troubles, but must be understood in terms of public issues and in terms of the problems of history-making. Know that the human meaning of public issues must be revealed by relating them to personal troubles and to the problems of the individual life. Know that the problems of social science, when adequately formulated, must include both troubles and issues, both biography and history, and the range of their intricate relations" (p. 226).

Alice: Framing questions as having both personal and historical roots was considered a useful determinant for what makes a piece of self-study writing research and not just good practice (Bullough \& Pinnegar, 2001, p. 13).

Mooney (1957): "Research is a personal venture which, quite aside from its social benefits, is worth doing for its direct contribution to one's own self-realization. It can be taken as a way of meeting life with the maximum of stops open to get out of experience its most poignant significance, its most fullthroated song" (p. 155).

Alice: So we should work together to investigate situations and critique the critiques hoping to come to a deeper understanding through collective works. Often if a critique is offered towards autoethnography, self-study, the use of self in research, or of deeply exploring social practices, the voice used is pejorative, using power to speak the truth with the authority of language.

Over recent years there seems to be more comfort in, and acceptance of, these methodologies of 'self' research. Evidence to exemplify this comes from Tolich's recent article.

Tolich (2010): That's right Alice, "[f]irst, Chang (2008, p. 43) stated that autoethnography transcends mere narration of self to engage in cultural analysis and interpretation. Second, autoethnography, as any social science research method, has situated ethics, determined by its position within risk adverse institutions (Institutional Review Boards) prescribing its members to use informed consent. Third, autoethnography or ethnography are not so much about the unusual, but the mundane or everyday (Silverman, 2007). Fourth, and perhaps most important, persons featured in autoethnographies are typically friends and family members, not public figures" (p. 1606).

Alice: There seems to be greater acceptance for both methodologies currently as acknowledged by Chang (2008), Delamont, (2009), Hughes, Pennington, \& Makris, (2012), and McMillan \& Price, (2010). Actually, most of the negative critiques of autoethnography and self-study were written in the late 1990s to 
early 2000s. I suspect that part of the reason for this more recent acceptance is that Self-study has enjoyed a rich and long history of rigorous performance (and self-scrutiny) via the Self-study of Teacher Education Practices (S-STEP) Special Interest Group (SIG) of the American Educational Research Association (AERA) since 1992, and the annual "Castle" conferences since 1996.

Samaras and Freese (2006): Members of this SIG are committed to "studying their practice in an effort to make their teaching, curricula, and/or programs more relevant and effective" (p. 17) and AERA "is a prominent international professional organization with members interested in improving the educational process through scholarly inquiry related to education, dissemination, and practical application of research and results" (p. 17).

Alice: The support that comes from such structure ensures that educational researchers within this organisation can look closely and critically at their own practices (and research practices specifically) working to reinscribe rigor and critical methodological and method practice. Not surprisingly, most critique comes from within the SIG and has been countered with methodological and method clarification.

However, autoethnography has encountered some very specific critique and it is best to unpack this in some detail, ensuring that my use of these methodologies is undertaken with the most useful methods.

Chang (2008): Well Alice, as I see it, there are five pitfalls of autoethnography that may result in research having less social impact. The first reminds us that autoethnography is cultural work and therefore an inherently group-orientated concept; not excessively focused on the self in isolation of others.

Alice: Good point... the interconnectivity of self and others encourages researchers to dig deeper into the self, as well as wider into cultural contexts. That is why I have used critical friends to help me unpack my autoethnographic and self-study reflections.

Chang (2008): The second potential pitfall suggests an over-emphasis on narration and, perhaps consequentially, a lack of focus on cultural interpretation and analysis. The power of story telling can be compelling (for the writer and the reader); however, autoethnography values both the story and the interpretation and analysis as it elaborates on the self within cultural contexts.

Alice: Questions of validity, reliability, and generalisability still apply here, although 
the context and meaning differ (Ellis, Adams, \& Bochner, 2011). So, as I continue to reflect and unpack with critical friends, I deepen and broaden my ability to understand my experiences leading me to retell from a position of analysis rather than description.

Chang (2008): More practically oriented, the third pitfall reminds researchers to carefully collect data without an over reliance on personal memory as it is the meaning that counts, rather than the truth. "Memory can sensor past experiences" (p. 55).

Alice: Validity of data and the credibility of the findings with appropriate checks and balances, applies to this methodology as researchers endeavour to support their arguments. Critical friend meetings, documents, and student focus groups as forms of external data can be woven with internal data such as reflective journaling to produce multiple sources for analysis, as was the case in my research.

Chang (2008): The fourth pitfall reminds researchers that while this story is told by them, they do not own it and, as such, the same necessary ethical principles of confidentiality apply as to any other data collection.

Alice: Carefully told autoethnographies will reveal much about the storyteller; however, much may also be revealed about other characters and all players need to be carefully, ethically, protected.

Chang (2008): Finally, an autoethnography is not any kind of narrative inquiry. The specific requirements, as detailed above, are necessary to deliver autoethnography as opposed to highly descriptive selfnarratives.

Alice: The focus of self within culture and the need to move from description to analysis ensures that autoethnographic writing is more than just any story. What about the critique that autoethnography is too artful or not scientific (although this question, in itself, seems to set research methodology back 20 years)?

Ellis, Adams, and Bochner (2011): Alice, here come our thoughts on these critiques. As part ethnography, autoethnography is dismissed for social scientific standards as being insufficiently rigorous, theoretical, and analytical, and too aesthetic, emotional, and therapeutic (Ellis, 2009; hooks, 1994; Keller, 1995). Autoethnographers are criticized for doing too little fieldwork, for observing too few cultural members, for not spending enough 
time with (different) others (Buzard, 2003; Dalamont, 2009; Fine, 2003). Furthermore, in using personal experience, autoethnographers are thought to not only use supposedly biased data (Anderson, 2006; Atkinson, 1997; Gans, 1999), but are also navel-gazers (Madison, 2006), self-absorbed narcissists who don't fulfill scholarly obligations of hypothesizing, analyzing, and theorizing.

As part autobiography, autoethnography is dismissed for autobiographical writing standards, as being insufficiently aesthetic and literary and not artful enough. Autoethnographers are viewed as catering to the sociological, scientific imagination and trying to achieve legitimacy as scientists. Consequently, critics say that autoethnographers disregard the literary, artistic imagination and the need to be talented artists (Gingrich-Philbrook, 2005). Moro (2006), for example, believes it takes a "darn good" writer to write autoethnography. (paras. 37 \& 38)

Alice: As suggested, autoethnography attempts to disrupt the art/science binary encouraging research to be... more!!

Delamont (2007a): I believe there are six concerns with autoethnography as methodology. Ultimately, it can be described as lazy, intellectually and literally. Specifically, autoethnography cannot fight familiarity; it cannot be published ethically; it is experiential not analytical; focuses on the wrong side of the power divide; and data is not collected merely reflected upon.

Alice: And Delamont (2007b) also believes that "we" are not interesting enough to write about.

Delamont (2007b): "Autoethnography is an abuse of... privilege - our duty is to go out and research the classic texts of 2050 or 2090 - not sit in our homes focusing on ourselves" (p. 6).

Alice: So I am pleased to have revealed considerable support for exploring the personal as political and the careful methodological practices that infuse autoethnography, so that it does not slip down this rabbit hole that Delamont (2007b) cautions against.

Holt (2003): Hey, Alice it's important to acknowledge that traditional criteria used to judge qualitative research "may not be suitable for autoethnography" (p. 20).

Sparkes (2000): "Work like autoethnography ... that operates on the boundaries of disciplines, that cross or blur boundaries, seems to cause problems for those concerned with criteriology" (p. 36) and yet, criteria change over time. So we aim for evocation, authenticity, credibility, verisimilitude, fidelity, and believability (p. 37).

Alice: And as long as we are aware of the potential pitfalls and actively work to address concerns in methodology we can be confident that we are producing 
useful social research via autoethnography and self-study.

Sparkes (2000): Exactly Alice, rather than "tension, contradiction, conflict, and difference of interpretation" the diversity produced through these methodologies could be seen to "deepen our understanding and sharpen our judgments" of the specific pieces, the issues, and research in general (p. 38).

Richardson (2000): To support this proactive movement I delivered five criteria for evaluating ethnographies. These include: substantive contribution, aesthetic merit, reflexivity, impact, and that the work expresses a reality are the "high and difficult standards" (p. 254).

Holt (2003): It could be argued that "[r]esilience and conviction are required to pursue this methodology" ( $p$. 19).

Alice: Connections between autoethnography, self-study, social activism, and social practice are gaining recognition (Ellis, 2002). While the individual perspective with concrete detail is valuable research, so is the social movement research with abstraction and collective perspective.

Ellis (2002): "Ultimately, both approaches are about making a better world. Thus, social movements and personal stories are intimately and inextricably connected" (p. 403).

Alice: In conclusion, these critiques of autoethnography and self-study provide details and highlight concerns, which, if addressed in the methodological implementation, then the value of self-focused data to produce rich, valuable, embodied, credible, and powerful research seems apparent.

Apple (1996): Autoethnography and self-study should not be a vehicle for "privileging the white middle-class woman or man's need for self-display above all else" (p. xiv).

Walker and Unterhalter (2004): Similarly, "in excavating our own subjectivity, the point is not to produce research as therapy or stories for their own sake, but a disciplined and reflexive understanding of the known and the knower" (p. 290).

Alice: And so, the controversy has diminished as 'self' research takes on a new position within the academy. Its legitimacy is continually being reinscribed as researchers are choosing to privilege these ways of knowing over other methodological choices. The deep self-exploration that can provide critique on our cultural practices usefully contributes to our collective understanding of social interactions. In this way, 'self' research can prove valuable in exploring situations where action orientated work requires some unpacking or interpretation. 


\section{Autoethnographic Methodology: Personal Change}

A balancing act that holds self and culture together (Holman Jones, 2005, p. 264), autoethnography engages the individual in cultural analysis and interpretation (Chang, 2008). "[R]esearch, writing, and method... connect the autobiographical and personal to the cultural and social. A form that usually features concrete action, emotion, embodiment, self-consciousness, and introspection...[and] claims the conventions of literacy writing" (Ellis, 2004, p. xix). In an autoethnographic construct, and with more poetic phrasing, autoethnography has been described as "setting scene, telling a story, weaving intricate connections among life and art, experience and theory, evocation and explanation... and then letting go, hoping for readers who will bring the same careful attention to your words in the context of their own lives" (Holman Jones, 2005, p. 765).

Ellis and Bochner (2000) define autoethnography as "autobiographies that selfconsciously explore the interplay of the introspective, personally engaged self with cultural descriptions mediated through language, history, and ethnographic explanation" (p. 742). Autobiography, in contrast, is described as a self-written account of one's life while, writing about a shorter episode of ones life results in a memoir. Both autoethnography and memoir lack the critical consciousness of societies' interactions and cultural examinations that autoethnography elicits. Autoethnography reflects a changing conception of self and society; it synthesises a postmodern ethnography (where the realist conventions and objective observer positions have been questioned) and a postmodern autobiography (in which notions of the coherent, individual self has been challenged) (Reed-Danahay, 1997). 
With a focus on either self-ethnography or autobiographical ethnography this potential dichotomy is to be transcended to "question the binary conventions of a self/society split, as well as the boundary between the objective and subjective" (ReedDanahay, 1997, p. 2). As a boundary crosser, the autoethnographer foregrounds the multiple nature of selfhood, opening up new ways of writing about social life and, similarly, questioning voice and representation. "Who represents whose life, and how, are also central topics of concern in our current age of bureaucratization" (Reed-Danahay, 1997, p. 3).

Autoethnography is framed around four assumptions: 1) where self is always connected to others so that culture is a group-orientated concept; 2) self-narrative provides windows through which self and others can become understood; 3) cultural understanding requires analysis and interpretation and does not necessarily come from the telling of one's story; and 4) this methodology is useful as an instructional strategy assisting in the development of profound understandings of self and others (Chang, 2008, p. 13).

"Postmodernism awakens us to the problematics of collecting and reporting "data", and challenges disciplinary rules and boundaries on ethical, aesthetic, theoretical, and empirical grounds" (Richardson, 2000, p. 253). Autoethnographers view research and writing as socially-just acts; rather than a preoccupation with accuracy, the goal is to produce analytical, accessible texts that change us and the world we live in for the better (Holman Jones, 2005, p. 764). Autoethnography is a methodology that makes the personal political (Holmes Jones, 2005, p. 763). It can be a radical democratic politics committed to creating space for dialogue and debate that instigates and shapes social change (Reinelt, 1998). It can help us see how to move from what is to what could, and 
perhaps should, be. The goal of social impact can be realised through this methodology, working from the personal through to the political.

Autoethnographic writing can be presented as stories, which was a strategy employed throughout my research, where these stories provide the detail, or content, of the insider's perspective. Why are stories so useful? As windows to our inside thoughts and ideals, stories evoke emotions in readers/audience, which seek to create a life, charged exchange (Holman Jones, 2002, p. 51). "[H]umans are storytelling organisms who, individually and socially, lead storied lives" (Connelly \& Clandinin, 1990, p. 2). Every story can be told from a different perspective, and from different positions. In poststructural theory a body is home to multiple positionings and it is possible to tell the same story differently from many of these positionings and, in each telling, reveal different aspects/issues/understandings (Chang, 2008). Additionally, a story really doesn't have an ending, or not just one ending, and this creates the possibility of rethinking different possible endings.

The goal of this methodology was to perform research in such a way that legitimate stories can be presented to the readers. As Holman Jones (2005) points out we are "hoping for readers ... [to] bring the same careful attention to your words in the context of their own lives" (p. 765). Chang (2008) suggests that reading autoethnography can evoke self-reflection and self-examination as much as writing it can. Thus, data collection and analysis is as important as the representation. Autoethnographic work may remain 'just research' unless there is a triadic balance: "ethnographic in its methodological orientation, cultural in its interpretive orientation, and autobiographical in its content orientation" (Chang, 2008, p. 48). The interpretation of culture through 
narrative details is the hallmark of good autoethnography. Without the cultural interpretation and explanation the result is good autobiography.

There can be many benefits to using autoethnography as a research methodology; four are mentioned here. First, the self-reflective method may result in selftransformation due to greater awareness and understanding about self and self in society. As presented in the Findings (chapter 4) I detail the actions taken to transform my personal living strategies, yet it was the writing process and theoretical revelations that completed the transformation.

Second, "personal engagement in autoethnographic stories frequently stirs the self-reflection of listeners, a powerful by-product of this research inquiry" (Chang, 2008, p. 53). In my research, I was attempting personal change, however I realised that as I learned, and changed, so did the people with whom I communicated. My students changed, my colleagues changed, and so did my friends.

Third, the collection of data requires a close and careful exploration of memory and/or experience and the result is that "autoethnographers are privileged with a holistic and intimate perspective on their "familiar data". Such initial familiarity gives autoethnographers an edge over other researchers in data collection and in-depth data analysis/interpretation" (Chang, 2008, p. 52). I found that from writing autoethnographically I could see my transformation becoming more complete as I challenged myself to articulate and understand my choices.

Fourth, as previously mentioned, autoethnographic writing is reader friendly, appealing to readers through the unique voice and representations available. Gergen and Gergen (2002) suggest "using oneself as an ethnographic exemplar, the researcher is freed from the traditional conventions of writing. One's unique voicing - complete with 
colloquialisms, reverberations from relationships, and emotional expressiveness - is honored" (p. 14). I trust that my story is reader friendly and appealing as I retell the challenges and changes experienced on my research journey.

\section{Autoethnographic explorations of my sustainable living practices.}

In order to have a platform upon which to stand as an environmental educator, I devoted five years to crafting and embodying a living practice that focused on being more sustainable, while remaining immersed within my western society. I used the ecological footprint calculator (generated by the Royal Saskatchewan Museum, 1999) as it was calibrated to my current location (Regina, Saskatchewan, Canada). The calculation provided me with an indication of the relative success of the changes implemented in my living practices as a numerical value that could be compared over time (Wackernagel \& Rees, 1996).

The ecological footprint calculator compares all of the biological materials consumed and all of the carbon dioxide emissions generated by a person in a given year and is reported in hectares (HA).

To accomplish this, the amount of material consumed by that person (tonnes per year) is divided by the yield of the specific land or sea area (annual tonnes per hectare) from which it was harvested, or where its waste material was absorbed. The numbers of hectares that result from this calculation are then converted to global hectares using yield and equivalence factors. The sum of the global hectares needed to support the resource consumption and absorb their carbon dioxide emissions is that person's Ecological Footprint.

The Ecological Footprint of an activity, such as producing a good (an airplane) or service (providing insurance) in the human economy, is calculated by summing the Ecological Footprint of all of the material consumed and $\mathrm{CO}^{2}$ emitted during that activity. When calculating the Footprint of a business or an organization, the 
activities to be included within the boundaries of that organization must be clearly defined. (Global Footprint Network, n.d., paras. 1\&2)

The resulting number (measured in hectares) is not rigorously quantifiable and was used in this research as representational value for the purpose of comparison over time. I conducted the ecological footprint calculation every six months and recorded the data in a spreadsheet. The online calculator I chose (Royal Saskatchewan Museum, 1999) also generated ideas and research towards further footprint reductions and towards more sustainable living practices.

I undertook any living practice that effectively reduced my impact on the environment and that was doable given my current living location and some social limitations. I also undertook activities that worked to support environmental systems. At all times a close consciousness was maintained regarding the social discourse around these decisions. Sometimes my decisions were easy to make and sometimes I implemented a newly developed decision-making process. I always attempted to research my choices so that I understood their implications, attempting to make informed, conscious decisions. Sometimes it took time for me to discover that I could have made better decisions; and in those times I changed my practice to reflect my new understandings.

My exploration was recorded reflectively in a series of journals, blogs entries, and field notes. I wrote regularly about things that were troubling me, deemed as successes, or thoughts that penetrated. I used hand written field notes, as these felt more embodied (Noland, 2009, p. 119). I also wrote long emails to friends (Tillman-Healy, 2006) and colleagues expressing my latest ideas. Their feedback was welcome and contributed to my thinking and reflections. I read continuously about others explorations and 
experiences (Beavan, 2009; Flannery, 2006; Gilding, 2011; Homer-Dixon, 2007;

Kingsolver, 2007; Leonard, 2010; Moore Lappé, 1982; Monbiot, 2006; Nordhaus \& Shellenberger, 2007; Pollan, 2006; Turner, 2007) and watched films like Food Inc. (Kenner, 2008).

\section{Data analysis.}

The data of my living experiences was troubled through the process of discussion with my colleagues and students (critical friends). Such discussion often led to review and analysis, which may have resulted in further change in my practice or determination to maintain a practice. Similarly, these practices were challenged constantly through social interactions with others. My choices around how to practice living were often questioned and remarked upon and this constant bumping up against the dominant discourses ensured that I was conscious of the cultural norms I was reinscribing or disrupting. As such, the social/cultural implications of my actions and intentions were constantly brought forward.

Narrative strategies (van Manen, 1990) were used to craft an autoethnographic 'story' out of the data. Many events necessitated reporting in sequence, as the process of coming to or understanding the change in practice was chronological. Selecting a specific (and small) portion of 'the story' to share in the Findings (chapter 4) became necessary as the entire autoethnographic piece was long, very detailed, and deeply personal. The pieces selected are demonstrative of the entire journey, with a focus on food, one of the most useful areas of endeavour (see chapter 4). Parts of the autoethnographic narrative are presented throughout the chapter to offer supporting data to illustrate the story. Font changes (italics) are used to denote this personal voice. The year (date) of the specific 
journal the analysed reflection came from is presented. Journals were managed on a calendar year and began in September of 2005, when I began the program.

To counter the methodological critiques of autoethnography, efforts were made to continually reflect on the cultural implications or social discourses that impacted my change in practice. Discourses were revealed through conversation with colleagues and students, and through reading many others experiences (books, blogs), and through movies or documentaries. The data revealed a 'highly familiar' account (Delamont, 2007a), as I didn't find any way to make the reflective process useful without dwelling in the personal details. However, the presentation of the findings (the stories) took on a more meta-reflective genre and therefore became less detailed and familiar as they connected to the broader social/cultural positions. I worked to publish with ethical consideration. Obviously this story is not just mine, however, I attempted to limit the recognisability of others in my writing. The resulting autoethnographic piece was an analysis (not simple reflection) of my change toward living more sustainably. It is based on experience and action taken over five years, however the analysis came with the monitoring of the ecological footprint calculation and careful consideration given to processes such as decision-making. And in deference to Delamont's (2007a) final critique, I consider the findings of this research to be interesting and socially revealing: so too have the many conference delegates who opted to come to my presentations (White, 2010), interact with my posters, and follow up with rich conversation, as have my colleagues and, most importantly, my students.

The platform made available to me through choosing to live more sustainably and to reflect on this practice by employing autoethnography has enabled me to become a better (embodied, intentional) environmental educator. The process of critical review and 
transformation of my educational practices was methodologically made possible through self-study practices. These practices will be described in the next section.

\section{Self-study Methodology: Transformative Education}

The second stage of my research used the autoethnographic embodiment of learning to live more sustainably as a platform upon which I could focus my educational practices ensuring that they are transformational and environmentally sound. The goal was to become an educator that could present and participate in transformative environmental education with my students. These students were pre-service teachers that have great potential to carry this work forward to use with their future students. The following section describes the self-study methodology and then details the methods employed.

Van Manen (1990) explores the concept of phenomenology in educational research and then some time later Clandinin and Connelly (2000) (among others) heightened awareness of the narrative nature of knowing and the place of story in teachers' development and understanding of practice: "Experience is what we study, and we study it narratively because narrative thinking is a key form of experience and a key way of writing and thinking about it" (p. 18). These methodologies lend themselves towards explorations imperative to the purpose of my research, however they do not maintain the focus on the teacher that self-study encourages, which is crucial here. Selfstudy allows for a focus on the self, as in self-action, specifically within an educational setting. Self-study is an exciting methodology for this research where the consideration of environmentalism (its construction and deconstruction, and then possible 
reconstruction) focuses on the discursive and agentic opportunities within a class of preservice educators.

Within education, where self-study seems most firmly grounded, there have been four concurrent developments that contributed to the acceptance of this methodology: 1) the growing prominence of naturalistic inquiry methods; 2) the rise of the reconceptualist movement in curriculum studies; 3 ) the increased involvement of international scholars in teacher education research; and 4) the re-emergence of action research and its variations (Bullough \& Pinnegar, 2001, p. 13). Similarly, a shared understanding and language about this methodology has come from regular, open, and collaborative meetings and through frequent publication and critical peer review.

Self-study is a methodology that brings specific focus to teaching as it allows for "teachers' systematic and critical examination of their actions and their content as a path to develop a more consciously driven mode of professional activity" (Samaras, 2002, p. 2). At the forefront is the importance of self; it makes the experience of teacher educators a relevant resource for research, and it urges teacher educators to be critical of themselves and their practices as well as their roles as researchers and teacher educators (Feldman, Paugh, \& Mills, 2004, p. 943). The fundamental and underlying question, "How can I improve what I am doing?" (Samaras \& Freese, 2006, p. 55) is at the forefront of this important methodology. Self-study can be defined as

the study of one's self, one's actions, one's ideas, as well as the 'not self'. It is autobiographical, historical, cultural, and political and it draws on one's life, but it is more extensive than that. Self-study also involves a thoughtful look at texts read, experiences had, people known, and ideas considered. These are investigated for their connections with and the relationships to practice as a teacher educator. (Hamilton \& Pinnegar, 1998, p. 236) 
Self-study does not offer a quick fix to teaching dilemmas. It is an "opportunity to explore the challenges" (Samaras \& Freese, 2006, p. 56) and to find solutions through collaborative reflection (Loughran, 2004).

Self-study is not the same as reflective practice due to the critical awareness of the following two distinctive purposes: 1) how considerations of power undergird, frame, and distort educational process and interactions; and 2) how to question assumptions and practices that seem to make our teaching lives easier but actually work against our own best long-term interests (and those of the students) (LaBoskey, 2004). Self-study is similar to action research in that both methodologies inquire into problems situated in practice, use reflective cycles of research, and systematically collect and analyse data with the aim of improving practice. However "action research is more about what the teacher does, and not so much about who the teacher is" (Lassonde, Galman, \& Kosnik, 2009, p. 5).

Whitehead (1989) proposed this basic question for himself: How do I improve what I am doing (my practice) for personal and cultural/social benefit? Whitehead believes that what he gets from investigating this question is a 'living educational theory' (p. 41), where he practices self-study and uses action research methods. He records his lessons enabling a close reflection:

I have had to confront the questions which arise on recognising the ' $I$ ' in the question as existing as a living contradiction. In the production of an explanation for my practice I have had to question how to include and present values whose meaning can only be clarified in the course of their emergence in practice. I have had to face questions related to validity and generalisability. I have also had to question the power relations which influence the academic legitimacy of a living educational theory. (Whitehead, 1989, p. 3) 
Self-study offers the possibility to transform educational practice through critical reflection in, about, and through relationships asking how power is constructed and controlled. Challenge and transformation of power in relationships is inherently political (LaBoskey, 2004, p. 831). As such, the personal is political and power is exercised in all relationships (LaBoskey, 2004, p. 832). Thus, practitioners of self-study can be transformed, and, similarly, so are the students (and often these students are student teachers, who, in turn, influence their future students) and this transformation is only part of the total reform agenda (LaBoskey, 2004) that is required to reconceptualise what counts. Self-study is "a methodology for studying professional practice settings" (Pinnegar, 1998, p. 143) and, therefore, is one way of supporting educational transformation.

Self-study has been called "particularly postmodern" (Lassonde, Galman, \& Kosnik, 2009, p. 8) as it seems non-linear and often unpredictable. According to Cochran-Smith and Lytle (2004), self-study scholars have demonstrated that "self-study works from the postmodernist assumption that it is never possible to divorce the 'self' from either the research process or from education practice" (p. 607). Self-study doesn't claim to know a truth, but seeks to understand where knowledge is not a given before research but is produced as a cultural production (Samaras \& Freese, 2006, p. 47).

Samaras and Freese (2006) offer five central characteristics of self-study. They are that self-study is: 1) situated inquiry, 2) process, 3) knowledge, 4) multiple, and 5) paradoxical. First, a situated inquiry is inquiry driven from the researcher/practitioners questions that are obviously situated in their particular context. Such practice is inherently motivating and any change resulting is "personal, immediate, and compelling because it is connected to your learning and that of your students" (Samaras \& Freese, 
2006, pp. 40-41). "The multi-layered, critically-imbued, reality-ladened world is the text of the self-study scholars" (Hamilton \& Pinnegar, 1998, p. 235). Self-study scholars inquire into the epistemological underpinnings of their assumptions, acknowledging, reflecting, and acting upon the dissonance they uncover.

Second, self-study is a systematic and sustained process of inquiry that professes modeling not molding or a grand theory. There are no final answers, only permission to question, discover, challenge, hope, and change without feeling guilty over previous practice. "It changes the culture of blame and guilt and takes it to the frame of investigating and reframing practice over time" (Samaras \& Freese, 2006, p. 42). The aim is to become knowledgeable and to come to understand over time and continue to change as more information is gained. "The improvement-aimed work conducted by selfstudy teachers is designed to enrich the scope and breadth of one's ongoing understanding about practice and educational programs" (Samaras \& Freese, 2006, p. 43).

Third, "Self-study scholars' critical examination of their practices contributes to the knowledge and understanding of teacher education and the education reform movement" (Zeichner, 1999, p. 4). Knowledge of the individual, the professional, and the program (Kosnik, Beck, Freese, \& Samaras, 2006) is derived from complex self-study and can lead to change that is political (LaBoskey, 2004) and often has a social justice ethic.

Fourth, self-study is described as being multiple and multifaceted as researchers come from diverse theoretical frames and use multiple and various methods resulting in conceptually framing research differently (Lassonde, Galman, \& Kosnik, 2009, p. 9). Similarly, self-study can be implemented for a variety of purposes. I frame self-study through critical ecofeminist poststructural perspectives and use this methodology to 
improve my own practice as well as to develop transformative environmental education pedagogy and activism that leads to social/cultural change.

Fifth, self-study seems paradoxical, in three specific ways. As the title would suggest it is all about the individual, yet collaboration has been deemed necessary to really engage and provide alternative perspective. "Self-study requires a commitment to outside interpretations and a willingness to review one's existing frames" (Samaras \& Freese, 2006, p. 49). In fact, self-study validity and legitimacy is gained through multiple perspectives, including those of the researcher (Samaras \& Freese, 2006, p. 49). Secondly, self-study is personal and interpersonal as teachers examine their practices so that they can consider the implications of their actions on themselves, their students, their colleagues, and programs. In these ways self-study becomes a socially mediated interaction. Finally, self-study is private and public. Samaras (1998) declares "there is a definite disrobing in publishing self-study where one is immediately exposed to public view" (p. 55) as self-study scholars believe there is a commitment to make this work public. "It becomes collective knowledge when it is public and shared with an audience" (Samaras \& Freese, 2006, p. 52) especially as "the audience is critical in shaping selfstudy reports” (Bullough \& Pinnegar, 2001, p. 15).

The usefulness of self-study to this work is in how the practice of environmental education could form a critique against the notions of education itself. Similarly, the teacher plays pivotal roles in how students can, or cannot, uptake the possibilities explored that critique the systems of our society. Such critical, and reflective practice becomes relevant to explore power relations, social practices, and the possibilities of change towards more environmentally literate and respectful societies. Personal and social change will take thoughtful action that comes with a strongly reflexive practice. 


\section{Self-study of environmental education: In practice.}

My self-study research utilised the platform I created through autoethnographic

work, as someone who lives with an ecocentric worldview with sustainability as a priority and as an educator who attempts to walk her talk. My desire was to offer a transformative class through which becoming teachers could challenge their worldview and living practices at a personal level. With some success in choosing to create change personally, my endeavour was to support my students to bring their own sustainable living changes to the political level complimented with changes in their teaching philosophies and practices, now and into their future.

As a graduate student in the Faculty of Education I often sought employment as a Course Instructor. Previous to my research semester I had taught the undergraduate Environmental Education course four times, which provided a depth of experience and confidence upon which I could build. These previous environmental education teaching experiences varied by number of students and the program in which they were enrolled (elementary or secondary with differing majors) and time of year the course was conducted (fall, winter, or spring). I enjoyed teaching this course and I looked forward to being further challenged by conducting a self-study on my teaching practices.

I combined four data collection strategies to ensure this self-study revealed useful and varied data. The variety of data collected provided a form of triangulation and ensured the validity and credibility of this research. Each of these methods will be described in detail and then the data analysis process will be described. 


\section{1: Researcher self-reflections.}

Throughout the preparation and delivery of this course I recorded my observations, thoughts, concerns, ideas, and celebrations. I used a notebook that I could use in any location, especially in class. I regularly asked the students to take time to conduct their own self-reflections, so I modeled this practice myself. Reflective practice provided opportunities to think about my practice and to be attentive to the phenomena of the experience (Schon, 1983). Schon (1983) calls "knowing-in-practice" (p. 61) a post practice that allows reflection to serve as a professional tool to criticise prior understandings of situations with a deliberate effort towards preparation, or improvement, for future experiences.

The practitioner allows himself [/herself] to experience surprise, puzzlement, or confusion in a situation which he [/she] finds uncertain or unique. He [/She] reflects on the phenomena before him [/her], and on the prior understandings which have been implicit in his [/her] behavior. He [/She] carries out an experiment which serves to generate both a new understanding of the phenomena and a change in the situation. (Schon, 1983, p. 68)

Post mortem journaling allowed me to chronicle my practice, describe my actions, my reactions, and the reactions of students (Osterman \& Kottkamp, 2004). Hart, Jickling, and Kool (1999) suggest the engagement of teachers in critical reflection of their practice and thinking is a way to improve the quality of environmental education in lieu of a more prescriptive approach. Reflective practice is an effective method for improving an educator's teaching practice (Pereira, 1999). "To write is to measure the depth of things, as well as to come to a sense of one's own depth" (van Manen, 1990, p. 127).

Initially I recorded ideas and possibilities, and as the semester got underway, and I came to understand and relate to my students, I recorded more stories about reactions, and 
challenges. At the end of each class we (the students and I) discussed disruptions and reinscriptions that we experienced. These provided rich sources of data. We debriefed the entire semester during the last class of the course, which also provided rich sources of data.

Illustrative sections of these self-reflections have been included in the Findings (chapter 4). These data are presented in italics and the change in font denotes my personal voice. They were collected in one journal and referenced as "Self-study Reflection, 2009".

\section{2: Critical friends.}

Critical friends help "prevent self-deception" (Lomax, 1991, p. 14). Three different groups of critical friends were used throughout the research semester, and each group followed a similar practice. Initially, we critiqued my course syllabus and then, as the semester progressed, we turned our focus to issues that arose from the course.

Group 1: (3 critical friends) were environmental educators and researchers (one from Australia visiting the University of Regina for the semester, and the other two were locals with differing experience). Quotes from this group are referenced as "Critical Friend A-1, 2, or 3".

Group 2: ( 3 critical friends) were colleagues all employed in a similar position to me (Graduate Students and Sessional Instructors or Instructors). Quotes from this group are referenced as "Critical Friend B - 4, 5, or 6".

Group 3: (1 critical friend) was a colleague from Australia who was not familiar with my university, or pre-service teacher education; however he was an experienced 
environmental educator and provided a useful external critical point of view. Quotes from this critical friend are referenced as "Critical Friend C".

The first two groups met together every two weeks for an hour at a time. The third met via Skype regularly, although not routinely. The meetings were planned in advance and well attended. All meetings were (audio) recorded and transcribed.

Illustrative sections of these data have been included from the transcriptions in the Findings (chapter 4) to exemplify particular notions. These data are not presented in italics as they are not my personal voice. However, some times I use these critical friend quotations in my self-reflections and these are then italicised as they are from my journal reflections. The critical friends have not been identified by name in an attempt to provide anonymity and to adhere to ethical permissions.

\section{3: Student focus groups.}

Focus groups (Krueger \& Casey, 2009) were the strategy that I employed to hear from the students themselves. The student voice could determine the success, or not, of the transformative education and critical pedagogy experiences. During the first lesson of the semester the research program was introduced and students were informed about the research question, methodology, and goals. If they chose to participate they were to sign a consent form, a process managed by a colleague (and critical friend) while I was absent from the room. He held these forms and only released them to me once my student grades were submitted (and approved) at the end of semester.

Of the students who agreed to be involved, two groups of three were invited to attend a focus group meeting. The selection of students for the meetings was based on 
availability. To gain additional perspective, a group of three students from a previous class were invited to participate as an additional focus group. All three accepted.

During each focus group meeting the same questions were asked, although conversation was encouraged to meander. In focus groups, the goal was to let people spark off one another, suggesting dimensions and nuances of the original situation that any one individual might not have considered. Sometimes a totally different understanding of a situation emerged from the group discussion (Rubin \& Rubin, 1995, p. 140). Each meeting lasted an hour and all meetings were recorded and transcribed.

Illustrative sections of these data have been included from the transcriptions in Findings (chapter 4) to exemplify particular ideas. These data are not presented in italics, as they are not my personal voice. The students participating in the focus groups have not been individually identified in an attempt to provide anonymity and to adhere to ethical permissions. The reference used after each inclusion is "Student - Focus Group".

\section{4: Student self-reflections.}

Students in the environmental education class were asked to critically reflect on the course as they progressed through it. Their learning journey journals could take any form, although many of them were blogs (where students consciously chose an online, paperless format). The journal reflections from the students who agreed to participate in the research were used to prompt further self-reflection and to deepen the findings of the self-study addressing ideas of bringing change via transformative education and critical pedagogy experiences.

The student self-reflections were re-read after the focus group meetings and were used to deepen understandings regarding students' responses to particular aspects of the 
course. Students were asked to hand in three meta-reflections throughout the semester. These were reflections drawn from self-analysis of their ongoing self-reflections. The meta-reflections were evaluated during the semester and counted towards each student's final grade. Because it was the meta-reflection that was evaluated, the form of their selfreflection was determined by the student and not commented on by me. Thus, student self-reflection could take any form (and did). Some were very articulate and verbose; while others chose alternative forms of reflection and were more open to interpretation.

Illustrative sections of these data from the transcriptions have been included in the Findings (chapter 4) to exemplify particular ideas. These data selections are not presented in italics, as they are not my personal voice. The students participating in the research have not been individually identified in an attempt to provide anonymity and to adhere to ethical permissions. The reference used after each inclusion is "Student Learning Journey Journal”.

\section{Data analysis.}

Data analysis occurred iteratively and in a progressive manner where possible as I used a constant comparison method of data analysis (Glaser \& Strauss, 1967), although all student focused data analysis occurred after the end of the semester. The ideas resulting from the critical friend meetings were implemented whenever possible and many were reflected upon in the next critical friend meeting, resulting in an iterative or

cumulative process. The analysis of this process resulted in two forms: first, the ongoing changes and adaptations were recorded and examined iteratively through both my selfreflections and critical friend transcripts; second, the cumulative impact of the changes and adaptations were considered at the end of the semester. 
The student data (focus group transcripts and student self-reflections) were analysed at the conclusion of the semester. The analysis included dwelling in the data to reveal interesting comments and cross referencing these with the students' self-reflections made throughout the semester (via the evaluated meta-reflections). I chose to consider all impact as either being either negative or positive as both could lead to change.

Analyses were used to compile reflections, which culminated in further design and development of one pedagogical strategy: the Action Learning Group Project (ALGP). The ALGP strategy, more than any other, challenged the students personally and had the greatest potential to transform (and support) their future educational practice. The ALGP strategy underwent much development after the semester of self-study research culminating in an online presentation format and presented in the Findings (chapter 4).

\section{Meta-reflection: The Social/Cultural}

There is no third methodology employed in my research. However, as I have utilised a three-step model to represent this research (from the personal change to transformative education working towards social/cultural change) I will be explicit as to how the social/cultural work was conceived and conducted. The methods employed here have an autoethnographic tradition with more of a narrative inquiry outcome. I have called it a meta-reflection as this writing was drawn from my autoethnographic reflections with a focus on the discourses of social and cultural change. Meta-reflective writing relies upon a meta-cognitive understanding of the content. The term meta-cognition first appeared around 1975 in the work of developmental psychologist Flavell from Stanford University. He used the term to denote:

One's knowledge concerning one's own cognitive processes and products or 
anything related to them ... [and] refers, among other things, to the active monitoring and consequent regulation and orchestration of these processes ..., usually in the service of some concrete goal or objective. (Flavell, 1976, p. 232)

To give an example, meta-cognitive writing is similar to understanding the text, where as cognitive writing is similar to the skills required to read the text.

The analysis is presented as a partial story, similar to the personal autoethnographic pieces. These stories are deserving of attention as they articulate work towards my research question: to influence social/cultural change. The two stories presented are integral to illustrate how my thinking and action developed throughout the course of this research. They are presented in my personal voice and represented using italics, and referenced with the reflective journal number and year the story was written.

\section{Research Goals and Assumptions}

Although my research addresses the question (how) can I use personal change to inspire educational and social/cultural change? the doing part, or embodiment, of this exploration (addressing the (how) through an embodied, intentional practice) is important to me. Thus, I can articulate research goals where I anticipated achieving each through a cumulative and ongoing process. I also include two 'hopes for the future' and then work to state the assumptions that I bring to this research.

The goals of this research are such that working towards exploring the research question will achieve these actions and outcomes. These goals are:

1. Begin to deconstruct my environmental identity, subjectification, and positioning discerning the disciplining dominant discourses and also providing awareness that facilitates confident disruption and positive re-inscription for myself and, ultimately, others; 
2. Practice living sustainably within my society; watching critically as to how I come to perform 'intentionality' in my environmental education, effectively lowering my ecological footprint and talking about how I achieved (or failed) this task;

3. Using the work from 1 and 2; (re)focus my performance as 'transformative educator' towards a critical ecofeminist poststructural environmental educator, activist, and researcher employing critical pedagogies and transformative education strategies, specifically with pre-service teachers;

4. Develop one pedagogical and transformative strategy to a refined level where it can be implemented in a variety of educational settings with appropriate resources, and presented in an online, free to all, format; and

5. Using work from 1,2,3 and now 4; practice and perform activism in my community through working with environmental education organisations taking up opportunities for leadership that will facilitate a change in discourses.

Ultimately I hope that this work then affords me a pass into new ways of being and new ways of performing environmental educator, environmental activist, and researcher. First, I hope to be well regarded as an intentional practitioner and performer of environmental education. Second, I hope to facilitate the reflexivity of practitioners in the environmental education field and ultimately to continue the movement of the field into critical praxis.

The following assumptions articulate the place from which I begin:

- My living practices must embody environmental consciousness to be an intentional environmental educator (walking my talk at the personal level); 
- The dominant discourses in environmental education tend to trivialise and undermine what I can achieve through or even talk about in this field;

- Becoming an 'intentional practitioner' involves: education, activism, and research; theory and practice; praxis; there is no public/private division in this work;

- An educator is always performing. My research works to bring intentionality to this performance in a way that students can see themselves reflected and feel encouraged to bring a level of consciousness and accountability to their own practice, and ultimately that of their students.

\section{Research Ethics, Voice, and Representation}

The University of Regina Research Ethics Board approved this research protocol (see Appendix 1).

Self-focused research asks the researcher to be reflexive and critical in ways that are often uncomfortable. Finding confidence in and with this work took some time and effort. It was the process of writing that made my transformation possible. Writing is both a theoretical and practical process (Richardson, 2006, p. 1). What can be revealed is (a) epistemological assumptions, (b) grounds for questioning and hegemonic ideals, (c) ways to change, (d) connection to others forming community, and (e) a nurturing for our emergent selves (Richardson, 2006). With persistence and practice I found my voice.

Representation has been an area of research that I have become intrigued with. I toyed with ideas of theatrical performance, social media strategies, multi-media presentations, and even the production of a novel. I finally found my way forward with a more conventional dissertation, finding the appropriate vehicle for the message and the audience was a task that required careful consideration. This is a conventional 
representation that requires careful framing. There is time, in the future, for the Findings, the 'So What?' to be shared via more 'popular' strategies. 


\section{Chapter 4. Findings}

Another world is not only possible, she is on her way. On a quiet day, I can hear her breathing (Roy, 2003, p. 112).

Action orientated research takes the researcher on a journey of discovery through embodied experiences. The analysis of these experiences, as presented here, highlights the cultural implications as is necessary in autoethnographic work through three areas of interest: the usefulness of the ecological footprint, my decision making process, and food and food systems. In each area self-reflective snippets have been taken from my many journals to illustrate action and change in my personal living choices. Based on this selfwork, I troubled my teaching practices through self-study exploring how I can be an environmental educator who walks her talk. One critical pedagogical strategy designed and used as a major component of the environmental education course revealed itself as important and something to be further developed. A deeper exploration into this strategy, the Action Learning Group Project (ALGP), is offered. Further self-study analysis explores student resistances and power and relationship themes. Finally, the social/cultural aspects of my research are shared through two meta-reflective stories where I analyse my actions in an attempt to bring about change. Many of my findings were expected, somewhat, while some were a revelation that only became possible as I put my body into this research. There is no division in this work as it is personal and political. 


\section{The Story of Sustainable Living Practices: An Autoethnography}

I share aspects of my story of discovery about how I learned to live within my western society with critical awareness and consciousness towards being more sustainable, leading me to make living practice choices that would result in greater responsibility through my actions. There are many aspects to this story; I will share details of only three. I begin with a description of the ecological footprint as the tool used to guide the development of a sustainable way of living, in theory and practice. Then, I detail my decision making process which supported making choices with awareness of most of the implications thereby taking responsibility for these choices. Finally, I describe aspects of my practice in some detail. I chose to elaborate around food and food systems, as these are living practices that many will relate to on a daily basis and where small changes are always possible.

As is appropriate with autoethnographic work, these stories are personal, detailed, and comment on the culture within which they are immersed. They are not just autobiographical in their retelling, they attempt to offer comment on the society and culture within which I dwell, illustrating how my choices are not only my own. I am (co)constructed to believe and practice in certain culturally appropriate ways and often the foundations for these decisions are not pragmatic choices around what is good for me, or the environment. Thus, I reveal a critical self-examination of some of the discourses of western society and how they work to re-inscribe practices of excess and waste through our empty demonstrations of success. Unpacking these discourses is necessary if we are to reveal and take up a different way of living, one that is more sustainable. 


\section{Some grounded findings.}

I could have chosen to remove myself from living within society by stepping out

of the grids that bind us into being successfully western. However, 'running away' to live without the mechanistic systems that uncritically and excessively provide food, electricity, transport, housing, clothing, and a culturally acceptable western ways of being is not always an option. I could have escaped to live outside of community and by my own ingenuity and sweat: living in the country growing my own food, capturing my water, managing my wastes, and producing everything I needed in idealistic selfsufficiency. I could have run away, escaping the constant production of excess, but I chose to stay, to live within the social constructs and to learn to do it better, differently, and with a focus on sustainability.

I (re)learned how to live in our western society while becoming as sustainably as I could. These grids trap me into the role of consumer, a specialist within the economy, only a part of the system, necessarily relying on others. However, thanks to an agrarian, practical upbringing I knew quite a bit about how to provide for myself; I am one of the fortunate few, and with this (privileged) positioning, knowledge, and preparation I learned to make better choices for myself, and better yet, evoking my profession as an educator, I worked to help others to do the same.

I wanted to know and experience the discourses as they played out in my body. I struggled to make living choices based on different discourses, ones that are framed through ecofeminism honouring my ecocentric ontological positioning and worldview. I removed the automatically assumed privilege of being human by valuing all beings. I wanted to feel the impact of the controlling comments, the disciplining discourses constantly reminding me to not stray away from my privilege and societal rights and the 
incumbent expectations. I wanted to live sustainably, as if humans do not have a right to use everything; and I wanted to do this from inside society so that I could demonstrate that it could be done. And then I wanted to talk about it, sharing my findings with others, encouraging them to see that it can be done, and that they share this responsibility to act similarly, in whatever ways they find possible.

It's not easy, going against the constructing and disciplining discourses of your own society. Each time I stepped beyond the expected there were looks, friendly comments, jokes, explanations, or excuses made for my unusual desire or behaviour. I chose to accept these, to listen to them, and to enjoy them for what they were... loving reminders that I wasn't playing by the rules, challenges to climb back in, to behave properly, and to conform to the discourses. As I listened, I examined these opportunities in an effort to understand the discourses and their intentions. I played with the power and, more often than not, I stood my ground.

I tried living with the intention of becoming the best practitioner of environmental education that I can be, for now, given my current situation and limitations. To achieve this goal I had to change the way I lived, to whom I listened to, and I had to stand against the discourses of my society as they constantly challenged me in my lifestyle decisions. I used humour as a strategy and coping mechanism, and I found and developed my personal agency often choosing to walk away empty-handed if I wasn't able to practice within my self-imposed guidelines.

Prior to offering my findings of personal/social action I want to acknowledge that I am beginning to become aware of the power and privilege I bring to this work. I undertake this work as a graduate student with specific goals and purposes, considerable passion to be successful, and the support of my chosen situation (and the privilege to 
make these choices). Awareness of my privileges came as a bit of a shock and as I embodied the implications of it I began to become aware of further evidence and example of my power from privilege. I continue to work to become aware of and perhaps change my understandings and practice of my positioning. My privileges can be named in the following ways:

- White skin entitlement

- Middle class positioning

- International perspectives and experiences

- Focus and time to devote to the development of these intentional practices within the privilege of taking up self-directed work

- Graduate student status providing institutional resources, support personnel who encourage, scrutinise, and offer advice and direction.

I believe this work is critical, political, ecofeminist activist work: some of these discourses will be further examined. For now, three of my stories of becoming aware and becoming active in my personal/social responsibility will be described.

I find it interesting to note that in asking questions about how I might choose to live I have changed the possible answers. The act of reflecting on my practices has generated many questions, which were often addressed through initiating considerable change to the very thing I was investigating. Is this a case of the observer being observed? What has unfolded is a cumulative story, a reiterated and cyclical exploration, of which I share only three short stories.

I don't intend the following description as prescriptive instructions, because we each need to find our own paths and map our own journeys of self-responsibility towards 
sustainability. I frame this work as my attempt to live with certain (privileged) critical ecofeminist ethics, within western society, for a period of time, with the explicit desire to bring about critically informed change and cultural revolution through education.

(How) can I use personal change to inspire educational and social/cultural change? I wanted to see if it could be done and what it might feel like doing it. I have found this critical and conscious way of living to be somewhat achievable and even enjoyable, and I will certainly be continuing many aspects of my new practice into the future, wherever I choose to live. In fact, I am constantly looking for opportunities to delve deeper as I reveal more occasions for action and change, more socially constructed rules and traditions that are uncritically followed, more western ways of being and doing that could be challenged. And I constantly look for colleagues to bring along on this journey of self and social discovery, challenging all of us to live more sustainably.

I found that to live with intentionality (and/or critical consciousness) is a practice that requires constant vigilance and deep consideration of all actions, and reactions; time was spent unpacking my practices revealing myths and misconceptions generated and perpetuated by my society and unconsciously embodied by me over many years. Along with developing a heightened sense of what it feels like to live this way, I have also developed awareness around how I make choices and take action within my society. Awareness of discourses (especially the disciplining ones) and how I feel the need to conform, or to express agency and choose alternative practices (and alternative discourses) has been growing. Decision making strategies have evolved over time, and usually focus on limiting the amount of time and scope or method of research I use with each decision. Planning a decision making strategy was my first action when confronted with a new lifestyle problem. I unpack this process as one of my three stories. 
I struggle now with how to name the intentionality I want to bring to my living practices, and ultimately my educational practice. I used to call it living with an environmental ethic, or living in an environmentally aware way; however, I now believe that this is not clear enough. I don't believe that the environmental crises we are experiencing globally are necessarily 'environmental' in their genesis. Many of the issues undermining particular ecosystems leading to collapse, or an environmental system to develop abnormally, are, in fact, anthropogenic (human generated). Thus, we are experiencing social crises, not environmental crises. The false naming of these crises allows for a lack of recognition as to the underlying practices that generate such varied issues and consequences. Mostly these social crises are generated through western societal practices, where $20 \%$ of the world's population consumes $80 \%$ of the world's resources (Leonard, 2010). I am, therefore, choosing to name my intentionality as living with consciousness and consideration for all beings. I want to live in a way that acknowledges that I am part of all Earth systems, only one of which is the human, western societal system, and this is the system I desire to change.

\section{The ecological footprint: Theory and practice.}

My story began with a shocking realisation. The following is an excerpt from my first autoethnographic journal:

Here I am, having recently moved to Canada to study environmental education, and I have an ecological footprint of 16.4 hectares. Oh, the irony! Oh, the embarrassment! And it's not just the literal interpretation that is so devastating, it is the implied reality that comes from realising that not everyone can live like me and I feel almost gratitude that this is the case... this is what I mean by realitywhat a horribly privileged feeling! 
How can I possibly hold my head up in any educational situation and profess to know anything about environmental education when, right now, I embody the problem, and I am certainly not living the solution. This needs to change; I need to change how I practice living if I am to practice environmental education with any dignity, self-respect, and intentionality. (Journal 1, $3^{\text {rd }}$ October 2005)

It was the revelation that my personal living choices resulted in me not walking my talk as an environmental educator that initiated my embodied research journey. If change begins within, I needed to change.

Ecological footprint analysis provides a tool that can help translate sustainability concerns into public action - it is both analytical and educational. "It accounts for the flow of energy and matter to and from any defined economy and converts these into the corresponding land/water area requirements from nature to support these flows" (Wackernagel \& Rees, 1996, p. 3). The ecological footprint calculation is a tool that prompts a quantifiable measurement of how living practices have a real cost to the environment. It is a tool that facilitates comparison to how other individuals, events, or organisations might also impact the environment. While this tool is not without issues (it doesn't account easily for the cost to the environment of the infrastructure involved with our western ways of living), yet it makes an effort to provide some comparisons. Additionally, it offers ideas as to how I might continue to change my practices to reduce my ecological footprint even further.

I read about the creation of the calculation (Wackernagel and Rees, 1996) and was impressed with its logic and relevance. As I investigated the ecological footprint concept, I found it to be a treasure trove of ideas and possibilities for future action. Each question of the calculation offers many opportunities to (re)consider my current living practices in such a way that I might lower my total hectare (land/water) use. I found a local online calculator (Royal Saskatchewan 
Museum) that facilitated a quantified measurement while prompting and generating ideas for continued improvement. The beauty of using a locally generated calculator was that the factors relating to city infrastructure and governance were already accounted for. My data would be corrected for living in Regina. (Journal 1, $11^{\text {th }}$ November 2005)

The Royal Saskatchewan Museum Ecological Footprint Calculator allowed me to compare my results with other Canadians and people living in other parts of the world, which was useful when considering the implications of my privileged existence and the injustices experienced by others not immersed within my worldview, societal discourses, and western paradigms. However, over time I have come to understand that the living practices I changed the most are those of the western world. I make no claim to abstract these living practices towards societies not privileged with such excess and access to resources. This is an important consideration, and one that must be made very clearly when presenting my lived experience. This work is socially bounded.

Through using the Ecological Footprint Calculator my results were presented in ways that visually represented the magnitude and implications of my current living decisions and choices.

- The choices I make everyday affect every other living being. When used with honesty, this tool demonstrates how every decision I make has a result or an impact on others (human and more than-human). If everyone lived like me...

- The ecological footprint calculation makes the implications of my daily living choices more visible and obvious.

All those times when we are home alone, and no-one is looking, we decide to finally clear the hallway by putting all the recycling into the garbage, or to drive the car instead of catching the bus, or to leave the lights on in rooms we have just 
vacated. These are choices. They are not always made out of convenience. Sometimes it's willful; however, sometimes it is unconscious. It is our personal responsibility to think through these choices and to make better ones with the bigger (environment included) picture in mind. There is no easy way out of the situation (environmental devastation and/or social collapse) we are in. We are being socially constructed to let others do the hard work for us. In fact, the definition of 'convenience' is paying other people to do it for you. (Journal 2, $19^{\text {th }}$ February 2006)

I proposed that with some strategic changes to my living practices I could lower my ecological footprint and respectfully present myself as an intentional environmental educator who walked her talk, took her own advice, and could offer personalised experiences in and around how to make sustainable living choices. I set a goal. An ecological Footprint of 16.4 hectares is unacceptable, given my chosen profession and philosophical positions. While there are obvious reasons for this high hectare use (travelling from Australia to Canada), some changes are required in my living practices so that I am walking my talk and can become the intentional environmental educator I want to be. I aim to reduce my footprint so that if everyone lived like me, while valuing the greatest amount of biodiversity, we could all live on our one planet. I will make changes to my living practices until I achieve a stable ecological footprint of 1.8 hectares (where if everyone lived like I did we could exist on out one planet). I give myself permission and time to explore and embody these changes, ensuring that they become integral to my lifestyle choices. I will also look for the discourses that allow and disallow such practice, considering agency and positioning. I want to feel the rub of the dominant discourses as I come up against them. (Journal 1, $12^{\text {th }}$ October 2005) My journey was quite an intense experience and often I felt as though I was Alice, disappearing down a self-generated rabbit hole. Unpacking my decisions and becoming confident in my choices took time and embodied experience. It was only as I put my 
body into this research that significant changes occurred. It took time to raise my awareness regarding how to change, and then to work out how to embody that change in an ongoing manner.

Figure 2 offers a graphic representation of how my ecological footprint (measured in Hectares, HA) reduced from 16.4 HA in July 2005 to 1.8 HA in July 2009. The higher results coincide with a lot of air travel (I chose to visit Australia once every two years - to spend Christmas with my family). I was careful in my calculations to measure successfully embodied changes to my practice, not just anticipated or desired change. My results now hover around 2-3 HA, depending upon my transport choices as these choices are the most variable and environmentally costly.

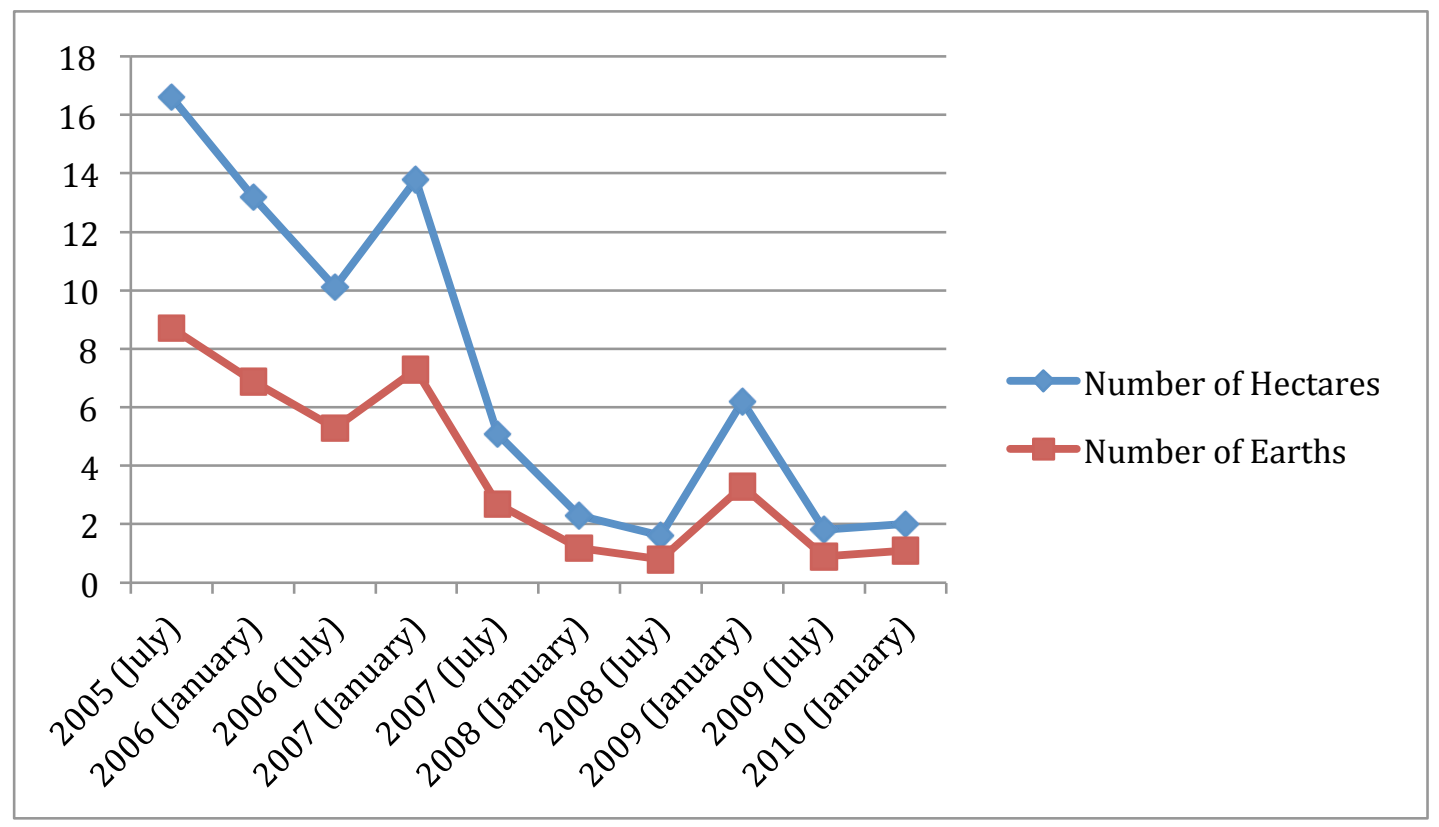

Figure 2. A graphic representation of my ecological footprint analysis from July 2005 through to January 2010. The blue line illustrates the actual hectare result while the red line is the calculated number of earths required if everyone lived like me.

It took some time for me to begin to unravel my (co)constructed notions of what it meant to live as a thirty something woman in our society. Once I began to become aware of the possibilities I actively looked for different discourses and I found how constrained I 
had become. After three years of constant consideration I had become more aware, passionate, knowledgeable, and determined; however, I'm surprised it took so long!

Figure 3 offers a visual representation of some of the changes I implemented in my daily life. The ecological footprint calculator gave me some ideas for areas in which I could take action, and others seemed to be obvious. I kept reading and talking and working on developing further ideas, testing the discourses around what it means to live more sustainably. The areas of action and challenge have been synthesised into the following headings: transport, energy conservation, water consumption, clothing, housing, consumerism, shopping, food, waste management, personal and cleaning products and others. Following are some reflections about these actions in some areas.

Transport: I reduced my air travel, which was challenging as my family and friends live in a different country (opposite side of the world), so I made a commitment to only go home for Christmas every second year. I also reconsidered travel within this continent, choosing alternatives to air transit whenever possible. I took the train across half of the US, I loaned my car so that one car was servicing two people, and I eventually sold it, choosing to manage my transport in other ways. These ways included a bike when feasible (not in winter for me), walking (possible though more difficult in winter), and public transport. Often my best choice was to not travel, and this took some effort to get my head around. As Westerners, we have become so accepting of travel, it feels like our right. If I couldn't find safe passage there and back I would just not go. I enjoyed feeling the discourses at play, especially when my friends were frustrated with my choices. Their comments and encouragements voiced many of the dominant discourses and allowed me to feel discipline in action.

Clothing: I learned how to shop for and wear second hand clothes, even shoes. I limited the amount of clothes I owned, returning any unnecessary items to a second hand shop. I attempted to streamline my choices producing a versatile 'classic' wardrobe rather than a selection of rapidly outdating fashions. I also 
valued spending time to mend my clothes and took extra care in laundering them so that most items experienced an elongated lifetime. I decided not to purchase clothes that were not natural fabrics or that were processed in environmentally damaging ways (like bleached cotton). I considered where an item was manufactured and attempted to buy locally made clothes.

Housing: I rented rooms close to the university area, house sat, and moved into residence on campus before purchasing an apartment just across the road from campus. These decisions meant that I utilised high-density living and limited the need for transport. Owning my own home meant that I could implement many energy and water saving strategies. It also meant that I could challenge myself to furnish a home without resorting to purchasing new items. If found garage sales very useful in providing well priced, quality items. I also found that I didn't really require much additional furniture, challenging another social discourse. My belongings grew, however, filling the available space, if I wasn't vigilant. Consumerism: I lived to the quote "every cent you spend is a vote for the kind of environment you want to live in". This kept me out of Dollar Stores and Walmart. I became very conscious of the items I purchased, becoming aware of the implications of the choices I was making. I considered where I was shopping and who had been involved in the production of the goods. I valued the environmental impact of each stage of production. I took time to learn about the processes that products underwent, and grew increasingly concerned at the international transit that many products experience before finding their way to the shop. I learned how to find alternatives to products that didn't live up to my ethics. I learned to live without, and liked it. I was determined to become (un)tied to stuff. (Journal 5, $20^{\text {th }}$ September 2009) 


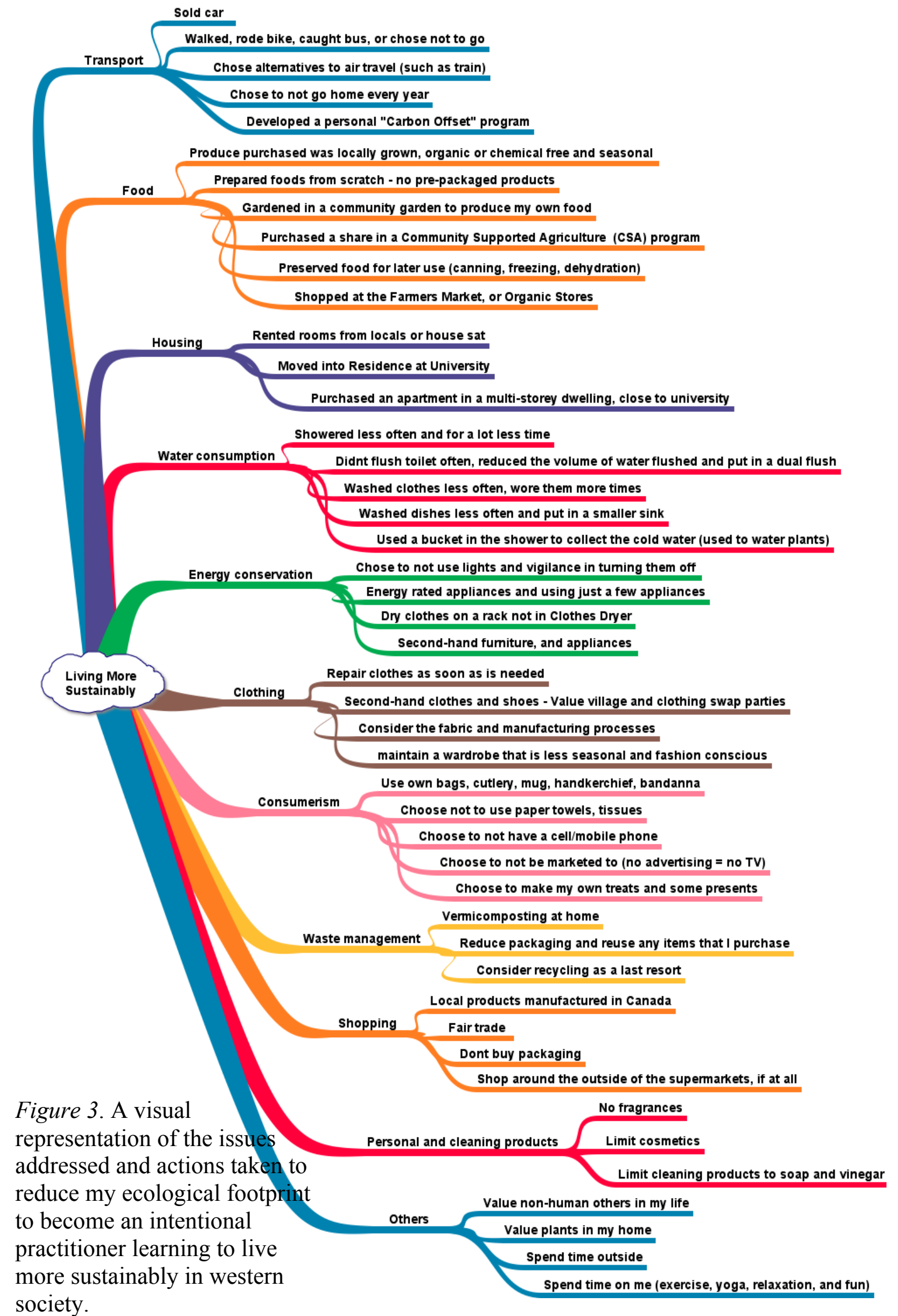




\section{My decision making process.}

I rarely go 'shopping' and if I do it is for specific items from a particular,

previously researched, shop. If the necessary shop is not available in my local area, I will shop online. In all instances I participate in my decision making process, where I set carefully considered criteria for what I require, and then spend a set time limit researching before purchasing the product, or not. In all cases, I remember my preparedness to walk away from the purchase.

My ethical considerations are usually environmentally grounded, although financial considerations play a factor. I think that each decision I make carries implications, even the most obvious, justifiable choice. Becoming aware of these implications is important when making informed decisions. Availability and low cost are the obvious criteria most people consider, I believe. However, I attempt to factor in the design and development process, the ingredients and manufacturing processes, transportation (especially if from out of province or beyond), and packaging. Sometimes I also consider marketing (promotion and advertising), as considerable environmental damage results when money is (in my opinion) wasted in this way. Ultimately I need to (re)consider if the product is just desired or is it required.

Each time a choice is made there are negative implications. Making myself aware of these implications and learning how to choose the less environmentally damaging products took some time and effort. Things I had to consider or learn included: learning to read and understand ingredients; developing an awareness of packaging and the recycling opportunities that actually make sense in my local setting; always considering the end-life of a product and what can be done with it once it has served its usefulness with me; how the products were manufactured or grown and whether ethical treatment 
was attributed at each step of the production line; whether a less environmentally damaging product is available even if it takes more effort (often encouraging me to make things from scratch); and whether I really need this product? The negative implications of each choice were often sufficient for me to put the item back on the shelf. For example, I have not purchased food packaged in tin cans for many years as there is no suitable recycling program in this city and I have no use for multiple tin cans. This demonstrates how I consider the 3R's (reduce, re-use, recycle) prior to making a purchase. In this example I couldn't appropriately recycle or re-use, so, I decided to reduce and not make the purchase! There is an implied hierarchy to the 3R's.

The days of spending hours strolling the aisles and haunting the change rooms are gone. I listen to friends talk about 'retail therapy' and wonder what is at the root of these modernistic rituals. I enjoy not buying into discourses around the cheapest, the greatest deal, or the best value for money, etc. I am choosing to value a different set of criteria: an environmentally aware and informed ethic of consciousness and intentionality.

\section{Food and food systems.}

The following is a detailed example addressing one of my favourite and most demonstrative areas of sustainable living practice. Food and health are the areas I encourage others to consider as an easy starting place when beginning to take action. I think food and food systems relate well to health and most people are concerned with maintaining a healthy body. We are constantly working to feed ourselves and many have a desire to do this in a way that promotes health. Throughout the day there are many opportunities to make some better choices and it doesn't take long for these better choices 
to start feeling worth it. Similarly, I find the discourses around food and our food systems fascinating and closely linked to social and cultural practices.

\section{Food... and how to ethically provide nutrition to a female body.}

Traveling in different countries brings many challenges and one of the most difficult is how to provide nutrition to 'your' body when food items are different and unfamiliar. Even though the Australian and North American cultures have many similarities there are some interesting differences, especially with regard to food.

When I first made it to this continent I found it was the basics that provided the most difficulty. The basics for me were bread, cheese, and yogurt. North American bread is very sweet and full of additional ingredients (bread should basically contain yeast, water, and flour). Good quality yogurt is hard to find, as there should be nothing in yogurt other than milk and bacteria. Low fat foods are fashionable and, like most fads, they are nothing but cheap replicas of the real thing. In order to mimic the consistency of 'real' yogurt the low fat varieties have additional ingredients (like thickening agents and preservatives). And as if this isn't bad enough, what is done to cheese is nothing short of ridiculous. Someone decided that North American consumers liked orange cheese better than white or cream coloured cheese. So most cheeses are died with food additives to ensure

they have a 'pleasing' orange quality. However, cheese should also only contain milk and bacteria and should therefore be cream coloured (and, if aged, perhaps a little yellowed). (Journal 5, $9^{\text {th }}$ March 2009)

Upon settling in North America I made most of my food choices based on financial and availability factors only. If I could afford it, and it was there, then I could purchase it. As time progressed I started to talk to new friends about the issue of appropriately providing nutrition to a body when we live in near arctic conditions for six months of the year. I discovered moral and ethical issues of surprising magnitude the 
more I investigated. Shopping in supermarkets became an adventure. The total number and sheer volume of products was overwhelming. As I began to take some time to investigate and read the labels of the products I was purchasing, I realised the incredible range of products available in these shops as they have large distribution networks, ones that spanned the world. Food items from Australia, Europe, Asia, were available almost everywhere. I was just beginning to consider the environmental implications of transporting my own body around the world so it was an easy leap to consider what it meant for my body to then consume foods from around the world.

Pollan (2009) suggests in his Food Rules book that shopping around the edges of a supermarket is the only safe way to proceed. Thus, unaware shoppers avoid all of the heavily processed and potentially dangerous foods. I have tried this strategy and shared it with students who are also looking to change their food practices, mostly with great success. (Journal 6, $10^{\text {th }}$ October 2010)

I have always liked to cook, often inflicting my creative food inventions on my long-suffering Father. As I became immersed in my studies I began to use cooking as a way to break up my day. I cooked food from scratch. I don't like following recipes at the best of times (to the chagrin of my Mother), so it was not surprising that the multitude of partially prepared foods available in North American grocery stores did not appeal to me. My land-lady passed on an invitation to attend a cooking class run by a friend of hers, just as an item of interest I was told (not because she thought I needed the skills so she said). I jumped at the chance "what a great way to meet some people and we get to eat what we cook - perfect!" (Journal 1, $9^{\text {th }}$ December 2005). And so I was introduced to Wholistic Cooking.

Wholistic Cooking reminds me that nutrition is the reason for consuming food. The aim of the game in eating is to provide your body with the necessary building blocks 
to be healthy. The way food is processed and the types of foods consumed should compliment each other. Previously, I had constructed meal plans based on what I liked, availability, and length of time required for preparation. I learned that with some simple organisational skills and some specific knowledge I could vastly increase my nutritional intake with little extra effort, often at a reduced cost, and by consuming less food. The net benefit for me would be a healthier digestive system and body.

Soaking beans, nuts, and seeds makes them more nutritionally available. So I soak rice the day I planned to eat it for dinner, I soak and then dehydrated nuts to snack on, and I soak chickpeas before cooking them for hummus. Sprouting certain seeds produces nutritious greens throughout the year, especially important when living this far north in the northern hemisphere. Locally produced, inexpensive greens, all year round... yes please! I also learned that some preparation processes like lacto-fermentation are key to producing healthy internal intestinal flora and, therefore, a healthy system. I had never considered this before and I certainly had never developed a palette that desired (or could even tolerate) such foods. I have been working on it for some time now... and I am getting there. Foods like sauerkraut, sour dough, and pickled vegetables are wonderfully nutritious and assist in creating the best possible internal flora that ensure my nutritional needs are met.

Considering the nutritional implications of fat and sugar consumption has been deeply concerning. Many fats cannot handle the high heat of cooking and they effectively become rancid as they breakdown during the process resulting in by-products that can be hazardous to our health. Coconut oil (solid at room temperature), butter (also solid at room temperature), and olive oil are three very useful and flexible oils. Equally concerning is the highly refined state of most commercially available sugars. Sugar cane 
is marketed as a white crystalline substance; however sugar only takes on such an appearance after considerable processing, including chemical bleaching. Raw sugars and natural sweetening alternatives (such a maple syrup, agarve, and stevia) provide an unexpected and pleasant alternative that also provides nutritional value, sweetness, and less toxic burden.

With this new knowledge and a deepening practice around feeding myself, I began to seriously consider my nutritional intake. If I looked to the ecological footprint for some guidance and suggestions and I found that consuming meat and dairy products weighed heavily on my calculation. I felt encouraged to consider vegetarianism as an appropriate choice, based mainly on sustainable reasoning. This was an easy conclusion to draw ethically however; it did not feel like an easy decision to embody. Becoming a vegetarian felt like a serious challenge.

Becoming a vegetarian was likely one of my Dad's greatest fears for me... I grew up on a farm where we produced all kinds of meat (beef, pork, lamb, capretto, duck, chicken, and often turkey). I had eaten meat three times a day for most of my childhood. All of our celebratory meals were served with the appropriate meat (for example: turkey at Christmas, duck for birthdays, and lamb for a Sunday night special). I like meat, I like the taste, I enjoy the texture, I have been personally involved with most parts of meat processing and I felt like a responsible consumer. Yet, right now, living in Canada, I felt encouraged to remove all notions of meat and dairy from my diet. My biggest concern is whether I will remember that I am now a vegetarian... I don't eat out that often, but when I walk into a restaurant and the smell of cooking flesh welcomes me, will I remember to say no? I'm worried about being able to say no, I know I am a pretty determined person, but what if I forget? (Journal 3, 20 th June 2007) 
So I gave it a shot and I only forgot twice. Once I picked up a shrimp and had it to my lips before I remembered. I saved myself from vegetarian corruption, but I did suffer from social humiliation as my realisation came with quite an exclamation! Surprisingly, my greater challenge was hanging out with my parents and visiting friends. I began this challenge on the $1^{\text {st }}$ July 2007 and my parents came to visit me in August of the same year. I had stabilised in my resolve by this time. And this was fortunate because at almost every meal either my Mum or Dad would say “mmmm you have to try this, It's amazing..." Especially around some kind of game meat that is North American and quite the novelty to visiting Australians. Or my personal favourite was "Oh go on, just take a mouthful, we wont tell anyone!”. After spending two months with them and only succumbing once (for some local elk meat) they finally got the picture and I felt totally tested, and successfully solid in my resolve.

Another challenge was remembering to inform anyone I was eating with about my new nutritional ethics. I had some friends that were not supportive of my decision and it became increasingly difficult to eat with them, and I had some other friends who went out of their way to support my decisions, often to the extent of making special vegetarian dishes or designing the entire meal around my needs. (Journal $3,28^{\text {th }}$ November 2007)

I decided to donate blood in August 2007, mostly because I knew that they performed a basic blood iron test before taking a donation. I was devastated to be told that my iron was too low to be a suitable candidate for donation. After practicing vegetarianism for only one month I concluded that this was likely not the cause for my iron deficiency but that I would have to be vigilant with my iron intake in the coming months. I worked hard to consider my diet and I thought that I had done quite well to ensure that I was receiving all the necessary nutritional aspects of a diet as a vegetarian. However, I became increasingly lethargic and eventually had to admit that I was quite 
seriously low in iron and would have to take iron supplements. Feeling anemic was distressing and challenging and yet this embodied experience prompted me to seriously reconsider my needs and choices.

Simultaneously, two other events offered opportunities for reconsideration of my vegetarian dietary choice.

As I began to get better at recognising some of the pitfalls with other food items in my diet (such as production processes, transport practices, and marketing implications) I discovered aspects of North American meat production that I had not considered before. Australia is an ancient landscape and one on which no hard hoofed animals evolved. Consequently the importation of hard hoofed stock for consumption has damaged the ecosystems (especially as many of these species have become feral and live in increasing numbers in fragile landscapes out competing or predating the endemic species). In this situation I have a hard time justifying the consumption of meat. However, in North America the landscape evolved with herds of bison and other large, hard hoofed, animals. Plant and soil species co-evolved with this grazing habit. Therefore, farming hard hoofed animals in a way that somewhat replicates the behaviours of bison, elk, moose, etc, feels appropriate and I feel ethically ok about consuming this meat. However, growing livestock in CAFO's (concentrated animal feeding operations) or feedlots does not replicate the co-evolved system. So even without considering the diminished health and happiness of the actual animals, the significant damage to the ecosystems where these factory farms exist ensures that I cannot support the consumption of this meat. (Journal 4, 25 ${ }^{\text {th }}$ March 2008)

It is disappointing that the ecological footprint calculator does not allow for more detail because I feel that consuming meat is ok in North America, as long as I am conscious and careful about how I access it. Consuming free-range, grass-fed, chemical free beef, for example, is a good practice. Good for my body and good for my environment. 
The ecological footprint calculator asked about food, especially meat and dairy consumption in a way that made me feel that I would be living more sustainably if I chose not to consume either, at all. In fact, I felt somewhat encouraged to consider refining my food preferences towards practicing veganism. I investigated the pros and cons of feeding myself this way. A vegan ethic ensures that no animal products are consumed. This includes bees wax, honey, silk, and wool which are relatively un-invasive animals product (meaning that the animals does not have to die to provide the product). I understand the ethics behind not killing animals, however, I cannot participate in supporting some of the alternatives. And I believe that this is a good example of needing to carefully think through all of the implications of our living practices. (Journal 4, $25^{\text {th }}$ March 2008)

For example, in Canada, keeping warm is quite a skill (especially when it is minus 40 degrees Celsius outside). Dressing in layers is something to be practiced and careful selection of under garments is a must. These garments must wick moisture away from the body. Cotton doesn't do this, and so it has earned the catch phrase 'cotton kills'. Wool, silk, and polypropylene clothing are the best, and most common, choices. However, I believe that supporting the petro-chemical production of clothing (polypropylene) is vastly more damaging to our environment than wearing woollen or silk clothing. There is not much wool production occurring in North America, granted, but Australia and New Zealand produce lots. I understand that they are not manufacturing this wool into garments in these countries, this usually occurs in China and Italy for example; however these are the same places where the petro-chemical clothes are being manufactured. The result is that although I ethically agree that killing animals should be carefully considered and that the humane treatment of animals is a must, I cannot embrace a vegan lifestyle if 
it means supporting one of the most environmentally devastating industries around today, the petro-chemical industry.

At the end of one year I reflected that not consuming meat and dairy was not my best choice, while living in Canada. Meat was, in fact, one of the best foods I could consume during the winter months. Eating meat made my body feel healthy. Meat was a product that could be easily accessed (ethical meat was more difficult, although with some work I made some wonderful connections with local producers). Meat was also a product that could be easily stored for use throughout winter. And so, after giving it a go for one year, my strictly vegetarian days were over.

Eating locally and seasonally was my solution and new resolution. I would choose local fresh foods that were seasonally appropriate and if I used my new network of environmentally conscious producers, local foods were easy to access. I began to visit the weekly Farmers Market and enjoy the produce and community.

My Saturday morning routine is a highlight of my week. I love the anticipation of wondering what goodies I might source at the market, the conversations I would enjoy, and the networks I would develop. I love living in this community. I like that I can practice eating locally and seasonally much more easily if I attend this market. I become in tune with what is seasonally appropriate by shopping in this venue. I also love chatting to the vendors and hearing how their seasons are unfolding. This information is interesting to my farming family at home, who are often experiencing similar issues. (Journal 4, 30 ${ }^{\text {th }}$ August 2008)

The result is that by choosing to source my foods critically I feel connected to my food systems and my community and I enjoy eating great foods. 


\section{Bananas don't grow in Canada.}

When I lived in Australia, I loved to eat bananas, make banana bread, and bake them with chocolate in an open fire while camping (best camping desert ever). I even ate them while I was travelling, however, once I arrived in Canada I realised that there are actually no banana plantations in Canada, or on this continent. I decided that I had better start walking my talk on this one, and I gave them up. Just like that, done with bananas. I don't buy them anymore, and I wont eat them if they are served somewhere. I can seasonally justify strawberries; they could grow here, at least. However, I can't justify bananas. (Journal 5, $20^{\text {th }}$ April 2009)

The choice to change my practice and to take this action has been one of my hardest to embrace and embody. I know that bananas are a 'super food' and great for our bodies, yet they are not a food that is ethically available to everyone and I believe that some of the personal lifestyle practice changes that we have to make should hurt a bit and shake us from our selfish, consuming habits. Bananas have a reputation for being high in potassium, each banana contains about $20 \%$ of our daily potassium requirement. Yet, there are many other sources of potassium that provide a greater daily percentage and can be ethically produced in Canada: for example, potatoes, beans, and Halibut fish. I suggest that we stop making socially acceptable yet uninformed decisions and start thinking for ourselves, choosing foods that are locally and seasonally appropriate that provide the nutrition our bodies needs, in the form we need it, and not in excess.

I told my yoga class that I didn't eat bananas in Canada and was surprised at their responses. Many were shocked which then turned into concern for my potassium intake. Others thought it odd that I should take my ethic so far. And a few just refused to even consider the necessity of this practice, showing their sense of entitlement towards banana access. I think this demonstrates our society's general lack of awareness around food issues. It also suggests the possibility of having a personally appropriate food ethic and the effort that embodying 
something like this takes. Critical action and becoming aware is challenging. (Journal 6, $9^{\text {th }}$ February 2010)

Similarly, chocolate is not grown on this continent and should be removed from its prominent place in western diets. This food is marketed as a treat for all, and suggested to be particularly attractive to women. But just like so many post world war two commodities, this product does not belong in our Canadian diets. I gave up chocolate... for six months. I now rarely consume it but I certainly do indulge occasionally. I wonder at this indulgence and I admit that sometimes I choose to because it is a socially acceptable discourse. I understand the adage 'everything in moderation' however, some things are just not kept to a practice of moderation. I suggest that western society's sweet tooth will actually bite back; in fact, I believe it already has as levels of diabetes and obesity are increasing in all western countries.

I am not against international trade, per se; I just believe that we could be more careful and critical about how it is used (abused). After all, trading food and spices was how western white men 'discovered' the world but it was also how the slave trade was perpetuated and colonisation began (Standage, 2009). International foods should be treats, uncommon items that are celebrated... just like the orange was at Christmas time in the orphanages of our bedtime stories (based in truth). These days we can walk into any North American grocery shop, at any time of year, and purchase an orange. Yet this seasonal fruit should be a welcomed treat as the autumn descends upon us. (Journal 6, $9^{\text {th }}$ February 2010)

\section{Community Gardens - growing my own, preserving my own.}

The last year I was living in Australia I grew a wonderful garden. I loved working in my garden on those amazing twenty-five degree Celsius, blue-sky days. An intense gardening effort was usually followed by a walk to the beach and a refreshing dunk in the cool Southern Ocean. I didn't practice gardening during the first three years I was in 
Canada, but I watched (and helped) my friends' garden and enjoyed some of the bounty they shared. Once I had my own apartment I located a nearby community garden, purchased (rented) a plot, and began to learn about Saskatchewan gumbo.

It was a seven minute walk to my community garden plot and I loved heading out there first thing in the morning. I made a friend who got me sorted out with the right varieties, the right timing, and the right tools for the job. I enjoyed our ambling conversations, watering, and taking out my frustrations on the weeds (of which there were plenty). The weeds almost beat me that first year. I was better prepared the second year. However, I was flooded out by an unfortunately wet summer the third year. A sad set of circumstances really; however the learning curve remains steep and the produce is still worth every bit of effort.

I love the community that comes with growing my food at a community garden plot. I have made some great friends, produced healthy foods that have a "known" history, and re-connected with the earth, food systems, and food items. I feel connected to people, place, and my body. I feel self-responsible and ethically appropriate in these actions and choices. I feel happy! (Journal 5, $13^{\text {th }}$ July 2009)

My August and Septembers have become a busy time. Not only does school/university begin, with the usual teaching load and work to get underway, but also the garden produce is to be harvested and put away. I spent long hours standing in my kitchen washing, chopping, blanching, cooling, freezing, and then packaging vegetables I grew myself or sourced locally. Some of it was made into preserves such as tomato sauce or tomato jam. Some of it was stored in the refrigerator or in a cooler place (hard to find in an apartment). Some of it I dehydrated, with or without an electronic dehydrator (a 
luxury appliance). Some of it I blanched and then froze. I even purchased a deep freeze so that I could preserve more vegetables.

I remember the look of horror on many friends as I cheerily offered a homemade jar of "tomato" jam. Some graciously accepted and even acknowledged they tried it. Luckily for us all, Dad was able to suggest this wonderful way to use up my last prized home grown tomatoes. I like tomato jam, however I appreciate that it is unusual (to say the least). I love the concept of using this fruit to create a preserve. And I love that this that idea came from my Dad: our family's most interesting jam maker. (Journal 5, $11^{\text {th }}$ September 2009)

\section{Fast foods - my experiment.}

Becoming an aware consumer takes time and effort. I have been working at this for seven years now. I have spent lots of time tuning into food as an issue through many forms of media. I was watching something via the internet about five years ago and a woman was describing how she had purchased a McDonalds burger and kept it to see if it would decompose. Her thesis was that there was so much preservative in this fast food that decomposition would be hindered, leaving her to conclude that fast food was not really food and certainly not good for us.

I decided to do my own experiment as I was beginning to prepare to talk to a large group of students about sustainable eating and I thought this kind of experiment would be particularly stimulating. I purchased a McDonald's cheese burger and fries, leaving them in a container open to the air. At the same time I made my own home made burger, although I used a hot dog bun instead of home made bread. I also placed a section of potato with this burger to watch its decomposition in comparison to the fries.

Five years later the only visual sign of decay on the McDonald's cheese burger is that the bun has cracked as it is completely dehydrated. There is no mould on the bread, 
the cheese looks perfect, and the meat is simply solid. The fries look fine - golden lengths of potato. The homemade burger did not fair so well. It is still recognisable as a burger but it is covered in mould and has obviously decomposed significantly. The potato section is shriveled and black, not obviously potato anymore.

I think about this experiment and what it really is showing us. I am aware that the rate of dehydration of these burgers affects the possibility of decomposition (as moulds and bacteria require moisture to grow). However, as the rates of dehydration were identical the results tend to suggest that the McDonald's cheese burger and fries do not decompose at the same rate as food made with fewer preservatives (likely none). From this I conclude, similarly to Pollan (2006), that real food is made from real ingredients and are best consumed when they are minimally prepared and mostly plants.

\section{(Re)thinking food - critically.}

I spent the summer of 2009 delving into the food literature reading great books like Kingsolver's (2007) Animal, Vegetable, Miracle, Pollan's (2006) Omnivores Dilemma, Standage's (2009) An Edible History of Humanity, Eisenstein's (2003) The Yoga of Eating, Millis's (2005) Eat Away Illness: Strategies and Recipes for healing, Matsen's (1987) Eating Alive I and (2002) Eating Alive II, Moore Lappé's (1982) Diet for a Small Planet, Safran Foer's (2009) Eating Animals, and Katz’s (2003) Wild Fermentation. I offer this list as a resource for those interested. My reading has convinced and reminded me about the importance of eating locally, seasonally, ethically, consciously, and not too much.

Food has become my new favourite environmental issue. I like considering consumption and I believe there are lots of possibilities for improvement around this area. Consider food sovereignty, food safety, food production, farming 
practices, chemicals in agriculture, self-sufficiency... and the list just keeps going. Food politics, food preparation, food transport, food consumption, access to foods, international trade, fair trade of food products, food regulations, organics, fast foods, and the nutritional value of the food easily consumed. Food has a special way of relating to everyone, because we all need to eat. The choice to eat well is often compromised by our lack of financial stability, yet this choice is a self-sustainable choice and we can pay now to eat foods that are good for us and our environments, or we will pay later with our own health and the health of our environment. Food is very motivating! (Journal $5,7^{\text {th }}$ October 2009)

Food discourses provide me with much to consider as I look to the broader social/cultural concerns. Our western society has become shielded from taking responsibility for our eating habits. Blame is attributed to others as serving sizes grow, ingredients are undefined and occasionally not even good for us, and marketing portrays food items differently than how our bodies consume them. Taking responsibility takes time, effort, and critical thought.

I recently found an article that represented (see Figure 4) how our food is becoming corporatised and how we have lost, and continue to loose, the genetic diversity that is necessary to sustain production with seasonal variation. Figure 4 demonstrates how the numbers of different varieties of many staple vegetables has been drastically reduced between 1903 and 1983. Lettuce, for example had 497 varieties in 1903 and in 1983 this has been reduced to only 36 varieties. I wonder at the loss of seed stock diversity since 1983 as we are now nearly 30 years beyond the data represented in this diagram. A decrease of diversity, on this international scale, should be of concern to everyone. I believe that we trust corporations to be doing the right thing, and that this trust is misplaced. 


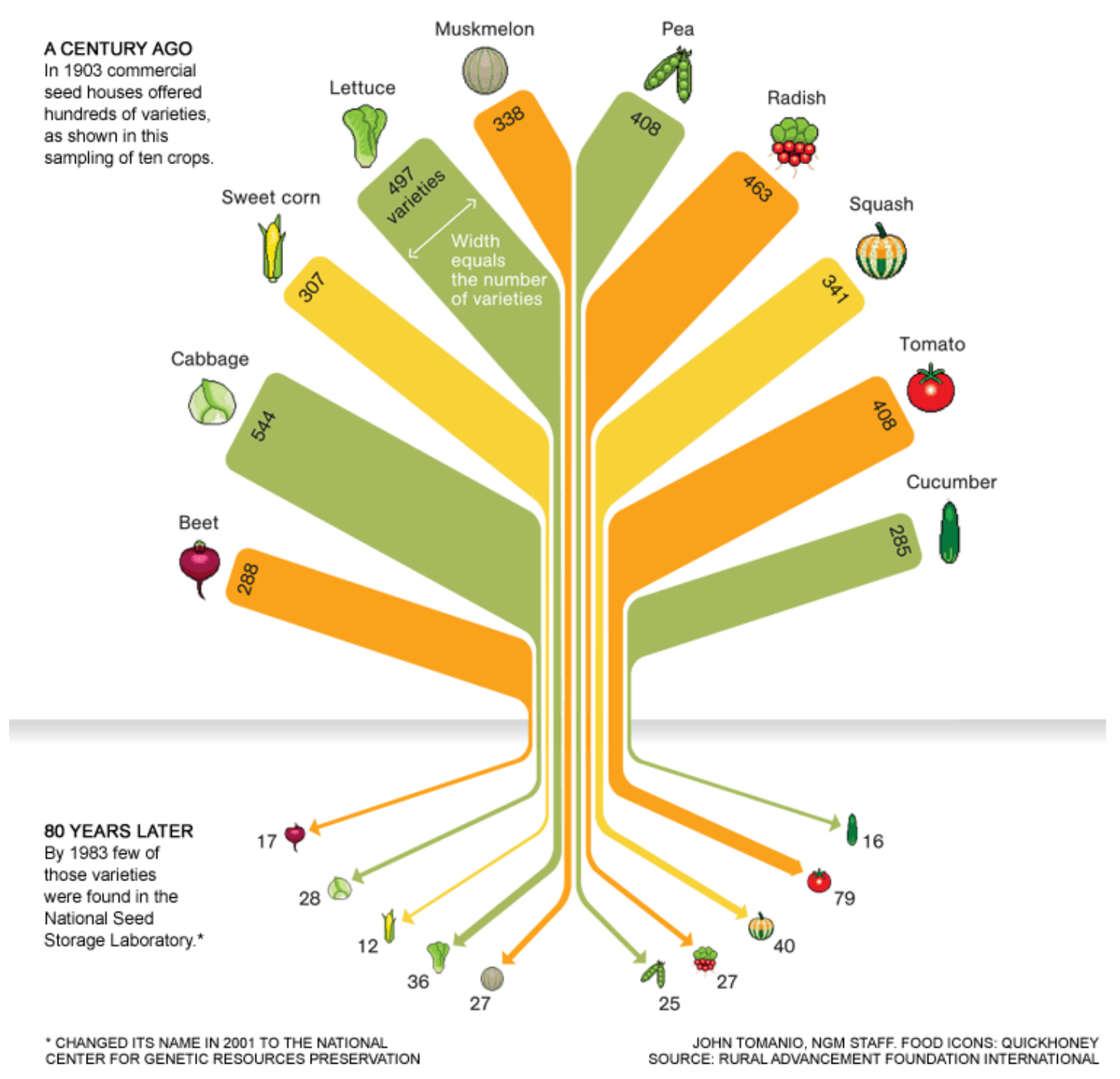

Figure 4. A visual representation of how diminished our seed stocks have become. The comparison is presented from 1903 (the top numbers) to 1983 (the bottom numbers) for a variety of vegetables (Rural Advancement Foundation International, 2012).

Recently I found a diagram (see Figure 5) that represented a similar reduction in diversity although this time it is in relation to the corporatisation of food producing companies. There has been great diversity in companies producing food products; however other companies have purchased these companies and in an interesting outcome there are now only ten corporations who own all of these food production companies. I find it hard to believe that these corporate entities, with their CEOs, Boards of Directors, shareholders, and financial members, have much concern for my welfare through the 
quality of their product. I worry that their ethics are not the same as mine and that their bottom line (based in economics) could come at the cost of my health. I am choosing to discontinue using their products, as is my right as a consumer.

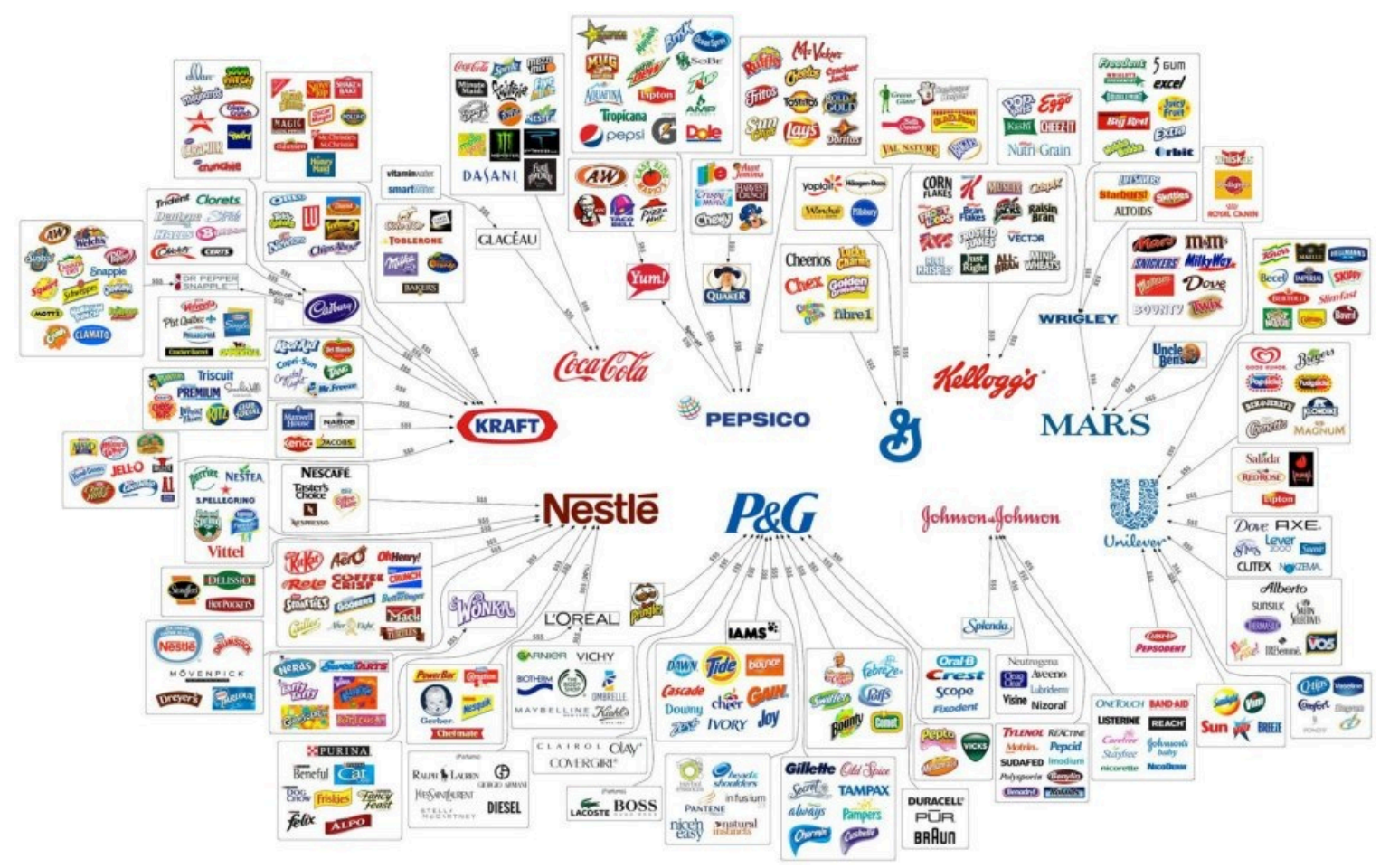

Figure 5. A visual representation of the corporatisation of our food producing companies. From the great variety once established there are now only ten corporate identities involved with this food production. (The Illusion of Choice, 2012).

\section{And where am I at now?}

I managed to work my way down to living with an ecological footprint of 1.8 hectares, where, if everyone lived like me, we could all live on our one planet. I continue to measure my ecological footprint every six months, acknowledging that sometimes my choices result in higher than desired analyses while at other times it remains low. I have purchased a car now, and yes, it hurts to have to increase my footprint calculation; however it was necessary given a change in my circumstance. I own an apartment that brings benefits of ensuring some of my living practices reduce my impact; however other 
challenges are created through this choice. It is okay to measure impacts and implications of my choices, to be aware of them, and to consciously change my mind, if deemed necessary. I find ways to live with less that result in making me feel that I actually live with more: greater consciousness and consideration, better health, and a deeper connection to my community, my ecosystems, and my body.

I continue to use humour to cope with many situations. I enjoy a good laugh at myself... regularly. I try to not get wrapped up in the craziness of my efforts and I try to keep it real. These challenges are useful... the disruptions are beneficial to me as they ground me in practices that provide a platform for how I want to be as an educator. I feel that I live with an intentionality that affords me a position of familiarity and knowledge that brings power, experience, and story to my educational practices. I have great passion for this work as it keeps me healthy, happy, connected, informed, challenged, in community, and alive.

I conclude this section reflecting on my personal change via autoethnographic research and move to consider using this consciousness and awareness as a platform for transformative education explored through self-study.

\section{Becoming a Transformative Environmental Educator: My Self-study}

The desire to live with greater consciousness, intentionality, and in an embodied way flowed into my teaching practice. I wanted to walk my talk. I used self-study to provide a reflective opportunity to work with my performance of teacher and environmental educator, focusing on how to support my students to undertake their own transformative educational experiences, as a direct result of our course. I designed a 
course that challenged the social norms of western living and environmentalism and used discussion, self-reflection, and action to work towards generating transformation.

In the following I offer some analysis from my self-study research that illustrate how useful and reflexive this work was. I then present a description of the course design with a focus on the major critical pedagogical strategy employed to support change in students. Following this I explore additional details of the self-study with focus on a critique of the curriculum and how personal change can come from transformative education. Some themes arose that were worthy of exploration and these include student resistances and power and relationships. In conclusion, I offer my reflective findings detailing aspects of my experiences in teaching this critical course.

My self-reflections, critical friends discussions (three different groups), student focus group discussions (three different groups), and student reflections provided the data, which has been analysed and presented to describe the above findings of this research. Comments have been used to illustrate findings. These are presented in quote format with the specific reference given, unless they were my self-reflections and these are presented in italics to denote my personal voice, following previous convention.

Not all students were receptive to all aspects of my teaching philosophies, as might be expected; however all participated, to some degree, in all aspects of the course evaluation strategy. Some negativity persisted in some students as the semester progressed, which could have been valuably unpacked; however the specific students who did not appreciate the intentions of this course also declined to participate in my research, which is unfortunate as their opinions may have been insightful and generative. The students participating in this research offered discussions and reflections that illustrated many of the concerns they felt their less positive classmates experienced. Most concerns 
were relieved and resolved by the end of the semester, as is often the way with students who focus only on the evaluation and not the learning journey. I have attempted to explore the student resistances and power and relationship themes and then I conclude this section by reflecting on the teaching-learning experience and drawing some conclusions relating to my practice.

\section{The self-study.}

The usefulness of this self-study was reflexivity: as I considered the platform that my conscious and sustainable living practices provided me to undergird my environmental education and activism. In my role as an educator, can a personal platform of walking my talk in living more sustainably lead me to offer engaging and transformative educational experiences, effectively guiding my students towards social and cultural change? I now answer with a resounding yes! Having experienced the changes required to bring my living strategies into a more sustainable practice I was able to lead others through critical pedagogies that brought them similar small successes further encouraging them towards greater awareness of the issues and leaving them informed as to how they could continue to change their practice, if they so desired. There was also an effort made to increase awareness and understanding about the need for change through investigating environmental issues, which may result in generating a deeper desire to find ways to change.

Undertaking a self-study of my environmental education practice resulted in an engaging reflection and close consideration, and, ultimately, changes in how I practice education. Many questions were raised through conversations with critical friends and in 
student focus groups and along the way choices were revealed, unpacked, and

(re)considered, resulting in changes in my practice as an educator.

That is why it is important to have the conversation about what you are feeling and what answers you jump to. What you put into practice and what were your actions, and what could have been the alternative actions? What are your conclusions about how you problem solve and why? (Critical Friend B-2)

Conversations troubled my practice, what I desired for my students, and how I might support them to consider change. I discovered inconsistencies with what I desired and what I received and through careful unpacking began to see different ways of going about transformative education and critical pedagogy.

\section{The course design.}

The scene was set around the third year pre-service teacher environmental education course delivered to secondary science majors, outdoor education minors, and others taking the course as an elective. During the fall semester of 2009, I planned and delivered this course for the fifth time, simultaneously undertaking my self-study research. I had taught this course during all semesters (fall, winter, and spring); however teaching during the fall was my favourite as the weather transitions from summer to winter provided a variety of experiences.

The syllabus was designed from cumulative experiences; my own and the experiences of other instructors who taught this course previously. I spent considerable time collecting course syllabi and holding discussions with previous course instructors. I refined the course from the previous four times I taught using course evaluations that were carefully critiqued and used to re-design aspects of the course, my own reflections, and ideas gleaned from other instructors. 
I spent time carefully unpacking this syllabus with my critical friends prior to the start of the research semester. One area of change was that the wording became more specific, yet also more encouraging and motivating. I was usually careful to present a syllabus that was detailed but not too daunting, yet with the support of my critical friends, I believed that this syllabus was clear and engaging.

The course syllabus was offered during the first class (in an online format as there was a strong desire to conduct this course with a paperless ethic) and discussed in some detail (See Appendix 2). Opportunity to re-negotiate aspects of the course was provided, although this appeared to be an unaccustomed option for these students and they were not particularly motivated to engage deeply with the proposed syllabus.

The course was designed to be action based with many guest speakers, off campus excursions, and a weekend camp. Additionally we engaged with many environmental education resources that were available throughout the province, becoming accredited users in many. The course goals were as follows:

- investigate what "environment" means to each of us, and those around us;

- experience environments in Saskatchewan and consider appropriate learning opportunities;

- research environmental issues in depth via an action research project;

- become engaged citizens through participation and action;

- participate in and consider inquiry learning processes;

- become reflective educators, actively asking deeper questions while watching for assumptions;

- examine and utilise the Saskatchewan curriculum and locate opportunities for student learning in, for, about and with the environment;

- devise a variety of resources that will be effective in the delivery of environmental education; and 
- develop a critical awareness of our relationship with the environment, focusing on your role as educator.

These goals were developed with insight and experience from the four previous courses I had taught and in consultation with the subject area faculty. I wanted this course to be action orientated and filled with experience. At each point we reflected on the question “what does this mean for me as a future educator?".

I hoped that this course would be challenging in content and process. I wanted students to feel disrupted often. My desire was to offer a variety of experiences that took these students out of their comfort zone and gave them alternate experiences that could be seen as possible alternative practices useful in their future teaching practice. I wanted them to start to critique the purpose of education and their involvement as future educators. Environmental education is well suited to be the vehicle for creating possibilities and, ultimately, change in education.

Many rich discussions evolved, some frustrations developed, and the journey was far from smooth. However, we all learned something, in my opinion, and most of us could reflect (in written or verbal form) on some positive learning experiences that will likely shape our future teaching practices. The following is a detailed description of the Action Learning Group Project (AGLP), which was the critical pedagogical strategy developed and implemented in this course with the intent of encouraging personal change and transformative education that led to social/cultural change. It forms the central inquiry/action/project/evaluation for the course that leads students towards achieving the course goals and personal transformation. 


\section{The 'Action Learning Group Project'.}

The Action Learning Group Project (ALGP) is a framework with a 12-step process facilitates the pedagogical strategy developed and utilised throughout this environmental education course. Central to this critical pedagogical strategy is the scaffolding of the basic action research cycle (plan, act, reflect) and the focus on the need for specific skill development such as how to work cooperatively, telephone skills, letter writing skills, media and communications, running a meeting, project planning and more. The following will describe the background to this strategy, and then I suggest why this strategy requires both action learning and project based group work. Finally, the details of the strategy are offered along with a diagrammatical model (see Figure 6).

\section{Background to the Action Learning Group Project.}

In the recently released (2007) Ontario policy Shaping our Schools, Shaping our Future, Environmental Education was defined as a field that "seeks to promote an appreciation and understanding of, and concern for, the environment, and to foster informed, engaged, and responsible citizenship" (Bondar, Dudar, Foster, Fox, Mahler, Schwartzberg, \& Walsh, 2007, p. 6). If the purpose of education is to 'produce' active and engaged citizens then, as educators, there is an opportunity to provide frameworks to our learners that demonstrate how citizens can appropriately take action. Action learning offers critical pedagogical strategies that support learners to change aspects of how they choose to live, by doing it in a critically aware way. Action learning, or learning through taking action, can also be called critical pedagogy, experiential learning, embodied learning, action research, activism, social action, socioecological pedagogies, hands-on learning, engagement, student-centered learning, or inquiry learning, and I am confident 
there are many more ways to name what is becoming common practice in our education systems.

I have chosen to see environmental education as an opportunity for two things: 1) supporting the development of active citizens, focusing on themselves as social change agents, leading towards a cultural revolution; and 2) providing space, desire, and processes to critique our current educational practices. It is the choosing of an environmental lens through which we see the world, our society, the education system, our practices, and ultimately ourselves as learners and teachers, that encourages us to see, do, and be... differently.

In 2005, a Youth Forum on Sustainability was conducted at the Royal Saskatchewan Museum, Regina, Saskatchewan (Barrett, Hart, Nolan, \& Sammel, 2004). Although this was not the first Youth Forum as there had been one the previous year, it was my first. At the forum students gathered with one representative teacher to think about sustainability issues. After a keynote speaker and some time to meet each other the participants were separated into two groups: students and teachers. The students were further divided and rotated around a series of skill development sessions. The teachers spent time working through resources designed to enable them to further support their students to continue to take action. By the end of the day students had pitched ideas for projects that they were interested in exploring; discovered some resources to enable them to take the first few steps; and many had achieved the initial stages of project planning towards taking action. The teachers received training in action learning. They participated in a workshop that stepped out the action learning cycle using a model that was the beginning point for the development of the Action Learning Group Project. The workshop supported the teachers to consider the details of how students plan, act, and 
then reflect, ready to repeat the cycle as required. Each step provided activities that the teacher could initiate with the students, thus providing them with the skills to apply to their own action projects.

I enjoyed watching this unfold, and was excited about the possibilities and potential of the Youth Forum concept. Later that year I was given my first opportunity to teach the undergraduate class in Environmental Education. I reflected on the Youth Forum experiences and decided to bring some of these resources and scaffolds to my students as future educators. I asked a colleague to help me by delivering the same workshop to my students as the teachers received at the Youth Forum. By then this workshop had been further developed by Learning For Sustainable Futures (LSF) and was presented in a workbook format. My students enjoyed the project and had what I believe to be many successes with personally taking social action. Projects took a critically reflexive personal perspective about how choices around living practices could become more environmentally aware and less impactful.

The following year I came across Payne's (1997) work on Embodiment and Environmental Education and enjoyed reading how he had worked with pre-service teachers in a similar way, valuing personal reflective practice leading to personal and social change (Payne, 1997). I found this greatly encouraging and, believing that I was onto something that was useful and that facilitated good work in the field of environmental education, I began to work on redesigning and augmenting the workshop and workbook (from the LSF original).

I offered my students the same statement that Payne (1997) offered his students: "My body is a 'site' for describing how the 'ecological crisis' is re-inscribed and/or disrupted by my actions or interactions" (p. 138). The result was that students took a 
more personal perspective in their actions, and thought more deeply about the environmental impact of their personal living choices. I found their actions to be more significant than those of the previous cohort, although I had to offer considerable support to encourage them to take them to the social action stage.

Over the next two years I used this same strategy and the LSF workbook to support my pre-service teachers to gain skills and understandings about the importance of action learning projects. I maintained the individual aspect of this evaluation piece, choosing to require group work in different places throughout the course. During 2009, and in time for this self-study research, I revised this strategy completely, as I thought more deeply about the implications social learning could have on this pedagogical strategy. I later changed the action learning strategy and evaluation piece again, specifically for a graduate class I taught in the summer of 2010, and was richly rewarded through this restructure. These students took the idea of a group action learning project to new heights, delving more deeply into their individual practices as well as considering the social implications of taking action.

I suspect that the ground was fertile and well prepared with these graduate students, as the movie (and resulting book, curriculum package, and website) No Impact Man (Beavan, 2009) was recently released and greatly discussed. In this story Beavan took himself and his family through an action learning group project focusing on reducing their impact while living in New York, USA.

Prior to teaching this graduate class, I decided that the LSF workbook was not quite as supportive as it could be as my thinking and desires for scaffolding had now moved beyond what was offered. With support and appreciative encouragement from LSF, I redesigned the workbook, further developing the strategy into a 12-step process 
that encourages the implementation of action learning group projects. I placed this material in an online format greatly increasing its usefulness and adaptability. I have since used this online resource, the Action Learning Group Project - 12-step process, with another cohort of environmental education students, with greater success and ease of operation. I also feel that the practice of using a website to share the content and process walks my talk around minimising paper use through education, as well as sharing resources freely so that many can benefit.

\section{The presentation of the critical pedagogical strategy.}

The Action Learning Group Project is presented via a website https://sites.google.com/site/actionlearninggroupproject/home. I used Google Sites as the platform within which to create this site, as it was free, easy to access, and easy to use. A website was a great choice of presentation medium as I could easily make changes and additions as the process continued to unfold. I also could walk my talk in offering a resource that does not require paper to share. One of my concerns with the LSF workbook was that it was paper based and (environmentally) costly to use with students. Additionally, I can now use this website as a repository of student projects as they continue to be completed. The repository will grow and share further actions, ideas, and resources. Finally, I like that this is a resource that is free and available to all. There is no copyright, and all activities have been referenced and acknowledged.

The structure of the action learning group project is a more detailed and scaffolded, or supported, action learning process: reflect, research, plan, act, reflect... repeat. The ALGP 12-step process was designed to support pre-service teachers to embody an experience of action learning, group work or social learning, and to provide 
access to a critical pedagogical strategy capable of engaging their future students. The ALGP 12-step process was presented in a way that all educators can navigate a suitable path for their learners, from the multiple activities offered in each step. The multipurpose design will hopefully support a variety of users: school classes, in-formal groups such as scout groups, and non-formal training possibilities for people of all ages.

Through the ALGP students/participants will learn about: themselves and their local environment; action learning and how it helps them and others achieve social/cultural change; how to work as part of a group, be in community, and work together to achieve a goal; important skills to take action and encourage others to take action too; and how to effectively communicate actions. Learners undertaking the action learning group project will address the following statement: "My body is a 'site' for describing how the 'ecological crisis' is re-inscribed and/or disrupted by my actions or interactions" (Payne, 1997, p. 138). This can be translated into the following directions:

Use the action learning 12-step process to explore environmental issues (ecological crises) that are of interest to you (your body) and your group. This may be an aspect of how you live, what you believe in and practice, and/or something your society practices. Re-inscribing these practices implies assigning a value to that practice that results in its repetition (consciously or not).

Disrupting these practices implies a change is implemented (consciously). (White, 2010)

The ALGP 12-step process is visually represented via the diagram below (see Figure 6). Briefly, after reflecting on the current state of the environment (step 1) to gain some understanding about possible issues, the group is organised (step 2) where they select an issue that is important to all of them (step 3) possibly using a consensus decision making model. They then research to form a plan (step 4 and 6) to take action. Actively 
working to maintain motivation within the group (step 5) and to define and measure success (step 7). Doing the action involves developing some skills (step 8 and 9) before actually taking action (step 10). Celebrating success and communicating the actions (step 11 ) is necessary all along this ALGP 12-step process. Reflecting on the results of the action (step 12) may be that start of the next iterative action learning cycle.

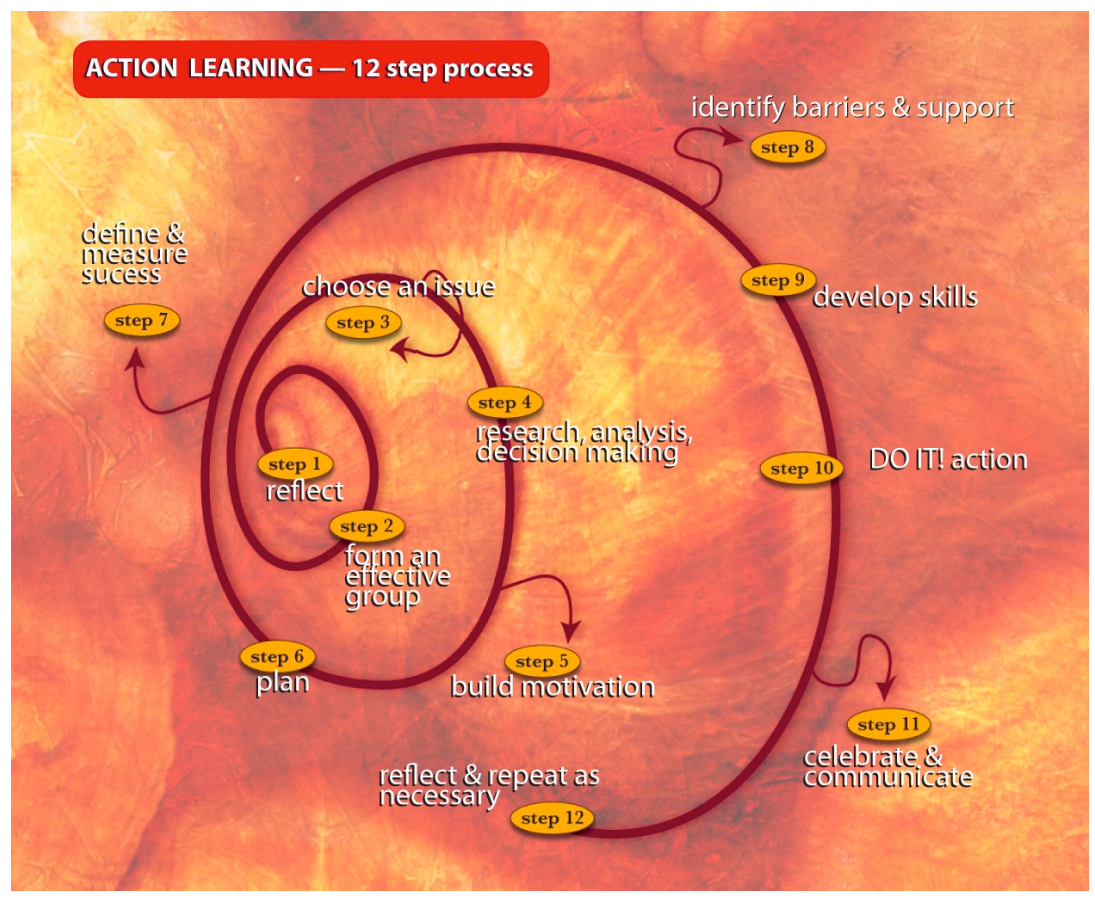

Teacher/Instructor: Decide on Goals, Parameters, and Assessment Plan STEP 01: Reflect on Your Environment, Community, and Your Living Practices STEP 02: Form an Effective Group

STEP 03: Choose an Issue and Generate Ideas for Action

STEP 04: Research, Analysis, and Decision Making

STEP 05: Build Motivation

STEP 06: Choose an Action and Make a Plan

STEP 07: Defining and Measuring Success

STEP 08: Identify Barriers and Supports

STEP 09: Develop Skills

STEP 10: Do it! ACTION

STEP 11: Celebrate and Communicate

STEP 12: Reflect and Repeat as Necessary

Figure 6. The nautilus shell and spiral shape of the diagram represents the reflexivity of the process, encouraging constant reflection, reconsideration, and eventually leading to a possible repeat of the entire cycle. Each step title is presented under the diagram. (White, 2010) 
I introduce the ALGP 12-step process through an interactive workshop where groups of learners (pre-service teachers) unpack each step for the rest of the class. This strategy means that each group becomes the teachers and the learners for each step. Given that this is usually presented to a group of environmental educators or pre-service teachers, this strategy of peer teaching has some merit. I introduce the activities that scaffold the action learning group project by specifically walking these groups through the ALGP 12-steps.

Once I introduce the idea of the action learning group project, I discuss what action learning is and then why group work which embodies social learning theories, is useful. From here I introduce the ALGP 12-step process and briefly discuss the cycle (as described above). I describe the evaluative aspects of the AGLP by discussing Payne's (1997) statement reiterating this in a way that is relevant to the 12-steps and the students' needs. I offer a brief explanation as to how the workshop might be conducted (as described above). I then share some of the past experiences that other students gained as they progressed through this pedagogical strategy. I close by asking why might we do this work.

There are a few people who have undertaken specific and amazing journeys to make change through their own actions. Notably: Colin Harris ran across Canada to raise awareness about the need to take children outside; and John Francis spent 17 years not talking, but listening, and refusing to contribute to the oil consumption of our western society by refusing to ride in motorised vehicles (he walked across America, stopping to undertake university study to provide him with the necessary qualifications to make a difference). These inspirational examples lift up my spirits, encouraging me to keep on doing all that I can to encourage others to reconsider their own actions, leading us 
towards social/cultural change. I offer them as examples in the Action Learning Group Project web based support material.

\section{Student responses to the Action Learning Group Project.}

The following comments were made by students who have experienced the ALGP and were part of this self-study research. Student comments are genuinely positive, which I attribute to the timing of the data collection as it was gathered at the conclusion of the strategy and the end of the semester. Many students experienced frustrations as they proceeded through the semester, as would be expected. Some comments focus on aspects of the learning outcomes as a result of the ALGP.

It is important for students to recognize what they can do on a day-to-day basis; even the little things (like not using plastic straws) make a difference. Even though I consider myself an environmentally conscience person, it took another individual to point out to me that I was using unnecessary materials. This is what students need, someone to keep them accountable, to point out their 'flaws' in sustaining our environment and to suggest other options. I think that assigning students the task of coming up with a challenge for themselves to respect their resource use or to better treat the environment is a good idea, and to encourage them to have an accountability partner to help them through the process. (Student Learning Journey Journal)

The above comment offers an interesting view on how to develop critical awareness through partnering and asking questions about resource use, holding each other accountable.

I definitely would use this strategy in my classroom. I absolutely think it's a valuable experience for students. It provides an opportunity for them to research a topic or change something about their lives to make it more environmentally friendly and really understand why they're doing it and why it's important. The 
actual cycle itself is a great way to set up the project. It provides a structure for the students but still allows them to be creative and adaptive. Actually having to go through the process of creating our own action plan gave me a perspective of what the students will be going through and how they may handle it. I went through major stressful and panicking stages but eventually deconstructed my thoughts and was able to proceed with little frustration. (Student Learning Journey Journal)

The above student had to do some work so that they could proceed and it was by doing the work in an embodied way that they finally enjoyed some success. Similarly the student below indicates how leading students through a supported process encourages them to learn how to make better decisions. They also describe preference for teaching strategies that are less like indoctrination and are more inquiry based.

I think the Action Learning Group Project is a good way to bring different environmental issues into the classroom without standing up there and preaching about them. It allows students to do the research and present their findings to the class. This way it doesn't seem like any one issue is worthy of more attention and the students can form their own opinions about issues. It eliminates a bit of bias that could come from the teacher being the only one presenting issues. Instead of the teacher just talking about issues and telling the facts, the students actually get involved and make critical decisions for themselves. Making critical decisions is an important skill for students and using the Action Learning Group Project is an awesome way of fitting that into your teaching. (Student Learning Journey Journal)

Again the embodied nature of the experience is mentioned by the student's comments below.

Overall I find the Action Learning Group Project an excellent strategy to begin changing our environment. This is an exceptional project for students of all ages and can be very easily adapted into multiple curricular areas (Ex. Science 10- 
Sustainability, Social- current/historical events, English- research essays etc.).

This project allowed me to learn how benefiting the environment can also benefit my body and mind. It helped me to visually see how small steps can actually make a difference and I now know that there is so much more to be learned about environmental issues. Sharing all of our findings helped us create awareness for one another that can now be passed on to others. As an emerging teacher I feel that this was an awesome experience and I am happy to have participated. I now have a first hand look at how to carry this procedure out within a class and feel I am on my way to being a successful environmental educator. (Student Learning Journey Journal)

As described above, the Action Learning Group Project (ALGP) offers students a scaffolded experience to undertake personal change and is a strategy that supports critical pedagogy and transformative education leading towards social/cultural change. The ALGP was one of many critical pedagogical strategies in the environmental education course, yet this one comprised the greatest amount of work and time commitment. Following is a critique based on my self-reflections and student feedback (student focus groups and student reflections from their Learning Journey Journals) of a few of the other strategies implemented and the environmental education course curriculum.

\section{A critique of curriculum.}

With these reflections I can determine the levels of interest in and success of some of the activities we used in this class. These students reflected on their favourite or most interesting aspects of the class. The reasoning offered for choosing each activity provides further opportunity for critiquing education and my performance of it in this class. Each small story was presented to illustrate the diversity of interests. Many activities were undertaken throughout the semester (we had the luxury of having six hours of class time 
per week), and some activities appealed to some and not others. I often feel surprised at the diversity of interests, although I shouldn't.

The course description (in the University Calendar) states that this course is about: theory and practice in environmental education, including the history and philosophy of environmental education, course design (K-12), and issues investigation. In coming to define environmental education I am slow to evoke the wisdom of others and, instead, encourage a slow pedagogical approach (Payne \& Wattchow, 2009) where, through modeling and embodiment with activities and strategies, students come to understand what environmental education can be by experiencing aspects of it and participating in discussion that troubles the possibilities. Through reflective practices I encourage students to ask what is being disrupted and reinscribed through our actions and discussions. The reflective question "what does this mean for you as a future educator?" is at the heart of our discussions and their reflective journaling. Many students come to class with preconceived notions as to what we will be spending our time doing throughout the semester: this often does not play out as they may prefer. I attempt to be conscious of their interests and experiences and try to allow spaces for both through open-ended strategies where students can build their own interests into our learnings.

Over the years I have gathered some inspirational resources and I find many new and exciting ones become available each year. I encouraged my students to carefully consider that all resources are (or can be) environmental education resources as opportunities for social critique are bountiful. I suggested that resources usefully fall into four categories: people, packages, places, and programs. People and places are obvious, yet often not considered as resources in education. Packages and programs are the more common types of resources and include training programs and web based resources. 
Companies that make their living from mining or ab/using environmental resources often attempt to influence people towards their practices by developing curriculum resources. It is particularly important for an educator to be mindful of developers' potential bias in all resources, especially environmental issues.

Environmental education is not a course in environmental science. We don't explore the ecosystems of the province, unless we are out in them. This course does not provide a life sciences foundation, or a biology update. This course deals with issues of power and domination through deep, yet personal and embodied, exploration of the current socioecological concerns of this western society in the twenty-first century. This course offers a critique to education through action orientated learning.

Student responses to some of the pedagogical strategies have been presented below, illustrating highlighted aspects of this course. The purpose here is to illuminate what stood out for the participating students. The activities they chose to comment on may have been particularly disruptive, or expected, but interesting and engaging to them personally. These stories follow.

Taking students outside to enjoy learning experiences and yet, to also reflect on these experiences from a future teachers perspective is integral to how I teach environmental education. Following are some thoughts from the students about being taken outside.

I loved the trips. I love how you incorporated Project Wet and Project Wild. I love how we did geocashing the park. I loved our trip to Grasslands National Park. I had never had that in a class before where the professor took us out and actually did stuff and showed us. And you did that. I loved that. Yeah. I still talk about that. I say, "We did this in 302 ! We actually went somewhere and did something." I loved it. (Student - Focus Group) 
You know when we were in class we were always doing activities and learning through our reflection of the activities not just reading about the activities. But actually participating in them! Now I am more likely to remember them. I'm going to remember the Bird Olympics more than if you would have given us a handout on it. And I now know how I would use it with a class. (Student - Focus Group)

Putting their bodies into the learning, in an embodied way, provides greater impact for many students. Getting and being outside was not many students preference, so I adapted our activities and encouraged students to do what they felt comfortable doing (and to challenge themselves appropriately).

Some students were concerned about how to teach environmental education. They believed it was important, but they were not sure how to actually go about it. The activities we did provided useful entry points to some rich discussion and reflection for these students.

For me I guess it was that I want to teach about the environment, but how to do it. You know you don't have to do it by beating students over the head with climate change and global warming drama. All these big nasty issues. It brings out everyone's natural appreciation of what the environment is, how to incorporate it into everything we do. Which came back to the activities around unit planning. I'm never going to teach English. But by doing an English unit I appreciated how it's very easy to incorporate these things into everything. Incorporate English. I can do it in science, easily. So, that's kind of what I took from it. This whole idea of it being experiential really helped to formulate how I want to bring this into my classroom. Cause I never thought about how am I going to actually do this. (Student - Focus Group)

There's definitely times when I've thought, "Okay, this is how I'd like to do it with a class." One thing I'm definitely thinking of is when we went on the nature walk at the conference. And I thought, "okay how is this working?" Some people 
aren't really paying attention. Some people are interested in some of this stuff. Okay, people are picking up on things on their own. Let's run with this. That was one time when I really thought - I was really thinking as an educator. But there are a lot of times where you just get caught up in the experience. You know it's "Oh, this is fun." You really have to force yourself to think as an educator while I'm doing this. (Student - Focus Group)

Thinking like an educator was the central reflective question asked of the students continuously throughout the semester. The resulting discussions about how to adapt activities and strategies were rich. This seemed to be relevant to students who were not from the city, as the outside activities presented a way for them to come to know the city more deeply. Or to address the students concerns that a field trip in the city would have nothing to offer an environmental education class.

I liked the fieldtrips cause I hope to teach in Regina sometime. So I remember the bird sanctuary being a good visit and thinking that this is something I would do with my class. To be right in Regina, nice and close, the lake is a really nice area. Just to show them how you can do outdoor or environmental stuff right here in the city. That was a big one I remember. (Student - Focus Group) I enjoyed the amount of out-of-class experiences that we had. I think that if you're bringing an environmental component into a school or a classroom that out of the normal classroom environment is opening everyone's mind to other environments, and I think a lot of what we talked about or a lot of what I took away from that was having people enjoy positive experiences in nature allows people to kind of show their gratitude towards the nature and, therefore, maybe in their practices they wouldn't want to spoil that for future generations or for others. Another thing that I noticed is a lot of people that were brought up in the city or had no opportunity to live like that a lot of the time when they were younger and we had quite a few people from like farms and small communities or smaller towns and stuff that had all those experiences, and I think that it allowed the 
people that grew up in the city to kind of understand where people from the smaller towns were coming from in that sense. (Student - Focus Group)

One student made an interesting comment regarding the course design. "I liked the spiritual aspect of it. No other class did anything like that" (Student - Focus Group). This was particularly interesting, as I didn't design a focus on spirituality into the course, yet coming to ideas and experiences in different ways was definitely a strategy, which can allow students to resonate differently and individually.

One activity in particular, "what environment means to me", was designed, in a constructivist way, to ask students to deeply consider how they interact with the environment. They are given a lot of freedom in how they might share their reflections, and this activity was done very early on in the semester, so that students could come to understand each other more deeply. I model my reflection on the first day of class, so that students can come to know me. I chose not to evaluate this piece.

I really liked the 'What does the environment mean to me'. And I actually did it with my Science 10's class during internship because I wanted to see what they thought and for me it was very self-reflective. I don't think the grade 10's necessarily got as much out of it as I did, but it made them focus on what they use the environment for and what they would miss if it was gone. Using this activity is how I started off the Sustainability unit and I think they liked doing it. I think I needed to add more structure, more scaffolding, so that's how I would change it for next time. (Student - Focus Group)

The thing that stuck out for me most - well, not the most but one of the things that stuck out for me was the very first activity you had us do with our own environment or what environment means to us. I really liked getting other people's views on it and I liked - I liked that there was no grade because that meant that everyone could interpret it their own way and they weren't really pressured to feel they needed to have a certain thing in their presentation, and I 
really liked that 'cause mine was completely different than both of the others that I watched, and I think I got a feel for what other people take that word to mean. (Student - Focus Group)

I was interested in how there seems to be a difference in attitude and commitment to a project if it is not being formally evaluated (towards the final grade). Here is an opportunity to disrupt students' pre-conceived notions of what it means to evaluate in schools.

\section{Personal change from transformative education.}

Providing educational experiences that disrupt and suggest that things need to change on a personal and social/cultural level can be tricky. Students, as demonstrated above, don't always like to be pushed and encouraged in different ways.

I almost thought it was gonna be like, I don't want to say brainwashing but kind of. Like you were gonna try and push your views. And I really did think that after the first class "She's gonna try and make me some tree hugger." You know. And it wasn't like that at all though. (Student - Focus Group)

However, I believe that I have taken some positive steps in this research to show the value of making attempts towards transformative education. By changing the way I live through making informed choices to live more sustainably, I have created a platform upon which I can educate others. Modeling my choices and providing opportunity for others to (re)consider their choices through educational activities and strategies has resulted in creating change in how these students choose to live. It is possible that their change will be further replicated by their actions with their future students, creating a broader wave of social/cultural change.

Even though there were issues and challenges in our semester of learning and participating in environmental education, many great things came from this course. I 
asked the students what their ideas were as to how we created change. Some of their responses follow:

Although you had your views, you respected our opinions and our slow growth, as opposed to "let's jump right in and do it". By not saying anything negative I didn't feel judged. Although I had strong opinions, I didn't feel judged. By telling us your stories and not being like, "Okay, we're starting this recycling. Everyone has to help or else." You'd be, "This is what I do. This is how I have tried to change". You just told us that so we thought about it. And obviously it imprinted in all of our heads that we remember it. But just your stories. You didn't push. (Student - Focus Group)

But what I liked the best was your stories and how you were trying to lower your footprint. And to this day when I see a kid throw a piece of paper in the garbage I think "Peta". And then I'm like "Recycle". (Student - Focus Group) And with the projects we had in this class and the discussions we had, you let us be ourselves. And I think through reflecting now, you know the environment is extremely important to me. And I think you respected me as a person for, okay, this is important to me. This is how I'm gonna do my project. And even though at the beginning of the class we were complete polar opposites, I think doing the research and talking about it, presenting it to the rest of the class, we kind of all came together. We all have different views. And I think allowing us to be ourselves and letting us do what we wanted to, you know research what we wanted to research. (Student - Focus Group)

You always gave both sides. You didn't just give one. Because you said, "Okay, this is important to me. Clearly I'm ecocentric. But there are other ways to look at it. What's your opinion?" And you would always ask us, "So what do you guys think?" And that helped us along in the process. (Student - Focus Group) And you connected it to our lives. Because when I can connect to things personally or individually that's when I get it. (Student - Focus Group)

It would be interesting to see if the personal changes stuck with the students over time. In an attempt to determine this I asked students from the previous year to form a Student 
Focus Group. I found that while they may have used some strategies from our class during their internship, they were not really into their careers enough to demonstrate long-term action and uptake. Additionally, I wondered if I had become some kind of stimulus for change and if the reaction students experienced was internalised or just an uncritical response. I believe, due to the length of our course (a semester long) and the intensity that many students bring to the content, and the comments made by students who had participated in the course over a year previously and were still engaged in critical reflection, that the response came from a deeper, more internalised place.

Encouraging student self-reflection can come with initial resistances, however perseverance is worth it. The LJJ is the Learning Journey Journal.

Upon reflecting on the experience of writing this LJJ, I have come to recognize the significance of taking time to think about each learning opportunity, each life experience and the environment that continues to change around us. In sitting down and taking time to reflect on the events of each day, I have begun to appreciate the relevance of every daily activity that I find myself in, and I have begun to identify random places, pieces of literature, movies, songs, and activities as resources for teaching. I have found the process of this LJJ assignment extremely beneficial to the way I observe the environment around me and the way that I view every experience as a learning resource. I am confident that such an assignment (adapted to fit the particular students within a classroom) would be beneficial to implement in a high school classroom, for it allows for creative thought and close observations of the environment. (Student Learning Journey Journal)

Providing education opportunities that encourage personal reflection and critical reflexivity, modeling options, and allowing students to make up their own minds can be a difficult process. I found resistances and had to work through many situations that were 
less than ideal, but I had great intentions, desires, and passion. I still do. A critical friend offered the following during our discussions:

One of the things I think we have in common in our teaching is that we both have a real passion for our content. I think for both of us it is difficult to see how anyone could think differently. One of the things that I face in my teaching is how do I challenge my students to really think about what they are doing, without pouring on the guilt. How do I facilitate the learning without alienating them? In my experience, if you make people feel badly and put them on the defensive, then they are more likely to walk away. If you leave the decision to change up to them, and provide enough food for thought -they might be more open to it. (Critical Friend B-3)

Walking the talk around living more sustainably gave me a platform from which I could share stories of my experiences. I had embodied experiences where I knew what it felt like to become vegetarian for a year, to live without a car in Regina, to change how I chose to live because I wanted to change the way our society lives. One of my critical friends acknowledged:

It would be far easier for you to give an exam than to take in the learning journey journal three times throughout the semester and yet you use this evaluation because you are so passionate about supporting the reflective process. You know there is nothing you can do externally to help students learn and change, but you can cause some disruption by having them reflect and write and learn in a safe environment. (Critical Friend B-2)

Thus, I feel somewhat successful in my desire to use education to transform the way these students think and act for the good of our environment... including us.

Some examples of change were offered. They may not be life long changes. I have no way of knowing as this research was limited to one semester with the addition of 
reflections from a previous cohort. However, some student responses indicate signs of deeper change:

I don't know what you did but you are in my head all the time when I see something like water bottles or composting. When I drive I feel guilty. Like today I could have walked. You were in my head. And I still drive, but I feel guilty about it. Baby steps. Baby steps (Student Focus Group).

Yeah. It's the smallest, smallest thing ever but in my house before I wouldn't care if my roommates like left the lights on. Or if, you know, the computer was on, TV was on, lamp was on, all this stuff. Now if something's unnecessarily on I will go out of my way to turn it off. Or go out of my way to recycle. And it seems like the smallest stuff. But at the same time I actually care now. And before at the beginning of the semester I was just kind of doing it cause I had to, cause it was part of my action research. But now it's almost like this guilt in my head. (Student Focus Group)

I believe this course was designed to provide an extended opportunity to challenge these students personally and through carefully scaffolded and supported critical pedagogical strategies that led them to create change in their own lives. The process wasn't always comfortable and easy, and after dwelling further in the data from critical friend meetings, student focus groups, student reflections, and my own reflections I discovered a few arising themes that were not just curriculum related. These related to student resistances and power and relationships.

\section{Student resistances.}

The first indication of class success, or not, is often revealed through student resistances. In this class I felt a variety of student resistances. I name these as occurring in the following spaces: my teaching philosophy, learned helplessness, and content guilt. 


\section{My teaching philosophy.}

Through my self-study work I have come to realise that much of what I am troubled by and challenged with is bigger than my daily performance as an educator, yet fundamentally interwoven. I believe that this semester, as with most semesters, I have come up against student resistance to my performance of my teaching philosophy. I practice social learning theory with strong constructionist roots as a teaching philosophy and realise that this can be a disruption to the schooling that most of my students have previously experienced and are comfortable with.

By the time students make it to third year university they are quite familiar with the positioning of student as passive receiver and retriever of information. They are obviously quite successful in this discourse, as they have maintained passage through the education system. They find direct instruction methods comfortable even if the methods seem a bit boring. The effort required to learn in this model is minimal, whereas a more constructivist teaching philosophy often requires active involvement in the learning process, such as decision making and negotiation, which takes more effort and requires higher levels of consideration and engagement.

I have experienced gender and age related student resistances and occasionally a resistance to my desire to teach for social and cultural change. However, I now believe that these concerns are secondary to the social learning theory and constructivist philosophical position I take in organising and structuring my teaching practice and the resistance students display to having to share responsibility for their learning.

The result of my teaching philosophy is that many of my students experience a major disruption, which results in negative feedback and student resistances to process and content, but more often, towards me personally. "You are fighting traditional 
schooling and it's probably not just a cultural difference" (Critical Friend B-1). I have been called abrupt and even rude in anonymous end of semester evaluations, which I naively put down to my difference in culture. Australians are well known to be more direct than Canadians, and I believe that I portray this cultural difference even after a longer intercultural experience. I worried about this cultural difference, wondering how best to address these student concerns and now I feel that there is a deeper, more philosophical, issue at play here.

Students who have not experienced constructivist learning before sometimes get frustrated as they seem to assume that the responsibility for their success in the class should fall to the instructor (as it relates only to the marks and final grade). If they do what they are told then they will pass. "They want to sit, spit, get, and forget" (Critical Friend B-3). In this class, for example, students were asked to negotiate the evaluation criteria, having had aspects of the evaluations modeled for them, lots of discussion about each evaluation over many classes, a clear description of the intent of each evaluation presented in the course syllabus, and then they were given latitude to make the evaluation work for them (with little explicit directive and quantifiable structure). I understand that this feels uncomfortable and unknown, yet I'm surprised at the negativity directed to me personally. (Self-study Reflection, $11^{\text {th }}$ October 2009)

Unfortunately "[s]tudents like it when they know how you think they are doing and you expressly tell them; it's not about the learning" (Critical Friend B-2).

I am pleased to have been able to use my self-study to trouble this philosophical issue as my realisations come with some ideas as to how to address these student concerns and resistances. In critical friend conversations we troubled the specific examples of student resistances and came up with strategies that might appease each situation. Upon reflection, I can now see how these ideas are germane to my teaching 
practice and desire to create transformative learning, and thinking through them will benefit my teaching in general.

What is the student role in the constructivist learning model? What is your role as the instructor? ....and if these roles are not explicit, then students will give you backlash. Because their background knowledge and experience says, "this is not like school was". You're making them work too hard for their liking and they just want the marks and to move on. (Critical Friend B-3)

I should have been much more explicit as to why I was choosing to offer our class with the philosophical underpinnings I value and I should have used theory and research to explicitly support pedagogical strategies and teaching decisions.

At the moment these students think I am being a maverick, doing exactly what I want. They don't realise that I am teaching in an informed way. "They really don't think you know what you're doing-you're kind of like a Hippie or a Gypsy - one of those people who are not understood, you're just going in your own little way. You evaluate people based on what you think they should be doing, they feel judged harshly, personally judged. Because they don't see you as informed, as an intellect, as someone who has much background knowledge" (Critical Friend B3). So I need to share my story, place the pedagogical strategies in theory and research. Connecting it to the current environmental issues and the future. "They think you're just somebody living in their own little world who thinks everybody should do the same thing as you" (Critical Friend B-2). No one signed up for a life change. "But how do you handle this when you are lying in bed at night. You're feeling totally attacked and hung out to dry, with no support" (Critical Friend B-3). I am so glad to have these critical friends in place to help me trouble my way to seeing things differently, more clearly, and from my students perspective. (Self-study Reflection, 20 ${ }^{\text {th }}$ October 2009) 
Students need to understand 'why' as well as 'how' to go about pedagogical and evaluation strategies and sharing my thinking in making decisions is one useful way to model my teaching philosophy.

I need to take the time to give explanations about why I am choosing to undertake specific strategies and actions. With a more detailed and explicit elaboration as to why I make my teaching choices, I model my teaching philosophy, make my thinking clear and transparent, and share the intent for what is to come for the student's. I received considerable resistance around the evaluation strategies for this class and I suspect that if I had shared the current literature around negotiating criteria, for example, I would have had greater acceptance of the strategies I wanted to utilise. The current assessment and evaluation literature describe negotiating criteria as one strategy that may result in sharing the responsibility for learning effectively increasing the ownership of learning for the student, increasing the likelihood of the student's accessing prior knowledge, and increasing the student participation in the learning processes as they will be more clear as to what is expected of them (Davies, 2007). I know I am not great at debriefing activities or strategies, which is an area of my practice I constantly work to improve. Now I have some real structure around how to undertake this improvement. (Self-study Reflection, 20 ${ }^{\text {th }}$ December 2009)

\section{Learned helplessness.}

We are now at the point of the semester that is crunch time as far as delivering on evaluations is concerned. We have spent considerable time this semester scaffolding parts of each evaluation. The directions were given in the syllabus on the first day of class and some possibilities were modeled, then activities were used to break down each step of the evaluations in the weeks after that. In week three we negotiated the evaluation criteria as a class and they have been available for comment ever since (no-one has commented). We have continued to scaffold steps, model aspects of all evaluations, and often took class time to get work done throughout the semester. Yet, with all of this focused action I now 
realise that some students have just been reacting to each opportunity and they have not really been contemplating or planning for the bigger picture and evaluation success. Some students have just not spent the time thinking about what this all means. So, with timelines becoming increasingly short, the stress levels are rising. With stress comes less enthusiasm to really delve into the possibilities and the desire to "just get a pass" takes over. It is such a shame that a scaffolded and stepped-out process is now condensed into a few crazy and unhappy weeks. Time management, planning, and organisation are not things usually considered necessary to teach adult learners at university. I know there is no magic line between the end of high school and university, but these students are at least third year, with some having successfully achieved one degree already. So, I wonder how do they get to this stage and not have well-honed learning skills? And then, I wonder what this means for them as future educators. (Self-study Reflection, $3^{\text {rd }}$ November 2009)

Naming this as learned helplessness reminds me that students often require additional processes to support them in their learning. A meta-reflective or meta-cognitive awareness of how they learn would likely sustain greater success. I found repeated opportunities where I needed to shift the responsibility for learning back to the students. Strategies such as: asking students to re-read the syllabus to discover the answer to their questions, asking students to form small groups to share strategies for success, taking teachable moments with regard to particular aspects of the evaluations, and setting scenarios so that students can practice how they would respond if they were the teacher. Each strategy aims to encourage and support the students to accept the responsibility for their own success and learning.

The choices that students make with regard to their behaviour in class often surprised me with their resistances to learning and experiencing new ways of thinking, including new content and making the shift from thinking like a student to thinking like a 
teacher. There seemed to be a strong desire to embrace what I call a 'service' model, where the instructor is paid to provide the student with the learning (or a grade), which is to be given with the least amount of student effort. Often decisions made by the instructor were taken to a higher authority for clarification in an attempt to prove the instructor wrong and free the student from the burden of making effort, thinking about the value of an activity, or looking for the best in situations.

I am thankful for my critical friends, as they have enabled me to dig into the specifics around the student issues I occasionally face. They remind me that even though the negative issues seem to take priority and concern me more, there are many positive situations that go unremarked and yet are just as valuable. They also remind me that students position themselves as 'the student where teaching is being done to them', rather than as 'a learner with shared responsibility in the learning processes'. This learned helplessness continually catches me off guard. I realise that this positioning may be unintentional however; the result is a choice that can be unpacked and examined if both sides are prepared to devote time and effort. (Self-study Reflection, $20^{\text {th }}$ November 2009)

Somehow framing the resistances found in many students creates a platform upon which student choices can be unpacked and jointly (and carefully) (re)considered. The teachable moment, the careful de-brief, and a reflective practice asking for consistent consideration as to how a teacher would and could manage these various resistances brings light and awareness, and hopefully consciousness, that most behaviour is a choice.

\section{Content guilt.}

My desire for this course is to provide an opportunity for students to experience a disruption to their socially constructed ways of being in our western society and then take the opportunity to research and come to understand a more ecologically aware position 
through explicit practice and embodiment. I am not only interested in changing their practices and generating social and cultural change towards living more sustainably, I want them to stop and (re)consider their actions as conscious choices that carry many environmental implications. With an increased awareness about alternative ways of being and doing that are based in more ecologically aware philosophies, often comes guilt. Guilt is that bad feeling that you have been doing things the 'wrong' way for so long and now that you are aware you feel terrible that you didn't know and didn't take the time to come to know. "I would expect that the students would go through a whole array of feelings as they are going through this course, and guilt would be in there. Guilt would be a big one. I would feel guilty" (Critical Friend B-2). It is not my desire to impart guilt; however it is a potential outcome from our work in this course and I need to remain aware of its implications.

I name this as content guilt as I am sure there is guilt about other aspects of our course and due to our time together; however it is the feelings around the students living choices on which I want to focus. Throughout the course there are opportunities for students to learn about and come to understand the environmental and/or social issues that impact our lives. In coming to think about these issues, I hope to turn the focus back onto the students, through thoughtful discussion, asking them how their own practices are choices and, therefore, they are implicated in these larger issues.

Often I shared a story, or two, about how I might have changed my living practice as a result of gaining awareness, and my intention was to model that change was possible and that there are more appropriate choices to make, if I take time to research the possibilities and alternatives. I didn't intend to generate feelings of guilt and cause resistance to hearing about the possibilities for change; however I suspect this occurred. 
"You may intimidate your students as they see you as not living in an extreme way, but as something that may not be possible in their lives" (Critical Friend B-3).

I think these feelings of resistance were hard to speak about, as students perceived that talking about resistances presented themselves in a negative light. I didn't record many student comments that directly referred to feeling guilty in a way that prohibited learning and therefore being resistant to change; though I am confident this occurred. My critical friends made comments, however, which brought the issue to light. From these conversation onwards, I considered the potential implication of content guilt in my students' reactions. It's interesting that perception of intention and issues of power play out in these ways, as I remain confident that my students didn't want to be seen as not trying or not succeeding for fear of not passing in the course.

\section{A critical friend suggested}

you can get really defensive with guilt and, you know, we hear it all the time when people refer to environmentalist as 'tree huggers'. That's just putting aside the cause for these feelings by creating a dismissive name or you can use that to change your ways. (Critical Friend B-2)

Another suggested, "I know, even for myself, there are times when I think "Oh I am so glad Peta can't see me doing this"', (Critical Friend B-3). And one admitted that throughout our entire experience "I have felt intimidated on multiple levels... but that is also what inspired me and intimidation can provide inspiration" (Critical Friend B-3). However, "when a student feels intimidated they probably feel more threatened and insecure" (Critical Friend B-1). I aim to provide conversation and safe spaces where sharing success and failure lessens the intimidation and negativity. A positive attitude and encouragement for even the smallest of details can be successful in offering support. 


\section{Power and relationship.}

The student resistances described above have potential to result in challenges in the student-instructor relationship and these issues are undergirded by the power differential of this relationship.

In our society the education systems infers a power differential as the instructor is the one who says, 'yes, you have it and you can move on', or not, and the student passively receives this opinion. I am prepared to accept this responsibility, ultimately. However, I want to share the responsibility for the learning along the way. I hoped to create a learning environment based in trust that would ensure that students would come to me with issues or challenges, first. We would then negotiate a way forward that satisfied both our needs. (Self-study Reflection, $28^{\text {th }}$ September 2009)

Making sure that our class was a safe space where a variety of opinions were welcomed and could be troubled in collegial ways was certainly my intention for this course.

When you really want students thinking and to delve deeper into issues, the class has to be a safe space. It has to be safe for the students and it has to be safe for you. And facilitating that safe space is a difficult thing and there is a limit to what you can do - if you have the odd person in the class who is not keen. (Critical Friend B-3)

I believe that we worked to achieve this early in the semester, which culminated in all students (except one who had an important family event) attending a weekend conference.

At the end of week three most of the students went to a conference over the weekend. They had so many great experiences at this conference: they were presenting so they felt creditable in being there, they had a very cheap weekend, and they bonded amazingly at the evening dance and sat round the fire singing 
songs. Everything seemed to be very successful. The reflections were very positive. The atmosphere in the class was wonderful. At the suggestion of another trip all students were excited and determined to start the planning. (Selfstudy Reflection, $3^{\text {rd }}$ October 2009)

At some point after this, however, the tone changed in this class. I noticed a reluctance to come to me, and a preference to complain to other students. I believe this was precipitated by one student's decision to take a dislike to this course and to work with his colleagues to undermine the experience for everyone else. The way that I became aware of this was through evaluating the Learning Journey Journals (one of the course evaluations) during the first of three intakes spread across the semester.

What have I done to deserve this lack of trust? If our class has gone well in that we have participated in many different and engaging activities, been off campus for field trips, had guest speakers, attended and presented at a conference, participated in trainings and workshops and really troubled what it means to learn about the environment in a very action orientated and embodied way - all of which requires high levels of trust, then why does this trust dissipate so quickly around evaluation. How do they assume that after they have been involved with negotiating every aspect of these evaluations, except for setting the original task, that I will burn them and not give them the marks that they know they deserve? (Self-study Reflection, $3^{\text {rd }}$ October 2009)

It took some critical friend support to begin to see a way through this situation.

They don't want to have to think. When we make them think, then that's when students stop trusting us. My first few student evaluations demonstrated that these students didn't think I had enough experience and qualification to teach the course because they could say things like "well, all she does is ask questions, we had to do all the work". They don't seem to understand how critical it is and how it is so much more difficult to support students to process and learn rather than just give them the answers. (Critical Friend B-3) 
I had anticipated that with a negotiated evaluation strategy the students would understand that this meant the negotiation didn't stop once the criteria were devised. I said to the class "we have negotiated many aspects of these evaluations and the negotiation continues beyond my appraisal of your work. If you're not happy with my descriptive feedback or the number feedback, then I encourage you to come and talk to me to explain what you think I have missed or need to re-consider. If you choose to you can always re-submit an evaluation after you have reconsidered it”. (Self-study Reflection, 29 ${ }^{\text {th }}$ October 2009)

"But a negotiated curriculum is a foreign concept for these students" (Critical Friend B3). And now I see that I should have spent more time offering examples and stories about how negotiation of my feedback might have looked. I also realise that we would all benefit from having an evaluation piece be completed early on in the semester. Through this process students would get to experience the entire process and come to understand how I offer feedback and how to manage negotiated evaluation processes, taking away some of the "unknown" factors and providing some level of comfort and safety. By comfort I mean in knowing that they are going to pass and reassurance that they are doing and thinking as I might hope them to be.

I also felt that a gender and ageism resistance was in play here. If I were older and male I wouldn't be questioned about my evaluation strategies. "Female instructors often receive very different [lower] evaluations from the students than the male instructors. The question here is why do the students feel that they can treat females with a disrespect that they wouldn't for older males" (Critical Friend B-1). So, I asked my critical friends what I should do and how has this come about.

The syllabus was thorough; you obviously spent time on it. You have done the homework to build up the students' understanding, helping them scaffold their 
understandings to develop over time, having the conversations. Maybe some of it is a lack of familiarity; it's not the way they are used to being evaluated. It's not the way they are used to living their life, or they are not used to being challenged on that. So if you are being challenged on what you value and your starting to feel a bit guilty, and most people will, and so we should, there has to be some reaction. But then if you are also feeling unfamiliar with the evaluation and maybe that you won't get a good mark, so your getting an uncomfortable feeling on multiple levels, you're going to get more pushback. (Critical Friend B-3)

I considered some of the strategies that I have attempted to put into place: being early to the classroom so that I am available for casual conversation and staying later for more of the same, having an office and an open door policy, being very responsive to email and communications, keeping in touch about personal issues students are experiencing and making an effort to generate personal connections, being calm and steady even when I'm not feeling that way, attempting to be consistent for each student and throughout the semester and, most importantly, laughing and telling stories of personal endeavour that include success and failure.

\section{Resistances to research.}

At the beginning of this semester I informed this class about my self-study research. I intentionally kept the description brief; however the process required that I have someone else in the room to facilitate the collection of the students' forms (so that I remained unaware throughout the semester as to who had chosen to be involved in my research or not). I believe that the presence of a different person, the students' limited experience with research in general and self-study in particular, and the added pressure of teaching/researching changed how I could be as an instructor, for the worse. 
I didn't share as many stories about myself, as I didn't want to keep referring to my research. I worried that such reminders would result in my students feeling that they were being taught by a fellow student (not a fully qualified instructor) and that I was just using them to pass my own degree. Neither of which were fair, nor true. However, my insecurities resulted in me keeping my experiences to myself. I believe this damaged some of the potential in this class. I could have been a better model had I shared more experiences. I could have been a better teacher if I had shared more of myself - as this is what helps relationships deepen. I could have taken more time to work with these students to help them come to understand the research process and what it meant for me, and, ultimately, for them. (Self-study Reflection, $26^{\text {th }}$ December 2009)

\section{My positioning as an educator in this program.}

Throughout the research semester I experienced a few opportunities to discuss my course with the Faculty Administration. I was being called in to justify my practice as some students had taken their concerns to a higher power. I appreciate that students need to have an avenue to seek outside (of the classroom) support; however I also believe that there is a code of conduct that requires students to first discuss any potential issues with the instructor (me). My concern in this experience is not that it happened, nor the outcome, but what was conveyed to me throughout the process.

"Perhaps you shouldn't teach this way! You're untenured; you're a sessional instructor with no permanent position here; you're a PhD student; you're being disruptive; and you're going to get terrible student evaluations. Work with your subject area, you don't have to do all of this disruptive stuff in your course. It's the programs job to be this disruptive - not yours".

This was some of the feedback I was given today, from the Administration. I feel a bit numb about it still. And although I didn't say it, here is my response... But this is my passion and my belief in education and this is what teaching environmental education should be all about. Environmental education offers a 
critique on education; see the calendar description. I think that being disruptive with these students is absolutely my job: as a way to challenge and critique education. What else should I do? Should I give up teaching this way and conform? Should I teach how these students want me to teach, in ways where they don't have to think and feel differently, where I just give them what they want? I could get great student evaluations and never have any challenges and everyone would think I was a wonderful teacher, but then I wouldn't be doing my job. I wouldn't be teaching! (Self-study Reflection, 15 ${ }^{\text {th }}$ October 2009)

The difficulty here is that my syllabus was carefully developed with considerable research from: previous instructors, my four previous experiences teaching this course, as well as being critiqued by seven critical friends as part of this research process. My mentor, the Chair of the subject area, and a critical friend in this research made the following comment in reference to my syllabus. "I like it. I think this should act as the template for our new elementary courses" (Critical Friend A-1). Which leads me to think that this was a well designed course and one that was appropriate in the eyes of my colleagues. Given this, what should I think? The administration is unprepared for the student backlash and unprepared to support their instructors, yet the subject area thinks this is exactly what I should be teaching. The students, even by third year, are unprepared for this kind of education, and I feel a sincere need to teach for social/cultural change and that this has to come with disruption and challenge. One of my critical friends believes that these are the 'tensions of teaching'. "What the students want, what the administration is willing to support, and what I believe. If we can't teach in line with our beliefs, for me, that's when I feel physically ill” (Critical Friend B-3). 


\section{My experiences throughout this course.}

Having invested considerable energy into the design of this course and wanting the best possible results (as this was the semester I conducted my research and I have a passion for environmental education), I felt that while all students might not have enjoyed all aspects we each learned something useful that will develop our teaching practice. I learned that planning was important, but flexibility was always part of good practice. I learned that students experience class activities in many different ways. Some look for the positive and others do not. The differences depended upon many factors, some within my control and many not. Experiences that I thought might be enjoyable were questioned in ways that I found surprising. Students seemed reluctant to really dig in to explore the possibilities of what was on offer in this course.

I feel that some students just want a textbook and to sit inside the classroom each class. As the out of class experiences often require more energy and effort on my part I feel some frustration with these students. Their attitude shuts down discussion and seems to hinder other students' enjoyment. I could be misinterpreting their actions but verbal confirmation makes this seem less likely and there have been some harsh written reflections submitted.

I found that I dwell on these negative comments more than positive comments when discussing with my critical friends. I think I am searching for ways to improve my teaching practice, and I feel the negative comments might have more to offer, but sometimes learning how to deal with (and disregard) overly negative commentary is necessary.

I'm not saying that I shouldn't look into these comments and adapt to suit the needs of these students, but at some point the course was designed to provide disruption and experience and, ultimately, learning about education. I suppose

it's more of a numbers game - if everyone is unhappy then rethink it, but if just a few remain displeased then they may have to adapt. Or perhaps there is some deeper underlying issue for these negative students. However, if they won't 
discuss their issues or concerns, how can I make any informed changes? Ranting negatively in a submitted written reflection is not the best way to make change. I wonder if these students could be happy with any change anyways - sometimes the ranting feels personal. I wonder how we could have become so disparate? I suppose the stress for these students comes from their relative lack of experience in the classroom. Many have not spent more than 2 weeks as an educator in a classroom. These students want to be given programs that 'will work' and can be implemented with the greatest of ease - on Monday! I want to offer experiences that can be critiqued and later adapted to suit each future teachers needs. I aim to offer a baseline experience that can be further developed and that takes work, effort, and adaptation.

At times I feel undermined and disappointed at these negative student reactions or comments. I worry and feel anxiety that I might be doing them a disservice. I consider ways to adapt, change, and flex to suit their needs. I try to find ways to have conversations where they feel safe to voice their concerns. I don't just ignore the negativity: I can't. It eats away at me and I found, this semester, that I have felt uneasy entering the classroom on occasion.

I'm surprised that education students can treat their educators this way; don't they see that in a few short years they, too, will be in this unenviable position of not being able to satisfy all students? This reminds me of a lesson I observed recently - 'it's ok to be angry, it's not ok to be mean'.

I'm really glad I have the support of my critical friends this semester. They have helped my trouble my way through some student issues. I have felt 'heard' by them, and explaining the students concerns and then discussing the possibilities has resulted in me having more confidence in my response and, likely, me giving a better response. I have learned compassion for different student experiences and ways of being less confrontational in negotiating solutions. (Self-study Reflection, $26^{\text {th }}$ December 2009)

Constant reflection resulted in reflexive action as a result of this self-study. I adapted my teaching content, style, and performances in an attempt to better suit the 
needs of my students. I didn't adapt to their desires though, as I was responsible for, and committed to, offering a quality educational experience. I chose to uphold the benefits of environmental education through critiquing our educational experiences.

In future teaching experiences I hope to continue to refine my educational practices and to walk my talk. I aim to continue to critique education with my students and I hope to develop skills where I don't take things personally. I will continue to look for the 'teachable moments' in each opportunity and ensure a strong reflective practice that offers a useful way to remain reflexive.

My experiences of generating social/cultural change will be explored in the following section. These grew and developed from both my intentional and embodied living choices and the critical pedagogies ands transformational education attempted through environmental education. They form the third component of my research as I move from the personal change through transformative education to societal/cultural change. This is the practice of ecofeminist activism.

\section{Social/Cultural Change: A Metareflective Account}

Learning how to share my wealth (conceived as time, knowledge, and financial) and using my good fortune to support others has provided great joy to me during this research. I have found ways to work on a personal level as well as in community. Following are two meta-reflective stories of how I have undertaken personal work to generate social/cultural change. Each stories was written based on several self-reflection entries and they were designed to be demonstrative of only two examples. 


\section{Ethical investments and sharing my monetary wealth.}

Returning to full-time student lifestyle is certainly financially challenging and being an international graduate student brings some specific issues. However, I think that I made a pretty good go of it with regard to sourcing scholarships and taking on small employment contracts. The more I took on, though, the longer it took to get it all done. And I will add that I am proud of the types of work I undertook, paid and not. I have achieved a lot in the last seven years, enjoying many experiences professionally and purposefully. I will admit that choosing to research my intentional practice and sustainable living lifestyle in an embodied action orientated way has certainly been a good thing with regard to working out how much is actually 'enough'. I live on a relative 'very little', which is fortunate because I earn a relative 'very little'.

What I earn and don't immediately consume is managed carefully and ethically. I used to put all my money away in an ethical investment fund. However, when I looked more deeply into this so-called ethical fund, it wasn't so ethical, certainly not in accordance with my ethics anyway. I also wanted my money to work harder for me. So I put all of my savings into purchasing my Canadian apartment, which took considerable pressure off my immediate financial situation.

I think the financial management choices we make are socially constructed and often unconscious, in that we are 'told' what are good decisions. Such information seems to be based on getting as much as you can and acting like an individual. I don't believe that this is the best way to practice living sustainably. Humans are social creatures; we live best when actively participating in community.

The individualistic pretences perpetuated by a capitalistic, materialistic, consumer society do not serve us well. I have tried to remove myself from the societal desires of owning a large house and driving a flash, fast car, holidaying in tropical countries, and always having the newest phones and technology. The result is a shifting of my desires, a redefining of success, and the confidence to be sure in my decisions.

I subscribe to several organisations that empower me to share my wealth. This practice ensures that while I have a little bit extra, I can pay it forward and support those who weren't born into my western privilege. My favourite organisation is Kiva.org: an organisation that manages micro-loans in developing countries. I invested \$500 in 2007 
into various projects through this organisation and I have now offered 110 loans and reloaned any moneys paid back to me. Figure 7 demonstrates where the loans have been placed. This means that I have now lent over \$3000. All of my loans are in the process of being repaid or already have been and I lost less than 1\% on delinquent loans, which I consider to be just fine. I choose to invest in projects that are agriculturally focused, and managed by women as I believe that this kind of support is the most important. I encourage you to participate. It's a wonderful feeling!

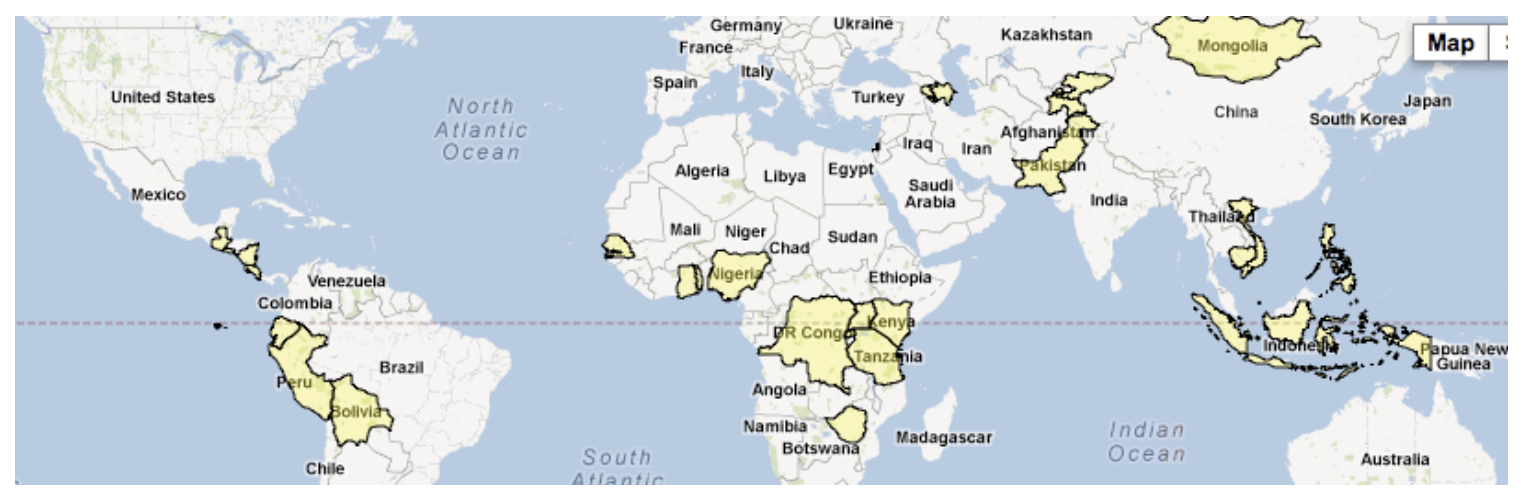

Figure 7. Countries where I have offered loans to agricultural based projects with Kiva.org

Three Christmases ago now, I considered my options for sharing the joy of giving and the spirit of Christmas and for disrupting the socially constructed consumerist ways of our western society. I had made the decision to not go home to Australia and if I wanted to give presents I would have to mail them... or would I? I hated thinking about presents as items of clothing, tools, other bits and bobs, as the decision would always come back to the question of what has my family not got already. The idea of finding something they actually needed seemed impossible. 1: how would I know as I don't live around them and we all enjoy different things, and 2: if they needed anything they wouldn't hesitate to purchase it. Food was out of the question with Australia's stringent quarantine laws, which is a shame as food is an easy item to gift, as everyone needs it. It is easy to put that extra bit of love into a homemade item, or a special exotic (as in culturally relevant) treat.

All of this thinking led me to consider using Oxfam Unwapped, the gift that gives many times. I purchased items (usually animals such as goats, donkeys, sheep, and chickens) for 'presents' to give to my family, and Oxfam delivered the actual animals to families in Africa where they can keep on giving (through their products or their life). I 
love that I could impose my environmental views on my family in a way that resulted in us all feeling good. I realise that this is a privileged action as I have enough to give some away, and my family also has enough to not need anything, except the wonderful feeling of giving. I will be repeating this practice again this year, although extending my family's concept of giving by sharing not only actual items (or animals), but also education and training focused on women and children. This giving practice ensures that I maintain a socially acceptable way of participating in Christmas, yet I can now do it in a way that is less consumerist, supports my family to come to understand some of my ethical and ideological perspectives, and supports people in other cultural situations to be more self-directed. The gift that gives twice, feels doubly good!

I continue this practice today and will continue to do so as I enjoy the feelings I gain from taking personal action and creating social goodwill and, ultimately, change for a more sustainable future. The stories offered above are purposefully detailed and should a reader like to emulate some practice enough information has been offered to describe how. Additionally, the details are important as I name this type of action 'armchair activism': the kind that doesn't require much time, knowledge, or effort. Sharing wealth and ethical investment are two easy ways that an individual can help change someone else's life, making the time to actually do it is relatively easy. However, recognising the importance to do so can be considered a proactive and positive step and this should be celebrated and encouraged. As I learn more about how to live with 'enough', I will continue to share the extra wealth I accumulate in meaningful ways that work to support social and cultural change. 


\section{Activism in the community.}

Often my wealth is not monetary based, but time and knowledge or skills. I have enjoyed finding ways to take personal action to support others to learn and grow, developing awareness and practices that result in social/cultural change.

As an environmental educator my activist practices are mostly around participating in environmental education organisations. I have given considerable time to the local organisation (Saskatchewan Outdoor and Environmental Education Association -SOEEA), as I was the President for three years and Past President for two. I have also been an active Board Member for the Canadian Network of Environmental Education and Communication (EECOM). And finally, I have been an active member and leader in the North American Association of Environmental Education (NAAEE).

I believe that to effectively participate in these organisations I need to consider supporting them with time, effort, knowledge, skills, and financial contributions. I have become a financial life member and shown strong support and financial input in all three associations. I have also given financial support, refused honourariums, and sourced additional funding to support aspects of each association. For example, I initiated the NAAEE International Travel Scholarships, and offered financial support to ensure the first scholarship could proceed in the first year. We received 16 applications, proving that this scholarship was needed. The second year of the program we received 45 applications and fortunately we had implemented a funding strategy that mostly supported 2 scholarships to be offered. Participating in this way leaves me feeling involved and useful as I can share my good fortune with those with less, which effectively results in us all having more.

Personal activism is a key part of my personal practice around living sustainably, as this practice of activism sustains my personal ethic in performing 'successful and considerate educator'. I consider this to be a community developing practice as it generates a community of practitioners for me to be collegial with, actions for me to participate in, and worthy causes for me to embrace. This activist part of my practice is most enjoyable and socially rewarding. 
Often time, knowledge, and skill is all that I have to offer and making contributions to organisations results in feeling like I make a difference beyond my self-practice. The work these organisations do is educational and therefore, I see this work as directly relevant to changing society through education. Much of this work is not particularly transformative; however the potential is there for great impact. Organisations such as SOEEA, EECOM, and NAAEE change people's lives. They recognise great effort and work and facilitate the celebration of both, which may be enough to encourage the continuation of great work. They put into place programs and events that share knowledge and understanding, increasing awareness about environmental education, has actions that have the ability to change the lives of the participants and others. Ultimately, these organisations facilitate conversation, which can lead to action. I like being a part of these conversations and I definitely like being a part of change. 


\section{Chapter 5. So What?}

"Who are you?" said the Caterpillar. This was not an encouraging opening for a conversation. Alice replied, rather shyly, "I - I hardly know, Sir, just at present - at least

I know who I was when I got up the morning, but I think I must have been changed several times since then". (Carroll, 2004, p. 55)

My research inspired a metamorphosis of my practice: personally and professionally. I believe I have become a better educator, researcher, and activist as a result of the critical consideration and reflexive practice undertaken. Self-focused research has enabled me to change, my students to experience transformational education that may have changed them, and, I want to believe, society to change. Through embodiment and doing as well as theorising and thinking I have come to know differently. Dewey (1929) suggested that theory must be accompanied with doing and making (p. 281) and this action orientated research undertook embodied practice to reveal not only an experience as to what it felt like to change, but also to establish a model of what change could be like for others. Thus, Cuomo’s (1998) “thoughtful practice” (p. 143) was evoked as choices were carefully considered and then modeled for others' consideration.

The so what? of this research is that these changes matter as they become a new way of being for me, inspire others to consider undertaking change, and begin to change the discourses around what is possible. I have heard and felt the dominant discourses as they rub against my intentions for a different, more sustainable practice. Seeing, hearing, and feeling the dominant discourses has been as important as finding ways to struggle against them, encouraging others to look beyond the socially constructed ways of being. 
Walking my talk has enabled a different way of seeing, being, doing and thinking with others and has resulted in what feels like a meaningful continuation of change, or critical reflexivity.

(How) can I use personal change to inspire educational and social/cultural change? With theoretical and methodological framings (ecofeminist critical poststructuralism undergirding an autoethnographic self-study) this research revealed many realisations, experiences, thoughts, and ideas. This final chapter explores the implications of the framings and the findings and offers future possibilities for change. The three-dimensional model of personal change leading to transformative education resulting in social/cultural change will be maintained as I offer three final stories (presented in italics to denote the personal voice) to share the passion that came with these experiences of life/research.

\section{Unraveling the Findings and Future Possibilities}

\section{Personal change: Being critically reflexive.}

Personal change, as investigated through autoethnography, and framed theoretically through critical poststructural ecofeminist activism, happened. I learned how to be critically engaged with my personal living choices, successfully lowering my impact on the environment while remaining within my culture. I decreased my ecological footprint, I refined my decision making strategy, I gained knowledge, changed my practice, and occasionally this influenced others to change as well. The following story discusses what this change in my personal practice means to my professional practice. 


\section{Hope and hopefulness.}

I explore options and challenge my (co)constructed notions continually. I practice making change in my life by doing the small things: many of the small things. I changed the light bulbs. I recycle and reuse and, better yet, I reduce and re-think. I use less water and energy and produce less waste. I look for alternatives to air transit and take these options when they make sense and I choose to travel less often than I have. I buy second hand clothes when I really need them. I eat locally and seasonally, forming relationships with food producers. I live close to where I work in a multi-story apartment building, reducing my need for ground transport. These small changes are relatively easy steps to put into practice. It is the cumulative action of these small changes that results in me feeling like I am making a difference and generating discourses of change. These small changes give me a sense of achievement and I choose to celebrate each as a success. I feel hopeful about my changing practice, increasing awareness of discourses, and the influence I provide to change the discourses and, ultimately, others 'practice.

I feel great about the time and energy I have put into critiquing my living practices; however it's the ability to hear, see, and feel the discourses as they rub against my new found understandings that is most interesting. As I take the time to explain some of my choices to vendors at the Farmers' Market or in other places I consume, I hope that my opinion might sway their practices a little. I encourage my friends to reconsider some of their practices. I challenge my students to take on their own challenges. But mostly, I listen and feel as the dominant discourses are applied with disciplining comments or actions or through permission giving advertisements and marketing strategies intending to maintain the excessively consuming ways of western society.

I believe that many are challenged by my discourse and practice around becoming more sustainable. I have been told that my presence makes people behave differently or feel differently about their practice and choices. I don't actively attempt to generate these feelings (usually of guilt I assume) but I am curious when they are expressed. I wonder at the reasons these people use for not practicing more sustainability if they can, just choose not too because there is no pressure to do so. Perhaps mandating change would be effective? It seems to be working well for Sweden. Ultimately, I'm reminded that it's just a choice and desire that changes practice towards being more sustainable. 
When offering a presentation to a group of students undertaking environmental activism in their class recently, I was asked if I ever felt anger at the constant application of dominant discourses that are wasteful and perpetuate overconsumption. Upon reflection of this great question I realised that I don't. I have considerable patience as my practice is about how I can change. I'm not able to change others'; however I can prompt, suggest, and offer the possibility of other ways of being and doing. Change begins within and as Gandhi offers, "you must be the change that you wish to see in the world". I strive to follow this mandate, hoping to influence others' along the way by changing the discourses around what is possible and acceptable.

I often receive critique that suggests that these small personal changes don't make any effective impact on the footprint of my society. I can see that the impacts of my changes are small in comparison to the changes large corporations need to make. However, changes to how I choose to live are the ONLY changes I can make. My practices impact larger corporations as I choose to purchase their products and services, or not. I use my dollars as a vote for the kind of environment I want to live in. I feel empowered through this critically reflexive practice. I am changing my impact and I am attempting to influence and encourage others' to do the same.

I feel hopeful as my changing practice becomes easier and more ingrained in my body. I no longer have to use my decision making process as often, although I need to remain aware of the implications of each choice. I'm getting better at becoming more aware. The choices I want to make are easier to embody now. Perhaps the item I want is easier to find because it's more available, or the ingredients have changed, or I am used to doing things a different way, or going without. Not eating bananas while living in Canada is now ok. I know where to look for the kind of shampoo I am prepared to use. I have developed deeper awareness of the numbers on the fruit and the ingredients in products.

Ifeel hopeful when I hear others talk about the changes they are taking on. Leonard (2010) offers great cause for positivity. I have had the pleasure of working with this activist twice now and each time she delivers a keynote address that generates hope and inspiration. Through greater awareness of the implications of our choices the audiences of Leonard are becoming more sustainable in their practices. I know this 
because I am one of them and my colleagues and friends confide their own challenges and successes.

The arc of history is longer than human vision. It bends. We abolished slavery, we granted universal suffrage. We have done hard things before. And every time it took a terrible fight between people who could not imagine changing the rules, and those who said, "We already did. We have made the world new." The hardest part will be to convince yourself of the possibilities, and hang on. If you run out of hope at the end of the day, to rise in the morning and put it on again with your shoes. Hope is the only reason you won't give in, burn what's left of the ship and go down with it. The ship of your natural life and your children's only shot. You have to love that so earnestly - you, who were born into the Age of Irony. Imagine getting caught with your Optimism hanging out. It feels so risky. Like showing up at the bus stop as the village idiot. You may be asked to stand behind the barn. You may feel you're not up to the task. (Kingsolver, 2008, para. 17)

I'm up to the task; I know this as I have proven it to myself. I lowered my ecological footprint from 16.4 HA to 1.8HA. I haven't sustained this low footprint, but I could as I now believe in myself and have developed the skills. I am aware of many of the implications of my choices and continue to research others. I strive to make better choices each time I consider making a purchase or taking action.

I remind myself, though, that my desire to live more sustainably and to create discourse that enable such practice is necessary in my privileged western society. As I have said before "I make no claim to abstract these living practices towards societies not privileged with such excess and access to resources. This is an important consideration, and one that must be made very clearly when presenting my lived experience. This work is socially bound." With this necessary delimitation of this work, I feel hopeful that my research, effort, and success have generated the possibility for others' to consider changing their practices too. This is success!

Finally, I remind myself that language matters. We are not participating in an environmental crisis. We are deeply involved in a social crisis. "The false naming of these crises allows for a lack of recognition as to the underlying practices that generate such varied issues and consequences." Humans have misunderstood our place in the Earth systems and we are overstepping our bounds causing damage to others' and the systems themselves. Yet, I reflect that in some ways a crisis is good!

Change comes with education, mandate, or crisis. Education works for some, sometimes. Mandating change takes considerable effort, requires policing, and has been 
a successful strategy in some cases. However, social crisis will come (and in many cases is here already) and almost inevitably with some major devastating catastrophe the over population and excessive consumption will end. I don't like this idea; it will come as a shock and with certain pain and distress, and I hope my friends and family are the ones who make it through. However I also believe that if we cant control ourselves and become aware of our place within our Earth systems then catastrophic social crisis will make us change.

Things will change... there is always change... change brings equilibrium. Ecosystems, for example, are in constant states of flux as they work to establish equilibrium. I suggest that the pendulum has swung as far out as it can and it is time for it to swing back in and western society will have little choice but to change. Peak oil is a concept that has been with us for a while and drives some change, what if we are now at peak humanity? Managing population pressure is a difficult concept. Yet, as with each social/environmental issue, it is one that each individual can take a stand on and make personal choices to practice with critical consciousness. I am reminded of the quote by Buckminster Fuller "You never change things by fighting the existing reality. To change something, build a new model that makes the existing model obsolete".

I choose to see the social crisis as an opportunity for hope and hopefulness.

"What we are looking for is empowerment of a particularly deep kind: the enablement of being - or even better, of becoming. For we humans are nothing if not human becomings, always in the process of change" (Fisher, 2006, p. 46). Learning how to live sustainably was where I began in this work. I want to re-name the work to learning to 'live critically'. Change is constant in our society. New ideas and trends take hold each day. So, to be clear, it is not unbounded change that I'm after, it is specifically related to: resource consciousness, limiting energy, water, and waste production, learning to respect all beings and to know and live as part of the Earth systems. I want western society to become critical about our place in the Earth systems; acting as if we are a part of this system, not owner of all systems is imperative to our survival. I feel as though I have achieved steps towards practicing this way and I hope others' will act similarly.

Finding words to clarify my worldview, as well as others' that share elements of my worldview was inspirational and resulted in me finding my community. In this 
community I discovered strategies and ideas regarding practices and ways to articulate and theorise. For example, I learned to unpack the complexity, develop an awareness of my assumptions (Cuomo, 1998) and the discourses from which they came, look for synergies rather than difference (Robinson, 2009) and to consider Earth as a complex system rather than discrete parts that can be completely knowable (Meadows, 2008). Appreciating the intricate and interwoven nature of these systems and my small part within them holds me accountable for my every action. I now have a solid platform upon which I can walk my talk when practicing/performing environmental education/educator. I have been transformed through an educational strategy. I embodied these changes and learned to feel the impact of discourses. I have become and continue to become critically reflexive when choosing the possible implications of my choices. And as a result of this personal change my ability to teach others has changed.

Changing my personal practice to be more theoretically grounded as well as more critical has changed many aspects of what is now possible in my life. I practice environmental education from a different perspective now, one that is embodied, intentional, and grounded in my own practice and critical thoughts as I walk my talk. I have become more aware of my potential impact on others and take this as a responsibility to generate sustainable change whenever possible: walking the talk in practice and through generating discourses of change and possibility.

\section{Transformative education: Critical pedagogy.}

Palmer (1998) suggested that the field of environmental education is characterised by a paradox: "whilst few would doubt the urgency and importance of learning to live in sustainable ways, environmental education holds nowhere near the priority position in 
formal schooling around the world that this would suggest” (p. ix). Environmental education remains marginalised in most school systems. One way to 'subvert the system' and to bring about change is to work with pre-service educators, providing them with the skills necessary to experience changes to their worldview so that they may prioritise environmental education in their future teaching practice. Experiential learning and transformative learning are necessary for these future teachers to see and feel the benefits of coming to know and do in different ways. While teacher education can be fraught with issues and difficulties, there are many wonderful moments of joy and learning filled with great potential to bring changes to the profession and the learning outcomes around environmental responsibility and sustainability or 'living critically'.

\section{Walking the talk.}

I came to realise that pre-service teacher education was one way of working through the system to effect change of the system. hooks (1994) calls this 'teaching against the grain' or 'teaching to transgress'. Student teachers were asked to engage in experiences or to use perspectives different from what they might be familiar with, which often resulted in shaking up their worldviews around education and sustainability. I wanted to use the opportunity that teaching one course in environmental education gave me to bring new awareness and possibilities to these student teachers and future educators. I wanted to teach against the grain with respect to sustainability and personal living choices or living critically with the aim of continuing the work towards creating a cultural revolution in the western society.

I realised that just offering awareness or a differing perspective wasn't going to change the practices of my students: these future educators. They required an experience of their own, something that was personal and yet profound. They needed to see how a different discourse could be implemented and that it didn't have to cost them all the benefits they received through being white, western, and privileged. In fact, change in this way could feel freeing and empowering. 
Seeing alternative discourses in action was crucial to illustrate that change was possible and to demonstrate what it looked like. Yet it was experiencing or feeling aspects of the change as well as the empowerment that could be derived from this change that undergirded any success that teaching against the grain might produce. The ideas around 'walking the talk' came from such a place. It wasn't until I embodied intentional change myself and felt that the effort wasn't too extreme yet the outcome felt better that I realised how important the actual 'doing' was in this research. Here was the beginning of success in establishing an alternative discourse of living critically.

Using my newly reformed practices as a model and offering this model as a possibility not as prescription proved successful. However, intuitively I knew that these student teachers would need to feel their own personal success of bringing change to how they could live critically to find alternative discourses that they could use as their own. I began working with the action learning group project (ALGP) and refined the protocol into the 12-step model presented in this research. It took time and reflexivity to refine the model into something that was useful to provide a successful (well scaffolded) protocol for my students as well as a pedagogical strategy that they could use with their student sin the future. The ideas of critical pedagogy were germane to the success of the ALGP.

With any change comes resistance and this teaching experience was no different. I found many student resistances and named them previously (in the Findings - chapter 4): my teaching philosophy, student learned helplessness, content guilt, and power and relationship. Yet, even with the greatest resistance came some form of success in implementing the ALGP and awareness and action around living with greater criticality. Even students who took a vocal stance against many aspects of the course produced a successful ALGP. The conclusion I want to draw from this is that a personalised focus or the ability to choose the topic of research is a well employed strategy. Students can overcome feelings of guilt and rage against relationships of power when they maintain some of the control. Similarly, when they are working on their own projects or inquiries, drawn directly from their own living practices, they find it hard to show helplessness. However, some students fulfilled their learned helplessness prophecies by not getting started early enough. And finally, as students were operating in an open spaced project 
with responsibilities to the group, my teaching philosophies didn't impact their experiences as much.

Some students still only interacted with the possibilities of this transformative pedagogy at superficial levels. Their resistance to change was fascinating. Often they would rant and rage; only to have other classmates offer different discourses. I maintained a level of support for the process and left the content to the students (however, offering assistance where I could). However, I felt that some students maintained their resistances and although they produced a great project and enjoyed obvious success in with the pedagogical strategy, some were just not convinced that change was required by them. I wonder at these individuals' ability to not take action personally when a social crisis (or environmental crisis) is looming around them. How do they remain so oblivious to their complicity in these problems?

Shunyamurti (2009) explains why many cannot see that their living practices are contributing to environmental degradation and social crisis. He calls this a 'passion for ignorance', suggesting that "[i]t's not that they cannot see, it's that they will not see" (0.05 mins.). Stemming from a Buddhist belief, the ego censors the flow of knowledge and understanding where the agendas are not self-serving. The result is that we can't receive all the available information and we, instead, live in egocentric 'fantasy'. Such passion for ignorance is maintained by the unconscious mind where there isn't the strength or will to go outside of the ego's patterns. The ego does not have power to invest in change and it is this weakness of the ego that is the problem. Even with moments of clarity and understanding, old patterns are taken up again due to this weakness. People are then stuck and unable to come out of denial, until they hit bottom and have no choice but to begin to see their stuckness and start to rebuild their lives with awareness of how the ego manipulates. Most 12-step programs utilise awareness that comes from hitting the bottom as a starting point for individuals to admit they have a problem and to begin to re-build their lives without the self-damaging practices. Perhaps the 12-step program offered in this work also requires a similar kind of awareness.

Britzman (2000) uses the term "passion for ignorance" from Lacan (1998) where he suggests that we have a passion for three things (love, hate, and ignorance) (p. 106). Exploring this term within an education context we can ascribe a passion for ignorance 
to students, teachers, and to the system itself. Britzman offers a paradox, which seems deeply concerning and somewhat unknowable.

The wager for education in the professions is whether we can stand the ideas and feelings made when ignorance takes its own novel time, not as passion for itself, not as narcissistic defense, and not as disclaiming affect and our impressive subjectivity. Rather, what if our education helped us understand ignorance as a condition of not actually knowing. The paradox is that not knowing can be represented through the wandering mind and the unconscious, which opens a potential space that our instituted education, in its own passion for ignorance, more often than not, fears and even hates. This is education's secret narcissism. (Britzman, 2000, pp. 147-148)

As far as understanding anthropogenic (human generated) environmental and social issues, I believe that there are not many (if any) western society members who could claim an actual 'not knowing' of these issues. Similarly, linking the personal practices of living our societies excesses that drive consumerism to the environmental and social issues seems like an easy thought process. Yet there seem to be many who could claim a passion for ignorance through their lack of preparedness to change their own life choices towards those that are more sustainable and more critical.

Norgaard (2011) used the term "double bind" suggesting that the information is not rejected, yet it is not integrated into the everyday life, rendering the transformation of this information into social action impossible. This situates the opportunities for education differently. No longer focusing on information transfer and awareness raising, now environmental education can focus on activism or action orientated learning which supports the transformation of our awareness into everyday discourses (as Gore's Climate Change Project called for).

Throughout my research this experience was reiterated. Students offered resistance to undertaking personal change. These resistances manifest in different ways for each student. Some required more individualised support to find their way. Others relied heavily on the scaffolded 12-step process to guide their journey. A few undertook projects of change that were not deeply troubling of the larger issues, therefore reducing their embodied experience and potential for success in really effecting change. Happily, none were lost along the way and even the students who expressed their concerns, claimed they couldn't find the connections, and complained in general, found ways to 
bring about change in their practice and demonstrated increased awareness leading to action in how they could live more sustainably.

The personal agency demonstrated by these students produced fascinating results. Many learned to see the dominant discourses, feeling them rub up against their newfound understandings of over-consumption, for example. Many also connected that these discourses are generated by our societies to give permission to the practices of living in excess. However, the pedagogical strategy, the ALGP, gave these students protocols to work through that delivered a capacity to resist and, ultimately, change the dominant discourses. The alternative practices empowered an alternate discourse that permeated their families and friends and, therefore, societies.

Lather (1991) asks:

How can we position ourselves as less masters of truth and justice and more as creators of space where those directly involved can act and speak on their own behalf? How do we do so without romanticizing the subject and experience-based knowledge?... [M] any do remain ensnared in and constituting of disempowering frameworks of meaning. The best solution I have been able to come up with is to position intellectuals as other than the origin of what can be known and done, some positioning of ourselves elsewhere than where the "Other" is the problem for which we are the solution. Such a "solution" accepts the importance of specificity in critical practice. Situated in locatable, embodied critical, cultural practices it probes political conditions and circumstances in a way other than ideology critique. (pp. 137-138)

The challenge to teach against the grain continues. My desire to provide students with opportunities to take personalised action that leads to social change remains strong. While I might not practice living critically to perfection at every step, I simultaneously wonder if anyone could. The least I can offer is to position my own practice as an embodied example upon which my students can bounce, build, correct, and challenge.

I suggest a new framing for environmental education, not a new name. Sustainability education or education for sustainability: neither really matters, as it's what we do with it that counts. Framing environmental education as a critique to education and our social systems can become transformative education. Using critical pedagogies to bring real life challenges to our student teachers offering them opportunities to examine aspects of how they choose to practice living and their worldviews that might lead them to embody change towards greater sustainability is a 
worthy goal. Action orientated pedagogies brings this opportunity to student teachers and provides them with 'do it on Monday' strategies that might just change how they see and can be in the world.

Of course, this is all fine in theory, and fine in aspects of practice as well, yet the positivist frames of the university work to maintain and undo much of the good work possible through alternative discourse education. Student expectations, grades, and learned helplessness are often reified through the education courses rather than challenged. Ultimately a university education should have the ability to reveal alternative discourses to those the students enter a course believing. The requirement here is that students can allow such change, or, at least, be open enough to participate in it. My experience suggests that some are and some are not.

Student expectations of instructor performance, time commitments, and action orientated learning vary. The environmental education course I taught had high expectations of all three, and more. With six hours of class time per week, I spent considerable time scaffolding the main themes, which related closely to the evaluation strategies. Students were also given time to work in groups and on projects during classes. This was appreciated although not always well utilised, in my opinion. Practicing critical reflexivity, I could have offered more concrete and discrete learning strategies enabling students to feel shorter term success at the completion of course outcomes.

Evaluation strategies seemed to cause considerable stress. Planning towards step-by-step achievement or chunking of the evaluations was not always well implemented by the students. The resulting crunch and anxiety often caused tensions to rise between students and myself. I could have done more to implement deadlines that scaffolded the students' progress more; however I worried that such micro-managing would hinder the creative process. Practicing critical reflexivity, I would now change to create these deadlines, through negotiation with the students.

It is a shame that grading causes such tension. Ifound that the classes were engaged and friendly right up until the first due date. At this point stress and fear of the unknown took over and unreasonable behaviour often followed. Practicing critical reflexivity, I could have staggered the due dates more effectively. Giving the students 
familiarity in experiencing negotiated curriculum and evaluation would have provided comfort to some students.

It seems odd that in a course that was attempting to critique education I was constrained to offer grades based on a bell curve. I was given a prescribed course average that had to be achieved as an effort towards grade comparability. Knowledge of this grading system caused students concern, I believe. It ensured that the evaluation tail wagged the curriculum dog - so to speak. Practicing critical reflexivity, I could have spent more time explaining how this system worked and providing successes earlier in the semester would have demonstrated my intentions in the evaluative process.

I would also reconsider the evaluation strategy for the ALGP as I am no longer convinced that group evaluations are appropriate. I believe that group work is useful in actively teaching social learning and cooperative strategies; however evaluating one students learning when it relies on the achievement of other students is not fair practice. Alternatives exist and could easily be explored.

With these tensions limiting the goodwill between students and instructor, effective work towards changing discourses became muddied. Students required an open, trusting environment to begin to explore their worldviews and values. The tensions that arose around evaluation damaged feelings of openness. Practicing critical reflexivity, I would have worked harder to ensure these particular tensions were minimised.

Finally I believe that the students' had little experience in the classroom and were constantly worried about how to cope on Monday and not the bigger picture of what is the purpose of education. I understand these tensions, and share the students concerns. Practicing critical reflexivity, I could have balanced these conversations with greater clarity, aiming to provide a mix of both bigger picture discussion and troubling and specific activity based strategies. I believe I worked towards this balance; however I wasn't explicit about these intentions. Using current education theory would have supported the students to understand that I was operating based in theory and not just as a lone maverick.

The aspiration of this environmental education course was to provide opportunities to critically reflect on education, to embody transformative education, and to undertake action orientated learning. With greater awareness and deeper perspective 
I critically reviewed the pedagogical decisions made for my students to undergo transformative education experiences. The students' responses revealed a range of themes that acted as resistances and encouragement for my teaching and learning practice, as well as for their own practice. The 'so what' is that theoretical support was necessary for me to come to know why I desire to teach and learn the ways I do, to challenge myself, and to find new ways of being and performing 'embodied, intentional educator'. It was the searching for undergirding theory that enabled my practical development, yet it was putting it all into practice that created change.

Walking the talk in environmental education means that I am able to model some action towards finding alternatives to the dominant discourses as well as navigating the educational systems in this learning institution. Awareness of the discourses is where change begins and through the experiences of teaching this course I gained experience in these discourses, effected some change, and enjoyed some small successes. There is much more to learn and I look forward to opportunities to continue to trouble what it means to educate with, through, in, and for the environment.

Environmental education, in most education systems, doesn't fit into any subject area in entirety, and neither should it, I believe. It seems that many recently revised curricula around the world are choosing to use the ideas expressed within environmental education as foundational or overarching themes underpinning the entire curricula. The Western Australian Government, for example, situated 'environmental responsibility' as one of the five core shared values of the Curriculum Framework during its most recent curriculum reform (now 15 years ago). Thus twenty percent of all lessons taught in all learning areas addressed the enactment of values and action around the environment (Curriculum Council, 1997). A lofty goal indeed, and one that can be supported through appropriately focused teacher preparation programs. 


\section{Social/cultural change: Ecofeminist activism.}

Silent Spring set the template for nearly a half a century of environmental writing: wrap the latest scientific research about an ecological calamity in a tragic narrative that conjures nostalgia for Nature while prophesying ever worse disasters to come, unless human societies repent for their sins against Nature and work for a return to a harmonious relationship with the natural world. (Nordhaus \& Shellenberger, 2007, p. 130)

Unfortunately the discourse around environmentalism seems polarised: tragic and terrifying eco-apocalypse narratives on one side and overly positive proactivity and survivalism on a small scale on the other. "For the most part, these environmentalist cautionary tales have had the opposite of their intended effect, provoking fatalism, conservatism, and survivalism among readers and the lay public, not the rational embrace of environmental policies" (Nordhaus \& Shellenberger, 2007, p. 131). The public may not be in denial, or acting irrationally, and the lack of change doesn't reveal a darker side to humanity such as a "disregard for nature" (p. 131) or a "lust for power" (p. 131). Humans always aspire to change their environments (Nordhaus \& Shellenberger, 2007, p. 135) creating comfortable shelter and regular food supplies, as do beavers. We are not an unnatural part of the system; however I believe that we are taking advantage of the Earth systems to a dangerous extreme and this is why I name the 'issues' we are currently experiencing as social and not environmental.

With a change in social/cultural discourse, education may undergo a change towards a more sustainable education (a system that teaches and models sustainability and living critically). Huckle (1999) suggests that sustainability education is "a process of critical reflection and action on those forms of technology and social organization that may allow us to live sustainably with one another and the rest of nature" (p. 38). And 
this, as Berry (2003) suggests, makes 'sense' not 'cents' and will involve each of us taking responsibility for our choices and their implications.

Saylan and Blumestein (2010) suggest that taking action towards living in sustainable ways is often missing from environmental education programming and that awareness raising about the physical environment is not enough to bring about the societal change considered necessary (p. 2). They also suggest "real change will require a shift in global consciousness and consumption patterns beyond the scope of the individual action" (p. 96). And I agree, however, shifting global consciousness has to begin with a few and then exponentially move to many. Perhaps environmental educators could be one group leading this call to change and modeling how to make these changes in our daily lives as we learn to walk our talk.

Robinson (2011) talks about bringing cultural revolution to and through the education system. Over the last decade he suggests that the system has become less personal with an increasing focus on standardisation. He goes on to suggest that education needs to become more personalised, where students are supported to focus on their interests, to a greater extent. Developing this level of personalisation reminds us that teaching is an art form, not a delivery system.

Education change needs to lead us to a place where the experience is customised for students with a focus on their needs, interests, local communities, and local environments. The concept of nationalising the curricula and implementing standardised testing seems to be a backwards step as described by Robinson (2011). He suggests that this offends the notion of valuing diversity, something that will enhance our communities in the same way that diversity in species enhances ecosystems. One way to consider moving forward with these ideas is to work in partnerships within our communities. 
Broadening the concept of educational community to embrace a diversity of local individuals, groups, organisations, centres, and other possibilities could bring greater richness to what a school system can offer its students. Finally, Robinson (2011) suggests bringing the curriculum into balance where the educational experience of our students can be transformed into a process that supports the rich development of future generations.

As shown through my research (personal change and transformative education), efforts were made to bring the content and process of educating others into a more personal realm. I needed to embody an experience of successfully living within society and living with a conscious practice that resulted in a lower ecological footprint, that enabled intentionally at being able to practice environmental education from a critical ontological place. I needed to be able to consider and change my educational practices so that they were informed by my worldview and through my epistemologies. This took time, consideration, practice, and support from critical friends and students. I believe that I have made a shift towards a more personalised style of educating.

Many challenges still exist! I have myself in a place of experience and confidence, yet I find that not all students are able (or willing) to come along with me. Similarly, not all colleagues believe in the work I am doing. And finally, many friends and community members don't see any need for changing what doesn't seem to be broken. Coming to understand why others can't see the issues and take action towards different potential outcomes brings peace to my teaching practice. Understanding why change is so difficult for some encourages me to be patient, to continue to support and scaffold, to maintain my own practice, and to keep the conversations alive. 


\section{The 'so what' of change.}

At a conference recently, I offered a presentation titled "Do you walk your talk? Intentional EE practice" (White, 2010). I scored the last time slot on the second last day of the conference, yet, the room filled to beyond capacity. For 45 minutes I presented and for another 30 minutes we discussed, going beyond the allotted time slot. We were transfixed by the ideas of how to be transformative in our practice, how the idea that we could walk our talk could be socially transforming. We discussed practices, the effects of these, and the transformations that unfolded around us. We felt invigorated, responsible, and motivated towards more action. Challenges were discussed and possibilities for action arose. It was the most rewarding presentation experience I have had in a long time.

The experience described above reminded me that we are in community and sharing our personal narratives is necessary work (and a fundamental part of activism). Enjoying our successes, unpacking our challenges, and finding ways to move forward together, supporting each other is how we transform systems and societies. Ideas are generated and shared and manifest into further ideas: this grows and spreads and brings change. As such, conference gatherings, articles, websites, resource sharing, books, and the list goes on ... are methods that can progress the conversation and maintain movement towards more sustainable practices and critical living.

The original definitions of environmental education call for action, and I found that through undertaking my own action learning projects I came to know in ways that surprised me and continued to inform my practice. My embodied knowing was key to transformative education. Finding ways to support students to take action and then share their findings (possibly under the guise of activism) is transformative to these students and, likely, also to the audiences.

Creating a culture of possibility and questioning through action, leading to change and cultural revolution, is our job as educators, in my opinion and experience. Bringing education back to the personal experience through supporting all students to explore their own passions and challenge their cultural norms can lead to cultural revolution, and with guidance from experienced practitioners perhaps this will lead our society into greater sustainability and criticality. It's time to walk our talk! 
I can only change myself. My desire is that through my position as an educator and social activist I will be able to positively influence others to re-consider their own practices and to make change themselves. I want to call this work activism; however I realise that this is a somewhat contested term. I will continue to work at redefining this term and hopefully, in time, activism will be more broadly applied. I hope to tie the concept of activism to thinking outside the box, or removing the dominant discourses and socially constructed notions of what is ok.

This is not selfish action. It is action with a desire to influence others. Similarly, this is not indoctrination, as it requires critical engagement with ideas and seeking of alternative discourses. Taking action is a community act as much of the limitations to practicing critically and with sustainability in mind is limited by what our society is practicing and how the infrastructure is organised. Both of these can be changed, when there are enough individuals to bring that about.

The first steps involve raising awareness of what is possible. I hope to model some ideas, talk about others, and build communities that struggle to continue to challenge and change how we exist in western society. The second step is to take action so that others can see the implementation and the results. This is where working in community is wonderful as conversation and multiple thinkers can reflexively generate change.

The largest struggle in creating sustainable change is the inevitable fight against individualism. Western society seems to have developed with an attitude that encourages individuals to look after themselves. Once we move to a more community based model change will follow the new dominant discourses and bring greater sustainability.

If the discourse could embrace community support, shared responsibility, local economies, and local governance then our food systems could change, our transport systems would change and this would be a great start. I'm not suggesting a retreat to living standards of the 1950s as that would be counter-intuitive (and futile) with the current technology. However, I believe that with careful, critical use of resources, including sharing resources at the local level, the needs of individuals would be decreased and become more community focused. The benefits of this practice could be wonderful. The basis of the change becomes self-care within community. 


\section{Chapter 6. Conclusions}

Your beliefs become your thoughts Your thoughts become your words Your words become your actions Your actions become your habits Your habits become your values Your values become your destiny Mahatma Gandhi

\section{What Have I Learned?}

Understanding my (co)construction, as it has been, and continues to become, has provided a reflexive space where I dwell in the present while being fully aware of the past. Being connected to my worldview and understanding the implications of these beliefs has enabled an awareness around how I make choices. Valuing my ecocentrism, where I recognise my place within the earth systems, provides me with a solid grounding. From this place of knowing I can make informed decisions.

Living with an ecocentric worldview doesn't mean that appropriate choices come easily. Each choice brings implications for Earth systems. Taking time to make informed decisions where the implications are investigated and compared allows for some level of conscious choice. I developed a decision making process that supported taking time to come to practice living more sustainably, critically, and with 'enough'.

Changing my living practices took time. I used tools like the ecological footprint calculator (Royal Saskatchewan Museum, 1999; Wackernagel \& Rees, 1996) to come to think differently about how I was practicing living. I took time to learn with others, especially my students, sharing knowledge and taking heart in our communal desire to 
live with 'enough'. I practiced ecofeminist activism as an educator and leader, sharing my learned skills and beliefs with others.

My personal living practice grounded my professional educational practice. I was able to speak from an embodied place resulting in students feeling supported to (re)consider their own practices, rather than judged. I renamed my practice to that of living critically as I believe that it is critical consideration that comes with an inbuilt desire for change towards greater sustainability that is important.

I believe, as do others, that we are not talking about environmental issues. We are, in fact, describing social issues. Much of what is 'of concern' in out environment is anthropogenic, or human generated. Interestingly, environmental education came out of the late 1960s when point source pollution was generating human health concerns. Now the issues are often of global context rather than specific in location; however human involvement is still fundamental to the issue. For this reason I believe that naming the issue correctly will support western society to take responsibility and, hopefully, learn to take action.

Change is constant in our society. We see it each day as fashion or technology offers new and exciting options. Change can also come through education, mandate, or crisis. Education works for some, as does mandating change. However, crisis will be the inevitable result of western society inaction towards becoming more sustainable. In many ways I look forward to this time.

My autoethnographic self-study enabled me to explore my personal, everyday, experience of teaching and learning through critical, ecofeminist, and poststructural framings. In this research I was able to position myself with theoretical grounding that helped me realise that although I am changing within, making efforts to adopt new ways 
of being as an educator, and considering many and varied interests and opinions in my practice, I was never breaking ground completely. Someone 'out there' had my back and could help me understand my experience more deeply. Through conducting, analysing and writing this research I have learned about the processes of research but also the importance of embodied practice and that the doing part of research is as important as the theorising.

I discovered that resources that scaffold and support through a step-wise process are useful as tools to engage learners. Often undertaking a change adventure is difficult without some structure to cling to. One of the most valuable resources is experience. The resource I further developed has been adapted and is provided in an open, online source. Sharing learning through community is good learning and practice. Working in community means sharing and taking responsibility, at the same time. Opportunities for undertaking leadership are found. Becoming a leader is a great learning experience.

Activism has become a way to effect change. Although the title (activist) might be difficult for some, I seek to reclaim it for "good". Practicing with intention and making the effort to share the learning: activism.

I conclude with feeling good about how I have come to live within my society without being constrained by their practices. Thinking for myself and wanting to do things for myself doesn't mean that I don't rely on others or lack trust in my community. It just means that I want to accept responsibility and share my part of the load. I don't buy into the convenience of having someone else do it for me, or the consumerist option of paying instead of doing. I am proud of who I have become through this work and in this work. 


\section{Theoretical grounding: What did it allow and disallow.}

In the following I address the theoretical and methodological framing used in this research, describing how it was most useful. Then I review my privilege, assumptions, and the goals of the research.

I considered ecofeminism, critical theory, and poststructuralism to undergird my thoughts about how I take up and practice environmental education. The benefit of these frames was the language they offered me to express my ways of knowing and being. I came into this research with ideas about what I wanted to investigate, yet it wasn't until I learned the language that comes with these frames that I could begin to articulate my desires in ways that others could comprehend and that I could seek support from the literature. Discovering this 'new' language at such a late stage of my life was unraveling and invigorating, all at once.

Similarly, I found the conversation and support available through research writing new and exciting. I engaged with literature prior to starting this program but becoming so immersed resulted in my experience being one of ongoing conversation. The support I could draw from these conversations, even though they were one sided, was supportive as it enabled me to compare, contrast, and consider my thoughts and actions as though I was in consultation with the authors. I loved the support that came from theory almost as much as I loved the challenge that came from doing.

Exploring ecofeminism and its critiques enabled me to understand how I am often positioned as other or less than in my own society in similar ways to how the environment is often positioned as a resource to be used and exploited. I valued the opportunities to experience this new North American environment with reverence and joy and I took notice of how others didn't. I became active around some issues, as I believe this is part 
of being an activist. Additionally, the critiques of ecofeminism reminded me to not fall into the motherhood environmentalism notions so often confused with useful ecofeminism.

Through ecofeminism I became aware of my ecocentric worldview. I realise now that I am quite extreme in my beliefs around how humanity should be positioned within the Earth systems. I want to see change towards a greater acceptance of our place as part of the Earth system, not as dominator or user. I continue to find ways to explore my ecocentricity and to share my thoughts, as they are often alternative to others. I find that sharing an alternative to the anthropocentric way of viewing the world can be useful in opening up possibilities for others to explore.

Ecofeminist activism (Cuomo, 1998) provided direction to my activist desires. With a thought to the precautionary principle that encourages pause and contemplation before surging ahead with environmental use (or abuse); however this is not often implemented in western society, unfortunately. Applying this framing to notions of activism often gave me pause to critically consider if my position or actions were going to cause harm or the intended good for the environment of concern. Additionally, the frame of ecofeminism applied to activism made me feel less alone in my struggle to raise awareness and generate action towards living critically and with greater sustainability.

Ecofeminism is not without critique and exploring the critique deepened my understanding about how I could find usefulness within this theory. I didn't find a sisterhood of 'tree-huggers' as might be a more popular belief of ecofeminism. I found a careful, critical, articulate conversation that brought theory together with practice with awareness of embedded assumptions that demanded activism in multiple forms. 
Critical theories supported my desire for change and enabled greater understanding as to how to go about achieving this goal. In critical theorists I found careful academics that presented well-considered arguments. Colonisation of our cultures and environments is still rife and it is OK to work towards creating change. Critical theorists are leading change in many areas of education; however not so much in environmental education. I believe there is much to be gained from these theoretical frames. I found that by including critical theory in my framing I was constantly reminding myself that I was working towards a bigger picture, one that desired societal/cultural change, or revolution (as Robinson, 2011, names it). The inclusion also granted permission for me to change my practices and worldview, or at least come to know them through a shared language.

Critical pedagogies applied the theoretical desire for change as they offered students an opportunity to re-think their worldviews through taking action. I learned that there was a name (critical pedagogies) for the type of strategies I like to use in class, which opened up a realm of literature to extend and support my educational desires. Critical theories and pedagogies are not prescriptive and do not address issues specifically, as they encourage perspective and worldview examination.

Poststructuralism supported me to see differently. I learned to use a different language that more precisely enabled questioning of the dominant discourses, to view power as limiting and enabling, to deconstruct binaries that seem so prevalent in western society, and to disrupt and provide pause for reconsideration of ideas and practices or to re-inscribe or re-iterate ideas or practices. Poststructuralist theories challenge me to reconsider what I can really know and suggest that constant interrogations and willful contradictions are the work I must do. 
I didn't find poststructuralism took me to the point of nihilism and inactivity although this has been a constant critique. I chose to find the usefulness of these theories and put them to work for the betterment of my practice and my understanding. I really enjoyed the freedom that came from understanding social constructionism, dominant discourses and binaries.

From the support drawn from these three theories I believe I forged a crucible of change, agency, and activism for myself as an educator and for my students. I learned new languages and possibilities. I gained clarity and support for ideas through others scholarly work. The use of these theories has delimited my research, supported my desires and generated success in my work.

\section{Methodological grounding: What did it allow and disallow.}

Methodological framings of autoethnography and self-study resulted in this research being a well grounded, exciting, useful. In the same way that theoretical framing delimited and supported this work, the methodological frames provided guidance and grounding as to how the research could appropriately be conducted. The methodology choices were made to push me in certain directions as I was planning and conducting this research. These will now be discussed.

Choosing autoethnography as opposed to autobiography meant that each time I though about my actions I had to place them within the appropriate cultural context. This was important in my research, as I was not a maverick doing what I pleased; I was using my culture to construct and design a path forward. I wanted to remain within my culture to attempt to lower my ecological footprint so that I could prove it could be done, experience success, and model the potential for change to my students and others. 
Operating from a cultural place as opposed to a personal place meant that the decisions made to decrease my ecological footprint and to live more critically and sustainably came from socially or (co)constructed beliefs and practices.

I didn't experience any limitations with this methodology; however I would have liked to have done more with representation and may do so in the future. I believe that performance autoethnography could be a valuable methodology in prompting others' selfreflection leading to changes in practice. I look forward to exploring options.

Self-study is a specialised methodology that was well suited to conducting teacher education research. Based along the lines of action research, self-study enabled me to gather support to analyse and consider my teaching practice as it unfolded throughout the semester. I felt prepared to teach and supported as issues arose and successes resulted. My critical friends and student focus groups provided alternative context to my own reflections. Self-study enabled me to remain focused on the processes of teaching and to not get lost in the content.

\section{My privilege.}

As previously described my privileges can be named in the following ways:

- White skin entitlement

- Middle class positioning

- International perspectives and experiences

- Focus and time to devote to the development of these intentional practices within the privilege of taking up self-directed work

- Graduate student status providing institutional resources, support personnel who encourage, scrutinise, and offer advice and direction. 
As I spent more time in North America I found myself adapting to cultural specifics of Canadian lifestyle. In some small ways I felt what its like to be othered due to my different (non- North American) cultural background. Similarly, as I became more familiar with the university context, I found that what I could and couldn't achieve shifted and generated a greater desire for change and to engender awareness with action.

I have learned to live without many of the excesses that so many members of western society accept as their right. And this embodied experience provided great insight into how those who live without western societal privilege may feel. I found the experience freeing, which reifies my privilege as I experience this lifestyle as a change and not as the only way possible. If I chose to I could easily revert to living in excess. I am confident I won't, as I have no desire to; however the underlying knowledge that I could changes my experience. I am also conscious that when it suits me I can use (and occasionally do) the excess of my society to my benefit. Acknowledging this as a privilege encourages me to remain vigilant and to appreciate my position. It also reminds me to share my good fortune as often and as much as possible.

\section{Research assumptions.}

The following assumptions articulate the place from which I began and they have not changed throughout:

- My living practices must embody environmental consciousness to be an intentional environmental educator (walking my talk at the personal level);

- The dominant discourses around environmental education tend to trivialise and undermine what we can achieve through or even talk about in this field; 
- Becoming an 'intentional practitioner' involves: education, activism, and research; theory and practice; praxis; there is no public/private division in this work;

- An educator is always performing. My research works to bring intentionality to this performance in a way that students can see themselves reflected and feel encouraged to bring a level of consciousness and accountability to their own practice, and ultimately that of their students.

These assumptions were considered as I moved through my research. I have not added to them; however I have lived through them. Learning to live critically with aspirations of becoming more sustainable was more difficult and all consuming than I thought it might be. I enjoyed the challenges and took them on wholeheartedly. Learning to see and feel the dominant discourses came with considerable repercussions. I was often quite disconcerted by the dominant discourse, confronted by how privileged and selfperpetuating it was, shocked at the excess and waste involved.

\section{Research goals.}

The goals of this research were attained, mostly. The following is a brief reminder of these goals and a succinct referral to their achievement.

1. Deconstruct my environmental identity, subjectification, and positioning with clarity and depth discerning the disciplining dominant discourses providing awareness within that facilitates confident disruption and positive reinscription for myself and, ultimately, others

Using autoethnographic self-study methodologies ensured that, as the researcher, I was deeply embedded within this work. I have taken up the struggle to articulate how I came to practice environmental education, focusing on my (co)construction through the many discourses and experiences. In this retrospective I provided clarity and some feelings of self-confidence. I adopted a position with my personal practices, providing a 
platform upon which I could stand in my educational practices. I used my personal experiences to position my teaching practice. Experiencing dominant discourses as they played out in front of me as I bumped up against them was difficult at first, and as I learned appropriate ways to maneuver around them I felt less troubled and bumped less. I took solace and advice from my colleagues and learned to embrace small successes. This success fueled my enthusiasm to continue, attempting greater challenges, which, ultimately, led to greater success. The cycle was cumulative and self-perpetuating. From here I realised the value in scaffolding and developed decision making processes for myself which led to working on pedagogical strategies that would support others. The experiences of doubt and anxiety were particularly useful as many of my students and colleagues expressed similar emotions at times and having my own embodied experiences to draw upon was valuable.

\section{Practice living sustainably within my society; watching critically as to how I come to perform 'intentionality' in my environmental education, activism, research}

I changed how I practiced living to reduce my ecological footprint from 16.4HA down to 1.8HA. This took energy and effort to rethink how I was making decisions and what ethical groundings and worldviews I embodied in each decision. I lived within my society (not removing myself from the obvious structures and systems). I didn't stand out as someone who practices differently; I am not visually obvious, nor do I practice living so differently that I am recognisable. I believe this is necessary when encouraging others to consider taking up a critical living practice. The stigma that can be associated with seeming different would have provided an added distraction. I learned from my students as they pushed practices that I felt unwilling to push at that time. I learned from my 
colleagues as we worked together supporting each other in our desire to live critically, with intention, in an embodied way.

Seeing my work as ecofeminist activism brought a stronger aspiration for success and deeper understandings as to the potential for this work. To be an activist seems to imply having a community to be working with. I really enjoyed finding and developing relationships within my communities. I undertook active roles within each organisation and performed "active member". I also explored positions of leadership and undertook a variety of opportunities as they arose.

Having the grounding and support that comes from undertaking research as part of a program within an institution (university), was invaluable. The time to deeply immerse myself into the Faculty of Education at the University of Regina enabled me to see different ways that this research could unfold and take a stand. Through this connection I took the opportunity to teach courses in environmental education, developing a connection with students who would be future teachers. I was able to design my research in such a way as to explore this relational connection, which resulted in a wonderful realisation that teaching teachers is something I want to undertake in the future, continuing to develop my practice as an environmental educator and transformative educator.

3. Using the work from 1 and 2; (re)focus my performance as 'educator' towards a critical ecofeminist poststructural environmental educator, activist, and researcher employing critical pedagogies and transformative strategies, specifically with pre-service education

Coming into this graduate experience as a professional in my field with many years of experience was unnerving. I discovered different ways of seeing, thinking, and speaking. I loved the passion I found for coming to know my colleagues and myself. 
Mostly, I relished the opportunity that I was afforded (through my privileged position) to embody different ways of knowing and being. I became an educator, researcher, and activist through this work. I also became a practitioner who performs education with passion and persistence, walking their talk.

Critical, ecofeminist, poststructural framings gave me a language through which I could see the world differently. These framings also provided a starting place, as there is just so much worthy work in education, having a focus proved useful. Through immersion into these frames I found colleagues who pushed me further in my thinking and action than I imagined possible. Instead of relying on what I, alone, could know about my educational practices, I now called upon and drew support from many others who were similarly framed. Occasional bumps against practitioners who operated within different framings also proved to be a rich experience as these challenges were explored and unpacked, often resulting in a deeper understanding.

Pre-service education is rich with learning and possibility. I feel excited about a future engaging these strong minds in the challenges of our times, supporting coming to know and understand differently, and taking action towards a more sustainable future. Critical pedagogies and transformative strategies are engaging as they bring about awareness through action and work towards creating cultural change (or cultural revolution as Robinson (2011) names it).

\section{Develop some of these pedagogical and transformative strategies to a refined level where they can be implemented in classrooms with appropriate resources}

Once I discovered how difficult it was to begin to practice living critically, I realised that this self-practice and embodied recognition of these difficulties was an 
important part of my journey. I created strategies and protocols around how to move forward. I used my colleagues to hold conversations that would inevitably move me forward in my own practice. I read others experiences and gleaned other ways of practicing. I became more observant and critical of many accepted societal practices. All of this became apparent through reflection. At this point I realised that if I required these many and varied supports, my students would need the same: I began to theoretically investigate my pedagogical strategies.

Transformation comes when a student accepts the concepts or protocols from a learning experience into their own lives, taking it on as their own, becoming something more because of the learning experience and wanting more for their future experiences. I embodied the process and because of this I wanted to reconstruct learning opportunities that enabled others to experience similar transformations. I discovered a process was necessary, as were resources, conversations with peers, and additional support. This is how I developed my curricula and engaged my class.

The action learning group project (AGLP) started with a resource I discovered through conversation. After exploring its use with my classes I began to see how I could successfully adapt it. From here I refined the resource to suit my own thoughts and desires for my students. Finally, I made this resource easily available by setting it up as a web-based resource. I have since used this resource with a variety of students (undergraduate and graduate) and have had great feedback about the process and the presentation. Students also report that they have used this with their classes and enjoyed success. 
5. Using work from $1,2,3$ and now 4 ; practice and perform activism in my community through working with environmental education organisations taking up opportunities for leadership that will facilitate a change in discourses

In addressing this goal I offer one example. In 2006 the Saskatchewan Outdoor and Environmental Education Association (SOEEA) was looking for a president. I was new to Saskatchewan and looking for some community to join. I took on the position, with some concerns; most notably that I was Australian and only here for a relatively short time (or so I thought). And I am glad that I did. I had the privilege to lead this organisation for three years rejuvenating many aspects of its operation. I now enjoy watching SOEEA move into a new era of leadership and continued success with power, enthusiasm, and skill.

SOEEA operates with a new agenda, a revamped vision, mission, and goals, and is actively taking up opportunities to generate leadership and change. The infusion of critical ideas and actions that came from my experiences with pre-service educators led to the development of much of this work. Such a personal positive experience serves me well, as I will continue to look for opportunities within organisations and communities where I can use leadership positions and my developing skills to bring about change.

\section{Applications For This Research}

As mentioned already, pre-service educators passing through my class, experiencing the critical pedagogical strategies and the Action Learning Group Project, and finding success with it, have taken these resources into their own toolkit and used them, or aspects/adaptations of them, with their students. This includes the ALGP, some other pedagogical strategies, some of the community building and relational strategies, and many of the resources. The interest and ability to take these activities and resources 
to use and share them is demonstration of there perceived worth. The ability to adapt these strategies and resources demonstrates a deep understanding of the strategies and their usefulness. Many students stay in contact with me explaining how they have adapted and used these resources and I find this conversation particularly useful in developing further instruction and learning opportunities.

During 2011, a representative from the Saskatchewan Institute of Applied Science and Technology (SIAST) contacted me. He had been tasked with rewriting their environmental education course, which sat in the first year of their Recreation program. After offering a description of the ALGP and how it was positioned within the course including some details of the additional pedagogical strategies, SIAST requested permission to use all the course materials. After negotiations it was agreed and my Environmental Education curricula with the ALGP was to be adapted slightly and established as the Environmental Education 151 course to be run by SIAST in 2012.

\section{Maintaining The Wonder}

My research journey has been an intense seven-year adventure. The thesis undergirding this work is that embodying change and the practice of taking intentional action allows for different ways of coming to know and be in this world. As an educator, the successful experience of living more sustainably and critically within our society positions me as a reliable example, source of information, and emotional support to others wishing to change their practice. Developing pedagogical strategies that support individual learners to (re)consider their own living practices provides scaffolds and support that enables the most resistant to achieve some success. Working to embody a lifestyle choice, like living with 'enough', while working as an activist sets a precedent 
and paves the way for others to continue this work, and to take it forward, developing further ideas and actions. This ensures and supports the development of community.

I have been transformed, as has my practice, and my future. These adventures have served me well and I have great gratitude for those with whom I shared the learning. As we move forward together the lessons learned radiate into further networks. I look for community as conversation and fellowship is a rewarding way to learn and take action. I attempt to walk my talk and believe that most students respect embodied, intentional educators. I believe that taking action can lead to transformative learning, yet requires scaffolding and support. Reflection on the journey serves us well as remembering keeps the learning alive and real. Continuing the curiosity for better, different, and other ways of knowing and doing will push us onwards: living the becoming.

\section{Best wishes for a sustainable future!}

"The story never really begins nor ends, even though there is a beginning and an end to every story, just as there is a beginning and end to every storyteller" (Minh-ha, 2009, p. $1)$. 


\section{References}

Activism. (n.d.). In Merriam-Webster online dictionary (11th ed.). Retrieved from http://www.merriam-webster.com/dictionary/activism

Apple, M. (1996). Cultural politics and education. New York: Teachers College Press.

Apple, M. (2007). Afterword. In A. E. J. Wals (Ed.), Social learning: Towards a sustainable world (pp. 507-508). Wageningen: Wageningen Academic Publishers.

Archambault, A. (1993). A critique of ecofeminism. Canadian Woman Studies, 13(3), 1922.

Barrett, M. J. (2005). Making (some) sense of feminist poststructuralism in environmental education research and practice. Canadian Journal of Environmental Education, 10, 79-93.

Barrett, M. J., Hart, P., Nolan, K., \& Sammel, A. (2004). Challenges in implementing action-oriented sustainability education. In L. Filho (Ed.), Handbook of sustainability research (pp. 505-534). Frankfurt: Peter Lang Scientific Publishing.

Beavan, C. (2009). No impact man: Adventures of a guilty liberal who attempts to save the planet and the discoveries he makes about himself and our way of life in the process. New York: Farrar, Straus, and Giroux.

Berry, T. (1999). Forward. In E. O'Sullivan (Ed.), Transformative learning: Educational vision for the $21^{\text {st }}$ Century (pp. xi-xv). Toronto: University of Toronto Press Incorporated.

Berry, W. (2003). Citizenship papers. Washington, DC: Shoemaker and Hoard.

Bickford. S. (1993). Why we listen to lunatics: Antifoundational theories and feminist politics. Hypatia, 8(2), 104-123.

Bondar, R., Dudar, E., Foster, A., Fox, M., Mahler, C., Schwartzberg, P., \& Walsh, M. (2007). Shaping our schools, shaping our future: Environmental education in Ontario schools. Report of the working group on environmental education. Toronto, ON: Ministry of Education. Retrieved from www.edu.gov.on.ca/curriculumcouncil/shapingschools.pdf

Bouma, G. D., \& Ling, R. (2004). The research process. (5th ed.). Oxford: Oxford University Press. 
Bourdieu, P. (1977). Outline of theory of practice. Cambridge: Cambridge University Press.

Bowers, C. A. (1997). The culture of denial: Why the environmental movement needs a strategy for reforming universities and public schools. Albany: State University of New York Press.

Bowers, C. A. (2001). Educating for eco-justice and community. Athens: The University of Georgia Press.

Bowers, C. A. (2008). Why a critical pedagogy of place is an oxymoron. Environmental Education Research, 14(3), 325-335.

Bowers, C. A. (2011). Perspectives on the ideas of Gregory Bateson, ecological intelligence, and education reforms. Eugene: Eco-Justice Press.

Britzman, D. P. (2000). “The question of belief": Writing poststructural ethnography. In E. A. St. Pierre \& W. S. Pillow (Eds.), Working the ruins: Feminist poststructural theory and methods in education (pp. 27-40). New York: Routledge.

Bullough, R. V., \& Pinnegar, S. (2001). Guidelines for quality in autobiographical forms of self-study research. Educational Researcher, 30(13), 13-21.

Burbules, N. C. \& Berk, R. (1999). Critical thinking and critical pedagogy: Relations, differences, and limits. In T.S. Popkewitz \& L. Fendler (Eds.), Critical theories in education: Changing terrains of knowledge and politics (pp. 45-76). New York: Routledge.

Burr. V. (1995). An introduction to social constructionism. London: Routledge.

Butler, J. (1993). Bodies that matter: On the discursive limits of "sex". London: Routledge.

Carlson, D. \& Apple, M.W. (1998). Introduction: Critical educational theory in unsettling times. In M.W. Apple \& D. Carlson (Eds.), Power/knowledge/pedagogy: The meaning of democratic education in unsettling times (pp. 1-38). Boulder: Westview Press.

Carroll, L. (2004). Alice's adventures in wonderland. (Special ed). New York: Barns and Noble Incorporated.

Carson, R. (1962). Silent spring. New York: A Mariner Book Houghton Mifflin Company.

Chang, H. (2008). Autoethnography as method. Walnut Creek: Left Coast Press.

Cheek, J., \& Gough, N. (2005). Postmodern perspectives. In B. Somekh \& C. Lewin 
(Eds.), Research methods in the social sciences (pp. 302-309). London: Sage Publications.

Cherryholmes, C. (1988). Power and criticism: Poststructural investigations in education. New York: Teachers College Press.

Clandinin, D. J., \& Connelly, F. M. (2000). Narrative inquiry: Experience and story in qualitative research. San Francisco: Jossey-Bass.

Cochran-Smith, M., \& Lytle, S. L. (2004). Practitioner inquiry, knowledge, and university culture. In J. J. Loughran, M. L. Hamilton, V. K. LaBoskey, \& T. Russell (Eds.), International handbook of self-study of teaching and teacher education practices (Vol. 1) (pp. 601-649). Dordrecht: Kluwer Academic Publishers.

Connelly, F. M., \& Clandinin, D. J. (1990). Stories of experience and narrative inquiry. Educational Researcher, 19(5), 2-14.

Cuomo, C. J. (1998). Feminism and ecological communities: An ethic of flourishing. London: Routledge.

Curriculum Council. (1997). The curriculum framework. Retrieved from http://www.curriculum.wa.edu.au/internet/Years_K10/Curriculum_Framework

Darder, A. (1995). Buscando America: The contributions of critical Latino educators to the academic development and empowerment of Latino students in the U.S. In C. E. Sleeter \& P. L. McLaren (Eds.), Multicultural education, critical pedagogy and the politics of difference (pp. 319-348). New York: Suny Press.

Davies, A. (2007). Making classroom assessment work (2nd ed.). Courtenay, B.C.: Connections Publishing.

Davies, B. (2004). Introduction: Poststructuralist lines of flight in Australia. International Journal of Qualitative Studies in Education, 17(1), 1-9.

Davies, B., \& Gannon, S. (2005). Feminism/poststructuralism. In B. Somekh \& C. Lewin (Eds.), Research methods in the social sciences (pp. 318-325). London: Sage Publications.

Davis, W. (2009). A sacred geography. Retrieved from http://www.cbc.ca/ideas/massey.html

Delamont, S. (2007a, September). Arguments against auto-ethnography. Paper presented at the British Educational Research Association Annual Conference, Institute of Education, University of London, England.

Delamont, S. (2007b). Arguments against autoethnography. Qualitative Researcher, 4, 24. 
Delamont, S. (2009). The only honest thing: Autoethnography, reflexivity and small crises in fieldwork. Ethnography and Education, 4(1), 51-63.

Denzin, N. K., \& Lincoln. Y. S. (2000). Handbook of qualitative research (2nd ed.). London: Sage Publications.

Denzin, N. K., \& Lincoln. Y. S. (2002). The qualitative inquiry reader. London: Sage Publications.

Dewey, J. (1929). Quest for certainty. New York: Minton, Balch and Company.

Dobson, C. (2003). The troublemakers teaparty: A manual for effective citizen action. Gabriola Island: New Society Publishers.

Eisenstein, C. (2003). The yoga of eating. Washington, DC: NewTrends Publishing Incorporated.

Ellis, C. (2002). Being real: Moving inward toward social change. Qualitative Studies in Education, 15(4), 339-406.

Ellis, C. (2004). The ethnographic I: A methodological novel about autoethnography. Walnut Creek: AltaMira Press.

Ellis, C., \& Bochner, A. (2000). Autoethnography, personal narrative, reflexivity: Researcher as subject. In N. K. Denzin \& Y. S. Lincoln (Eds.), Handbook of qualitative research (2nd ed.) (pp. 733-768). Thousand Oaks: Sage Publications.

Ellis, C., Adams, T. E., \& Bochner, A. P. (2011). Autoethnography: An overview. Forum: Qualitative social research, 12(1), Retrieved from http://www.qualitativeresearch.net/index.php/fqs/article/view/1589/3095\#g44

Ellsworth, E. (2005). Places of learning: Media, architecture, pedagogy. New York: RoutledgeFalmer.

Feldman, S. (1998, August). Some problems with ecofeminism. In Twentieth world congress of philosophy: Philosophy and the environment. Boston, Massachusetts. Retrieved from www.bu.edu/wcp/Papers/Envi/EnviFeld.htm

Feldman, A., Paugh, P., \& Mills, G. (2004). Self-study through action research. In J. J. Loughran, M. L. Hamilton, V. K. LaBoskey, \& T. Russell (Eds.), International handbook of self-study of teaching and teacher education practices (Vol. Part Two) (pp. 943-978). London: Kluwer Academic Publishers.

Fien, J. (1995). A view of a sustainable world, In J. Fien (Ed.), Teaching for a Sustainable World: The UNESCO-UNEP international environmental education programme. International edition (Brisbane, Griffith University for UNESCOUNEP International Environmental Education Programme). 
Fisher, F. (2006). ResponseAbility: Environment, health and everyday transcendence. Melbourne: Vista.

Flannery, T. (2006). The weather makers: How we are changing the climate and what it means for life on Earth. Toronto: HarperCollins Publishers Limited.

Flavell, J. H. (1976). Metacognitive aspects of problem solving. In L. B. Resnick (Ed.), The nature of intelligence (pp. 231-236). Hillsdale, NJ: Erlbaum.

Foucault, M. (1980). Two lectures. In C. Gordon, (Ed.), Power/knowledge: Selected interviews. New York: Pantheon.

Foucault, M. (1985). The history of sexuality: The use of pleasure (R. Hurley Trans.) New York: Vintage.

Freire, P. (1995). Pedagogy of the oppressed. New York: Continuum. (Original work published 1970).

Freire, P. (2002). Pedagogy of hope: Reliving pedagogy of the oppressed. New York: Continuum.

Freire, P., \& Macedo, D. (1987). Literacy: Reading the word and the world. Westport: Bergin \& Garvey.

Gannon, S. (2006). The (im)possibilities of writing the self-writing: French poststructural theory and autoethnography. Cultural Studies - Critical Methodologies, 6(4), 474495.

Gergen, M., \& Gergen, K. (2002). Ethnographic representation as relationship. In A. Bochner \& C. Ellis (Eds.), Ethnographically speaking: Autoethnography. literature, and aesthetics (pp. 11-33). Walnut Creek, CA: AltaMira Press.

Gerum, N. (2007). Finding the "I" in action: Defining activism to include me. In S. Cullis-Suzuki, K. Frederickson, A. Kayssi, C. Mackenzie, \& D.A. Cohen (Eds.), Notes from Canada's young activists: A generation stands up for change (pp. 189198). Vancouver: GreyStone Books.

Gilding, P. (2011). The great disruption: How the climate crisis will transform the global economy. London: Bloomsbury Publishing.

Giroux, H. A. (1994). Toward a pedagogy of critical thinking. In K. S. Walters (Ed.), Rethinking reason: New perspectives in critical thinking (pp. 200-201). Albany: SUNY Press.

Glaser, B. G., \& Strauss, A. L. (1967). The discovery of grounded theory. Dallas: Houghton Mifflin. 
Global Footprint Network: Advancing the science of sustainability. (n.d.). Frequently asked questions. How is an Ecological Footprint calculated? Retrieved from http://www.footprintnetwork.org/en/index.php/GFN/page/frequently_asked_questi ons/\#method1

Gore, A. (2011, September 15). The climate reality project. Retrieved from http://climaterealityproject.org/

Gray-Donald, J., \& Selby, D. (2008). Green frontiers: Environmental educators dancing away from mechanism. Rotterdam: Sense Publishers.

Gruenewald, D. A. (2008). The best of both worlds: A critical pedagogy of place. Environmental Education Research, 14(3), 308-324.

Guba, E. G., \& Lincoln, Y. S. (2005). Paradigmatic controversies, contradictions, and emerging influences In N. K. Denzin \& Y. S. Lincoln (Eds.), The sage handbook of qualitative research (3rd ed.) (pp. 191-215). Thousand Oaks, CA: Sage.

Hagger, H., \& McIntyre, D. (2006). Learning teaching from teachers: Realizing the potential of school based teacher education. Buckingham: Open Press.

Hagger, H., Burn, K., Mutton, T., \& Brindley, S. (2008). Practice makes perfect? Learning to learn as a teacher. Oxford Review of Education, 34(2), 159-178.

Hamilton, M. L., \& Pinnegar, S. (1998). Introduction. In M. L. Hamilton, S. Pinnegar, T. Russell, J. Loughran, \& V. K. LaBotsky (Eds.), Reconceptualizing teachers practice: Self-study in teacher education (pp. 1-4). London: Falmer Press.

Hart, P. (2003). Teachers thinking in environmental education: Consciousness and responsibility. New York: Peter Lang.

Hart, P. (2011). No longer a "little added frill": The transformative potential of environmental education for educational change. Teacher Education Quarterly, Fall, 155-177.

Hart, P., Jickling, B., \& Kool, R. (1999). Starting points: Questions of quality in environmental education. Canadian Journal of Environmental Education, 4, 104124.

Hart, S., \& Kindle Hodson, V. (2004). The compassionate classroom: Relationship based teaching and learning. Encinitas: PuddleDancer Press.

Hey, V. (2002). Horizontal solidarities and molten capitalism: The subject, intersubjectivity, self and the other in late modernity. Discourse: Studies in the Cultural Politics of Education, 23(2), 227-241.

Holman Jones, S. (2002). The way we were, are, and might be: Torch singing as 
autoethnography. In A. P. Bochner \& C. Ellis (Eds.), Ethnographically speaking (pp. 44-56). Walnut Creek: AltaMira.

Holman Jones, S. (2005). Autoethnography: Making the personal political. In N. K.

Denzin \& Y. S. Lincoln (Eds.), Handbook of qualitative research (pp. 763-792). London: Sage Publications.

Holt, N. L. (2003). Representation, legitimation, and autoethnography: An autoethnographic writing story. International Journal of Qualitative Methods, 2(1), 1-22.

Homer-Dixon, T. (2007). The up-side of down: Catastrophe, creativity, and the renewal of civilisation. Toronto: Vintage Canada.

hooks, b. (1994). Teaching to transgress: Education as the practice of freedom. New York: Routledge.

hooks, b. (2010). Teaching critical thinking: Practical wisdom. New York: Routledge.

Huckle, J. (1999). Locating environmental education between modern capitalism and postmodern socialism: A reply to Lucie Sauvé. Canadian Journal of Environmental Education, 4, 36-45.

Hughes, S., Pennington, J. L., \& Makris, S. (2012). Translating autoethnography across the AERA standards: Towards understanding autoethnographic scholarship as empirical research. Educational Researcher, 41(6), 209-219.

Katz, S. E. (2003). Wild fermentation: The flavor, nutrition, and craft of live-culture foods. White River Junction: Chelsea Green Publishing Company.

Kenner, R. (2008). Food inc. United States of America: Participant Media.

Kheel, M. (2008). Nature ethics: An ecofeminist perspective. New York: Rowman \& Littlefield Publishers, Incorporated.

Kincheloe, J. L. (2008). Critical pedagogies (2nd ed.). New York: Peter Lang.

Kincheloe, J. L., McLaren, P., \& Steinberg, S. R. (1997). Series editors' forward. In H. A. Giroux (Ed.), Pedagogy and politics of hope: Theory, culture, and schooling (pp. ix-xiv). Boulder: Westview Press.

King, Y. (1990). Healing the wounds: Feminism, ecology, and the nature/culture dualism. In I. Diamond \& G. Feman Orenstein (Eds.), Reweaving the world: The emergence of ecofeminism (pp. 106-121). San Francisco: Sierra Club Books.

Kingsolver, B. (2007). Animal, vegetable, miracle: A year of food life. New York: Harper Perennial. 
Kingsolver, B. (2008). How to be hopeful. Duke University Commencement Ceremony. May 11 at Wallace Wade Stadium, Durham, North Carolina. Retrieved from http://www.dailygood.org/more.php?n=5140

Kosnik, C., Beck, C., Freese, A. R., \& Samaras, A. P. (2006). Making a difference in teacher education through self-study: Studies of personal, professional, and program renewal. Dordrecht: Springer.

Krueger, R. A., \& Casey, M. A. (2009). Focus groups: A practical guide for applied research. Thousand Oaks: Sage Publications.

Kumashiro, K. K. (2004). Against common sense: Teaching and learning towards social justice. New York: RoutledgeFalmer.

LaBoskey, V. K. (2004). The methodology of self-study and its theoretical underpinnings. In J. J. Loughran, M. L. Hamilton, V. K. LaBoskey, \& T. Russell (Eds.), International handbook of self-study of teaching and teacher education practices (Vol. Part Two) (pp. 817-870). London: Kluwer Academic Publishers.

Lacan, J. (1998). On feminine sexuality, the limits of love and knowledge. Encore. The seminar of Jacques Lacan. In J-A Miller (Ed.), Trans. B. Fink. New York: Norton.

Lassonde, C. A., Galman, S., \& Kosnik, C. (2009). Self-study research methodologies for teacher educators. Rotterdam: Sense Publishers.

Lather, P. (1991). Getting smart: Feminist research and pedagogy with/in the postmodern. London: Routledge.

Leonard, A. (2010). The story of stuff: How our obsession with stuff is trashing the planet, our communities, and our health - and a vision for change. New York: Free Press.

Leopold, A. (1949). A sand county almanac. London: Oxford University Press.

Lomax, P. (1991). Managing better schools and colleges: The action research way. Bristol: Longdunn Press.

Loughran, J. J. (2004). A history and context of self-study of teaching and teacher education practices. In J. J Loughran, M. L. Hamilton, V. K. LaBoskey, \& T. Russell (Eds.), International handbook of self-study of teaching and teacher education practices (Vol 1) (pp. 7-39). Dordrecht: Kluwer Academic Publishers.

Manning, D. (2008). Auto/ethnography: a journey of self/indulgence. Refereed paper in the Proceedings of Australian Association of Researchers in Education (pp. 1-16). International Education Research Conference 2007, Fremantle, Western Australia. 
Matsen, J. (1987). Eating alive: prevention thru good digestion. North Vancouver: Crompton Books, Ltd.

Matsen, J. (2002). Eating alive II: Ten easy steps to following the eating alive system. North Vancouver: Goodwin Books Ltd.

Maxwell, J. A. (2005). Qualitative research design: An interactive approach (2nd ed.). Thousand Oaks, C.A.: Sage Publications.

McKenzie, M. (2004). The "willful contradiction" of poststructural socio-ecological education. Canadian Journal of Environmental Education, 9, 177-190.

McKenzie, M. (2005). Second thoughts on post-critical inquiry. Environmental Education Research, 11(4), 455-462.

McKibben, W. (2010). Something braver than trying to save the world. In K. D. Moore \& M. P. Nelson (Eds.), Moral Ground: Ethical action for a planet in peril (pp. 174177). San Antonio: Trinity University Press.

McLaren, P. (2003). Life in schools (4th ed.). New York: Allyn and Bacon.

McMillan, S., \& Price, M. A. (2010). Through the looking glass: Our autoethnographic journey through research mind-fields. Presented at the Invisible College, Denver Colorado at the American Association of Educational Researchers Conference.

Meadows, D. H. (2008). Thinking in systems: A primer. Vermont: Chelsea Green Publishing.

Merchant, C. (1996). Earthcare: Women and the environment. New York: Routledge.

Millis, P. (2005). Eat away illness: Strategies and recipes for healing. Self published.

Mills, C. W. (1959). The sociological imagination. New York: Oxford University Press.

Minh-Ha, T. T. (2009). Woman, native, other: Writing postcoloniality and feminism. Bloomington: Indiana University Press.

Mooney, R. L. (1957). The researcher himself. In Research for curriculum improvement, association for supervision and curriculum development, 1957 yearbook (pp. 154186). Washington, DC: Association for Supervision and Curriculum Development.

Moore Lappé, F. (1982). Diet for a small planet. New York: Ballantine Books.

Moore Lappé, F. (2011). EcoMind: Changing the way we think, to create the world we want. New York: Nation Books. 
Monbiot, G. (2006). Heat: How to stop the planet from burning. Canada: Doubleday.

Naess, A. (1973). The shallow and the deep, long-range ecology movement. A summary. Inquiry, 16(1), 95-100.

Nhat Hanh, T. (2008). The environment is you. Human Architecture: Journal of the Sociology of Self-Knowledge, 6(3), 15-20.

Newbery, L. (2003). Will any/body carry that canoe? A geography of the body, ability, and gender. Canadian Journal of Environmental Education, 8, 204-216.

Noddings, N. (2003). Happiness and education. Cambridge: Cambridge University Press.

Noland, C. (2009). Agency and embodiment: performing gestures/producing culture. Cambridge: Harvard University Press.

Nordhaus, T., \& Shellenberger, M. (2007). Break through: Why we can't leave saving the planet to environmentalists. Boston: Mariner Books.

Norgaard, K. (2011). Climate denial: Emotion, psychology, culture and political economy. In J. Dryzek, R. Norgaard, \& D. Schlosberg (Eds.), Oxford handbook on climate change and society (pp. 399-413). USA: Oxford University Press, in press.

Occupy Santa Ana. (2012). Wrong and Right. Retrieved from https://www.facebook.com/photo.php?fbid=284628378272032\&set=a. 206654372 736100.47691.206606292740908\&type $=1 \&$ theater

Oliver, M. (1986). Dream works. New York: Atlantic Monthly Press.

Oliver, M. (1992). New and selected poems. Volume One. Boston: Beacon Press.

Oliver, M. (2005). New and selected poems. Volume Two. Boston: Beacon Press.

Orr, D. (1992a). Ecological literacy: Education and the transition to a postmodern world. New York: State University of New York Press.

Orr, D. (1992b). Environmental literacy: Education as if the Earth mattered. Annual E. F. Schumacher Lectures, 12.

Orr, D. (1994). Earth in mind: On education, environment, and the human prospect. Washington DC: Island Press.

Osterman, K., \& Kottkamp, R. (2004). Reflective practice for educators: Professional development to improve student learning. Thousand Oaks, CA: Corwin Press.

O’Sullivan, E. (1999). Transformative learning: Educational vision for the $21^{\text {st }}$ century. 
Toronto: University of Toronto Press Incorporated.

O'Sullivan, E. (2002). The project and vision of transformative education: Integral transformative learning. In E. O'Sullivan, A. Morrell, \& M. A. O'Connor (Eds.), Expanding the boundaries of transformative learning: Essays on theory and praxis (pp. 1-12). New York: Palgrave.

Palmer, J. A. (1998). Environmental education in the $21^{\text {st }}$ century: Theory, practice, progress and promise. London: RoutledgeFalmer.

Parker, I. (1992). Discourse dynamics: Critical analysis for social and individual psychology. London: Routledge.

Payne, P. (1997). Embodiment and environmental education. Environmental Education Research, 3(2), 133-153.

Payne, P. (1999). Postmodern challenges and modern horizons: Education 'for being for the environment'. Environmental Education Research, 5(1), 5-34.

Payne, P., \& Wattchow, B. (2009). Phenomenological deconstruction, slow pedagogy, and the corporeal turn in wild environmental/outdoor education. Canadian Journal of Environmental Education, 14, 15-32.

Pereira, M. (1999). My reflective practice as research. Teaching in Higher Education, 4(3), 339-354.

Peterson, T. (2009). Engaged scholarship: Reflections and research on the pedagogy of social change. Teaching in Higher Education, 14(4), 541-552.

Pillow, W. S. (2000). Deciphering attempts to decipher postmodern educational research. Educational Researcher, 29(5), 21-25.

Pinnegar, S. (1998). Introduction to part II: Methodological perspectives. In M. L. Hamilton (Ed.), Reconceptualizing teaching practice: Self-study in teacher education (pp. 31-34). London, Falmer Press.

Plumwood, V. (1996). Nature, self, and gender: Feminism, environmental philosophy, and the critique of rationalism. In K. J. Warren (Ed.), Ecological feminist philosophies (pp. 155-180). Bloomington: Indiana University Press.

Pollan, M. (2006). The omnivores dilemma: A natural history of four meals. New York: Penguin Books.

Pollan, M. (2009). Food rules: An eaters' manual. New York: Penguin Books. 
Reed-Danahay, D. E. (1997). Auto/ethnography: Rewriting the self and the social. Oxford: Berg.

Reinelt, J. (1998). Notes for a radical democratic theatre: Productive crisis and the challenge of indeterminacy. In J. Colleran \& J. S. Spencer (Eds.), Staging resistance: Essays on political theatre (pp. 283-300). Ann Arbor: University of Michigan Press.

Richardson, L. (2000). Evaluating ethnography. Qualitative Inquiry, 6(2), 253-255.

Richardson, L. (2006). Skirting a pleated text: De-disciplining an academic life. In S. N. Hesse-Biber \& P. Leavy (Eds.), Emergent methods in social research (pp. 1-12). London: Sage Publications.

Robinson, K. (2009). The element: How finding your passion changes everything. London: Penguin.

Robinson, K. (2010, October 14). RSA Animate - Changing education paradigms. Retrieved from http://www.youtube.com/watch?v=zDZFcDGpL4U

Robinson, K. (2011, November 25). TEDxLondon - Sir Ken Robinson. Retrieved from http://www.youtube.com/watch?v=SUsP9Z0hx3U

Robottom, I., \& Hart, E. P. (1993). Research in environmental education: Engaging the debate. Geelong: Deakin University.

Roszak, T. (1978). Person/planet: The creative disintegration of industrial society. Garden City, NY: Anchor Press/Doubleday.

Rowe, S. J. (1994). Ecocentrism: The chord that harmonizes Humans and Earth. The Trumpeter, 11(2), 106-107.

Roy, A. (2003). War talk. Cambridge: South End Press.

Royal Saskatchewan Museum. (1999). Ecological footprints. Retrieved from http://www.royalsaskmuseum.ca/gallery/life_sciences/footprint_mx_2005.swf

Rubin, H. J., \& Rubin, I. S. (1995). Qualitative interviewing: The art of hearing data. Newbury, CA: Sage.

Rural Advancement Foundation International. (2012). Our dwindling food variety. Retrieved from http://ngm.nationalgeographic.com/2011/07/food-ark/foodvariety-graphic\#.T6-i6MVVgz4.facebook

Salleh, A. (1993). Class, race, and gender discourse in the ecofeminism/deep ecology debate. Environmental Ethics, 15(Fall), 225-244. 
Salleh, A. (1997). Ecofeminism as politics: Nature, Marx, and the postmodern. New York: Zed Books.

Safron Foer, J. A. (2009). Eating animals. London: Hamish Hamilton.

Samaras, A. P. (1998). Finding my way: Teaching methods courses from a sociocultural perspective. In A. L. Cole, R. Elijah, \& J. G. Knowles (Eds.), The heart of the matter: Teacher educators and teacher education reform (pp. 55-79). San Francisco: Caddo Gap Press.

Samaras, A. P. (2002). Self-study for teacher educators: Crafting a pedagogy for educational change. New York: Peter Lang.

Samaras, A. P. \& Freese, A. R. (2006). Self-study of teaching practices. New York: Peter Lang.

Sandilands, C. (1999). The good-natured feminist: Ecofeminism and the quest for democracy. Minneapolis: University of Minnesota Press.

Saylan, C., \& Blumstein, T. D. (2011). The failure of environmental education (and how we can fix it). Berkley: University of California Press.

Schein, E. (2001). Organizational culture and leadership. In J. Shafritz \& J. S. Ott (Eds.), Classics of organization theory (pp. 240-248). Fort Worth: Harcourt College Publishers.

Schon, D. A. (1983). The reflective practitioner: How professionals think in action. London: Temple Smith

Schugurensky, D. (2007, November 24). Education in activism, and activism in education. Presentation at Educational activism: Social justice in classrooms, schools and communities. Ontario Institute of Studies in Education, University of Toronto.

Scott, W. (2009). Environmental education research: 30 years on from Tbilisi. Environmental Education Research, 15(2), 155-164.

Siegel, H. (1988). Educating reason: Rationality, critical thinking, and education New York: Routledge.

Shiva, V. (2009). Forward. In M. McKenzie, P. Hart, H. Bai, \& B. Jickling (Eds.), Fields of green: Restorying culture, environment, and education (pp. ix). Cresskill, NJ: Hampton Press Incorporated.

Shor, I. (1992). Empowering education: Critical Teaching for social change. Chicago: The University of Chicago Press. 
Shor, I. (1999). Critical literacy in action: Writing words, changing worlds. Portsmouth: Boynton/Cook.

Shunyamurti. (2009). The passion for ignorance. Retrieved from http://www.youtube.com/watch?v=M0MSEJO1kPg

Somekh, B., \& Lewin, C. (2005). Research methods in the social sciences. London: Sage Publications.

Sparkes, A. C. (2000). Autoethnography and narratives of self: Reflections on criteria in action. Sociology of Sport Journal, 17, 21-43.

Standage, T. (2009). An edible history of humanity. New York: Walker \& Company.

Starr, L. J. (2010). The use of autoethnography in educational research: Locating who we are in what we do. Canadian Journal for New Scholars in Education, 3(1), 1-9.

Sterling, S. (2007). Riding the storm: Towards a connective cultural consciousness. In A. E. J. Wals (Ed.), Social learning: Towards a sustainable world (pp. 63-82). Wageningen: Wageningen Academic Publishers.

Stevenson, R. B. (2007). Editorial. Environmental Education Research, 13(2), 129-138.

Stevenson, R. B. (2007a). Schooling and environmental education: contradictions in purpose and practice. Environmental Education Research, 13(2), 139-153.

Stevenson, R. B. (2007b). Schooling and environmental/sustainability education: from discourses of policy and practice to discourses of professional learning. Environmental Education Research, 13(2), 265-285.

Stronach, I., \& MacLure, M. (1997). Educational research undone: The postmodern embrace. Buckingham: Open University Press.

Taylor, E. W. (2009). Fostering transformational learning. In J. Mezirow, E. W. Taylor, \& Associates (Eds.), Transforming learning in practice: Insights from community, workplace, and higher education (pp. 3-18). San Francisco: Jossey-Bass.

The Ahmedabad Declaration. (2007). Retrieved from http://www.tbilisiplus30.org/Ahmedabad\%20Declaration.pdf

The Belgrade Charter. (1975). Retrieved from http://www.gdrc.org/uem/ee/belgrade.html The Illusion of Choice. (2012). Retrieved from http://i.imgur.com/k0pv0.jpg

The Tbilisi Declaration. (1977). Retrieved from http://www.gdrc.org/uem/ee/tbilisi.html 
Thurston. (1962, April 15). Southtown economist (Chicago, Il1.). 6.

Tilbury, D. (2007). Learning based change for sustainability: perspectives and pathways. In A. E. J. Wals (Ed.), Social learning: Towards a sustainable world (pp. 117132). Wageningen: Wageningen Academic Publishers.

Tillman-Healy, L. M. (2006). Friendship as method. In S. N. Hesse-Biber \& P. L. Leavy (Eds.), Emergent methods in social research (pp. 273-294). Thousand Oaks: Sage Publications.

Tolich, M. (2010). A critique of current practices: Ten foundational guidelines for autoethnographers. Qualitative Health Research, 20(12), 1599-1610.

Trainer, T. (2010). The transition to a sustainable and just world. Canterbury: Envirobook.

Tripp, P., \& Muzzin, L. (2005). Teaching as activism: Equity meets environmentalism. Montreal \& Kingston: McGill-Queens University Press.

Turner, C. (2007). The geography of Hope: A tour of the world we need. Toronto: Random House of Canada Limited.

van Manen, M. (1990). Researching lived experience: Human science for an action sensitive pedagogy. Albany, NY: State University of New York Press.

Wackernagel, M., \& Rees, W. (1996). Our ecological footprint: Reducing human impact on the earth. Gabriola Island, BC: New Society Publishers.

Walker, M., \& Unterhalter, E. (2004). Knowledge, narrative work and national reconciliation: Storied reflections on the South African truth and reconciliation commission. Discourse, 25(2), 279-297.

Warren, K. J. (1988). Towards an ecofeminist ethic. Studies in the Humanities, 140-156.

Warren, K. J. (1995). The Power and the promise of ecological feminism. In P. A. V. DeVeer (Ed.), People, penguins and plastic trees (pp. 213 - 237). Belmont: Wadsworth.

Warren, K. J. (1996). Ecological feminist philosophies: An overview of the issues. In K. J. Warren (Ed.), Ecological feminist philosophies (pp. ix-xxvi). Bloomington: Indiana University Press.

Warren, K. J. (2000). Ecofeminist philosophy: A western perspective on what it is and why it matters. New York: Rowman \& Littlefield Publishers Incorporated. 
Watson, P. (n.d.). Terrorism is as terrorism does: A short little essay on my perspective on the concerns about terrorism. Retrieved from http://www.ecospherics.net/pages/watson2.htm

Weedon, C. (1987). Feminist practice and poststructural theory. Cambridge: Blackwell Publications.

White, P. J. (October, 2010). Do you walk your talk? Intentional EE practice. Presented at the North American Association of Environmental Education Conference: Buffalo, N.Y.

White, P. J. (2010). Action learning group project. Retrieved from https://sites.google.com/site/actionlearninggroupproject/home/the-project

Whitehead, J. (1989). Creating a living educational theory from questions of the kind, 'How do I improve my practice?' Cambridge Journal of Education, 19(1), 41-52.

Worts, D. C. (2010). Culture in the winds of change: Fostering a 'culture of sustainability' and making cases for cultural indicators. The International Journal of Environmental, Cultural, Economic, and Social Sustainability, 6(5), 241-254.

Youngblood Jackson, A. (2001). Multiple Annies: Feminist poststructural theory and the making of a teacher. Journal of Teacher Education, 52(5), 386-397.

Zeichner, K. M. (1999). The new scholarship in teacher education. Educational Researcher, 28(9), 4-14. 


\section{Appendix 1: Reasearch Ethics Board Approval}

\section{UNIVERSITY OF REGINA}

DATE: July 23, 2009

TO: $\quad$ Peta White

Faculty of Education

FROM: Dr. Bruce Plouffe

Chair, Research Ethics Board
OFFICE OF RESEARCH SERVICES

ME M O R A N D U M

Re: $\quad$ Environmental Education/Activism/Research: Walking my Talk (01S0910)

Please be advised that the University of Regina Research Ethics Board has reviewed your proposal and found it to be:

D1.

APPROVED AS SUBMITTED. Only applicants with this designation have ethical approval to proceed with their research as described in their applications. For research lasting more than one year (Section 1F). ETHICAL APPROVAL MUST BE RENEWED BY SUBMITTING A BRIEF STATUS REPORT EVERY

TWELVE MONTHS. Approval will be revoked unless a satisfactory status report is received. Any substantive changes in methodology or instrumentation must also be approved prior to their implementation.

2. ACCEPTABLE SUBJECT TO MINOR CHANGES AND PRECAUTIONS (SEE ATTACHED). Changes must be submitted to the REB and approved prior to beginning research. Please submit a supplementary memo addressing the concerns to the Chair of the REB. ${ }^{* *}$ Do not submit a new application. Once changes are deemed acceptable, ethical approval will be granted.

3. ACCEPTABLE SUBJECT TO CHANGES AND PRECAUTIONS (SEE A TTACHED). Changes must be submittied to the REB and approveut prior to beginning research. Please submit a supplementary memo addressing the concerns to the Chair of the REB. ${ }^{* *}$ Do not submit a new application. Once changes are deemed acceptable, ethical approval will be granted.

4. UNACCEPTABLE AS SUBMITTED. The proposal requires substantial additions or redesign. Please contact the Chair of the REB for advice on how the project proposal might be revised.

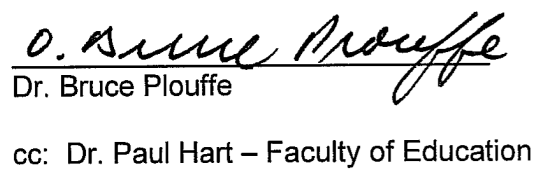

** supplementary memo should be forwarded to the Chair of the Research Ethics Board at the Office of Research Services (Research and Innovation Centre, Room 109) or by e-mail to research.ethics@uregina.ca 


\title{
Appendix 2: Course Syllabus
}

\author{
Faculty of Education \\ Environmental Education 302, Fall 2009

\section{Calendar Description} \\ Theory and practice in environmental education, including the history and philosophy of \\ environmental education, course design (K-12), and issues investigation.
}

\section{Course Information}

Instructor: Peta White (white20p@uregina.ca), Office: Ed 323, Phone: 5854541

Fall Semester 2009: $10.30 \mathrm{am}-1.20$ pm Monday and Wednesday

Classroom: Ed 320

\section{Course Vision}

At the conclusion of this course students will have developed:

- a strong sense of self as an educator;

- a sense of self in relation to the environment;

- as reflective learners;

- in their capacity to communicate; and

- in their capacity as successful, professional, and intentional environmental educators.

\section{Course Outline}

This course will provide an opportunity to "trouble" the concept of education through a critical environmental lens. We will explore what the environment means to you, and those around you. You will be asked to reflect deeply about your past, present, and future experiences throughout the semester. These reflections will challenge you to critique our practices and thoughts about environmental education. We will experience different environments and examine ideas about how to educate in, for, about, through, and with a series of field trips and conference opportunities. There will be a specific focus on conducting an action research project investigating environmental issues of personal interest (action orientated learning and learning orientated action). We will also examine the Saskatchewan curriculum using it to devise and evaluate appropriate learning opportunities and resources for your future classrooms. We will create, critique, and implement many environmental resources, understanding that EVERYTHING is a relevant resource for environmental education in Saskatchewan.

\section{Course Goals}

- investigate what "environment" means to each of us, and those around us;

- experience environments in Saskatchewan and consider appropriate learning opportunities;

- research environmental issues in depth via an action research project;

- become engaged citizens through participation and action;

- participate in and consider inquiry learning processes;

- become reflective educators, actively asking deeper questions while watching for assumptions;

- examine and utilise the Saskatchewan curriculum and locate opportunities for student learning in, for, about and with the environment;

- devise a variety of resources that will be effective in the delivery of environmental education; and

- develop a critical awareness of our relationship with the environment, focussing on your role as educator. 


\section{Course Outings}

A number of opportunities for experiencing different aspects of environmental education have been planned for this semester. Experiential learning, or the embodiment of learning experiences and place-based learning, is a focus of this course. Fieldtrips to explore local sites that provide valuable learning opportunities have been embedded into this semester's program (examples include: Wascana Lake, a food security and nutrition workshop, and the Royal Saskatchewan Museum). Some of these learning opportunities may require specialised equipment, such as bicycles and wet weather gear. If you don't have access to the necessary items every effort will be made to assist you to borrow some or to find a suitable alternative to ensure your participation.

This semester coincides with a valuable learning opportunity occurring right here in Saskatchewan: the SOEEA "Keepers of the Prairie" Conference on $25^{\text {th }}-27^{\text {th }}$ September. To encourage you to attend this weekend conference class time has been compensated (three classes). The conference cost is $\$ 30$ (inclusive of accommodation and food) plus SOEEA membership ( $\$ 10$ for one year) and has been heavily subsidised by SOEEA and additional funding may be possible (from the Education Faculty, the Student Union, and RPIRG). The conference is to be held at Manitou Beach, Camp Easter Seal. Transport to and from the conference will be negotiated and car-pooling will be an option. If you are unable to attend this weekend conference there will be an opportunity to negotiate an alternative learning experience (suggestions includes: a 3000 word descriptive paper titled "Environmental Education in Saskatchewan", developing teaching resources for particular EE activities, developing "issues" based learning packages etc).

Additionally, there will be other learning opportunities of which you may choose to take advantage. Resource guides that are linked to the Saskatchewan curriculum are available and if you choose you can participate in facilitated workshops that provide the training and the guide for a small fee. Again, if the class chooses, this fee may be subsidised by seeking funding. This additional training will take place in a variety of ways: integrated within the course, as a particular class, and/or on a weekend day extra event. Examples include Project Wet (\$25), Project WILD (\$25), Flying WILD (\$10), Below Zero (\$25), and Focus on Forests $(\$ 10)$. This will be negotiated early in the semester (week 1 ).

\section{Course Information}

UR Courses will be utilised for sharing information, class reflections, reading assignments, updated program schedules, and ideas throughout this course.

\section{Course Resources}

Books, DVD's, information packages, and resource packages have been made available for use during this course. Please care for these resources (some are expensive and some belong to your instructor). Please use the class process to sign out each resource and ensure you sign it back in (before class starts is a great time for resource swapping).

\section{Course Evaluation}

There are four evaluation pieces in this course:

1. Autobiographical learning journey journal (critical self awareness)

\section{CRITICAL $\quad 30 \%$}

2. Curriculum and workshop development and delivery (group project)

$$
\text { PRACTICAL 25\% }
$$

3. Environmental action research project (long-term project)

PERSONAL/SOCIAL 20\%

4. The Four "P's" of Resources (critical resources)

RESOURCEFUL $\quad 25 \%$

The due dates are open for negotiation, until ratified by the entire class. Once confirmed (week 2 ), extensions may be negotiated and the preference would be for this to occur one week in advance of due date via communication with the instructor. 


\section{Evaluation 1: Autobiographical Learning Journey Journal CRITICAL [1 task]}

Recording your learning journey in journal form can be a challenging task.

It is, however, a worthy task and one that will hopefully illustrate your struggles, concerns, learnings, successes, and enjoyment of your learning journey through this class.

"Change begins within..." You may present it in any format, using any media (there are some nice online tools if you are interested). Some examples may include:

presentation media forms (powerpoint, prezi, comic life, inspiration, podcast, video, digital story), written entries (web pages, blog, wiki, ning)... be as creative as you like, but be critical and aware.

You could ask questions like "what's going on here?" or "how could I use this in my teaching?" or "how does this disrupt or reinscribe notions around education and/or environmental

\section{Evaluation 2: Curriculum Framework and Unit Planning (group project) [3 tasks] \\ PRACTICAL}

Saskatchewan does not have an Environmental Education Framework, as do other provinces (Ontario, BC, Alberta, and Manitoba). Working in small groups, each will be assigned a grade level and asked to devise an environmental education framework that supports the implementation of environmental education across subject areas. Examples of documents from other provinces will be offered as a basis for this thinking.

Additionally, each group will plan a five-week curriculum unit from their grade level and prepare a workshop for the class that shares this unit and some of the activities (hands-on). A project-based program is to be developed. An important aspect of this curriculum and workshop will be the critical evaluation of each activity included (this will be something to reflect on for your Learning Journey Journal - Evaluation 1). This assessment can be conducted in (4) groups of 4 or 5 and will be presented for the class in a 1.5 hour interactive and participatory workshop. Please present this evaluation electronically so that we can share resources. See negotiated evaluation criteria (week 2).

25\% Due: $4^{\text {th }}$ or $9^{\text {th }}$ November 2009 Evaluation 3: Environmental Action Research Project. [3 tasks]

\section{PERSONAL/SOCIAL}

My body is a 'site' for describing how the 'ecological crisis' is re-inscribed and/or disrupted by my actions or interactions.

Use action learning cycles to explore environmental issues (ecological crises) that are of interest to you (your body). This may be an aspect of how you live, what you believe in and practice, and/or something your society practices. Re-inscribing these practices implies assigning a value to that practice that results in its repetition (consciously or not).

Disrupting these practices implies a change is implemented (consciously).

Add your critical reflections to your Learning Journey Journal (Evaluation 1). Describe the research you have conducted exploring all the alternative views and data around your issues, and the possibilities for using this pedagogical strategy with your students (include curricula connections with your specific content/issues). Present a version of your findings to class using any media (you will have 30 minutes).

In addition to your own action learning journey, you are asked to form critical friend triads (with two class colleagues) to reflect on their learning journey, and your own. Keeping a close watch on your colleagues journey will not only give you additional ideas, a timeline of action, and a person to compare notes with. It will also provide you with a birds eye view (or meta level view) of how a student carries out a task like action learning. This view will be important in developing ways to use this task with future students.

This assessment is to be conducted by your self and will be evaluated by yourself, your peers, and your instructor. See negotiated evaluation criteria (week 4).

You are encouraged to seek advice from your instructor regarding possible environmenta 


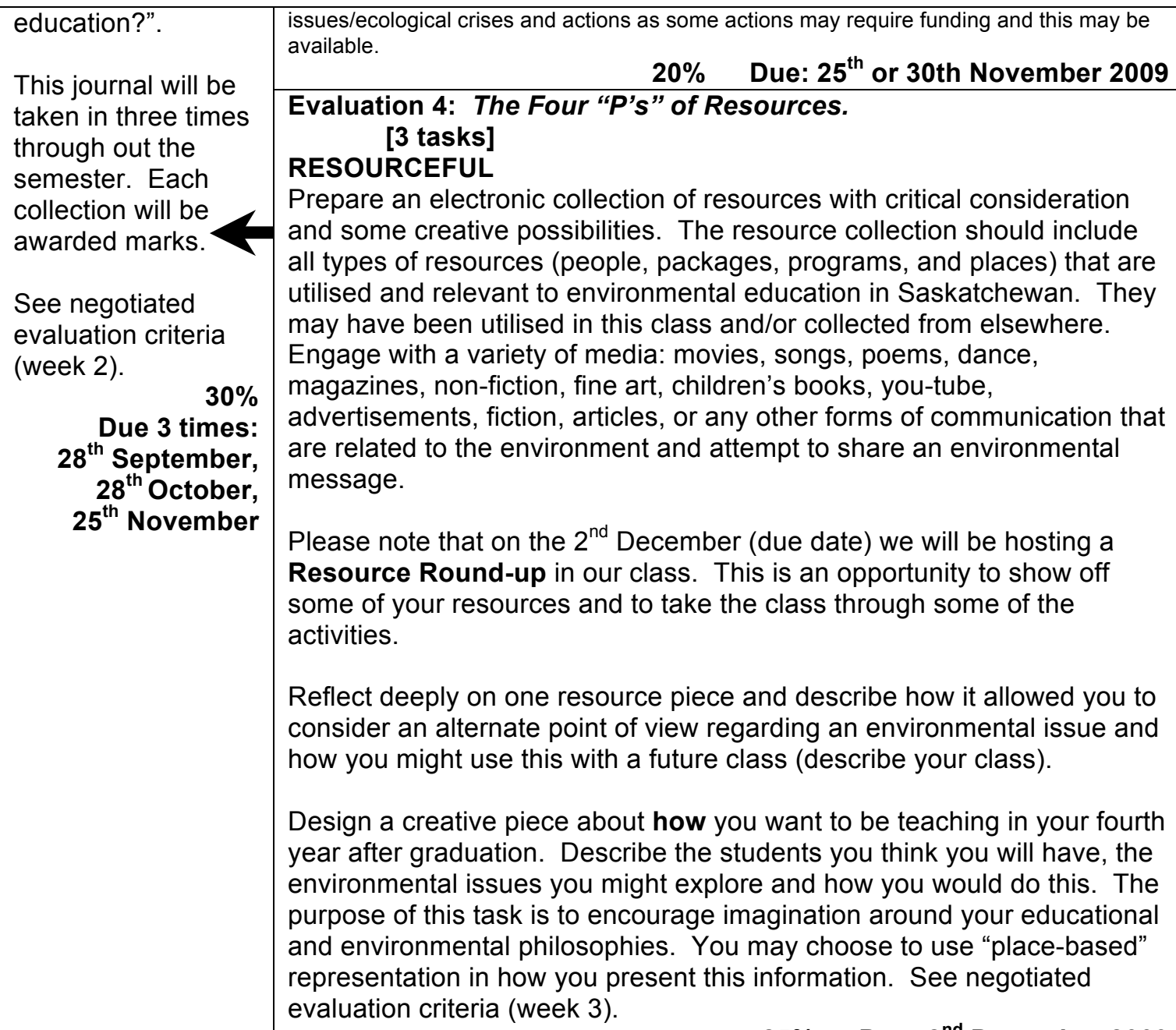

$30 \%$

Due 3 times:

$28^{\text {th }}$ September, $28^{\text {th }}$ October, $25^{\text {th }}$ November

issues/ecological crises and actions as some actions may require funding and this may be available.

\section{Evaluation 4: The Four "P's" of Resources.}

$20 \%$ Due: $25^{\text {th }}$ or 30 th November 2009 [3 tasks]

Prepare an electronic collection of resources with critical consideration and some creative possibilities. The resource collection should include all types of resources (people, packages, programs, and places) that are utilised and relevant to environmental education in Saskatchewan. They may have been utilised in this class and/or collected from elsewhere. Engage with a variety of media: movies, songs, poems, dance, magazines, non-fiction, fine art, children's books, you-tube, advertisements, fiction, articles, or any other forms of communication that are related to the environment and attempt to share an environmental message.

Please note that on the $2^{\text {nd }}$ December (due date) we will be hosting a Resource Round-up in our class. This is an opportunity to show off some of your resources and to take the class through some of the activities.

Reflect deeply on one resource piece and describe how it allowed you to consider an alternate point of view regarding an environmental issue and how you might use this with a future class (describe your class).

Design a creative piece about how you want to be teaching in your fourth year after graduation. Describe the students you think you will have, the environmental issues you might explore and how you would do this. The purpose of this task is to encourage imagination around your educational and environmental philosophies. You may choose to use "place-based" representation in how you present this information. See negotiated evaluation criteria (week 3 ).

$25 \%$

Due: $2^{\text {nd }}$ December 2009

\section{Special Note}

This semester your instructor will be conducting a self-study that critically examines her practice as an intentional environmental educator, researcher, and activist. Your participation in this research is voluntary and possible implications will be explained during the first class. You are under no obligation to participate, and should you choose to participate you can withdraw at any stage. Participation involves an interview and focus group meeting after the course is completed (at the end of the semester). Your instructor will not know who has agreed to participate through out the semester. Please see letter and consent form (Week 1).

\section{University of Regina \& Faculty of Education: Summary of Academic Regulations \& Reminders \\ Please refer to $\S 5.13$ of the University of Regina Undergraduate General Calendar for more information or please visit the website at http://www.uregina.ca/gencal/ugcal/}

1. Attendance and Punctuality - Regular and punctual attendance is very important in the Faculty of Education because courses are often based on participation and experiential learning rather than lecture. As well, group activities and assignments are often negatively affected by the absence of students. Instructors will monitor student attendance.

2. Cheating - (University of Regina General Calendar, 2009-2010, p. 34). Cheating constitutes academic misconduct. Cheating is dishonest behaviour (or the attempt to behave dishonestly), usually in tests or examinations. It includes:

- unless explicitly authorized by the course instructor or examiner, using books, notes, diagrams, 
electronic devices, or any other aids during an examination, either in the examination room itself or when permitted to leave temporarily;

- copying from the work of other students;

- communicating with others during an examination to give or receive information, either in the examination room or outside it;

- consulting others on a take-home examination (unless authorized by the course instructor);

- commissioning or allowing another person to write an examination on one's behalf;

- not following the rules of an examination;

- using for personal advantage, or communicating to other students, advance knowledge of the content of an examination (for example, if permitted to write an examination early);

- altering answers on an assignment or examination that has been returned;

- taking an examination out of the examination room if this has been forbidden.

3. Invigilators' Rights - An invigilator who suspects a student of cheating has the authority to ask the student to do such things as empty pockets, pencil cases, etc., and roll up their sleeves. The invigilator should ensure they have a witness when asking the student to perform the request. The invigilator should not badger the student or unduly disrupt that student's (or other students') ability to complete the examination. If the student refuses to cooperate, the invigilator can not do more except to make written note of the students' refusal when reporting on the matter under the disciplinary regulations.

4. Harassment - All members of the University community are entitled to a professional working and learning environment free of harassment and discrimination. This entitlement, however, carries with it the expectation that all members of the University community will conduct themselves in an appropriate and responsible manner, with due respect and regard for the rights of others. No member of the university community shall cause or participate in discrimination against or harassment of another person.

http://www.uregina.ca/presoff/vpadmin/policymanual/hr/2010510.shtml

5. Late Assignments - Action regarding late assignments may vary from instructor to instructor. Expectations or due dates for assignments, as well as the marks that may be deducted for late assignments are noted in the course syllabus. (For example, some instructors deduct one mark for each day late.)

6. Plagiarism - The Faculty of Education encourages students to obtain materials from multiple and varied sources for assignments; however, it is a student's responsibility to acknowledge the sources when submitting work for credit.

7. Language Competence - Students are expected to meet recommended standards of language competence as part of graduation requirements in the Faculty of Education.

8. Special Needs - Students, who because of a disability may have a need for accommodations, please discuss this with your instructor as soon as possible. You may also wish to contact the Coordinator of the Disability Resource Office (RC 251.15) at 585-4631.

9. Unprofessional Conduct - The Faculty of Education has established sound and reliable criteria and procedures for evaluating the suitability of aspiring teachers. The criteria specify appropriate conduct for students in teacher education programs. The procedures specify processes for screening, regulating and monitoring professional conduct.

\section{Textbooks:}

\section{Environmental Education 302 - Reading References}

1. Hart, P. (2002). Teachers thinking in environmental education: consciousness and responsibility. New York: Peter Lang.

2. Grant, T. and Littlejohn, G. (2009). Teaching Green: The High School Years. Hands-on learning in Grades 9-12. New Society Publishers

3. Ecoliving: Your Guide to Sustainable Living

4. Ecoliving: Working Together for a Sustainable World

Bibliography (if interested these articles can be provided - please ask)

Sauvé, L. (1996). Environmental education and sustainable development: a further appraisal. Canadian Journal of Environmental Education, 1, 7 - 34. 
Russell, C. L. (1997). Approaches to Environmental Education: Towards a transformative perspective. Holistic Education Review, 10(1), 21 - 27.

Palmer, J. A. (1998). Environmental education in the 21st century: theory, practice, progress and promise. Chapter $1 \mathrm{New}$ York: RoutledgeFalmer.

Hammond, W. F. (1997). Educating for Action: a framework for thinking about the place of action in environmental education. Green Teacher, 50, 6 - 14.

Moore, R., Taylor, D., \& Chamberlin, C. (1994). Red Deer social action project. In C. Chamberlin (Ed.), Don't tell us it can't be done (pp. 67 - 80). Montreal: Our Schools/Our Selves Education.

Tilbury, D. (2007). Learning based change for sustainability: perspectives and pathways (chapter 5). In: Social Learning: Towards a sustainable world. The Netherlands: Wageningen Academic Publishers.

McEIroy, M. W. (1997). Paradigms Lost: And the myths we teach our children. Green Teacher, 53(Fall), $6-10$.

Castro, W. M.-d. (1999). Grounding Environmental Education in the Lives of Urban Students. Pathways: Ontario Journal of Outdoor Education, 11(7), 438 - 440.

Engel, J. P., \& Sturgis, D. (2006). Ethics in Action: Adopting an environmental practice. Green Teacher, 78(Spring), 11 - 15.

Bak, N. (1995). Green Doesn't Always Mean 'Go': possible tensions in the desirability and implementation of environmental education. Environmental Edcuation Research, 1(3), $345-352$.

Russell, C. L. (1999). Problematizing nature experience in environmental education: The interrelationship of experience and story. Journal of Experiential Education, 22(3), 123 138.

Pleasants, K. (2006). Does Environmental Education Need a Thneed? Displacing The Lorax as Environmental Text. Canadian Journal of Environmental Education, 11, 179 - 194. 


\section{Environmental Education 302 \\ Course Schedule, Fall 2009}

- 14 weeks, 2 classes per week, three hour per class (28 classes, 84 hours per semester)

- 3 classes are traded off so that students can attend the SOEEA Conference "Keepers of the Prairie" Manitou Beach $25-27^{\text {th }}$ September

- 3 classes are missed due to holidays

- Total: 22 classes, 66 contact hours

\begin{tabular}{|c|c|c|}
\hline Week & Monday & Wednesday \\
\hline 1 & $\begin{array}{l}7^{\text {th }} \text { September } \\
\text { No class - University Closed }\end{array}$ & $\begin{array}{l}9^{\text {th }} \text { September } \\
\text { Introductions, syllabus discussion } \\
\text { (evaluations and schedule negotiation), } \\
\text { research participation } \\
\quad \text { Set reading (Hart Ch 1) }\end{array}$ \\
\hline 2 & $\begin{array}{l}\mathbf{1 4}^{\text {th }} \text { September } \\
\text { Environmental Education - defining, } \\
\text { planning time for the SOEEA Conference } \\
\text { workshop }\end{array}$ & $\begin{array}{l}16^{\text {th }} \text { September } \\
\text { "Environment - what it means to me" due, } \\
\text { class debrief, negotiate Eval } 1 \text { criteria } \\
\text { Set reading (Hart Ch } 2)\end{array}$ \\
\hline \multirow[t]{2}{*}{3} & $\begin{array}{l}\mathbf{2 1 ^ { \text { st } }} \text { September } \\
\text { Environmental Education - review of } \\
\text { frameworks, negotiate Eval } 2 \text { criteria, } \\
\text { planning time for the SOEEA Conference } \\
\text { workshop }\end{array}$ & $\begin{array}{l}\mathbf{2 3 ^ { \text { rd } }} \text { September } \\
\text { Environmental Education - in } \\
\text { Saskatchewan, negotiate Eval } 4 \text { criteria, } \\
\text { planning time for the SOEEA Conference } \\
\text { workshop }\end{array}$ \\
\hline & $\begin{array}{l}\text { Friday } 25^{\text {th }}(6 \mathrm{pm}) \text { to Sunday } 27^{\text {th }}(3.30 \mathrm{pm}) \\
\text { SOEEA Conference, "Keepers of the Prair }\end{array}$ & $\begin{array}{l}\text { September } \\
\text { ie" Camp Easter Seal, Manitou Beach }\end{array}$ \\
\hline 4 & $\begin{array}{l}\mathbf{2 8}^{\text {th }} \text { September } \\
\text { Evaluation } 1 \text { due } \\
\text { Action Research workshop, negotiate Eval } \\
3 \text { criteria } \quad \text { Set reading (Clarke) }\end{array}$ & $\begin{array}{l}30^{\text {th }} \text { September } \\
\text { Field Trip - Wascana Marsh (cycling tour) }\end{array}$ \\
\hline 5 & $\begin{array}{l}5^{\text {th }} \text { October } \\
\text { No Class - Trade off for SOEEA } \\
\text { Conference }\end{array}$ & $\begin{array}{l}7^{\text {th }} \text { October } \\
\text { No Class - Trade off for SOEEA } \\
\text { Conference }\end{array}$ \\
\hline 6 & $\begin{array}{l}12^{\text {th }} \text { October } \\
\text { No class - University Closed }\end{array}$ & $\begin{array}{l}\mathbf{1 4}^{\text {th }} \text { October } \\
\text { Dean Elliot, Ministry of Education }\end{array}$ \\
\hline 7 & $\begin{array}{l}19^{\text {th }} \text { October } \\
\text { Field Trip - Royal Saskatchewan Museum, } \\
\text { the ecological footprint calculator and the } \\
\text { Human Factor Exhibit with Dr. Glenn } \\
\text { Sutter }\end{array}$ & $\begin{array}{l}21^{\text {st }} \text { October } \\
\text { Triads, Evaluation criteria, Unit planning, } \\
\text { rest of semester plans. } \\
\quad \text { Set reading (Hart Ch } 3)\end{array}$ \\
\hline 8 & 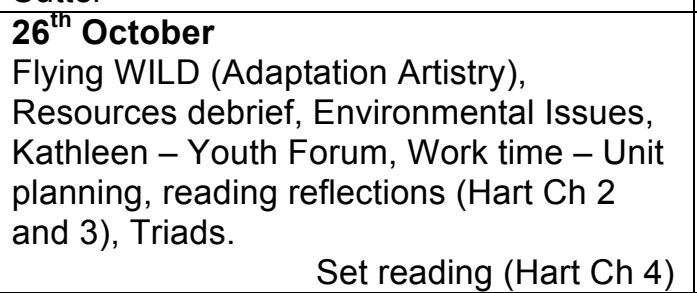 & $\begin{array}{l}\mathbf{2 8}^{\text {th }} \text { October } \\
\text { Evaluation } 1 \text { due } \\
\text { Food Security and Nutrition Workshop with } \\
\text { Sandra Brandt }\end{array}$ \\
\hline 9 & $\begin{array}{l}2^{\text {nd }} \text { November } \\
\text { Flying WILD (Bird Olympics - June), } \\
\text { Triads, Environmental Issues - poetry } \\
\text { slam, reading reflections (Hart Ch 4), Work } \\
\text { time - Unit planning, }\end{array}$ & $\begin{array}{l}4^{\text {th }} \text { November } \\
\text { Michael Gatin - workshop ( } 3 \text { hours) }\end{array}$ \\
\hline
\end{tabular}




\begin{tabular}{|c|c|c|}
\hline 10 & $\begin{array}{l}\mathbf{9}^{\text {th }} \text { November } \\
\text { Evaluation } 2 \text { due } \\
\end{array}$ & $\begin{array}{l}11^{\text {th }} \text { November } \\
\text { No class - University Closed } \\
\quad \text { Triads - via email!! }\end{array}$ \\
\hline 11 & $\begin{array}{l}16^{\text {th }} \text { November } \\
\text { Evaluation } 2 \text { due }\end{array}$ & 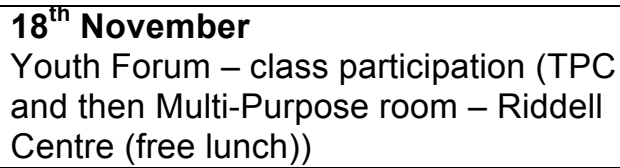 \\
\hline 12 & $\begin{array}{l}\mathbf{2 3}^{\text {rd }} \text { November } \\
\text { Curtis Dorosh (Sask Government), Flying } \\
\text { WILD (Create your own foodweb - June, } \\
\text { Jeop-birdy - June, Hidden Hazards - } \\
\text { June), reading reflections (Hart Ch } 4 \text { and } \\
\text { 5), Environmental Issues - debate }\end{array}$ & $\begin{array}{l}\mathbf{2 5}^{\text {th }} \text { November } \\
\text { Evaluation } 1 \text { due } \\
\text { Evaluation } 3 \text { due }\end{array}$ \\
\hline 13 & $\begin{array}{l}30^{\text {th }} \text { November } \\
\text { Evaluation } 3 \text { due }\end{array}$ & $\begin{array}{l}2^{\text {nd }} \text { December } \\
\text { Evaluation } 4 \text { due } \\
\text { Resource round-up } \\
\text { Student Evaluation }\end{array}$ \\
\hline 14 & $\begin{array}{l}7^{\text {th }} \text { December } \\
\text { Class celebrations, Flying WILD (Light as } \\
\text { a feather, the great Migration Challenge, } \\
\text { Just Ducky, Fill the Bill, Food for the } \\
\text { Brood) certification, Podcasts - Poetry } \\
\text { Slam, and class debrief }\end{array}$ & $\begin{array}{l}9^{\text {th }} \text { December } \\
\text { No Class }- \text { Trade off for SOEEA } \\
\text { Conference }\end{array}$ \\
\hline
\end{tabular}

